\title{
Effekte von Hypericin auf humane renale Karzinomzellen in vitro
}

\author{
Dissertation \\ zur Erlangung des Doktorgrades \\ der Mathematisch-Naturwissenschaftlichen Fakultäten \\ der Georg-August-Universität zu Göttingen
}

\author{
vorgelegt von \\ Ann-Christin Busse \\ aus Einbeck
}

Göttingen 2009 
D7

Referent: Prof. Dr. med. Uwe Groß

Korreferent: Prof. Dr. rer. nat. Sigrid Hoyer-Fender

Tag der mündlichen Prüfung: 22.01.10 


\section{Für Stephan}




\section{Inhaltsverzeichnis:}

1. Einleitung:

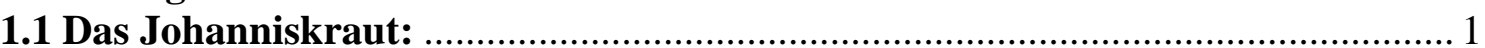

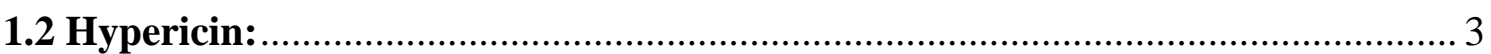

1.2.1 Eigenschaften und Wirkungen des Hypericins:.............................................. 3

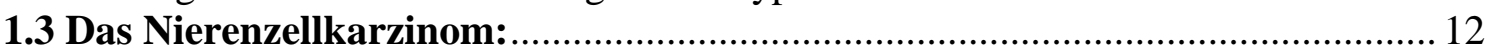

1.3.1 Molekularpathologie des Nierenzellkarzinoms: ........................................... 12

1.3.2 Prognose und Therapie des Nierenzellkarzinoms: ......................................... 18

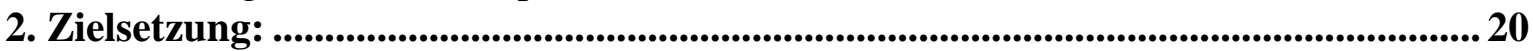

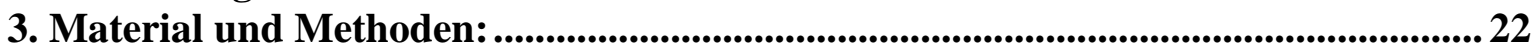

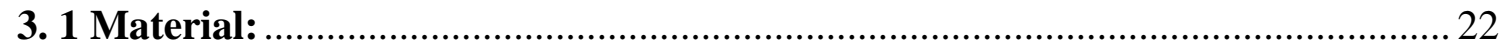

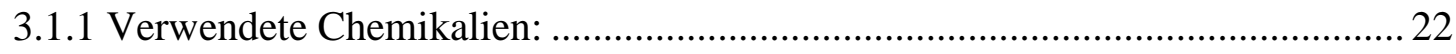

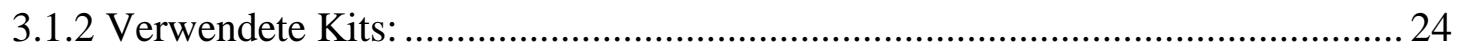

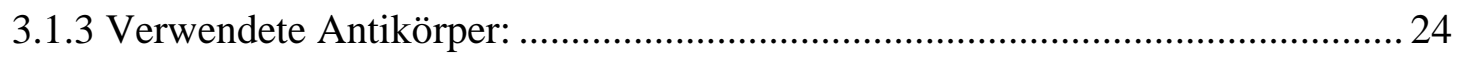

3.1.4 Verwendete PCR-Primer: ............................................................................. 25

3.1.5 Verwendete Hilfsmittel und Verbrauchsmaterialien: ....................................... 25

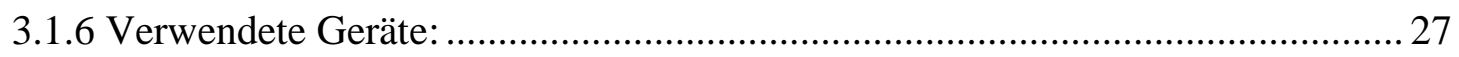

3.1.7 Verwendete Mikroskope und Zubehör:........................................................ 28

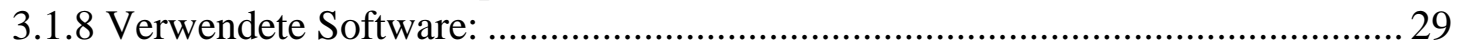

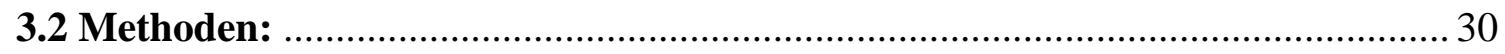

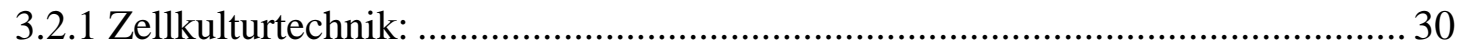

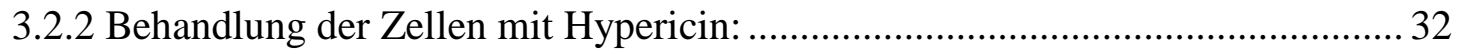

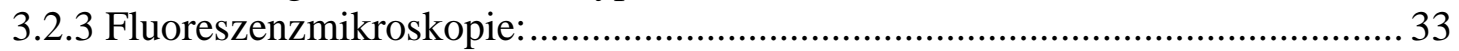

3.2.4 Untersuchungen zur intrazellulären Aufnahme (Influx), Distribution,

Akkumulation und Efflux von Hypericin in renalen Karzinomzellen: ........................ 34

3.2.5 Untersuchungen der Effekte von photoaktiviertem und nicht photoaktiviertem

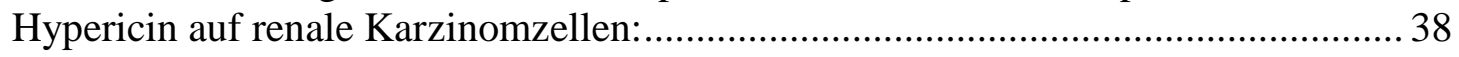

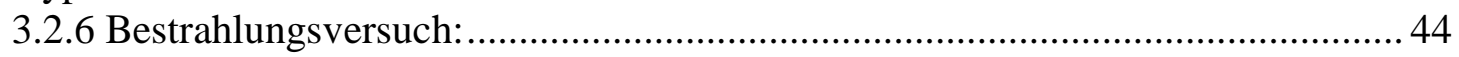

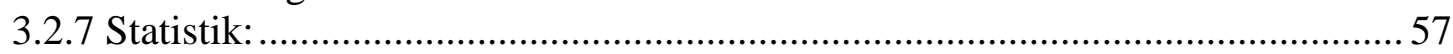

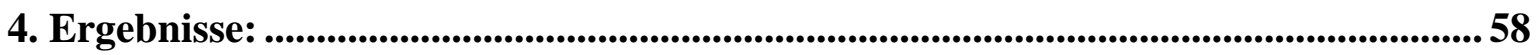

4.1 Ergebnisse zur intrazellulären Aufnahme (Influx), Distribution, Akkumulation und Efflux von Hypericin in bzw. aus renalen Karzinomzellen: ...........................58

4.1.1 Ergebnisse der Hypericin-Influx und -Efflux-Untersuchungen: ...................... 58

4.1.2 Ergebnisse zur intrazellulären Hypericin-Distribution:.....................................6 60

4.1.3 Ergebnisse zum Rhodamin-123-Efflux aus renalen Karzinomzellen: ................62

4.2 Untersuchungsergebnisse zu den Effekten von photoaktiviertem und nicht photoaktiviertem Hypericin auf renale Karzinomzellen: ........................................ 64

4.2.1 Ergebnisse zu den Dunkelwirkungen von Hypericin auf den Zellmetabolismus

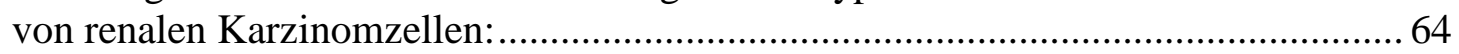

4.2.2 Untersuchungsergebnisse zu den Wirkungen von photoaktiviertem Hypericin

auf den Zellmetabolismus von renalen Karzinomzellen: ..........................................6 65

4.2.3 Versuchsergebnisse zu den Dunkeleffekten von Hypericin auf die

Koloniebildungsfähigkeit von renalen Karzinomzellen: ............................................ 66

4.2.4 Untersuchungsergebnisse zur Apoptoseinduktion durch Hypericin in

Kombination mit bzw. ohne Beleuchtung in renalen Karzinomzellen: ...................... 67

4.2.5 Ergebnisse des Singulett-Sauerstoff-Nachweis mittels redoxsensitivem GFP: . 68

4.3.1 Untersuchungsergebnisse zur Wirkung von Hypericin in Kombination mit

Bestrahlung auf den Zellmetabolismus von renalen Karzinomzellen:....................... 71 
4.3.2 Untersuchungsergebnisse zur Apoptoseinduktion durch Hypericin in Kombination mit Bestrahlung in renalen Karzinomzellen:

4.3.3 Untersuchungsergebnisse zu den Effekten von Hypericin in Kombination mit Bestrahlung auf die Koloniebildungsfähigkeit von renalen Karzinomzellen:....

4.3.4 Untersuchungsergebnisse zu den Effekten von Hypericin in Kombination mit Bestrahlung auf die Zellzyklusverteilung von renalen Karzinomzellen:

4.3.5 Nachweis strahleninduzierter Doppelstrangbrüche in renalen Karzinomzellen-

Ergebnisse der Immunfluoreszenz-Untersuchungen:

4.3.7 Wirkungen von Hypericin auf die Aktivität der DNA-Proteinkinase C (DNA-

PKC) in renalen Karzinomzellen-Ergebnisse aus Westernblot- und

Immunfluoreszenz-untersuchungen:

4.3.9 Wirkungen von Hypericin auf die Expression von Phosphoinositol-3-Kinase und $\mathrm{X}$-Ray Repair Cross Complementing-Faktor-4 in renalen Karzinomzellen- Ergebnisse

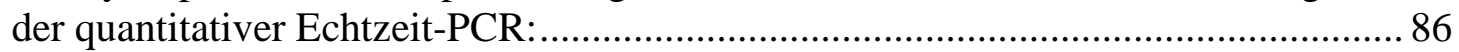

5. Diskussion:

5.1 Aufnahme, Distribution, Akkumulation und Efflux von Hypericin in bzw. aus renalen Karzinomzellen:

5.1.1 Aufnahme und Persistenz von Hypericin in renalen Karzinomzellen:................ 88

5.1.2 Intrazelluläre Distribution und Akkumulation von Hypericin in renalen

Karzinomzellen: 90

5.2 Dunkelwirkung von Hypericin auf renale Karzinomzellen: ............................. 91

5.3 Phototoxische Wirkung von Hypericin auf renale Karzinomzellen: .................. 92

5.4 Strahlensensitivierende Wirkung von Hypericin auf renale Karzinomzellen:.. 94

6. Zusammenfassung:

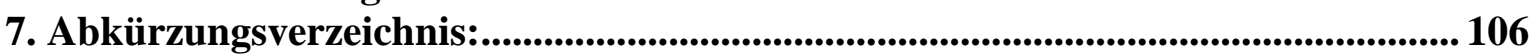

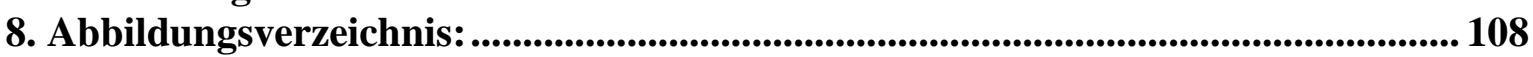

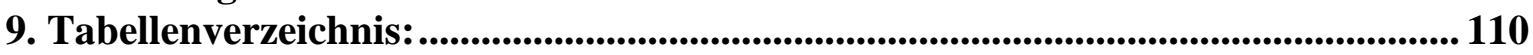

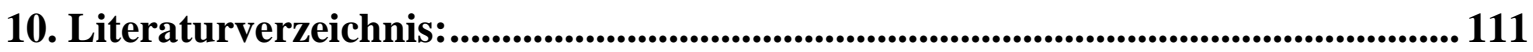

11. Eigene Veröffentlichungen und Tagungsbeiträge:...........................................121

12. Danksagung: ................................................................................................................................ 122

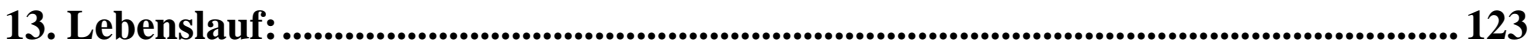




\section{Einleitung:}

\subsection{Das Johanniskraut:}

Das Johanniskraut gehört zur Familie der Johanniskraut- bzw. Hartheugewächse (Hypericaceae). Die Pflanzengattung Hypericum umfasst ca. 450 Arten (Robson, 2003). Das natürliche Verbreitungsgebiet des Johanniskrautes erstreckt sich über die tiefen bis mittleren Höhenlagen von Westeuropa, Westasien und Nordafrika. In Ostasien, Australien, Nord- und Südamerika ist es eingebürgert worden. Aufgrund der geringen Standortansprüche wächst es als Pionierpflanze in Gebüschsäumen, Brachen, an Waldrändern und -lichtungen, Wegen und Böschungen, in Magerwiesen, Ginster- und Heidekrautheiden und blüht von Ende Juni bis September.
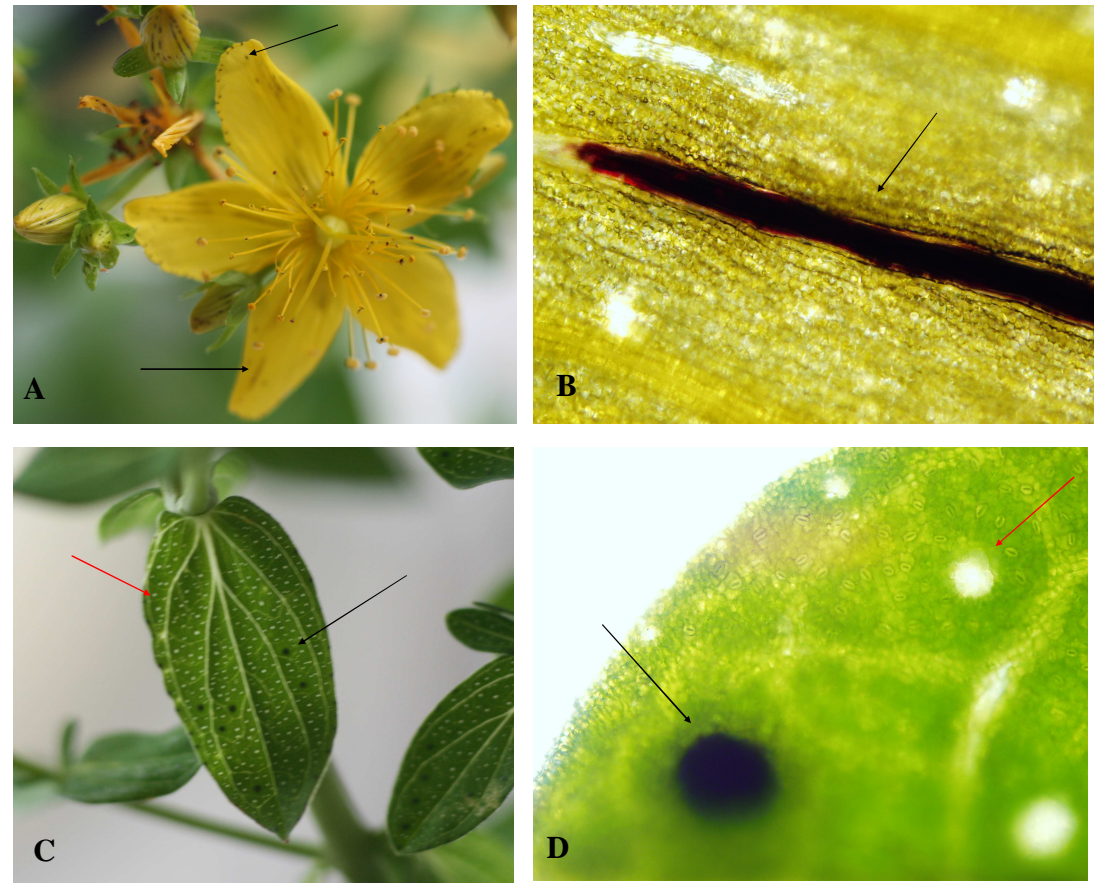

Abbildung 1: Blüte (A, B) und Blätter (C, D) des Gewöhnlichen Johanniskrauts (Hypericum perforatum L.). Die schwarzen Pfeile zeigen die Hypericin-sezernierenden Drüsen auf Blüten und Blättern, die roten Pfeile markieren die durchscheinenden Öldrüsen auf den Blättern, die die Blätter perforiert aussehen lassen.

Vor allem das Gewöhnliche Johanniskraut (Hypericum perforatum L.) ist wegen seiner verschiedenen Inhaltsstoffe eine seit der Antike geschätzte Heilpflanze. Die Blätter der Pflanze erscheinen aufgrund kugeliger Sekretbehälter durchscheinend punktiert, woraus sich der Artname ,perforatum“ ableiten lässt. Des Weiteren sind sowohl Blüten als auch 
Blätter mit schwarzbraunen Drüsen übersäht, in denen der Wirkstoff Hypericin sezerniert wird.

Johanneskrautextrakte, die seit der Antike in der Volksmedizin zur Behandlung verschiedenster Erkrankungen eingesetzt werden, enthalten neben Hypericin und dessen Derivaten (Pseudohypericin, Protohypericin, Protopseudohypericin) u. a. auch Flavonoide (Quercetin, Hyperosid, Luteolin, Kämpferol, Myrcetin, Rutin, Dihydroquercetin), Säuren (Chlorogensäure, Kaffeesäure, Ascorbinsäure), Hyperforin, Gerbstoffe (Catechin, Epicatechin), Farbstoffe (Lutein, Chlorophyll), Anthrachinone (Skyrin, Oxyskyrin), Xanthonderivate (Tetrahydroxyxanthon, Maculatuxanthon, Mangiferin), ätherische Öle (z.B. Thujen, Pinen, Camphen, Myrcen, Terpinen, Cymen, Campher, Geraniol, Caryophyllen, Humulen, Cubeben, Calamenen, Cadinen), Fette und Wachse (Roth, 1990). Die vermutlich frühste Erwähnung der medizinischen Verwendung von Johanniskraut geht auf Nikandros von Kolophon im zweiten vorchristlichen Jahrhundert zurück, der Hypericum gegen Vergiftungen durch Tiere einsetzte (Roth 1990). Von der Zeit der griechischen und römischen Autoren Celsus und Dioskorides über Galenus bis zu Paracelsus und Matthiolus gehört das Johanniskraut ohne Unterbrechung zum Arzneimittelschatz. Die Anwendungen reichten von magischen Praktiken bis zur Wundbehandlung und der Verwendung als Antidepressivum (Falk, 1999).

Paracelsus (1493-1541) erklärt entsprechend der Signaturenlehre der Alchemisten: "Ich will euch berichten, dass die Löcher, die in den Blättern sind, bedeuten, dass dieses Kraut für alle inneren und äußeren Öffnungen der Haut eine Hilfe ist. Was durch die Poren ausgetrieben werden soll, kann dadurch geschehen. Die Blüten faulen in der Form des Blutes. Das ist ein Zeichen, dass sie für Wunden und, was von Wunden kommt, gut sind. Auch soll man sie gebrauchen, wo man Fleisch zügeln muss. Die Adern auf den Blättern sind ein Zeichen, dass Perforata alle Phantasiegebilde im Mensch und auch außerhalb austreibt" (Vonarburg, 2005).

Die pharmakologischen Wirkungen des Johanniskrautes stehen auch heute noch im Interesse der Wissenschaft und sind in zahlreichen Untersuchungen bestätigt worden. So zeigen Johanniskrautextrakte u. a. antidepressive, antibakterielle und antivirale Effekte, die jeweils auf die verschiedenen Inhaltsstoffe zurückzuführen sind (Barnes et al., 2001). Auf die photodynamischen Wirkungen von Hypericum wurde man erstmals zu Beginn des 20. Jahrhunderts im Zusammenhang mit den Photodermatosen, die bei Weidetieren nach Fraß an Johanniskraut auftraten, aufmerksam (Hausmann, 1923). Aber erst Mitte des 
Jahrhunderts konnte der Wirkstoff Hypericin für die photodynamische Wirkung der Johanniskrautextrakte verantwortlich gemacht werden (Falk, 1999).

\subsection{Hypericin:}

Hypericin wird zur Substanzgruppe der Phenanthroperylenchinone (1,3,4,6,813Hexahydroxy-10,11-dimethylphenanthro[1,10,9,8-opqra]perylen-7,14-dion) gezählt und ist ein sekundärer Pflanzenstoff, der vermutlich durch den endophytischen Pilz INFU/Hp/KF/34B (Kusari et al., 2007) in den Drüsen auf den Blütenblättern und Blättern von Pflanzen der Gattung Hypericum zum Schutz der Pflanze vor phytophagen Insekten sezerniert wird. Der Gehalt an Hypericin in den Hypericum-Pflanzen beträgt $<0,05 \%$ und variiert in Abhängigkeit von der Art sowie den Standortbedingungen der Pflanze. Das Hypericin wird hauptsächlich aus dem Gewöhnlichen Johanniskraut (Hypericum perforatum, L.) extrahiert (Falk, 1999). Die erste detaillierte Publikation zur Isolierung von Hypericin aus Hypericum perforatum ist von Brockmann et al. (1939) veröffentlicht worden. 1942 publizierten Brockmann et al. erstmals die korrekte chemische Formel des Hypericins $\left(\mathrm{C}_{30} \mathrm{H}_{16} \mathrm{O}_{8}\right)$ und acht Jahre später die korrekte Struktur des Moleküls. Hypericin hat ein Molekulargewicht von 504,5 g/mol (Anker et al., 1995).

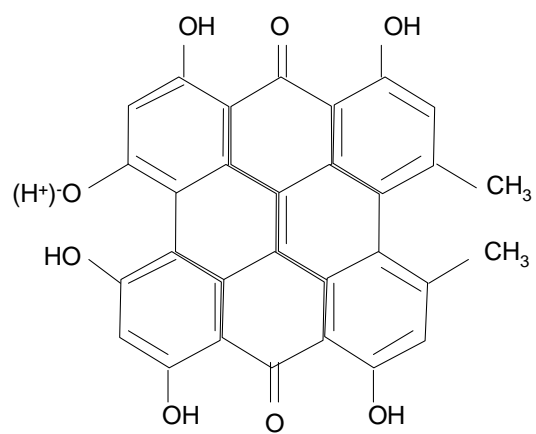

Abbildung 2: Chemische Struktur des nativen Hypericins.

\subsubsection{Eigenschaften und Wirkungen des Hypericins:}

Seit ca. 30 Jahren wird das Hypericin intensiv wissenschaftlich untersucht. Zahlreiche Untersuchungen berichten von antibakteriellen, antiviralen (bei HIV und Hepatitis C), antidepressiven, antineoplastischen, wundheilungsfördernden, entzündungshemmenden, 
strahlen- und photosensibilisierenden Wirkungen des Hypericins. Die den Wirkungen zugrunde liegenden Mechanismen bleiben jedoch häufig ungeklärt (Kubin, 2005).

Insbesondere die antineoplastischen Effekte des Hypericins sind von wissenschaftlichem Interesse. Während es zahlreiche Publikationen zu antineoplastischen Effekten auf verschiedene Malignome im Zusammenhang mit den photosensibilisierenden Eigenschaften des Hypericins gibt (Kubin,2005; Agostinis et al., 2001), berichten nur Zhang et al. (1996) von der Radiosensitivierung humaner maligner Gliomzellen durch Hypericin.

Im Folgenden sollen nur die für diese Arbeit relevanten Eigenschaften und Wirkungen des Hypericins kurz erläutert werden:

\subsubsection{Intrazelluläre Hypericin-Aufnahme und -Akkumulation:}

Hypericin ist hydrophob und unlöslich in Wasser, Öl, Methylenchlorid und vielen anderen unpolaren Lösungsmitteln. Jedoch löst sich Hypericin in basischen wässrigen Lösungen, organischen Basen wie z.B. Pyridin und polaren organischen Substanzen wie z.B. Aceton, Ethanol und Methanol. Des Weiteren bildet es Komplexe mit biologischen Makromolekülen wie z.B. DNA, humanem Serumalbumin, weiteren Plasmaproteinen, Membranen und zellulären Kompartimenten (Kubin, 2005).

Vermutlich aufgrund seiner Lipophilie zeigt das Hypericin eine Affinität zu zellulären Lipidmembranstrukturen (Mazur und Meruelo, 1993; Thomas und Pardini, 1992). Die zelluläre Aufnahme von Hypericin erfolgt daher weder über einen aktiven Transport noch über einen Rezeptor-abhängigen Transport sondern über Diffusion und Löslichkeit in Membranen (Thomas und Pardini, 1992). Hypericin akkumuliert vor allem in Zytoplasmamembranen und besonders häufig in den Membranen des Endoplasmatischen Retikulums und des Golgi-Apparates. Die intrazelluläre Distribution und Akkumulation des Hypericins scheint abhängig vom Zelltyp zu sein (Sattler et al., 1997). In Kolokalisationsstudien mit Hypericin und Rhodamin-123, einem spezifischen mitochondrialem Fluoreszenzmarker, kann keine Kolokalisation von Hypericin und Mitochondrienmembranen in HeLa-Zellen nachgewiesen werden (Agostinis et al., 2002). In Kolonkarzinomzellen der Linie Caco-2 akkumuliert Hypericin in zytoplasmatischen und nukleären Membranen.

Verschiedene in vivo-Untersuchungen zeigen, dass Hypericin vermehrt in Tumorgewebe im Vergleich zu gesundem Gewebe akkumuliert (Agostinis et al., 2002; Van de Putte et al., 2006; Chen et al., 2001a; Chen et al., 2002). Die vermehrte Akkumulation von Hypericin 
in Tumorgewebe variiert in Abhängigkeit von der Tumorart. So ist z.B. der Hypericingehalt im Gewebe eines subkutanen P388-Lymphoms um das 16-fache gegenüber dem umgebenden gesunden Gewebe erhöht (Chen und De Witte, 2000). Eine ähnliche Hypericinverteilung ist ebenfalls in RIF-1 Fibrosarkomen gefunden worden (Chen et al., 2001b). Die der tumoraffinen Akkumulation zugrunde liegenden Mechanismen sind noch nicht hinreichend bekannt, aber folgende Mechanismen sind denkbar (Pass, 1993):

- Verstärkte Aufnahme durch Makrophagen und Tumor-assoziierte Monozyten.

- erhöhte Zufuhr aufgrund von Tumorneovaskularisierung.

- erhöhte Retention aufgrund verminderter Löslichkeit im sauren Milieu des Tumorgewebes.

- verminderter Abtransport aufgrund unterentwickelter Tumorlymphgefäße.

\subsubsection{Inhibitorische Wirkung von Hypericin auf Enzyme:}

Hypericin zeigt eine hohe nicht spezifische Affinität zu Proteinen (Miskovsky, 2002), daher könnten einige der pharmakologischen Wirkungen von Hypericin auf der Interaktion mit verschiedenen Enzymen beruhen (Kubin, 2005). Zahlreiche Publikationen berichten von der inhibitorischen Wirkung des Hypericins auf Enzyme wie u. a. Proteinkinase C (PKC) (Kubin , 2005; Takahashi et al., 1989; Agostinis et al. 1995; Utsumi, 1995) , Tyrosinkinasen des Epidermalen Wachstumsfaktor-Rezeptor (EGFR = epidermal growth factor receptor) (Agostinis et al., 1995; de Witte et al., 1993) und PI3K (Phosphatidylinositol-3-Kinase) (Frew, 1994), die unter anderem bei Wachstum, Proliferation und Radioprotektion von Tumorzellen eine Rolle spielen (siehe unten 1.3.2). Die meisten Arbeiten zeigen eine lichtabhängige, inhibitorische Wirkung von Hypericin auf die unterschiedlichen Enzyme. Nur wenige Arbeiten berichten von einer Dunkelwirkung z.B. auf PKC (Utsumi, 1995), PI3K (Frew, 1994), Succinoxidase (Thomas et al., 1992) und Superoxiddismutase (Johnson und Pardini, 1998). Daher ist es schwierig $\mathrm{zu}$ beurteilen, ob die inhibitorische Wirkung tatsächlich auf die direkte Interaktion zwischen Hypericin und dem jeweiligen Enzym oder aber auf einen oxidativen Schaden am Enzym in Folge von lichtinduzierter Singulettsauerstoffbildung (siehe 1.2.1.3) zurück zu führen ist. Viele der bisherigen Publikationen beantworten diese Frage noch nicht ausreichend. 
1.2.1.3 Fluoreszenz und photosensibilisierenden Wirkungen von photoaktiviertem Hypericin:

Derzeit steht besonders die diagnostische und therapeutische Anwendung von Hypericin in Kombination mit Licht im Interesse der Wissenschaft. Hypericin ist ein roter Fluoreszenzfarbstoff mit zwei Excitationsmaxima bei 548 und 590nm und zwei Emissionsmaxima bei 595nm und 640nm (Head et al., 2006; Skalkos, 2006).

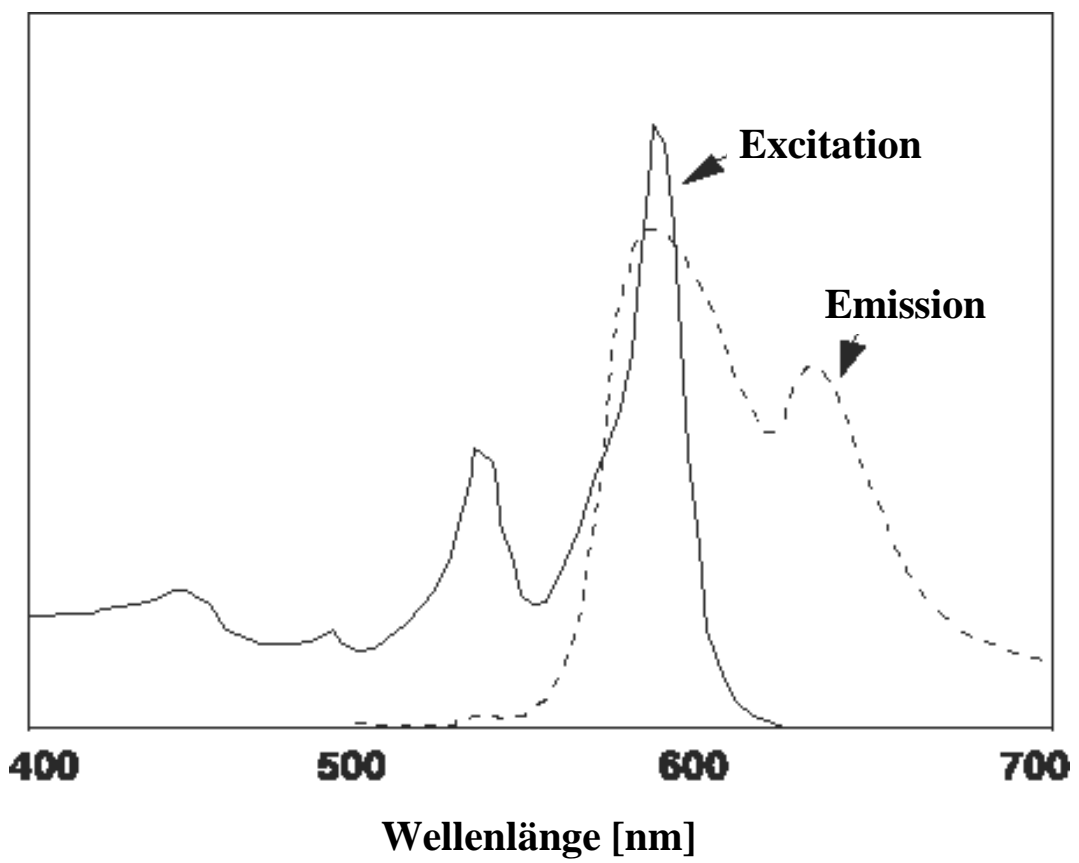

Abbildung 3: Excitations- und Emissionsspektrum von Hypericin (Head et al., 2006).

Aufgrund der roten Fluoreszenz und der vermehrten Akkumulation in neoplastischen Zellen scheint das Hypericin ein geeigneter Farbstoff für die Fluoreszenzdiagnostik von Malignomen zu sein. Tatsächlich wird das Hypericin bereits in der endoskopischen Fluoreszenzdiagnostik z.B. bei Harnblasenkarzinomen eingesetzt (Kamuhabwa et al., 2004; Pytel und Schmeller, 2002; D’Hallewin et al., 2000; Olivo et al., 2003; Kubin, 2005).

Des Weiteren ist Hypericin ein Photosensitizer, der unter oxischen Bedingungen und Lichtexposition verschiedene Elektronen- und Energietransferreaktionen auf Sauerstoff katalysiert. Der dabei intrazellulär entstehende hoch reaktive Singulettsauerstoff induziert Apoptose bzw. Nekrose in den Zellen (Agostinis et al., 2000; Agostinis et al., 2002; Kubin, 2005). Diese phototoxische Wirkung des Hypericins wird im Rahmen der so genannten 
Photodynamischen Therapie (PDT) zur Behandlung von oberflächlichen Tumoren genutzt (Alecu et al., 1998; Kubin et al. 2000).

Die allgemeinen Mechanismen, die der Entstehung von Fluoreszenz und Singulettsauerstoff durch Anregung eines Photosensitizers zu Grunde liegen, sollen im Folgenden kurz erläutert werden:

Im Allgemeinen entsteht Fluoreszenz durch die Anregung eines Fluorochroms mit Licht geeigneter Wellenlänge. Die Fluorochrome (z.B. Hypericin) haben häufig aromatische Ringstrukturen und besitzen delokalisierte Elektronen in den so genannten $\pi$-Orbitalen. Die Elektronen dieser Orbitale treten leicht in Wechselwirkung mit der Umgebung und werden durch Absorption eines Anregungsphotons in ein höheres Orbital $\left(\pi^{*}\right)$ überführt. Die dabei ablaufenden energetischen Prozesse können mit Hilfe des Jablonski-Diagramms dargestellt werden (Abb. 4).

\section{Jablonski Diagramm}

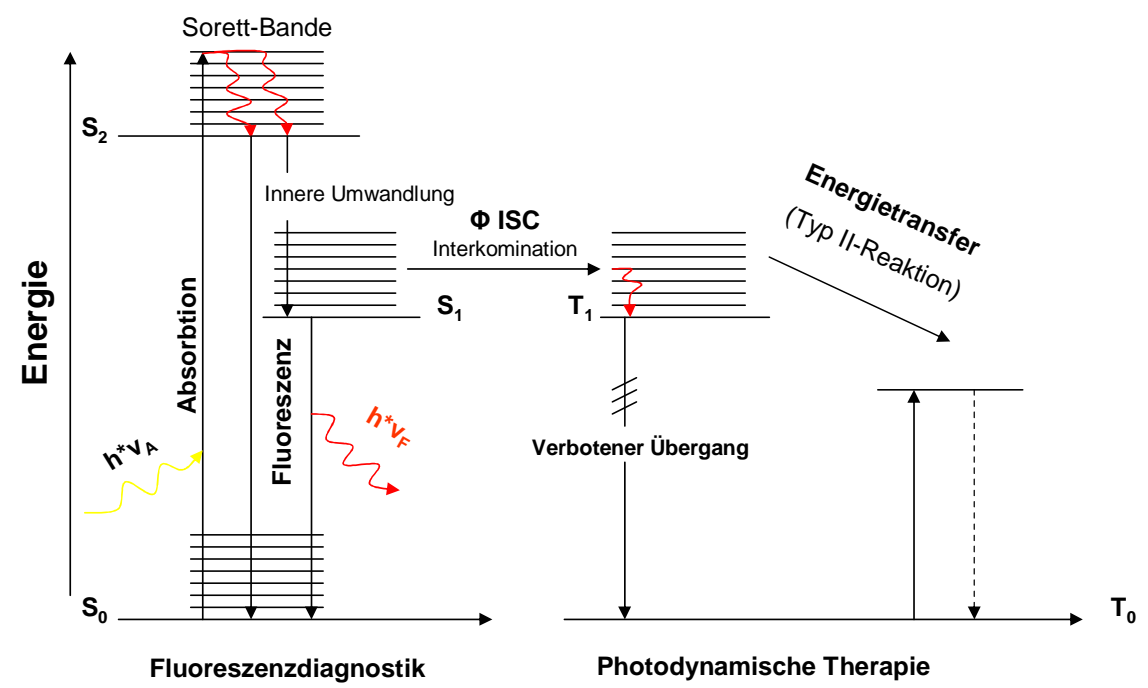

Abbildung 4: Jablonski-Diagramm: Allgemeines Schema zu den ablaufenden energetischen Prozessen bei der Entstehung von Fluoreszenz und Singulettsauerstoff durch Anregung eines Photosensitizers (z.B. Hypericin). 
Durch die Absorption eines Anregungsphotons $\left(h * v_{A}\right)$ wird ein Elektron aus einem inneren in ein äußeres Orbital angehoben und das Atom bzw. Molekül wird aus dem Grundzustand $S_{0}$ in einen der angeregten Zustände $S_{1}$ oder $S_{2}$ überführt.

$$
\mathrm{S}_{0}(\uparrow \downarrow)+\mathrm{h}^{*} v_{\mathrm{A}} \rightarrow \mathrm{S}_{1} *(\uparrow \downarrow) \text { bzw. } \mathrm{S}_{2} *(\uparrow \downarrow)
$$

Dabei bezeichnen die gegenläufigen Pfeile den Singulett-Zustand des Moleküls und der Stern den angeregten Zustand. Die Energie des absorbierten Photons ergibt sich aus dem Planckschen Wirkungsquantum $\left(\mathrm{h}=6,6262 \times 10^{-34} \mathrm{Js}\right)$ multipliziert mit der Frequenz $(v)$ des Photons. Die mittlere Verweildauer im angeregten $\mathrm{S}_{2}$-Zustand (FluoreszenzLebenszeit) ist bei vielen Fluorochromen im Bereich von 10 ns. Der Übergang des Elektrons aus dem $S_{2}$ - in den $S_{1}$-Zustand erfolgt ohne Emission eines Photons und wird als „innere Umwandlung“ (internal conversion) oder nicht strahlende Relaxation bezeichnet. Die absorbierte Energie wird dabei vollständig in Wärme umgewandelt. Bei dem Übergang des Elektrons aus einem der angeregten Zustände $\left(S_{1}\right.$ bzw. $\left.S_{2}\right)$ in den Grundzustand $S_{0}$ wird die freiwerdende Energie als Fluoreszenzphoton $\left(\mathrm{h} \nu_{\mathrm{F}}\right)$ emittiert und kann als Fluoreszenz beobachtet werden.

$$
\mathrm{S}_{1}^{*}(\uparrow \downarrow) \text { bzw. } \mathrm{S}_{2}^{*}(\uparrow \downarrow) \rightarrow \mathrm{S}_{0}(\uparrow \downarrow)+\mathrm{h}^{*} v_{\mathrm{F}}+\text { Energierest }
$$

Dabei ist die Energie des emittierten Fluoreszenzphotons $\left(h^{*} v_{F}\right)$ immer geringer als die Energie des absorbierten Anregungsphotons $\left(h^{*} v_{A}\right)$. Daher ist die emittierte Fluoreszenz in längerwellige Bereiche verschoben (Rotverschiebung) als das Anregungslicht. Die Differenz der Wellenlängen zwischen absorbierten und emittierten Photonen wird als Stokes-Shift bezeichnet:

$$
\lambda_{\mathrm{s}}=\left|\lambda_{\text {in }}-\lambda_{\text {out }}\right|
$$

wobei gilt:

$\lambda_{\mathrm{s}}$ : Stokes-Shift,

$\lambda_{\text {in: }}$ Wellenlänge der absorbierten Strahlung und

$\lambda_{\text {out }}:$ Wellenlänge der emittierten Strahlung. 
Die Energiedifferenz, die für die Erzeugung eines Photons aufgewendet wird, ermittelt sich durch

$$
\Delta E=h c\left(\frac{1}{\lambda_{\text {in }}}-\frac{1}{\lambda_{\text {out }}}\right)
$$

wobei gilt:

h: Plancksches Wirkungsquantum und

c: Lichtgeschwindigkeit.

Die Elektronen liegen regulär mit antiparallelem Spin im $\mathrm{S}_{0^{-}}, \mathrm{S}_{1^{-}}$bzw. $\mathrm{S}_{2}$-Zustand vor, was als Singulettzustand bezeichnet wird.

Bei Verbindungen (z.B. Hypericin), bei denen die Lebensdauer des angeregten Singulettzustandes lang ist, kann es zu einem Übergang aus dem angeregten Singulettzustand in einen Triplett-Zustand (T1) kommen. Bei diesem Vorgang, der als „Interkombination" (inter system crossing = ISC) bezeichnet wird, kommt es zu einer Spinumkehr des angeregten Elektrons.

$$
\mathrm{S} 1 *(\uparrow \downarrow) \stackrel{\mathrm{ISC}}{\longrightarrow} \mathrm{T} 1 *(\uparrow \uparrow)
$$

Dieser Triplett-Zustand ist relativ langlebig, da ein Übergang in den Grundzustand aufgrund der dafür erforderlichen Spinumkehr sehr unwahrscheinlich ist. Die lange Lebensdauer des Triplett-Zustandes ermöglicht Wechselwirkungen mit besonders vielen Molekülen der Umgebung. Bei einem Zusammentreffen mit molekularem Sauerstoff, der einen Triplett-Grundzustand hat, ist ein Energieaustausch zwischen den Molekülen möglich, wobei beide Moleküle in den Singulett-Zustand übergehen.

$$
\mathrm{T}_{1} *(\uparrow \uparrow)+\mathrm{O}_{2}(\uparrow \uparrow) \rightarrow \mathrm{S}_{0}(\uparrow \downarrow)+\mathrm{O}_{2} *(\uparrow \downarrow)+\text { Energierest }
$$

Dieser Energietransfer kann stattfinden, da die Energie des angeregten Hypericinmoleküls größer ist als die Energie, die für einen Übergang des Sauerstoffs aus dem TriplettGrundzustand in einen angeregten Singulett-Zustand erforderlich ist. Die Lebensdauer des dabei entstehenden hoch reaktiven Singulettsauerstoffes ist besonders lang. Aufgrund seiner chemischen Reaktionsfreudigkeit und der Langlebigkeit kann der Singulettsauerstoff in seiner Umgebung oxidativen Schaden anrichten, der je nach Ausprägung in einem apoptotischen oder nekrotischen Zelltod resultiert. Geringe Hypericinkonzentrationen in 
Kombination mit geringer Beleuchtungsstärke führen häufig zu einem apoptotischen Zelltod, währen höhere Hypericinkonzentrationen und/oder Beleuchtungsstärken eher Nekrosen verursachen (Agostinis et al., 2000; Ali und Olivo, 2003).

Die Apoptose ist ein physiologisch ablaufender programmierter Zelltod. Im Gegensatz zur Nekrose läuft dieser Prozess gerichtet $\mathrm{ab}$ und geht in vivo nicht mit einer Entzündungsreaktion einher. Die apoptotischen Zellen pumpen aktiv vor allem Kaliumionen nach außen und kontrahieren ihr Zytoskelett. Dies führt $\mathrm{zu}$ einer Schrumpfung der Zelle. Das Chromatin kondensiert und zerfällt in Fragmente. Die DNA wird ebenfalls fragmentiert. Im späteren Stadium der Apoptose bilden sich Ausstülpungen der Plasma- und Kernmembran („,blebbing“), die als so genannte ,apoptotische Körperchen“ (apoptotic bodies) abgeschnürt werden. Diese membranumgrenzten Vesikel, die Zellmembranbestandteile und DNA-Fragmente enthalten, sowie die geschrumpften Zellkörper werden von Phagozyten in den Phagolysosomen abgebaut.

Die Apoptose kann in die Initiations- und die Effektor-Phase unterteilt werden. Die Initiation der Apoptose kann über zwei verschiedene Wege erfolgen:

Der extrinsische rezeptorvermittelte Weg (Apoptose Typ I) wird durch Ligandenbindung (z.B. Tumernekrosefaktor $=\mathrm{TNF}$ ) an die Rezeptoren der TNF-Rezeptorfamilie eingeleitet. Durch Trimerisierung dieser so genannten Todesrezeptoren wird die Bindung von Adaptermolekülen wie das „TNF-Rezeptor assoziierte Protein“ (TRADD) ermöglicht, an das wiederum das „Fas assoziierte Protein mit Todesdomäne“ (FADD) bindet. Das FADD hat eine Todeseffektordomäne (DED, ,death effector domain“), über die die proCaspase 8 mit ihrer DED an den Komplex bindet. Diese kann sich nun durch die entstandene hohe lokale Konzentration autokatalytisch aktivieren. Die Induktion der Apoptose durch photoaktiviertes Hypericin erfolgt jedoch über den intrinsischen mitochondrialen Weg (Apoptose Typ II). Die Bildung von durch die Photoaktivierung von Hypericin entstehenden reaktiven Sauerstoffspezies (ROS = reactive oxygen species) ist assoziiert mit einem rapiden Zusammenbruch des mitochondrialen Membranpotentials. Dies führt zu einer Cytochrom C-Freisetzung aus dem mitochondrialem Intermembranraum in das Zytosol. Durch die Bindung von Cytochrom $\mathrm{C}$ an den apoptotischen ProteaseAktivierungsfaktor-1 (Apaf-1) kommt es unter ATP-Verbrauch zu einer Konformationsänderung des Proteins. Durch die Konformationsänderung wird die Bindung an die Procaspase 9 möglich, die nun autolytisch aktiviert wird. Dieser Komplex wird Apoptosom genannt. 
In der Effektorphase wird sowohl durch die aktivierte Caspase 8 aus dem extrinsischen Weg als auch durch das Apoptosom des intrinsischen Weges die Caspasen-Kaskade aktiviert, die letztlich zum apoptotischen Zelltod führt.

\section{Apoptotische Signalwege}

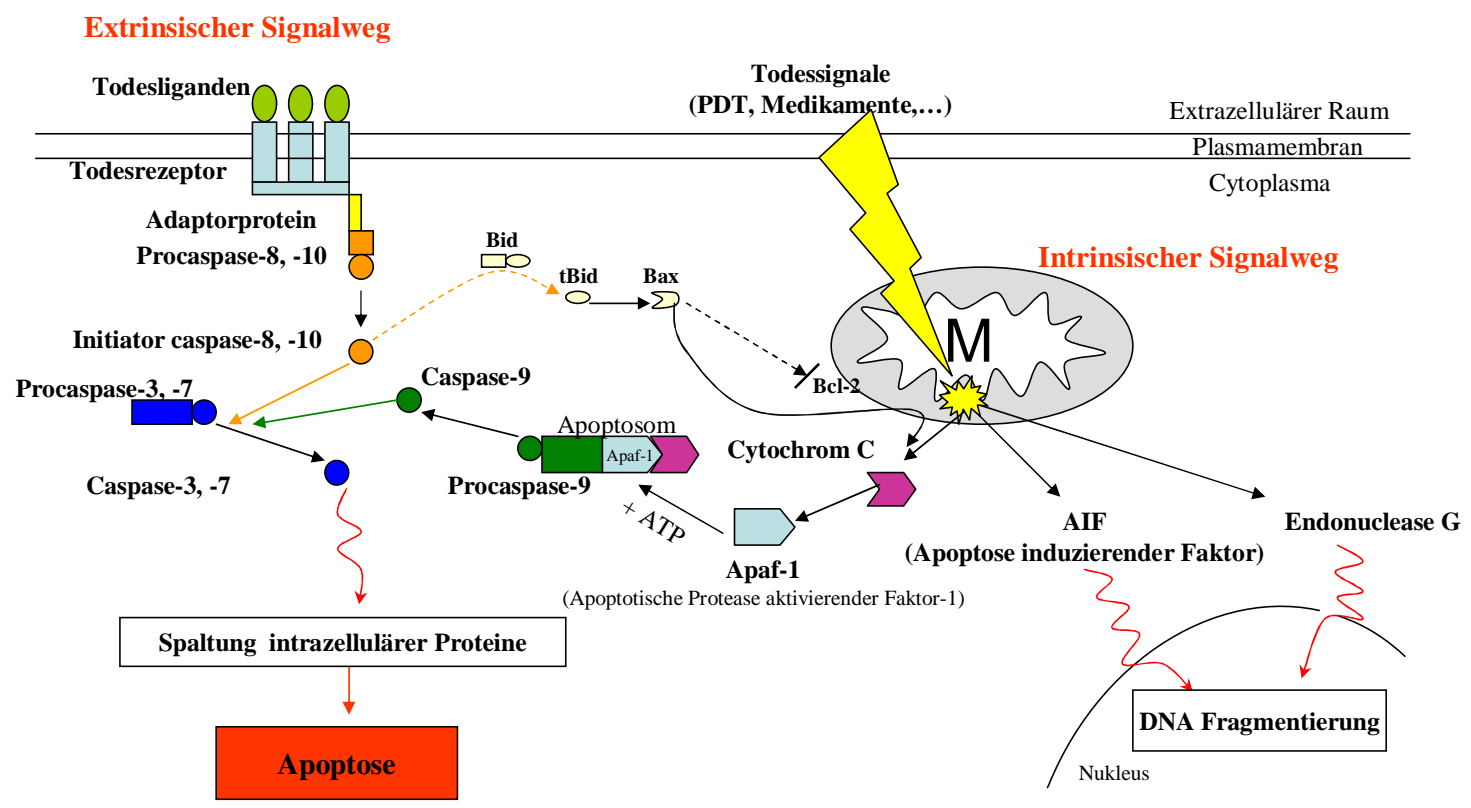

Abbildung 5: Schematische Darstellung der bei einer Apoptose ablaufenden extrinsischen und intrinsischen Signalkaskaden.

Aufgrund der Eigenschaften vermehrt in neoplastischem Gewebe zu akkumulieren und in Kombination mit Licht Apoptose bzw. Nekrose zu induzieren, scheint Hypericin ein geeigneter Photosensitizer für die so genannte photodynamische Therapie (PDT) zu sein. Daher gibt es derzeit viele Untersuchungen zur Behandlung verschiedener Malignome wie z.B. Bronchial- und Blasenkarzinom, neoplastische Erkrankungen des Gehirns, der Augen, Ovarien oder der Haut durch eine Photodynamische Therapie mit Hypericin (Agostinis et al., 2002). 


\subsection{Das Nierenzellkarzinom:}

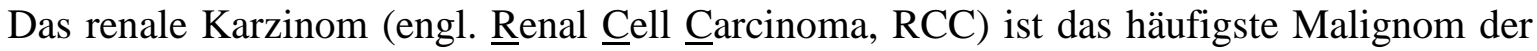
Niere. Männer erkranken etwa doppelt so häufig am Nierenzellkarzinom wie Frauen. Weltweit kann eine steigende Inzidenz beobachtet werden, wobei die jährliche Neuerkrankungsrate in Deutschland derzeit etwa bei 10.000 Männern und ca. 6.300 Frauen liegt (Kunec und Wolff, 2009). Die Erkrankung tritt häufig zwischen dem 50. und 70. Lebensjahr auf.

Das Nierenzellkarzinom lässt sich histopathologisch in folgende Typen unterteilen (Thoenes et al. 1986):

- Klarzelliger Typ (häufigster Typ, ca. 80\%)

- Chromophiler (Papillärer) Typ (10-15\%)

- Chromophober Typ (5\%)

- Seltene Formen: Sammelrohrkarzinom (Bellini-Gang-Typ) und nicht klassifizierbare Nierenzellkarzinome (3-5\%)

Aufgrund der epidemiologischen Relevanz wird im Folgenden nur auf das klarzellige Nierenzellkarzinom eingegangen.

Aufgrund des durch die tumorspezifische metabolische Fehlregulation bedingten hohen zytoplasmatischen Gehaltes an Glykogen und Fetten erscheinen die Zellen lichtmikroskopisch klar transparent. Die Tumoren wachsen solide und weisen eine ausgeprägte Neovaskularisierung auf (Störkel, 2007).

\subsubsection{Molekularpathologie des Nierenzellkarzinoms:}

Aufgrund genetischer Analytik konnten bisher einige Tumorsuppressor-Gene und Onkogene identifiziert werden, die bei der Entstehung humaner Nierenzellkarzinome eine wesentliche Rolle spielen. So kommt insbesondere dem von-Hippel-Lindau-Gen (VHLGen), dem Tuberosklerose-Gen-2 ( $\left.\mathrm{TSC}_{2}-\mathrm{Gen}\right)$ und dem MET-Protoonkogen eine wichtige Bedeutung bei der Karzinogenese des Nierenzellkarzinoms zu. Während Mutationen im MET-Protoonkogen bei der Entstehung papillärer Nierenzellkarzinome eine Rolle spielen, sind das VHL-Gen und das $\mathrm{TSC}_{2}$-Gen hauptsächlich an der Genese klarzelliger Nierenzellkarzinome beteiligt (Buentig et. al, 2002, Furge et al., 2007). Klarzellige Nierenzellkarzinome sind vor allem durch Mutationen im VHL-Tumorsuppressor-Gen charakterisiert, da etwa 70\% aller klarzelligen RCCs ein biallele Inaktivierung des VHLGenes (3p25) aufweisen (Störkel, 2007; Iliopoulos, 2006) . Das VHL-Genprodukt (pVHL) 
pendelt zwischen Zytoplasma und Kern und fungiert als Substratbindungsdomäne eines E3-Ubiquitinligase-Komplexes (Conaway et al., 1998), der Proteine der proteosomalen Degradation zuführt (Lisztwan et al., 1999). Demnach spielt das pVHL eine wichtige Rolle bei zellulären Funktionen wie z.B. der Zellzyklusregulation, der Stabilisierung von Mikrotubuli oder der Synthese von Bestandteilen der extrazellulären Matrix. Der Hypoxieinduzierte Transkriptionsfaktor (HIF) ist ein Substrat des pVHL und wird regulär unter normoxischen Bedingungen durch den pVHL-E3-Ubiquitinligasekomplex ubiquitinyliert und proteasomal degradiert. Unter hypoxischen Bedingungen oder bei inaktivem pVHL kommt es zu einer Stabilisierung des HIF (Störkel, 2007). HIF aktiviert die Transkription verschiedener Gene, die für Proteine kodieren, die in Angiogenese-, Proliferations-, Zelldifferenzierungs- und weitere metabolische Prozesse involviert sind. Die im renalen Karzinom durch inaktiviertes VHL-Gen verursachte HIF-Akkumulation führt zu einer Überexpression von:

- Kohlenstoff-Anhydrase IX (CAIX = carbonic anhydrase $\underline{\text { IX }})$,

- Vaskulärem endothelialem Wachstumsfaktor (VEGF = vascular endothelial growth factor),

- Platelet-derived Wachstumsfaktor (PDGF = platelet-derived growth factor),

- Epidermalem Wachstumsfaktor (EGF = epidermal growth factor),

- Transformierendem Wachstumsfaktor- $\alpha$ (TGF- $\alpha=$ transforming growth factor)

- Erythropoetin und

- Glucose-Transportern

und damit zu einer Dysregulation verschiedener Signalkaskaden, die in Neoangiogenese, entkoppelter Proliferation und Zellwachstum resultieren (Khasawneh und Bukowski, 2007; Klatte et. al, 2007).

Das Transmembranenzym CAIX ist bei $95 \%$ aller klarzelligen Nierenzellkarzinome überexprimiert und gilt derzeit als wichtigster molekularer Marker für das klarzellige Nierenzellkarzinom (Leppert et al., 2005). CAIX reguliert Membran-Ionen-Kanäle und somit den extrazellulären $\mathrm{pH}-$ Wert und spielt eine wichtige Rolle bei der Anpassung des Tumors an hypoxische Bedingungen (Klatte et. al., 2007). Es trägt dadurch vermutlich zur Tumorinvasion und Metastasierung bei. Die ausgeprägte Vaskularisierung von Tumoren des renalen Karzinoms ist auf die Überexpression von VEGF, PDGF, EGF und TGF und deren Rezeptoren zurück zu führen. Die Liganden binden an die extrazelluläre Domäne von transmembranen Tyrosin-Kinase-Rezeptoren (TK-Rezeptoren) und lösen darüber 
Signalkaskaden aus, die u. a. in Neoangiogenese und ungehemmten Wachstum resultieren (Khasawneh und Bukowski, 2007). Neben der vermehrten Expression der verschiedenen Wachstumsfaktoren zeigt das renale Karzinom ebenfalls eine signifikante Überexpression von Epidermalem Wachstumsfaktor-Rezeptoren $($ EGFR $=$ epidermal growth factor receptor) im Vergleich zu gesundem Gewebe. Der Grad der Expression von EGFR in Tumoren des renalen Karzinoms scheint mit dem klinischen Outcome und der Prognose assoziiert zu sein (Baumann und Krause, 2004). So kann gezeigt werden, dass Patienten mit renalem Karzinom ohne Überexpression von EGFR eine bessere Prognose haben, da die Tumoren keine Metastasierung, venöse Invasion oder regionalen Lymphknotenbefall aufweisen (Uhlmann, Nguyen, Manivel et al., 1995). Auch für andere Tumorarten wie z.B. Brustkrebs (Lo et al., 2005b) und Oropharyngeal-Karzinom (Psyrri et al., 2005) ist eine Korrelation zwischen der Überexpression von EGFR und einer schlechten klinischen Prognose nachweisbar. Demnach scheint der EGFR-vermittelte Signalweg eine wichtige Rolle in der Karzinogenese u. a. des Nierenzellkarzinoms zu spielen. Der EGFR ist ein transmembraner Tyrosin-Kinase-Rezeptor, der aus einer extrazellulären LigandenBindungsdomäne, einer Transmembrandomäne und einer intrazellulären Tyrosin-KinaseDomäne besteht. Bindet ein Ligand an die Bindungsdomäne kommt es zu einer Dimerisierung zweier Rezeptoren und zu einer Aktivierung der Tyrosin-Kinase-Domänen. Aufgrund der räumlichen Nähe der TK-Domänen wird eine gegenseitige Autophosphorylierung (Transphosphorylierung) bestimmter Tyrosinreste der Rezeptoren ermöglicht. An diese Phosphotyrosinreste binden bestimmte Proteine mit SH2Interaktionsdomänen, deren Rekrutierung in der Induktion der verschiedenen Signaltransduktionswege resultiert. Im Wesentlichen werden vier Signalkaskaden aktiviert:

- die Ras-Raf-Mitogen-aktivierte-Proteinkinase-(MAPK)-Kaskade,

- die Phospatidylinositol-3-Kinase- (PI3K)-Kaskade,

- die Phospholipase $\mathrm{C} \gamma$ - (PLC- $\gamma)$-Kaskade und

- der Jak/STAT-Signalweg.

Wichtige rezeptoraktivierende Liganden des EGFR sind der Epidermale Wachstumsfaktor und der Transformierende Wachstumsfaktor- $\alpha$. Da sowohl der EGF-Rezeptor als auch die Liganden EGF und TGF- $\alpha$ in renalen Karzinomzellen überexprimiert werden, kommt es zu einer autokrinen Schleife, die u. a. in einem entkoppelten Wachstumsstimulus resultiert (Störkel, 2007; Khasawneh und Bukowski, 2007). Eine unregulierte Aktivierung dieser 
zytoplasmatischen EGFR-vermittelten Signalkaskaden führt häufig zu Tumorgenese, Tumorproliferation, Metastasierung, Chemo- und Strahlenresistenzen (Lo und Hung, 2006a). Neben dem regulärem zytoplasmatischen EGFR-Signalweg gibt es einen nukleären EGFR-Signalweg, der vor allem in Tumorzellen und den Zellen anderer stark proliferierender Gewebe z.B. der Plazenta zu finden ist (Lo und Hung, 2006a,b; Cao et al., 1995; Marti et al, 1991; Lin et al., 2001; Lo et al., 2005a).

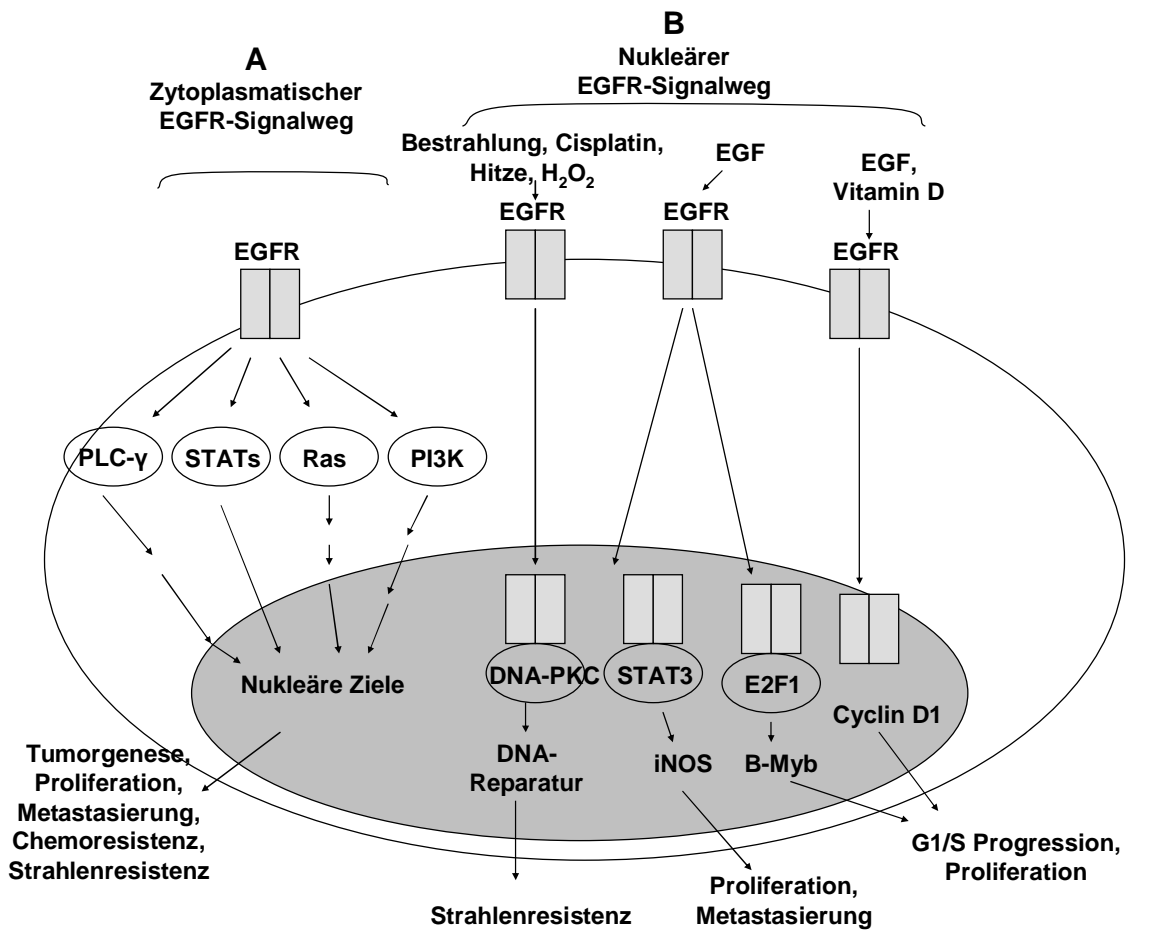

\begin{abstract}
Abbildung 6: Schema der EGFR-vermittelten Signaltransduktionskaskaden. Der zytoplasmatische Signalweg (A) wird durch Ligandenbindung aktiviert, während der nukleäre Signalweg (B) ebenfalls durch Ligandenbindung oder direkt durch z.B. Bestrahlung initiiert wird. Die EGFR-vermittelten Signalwege spielen eine wichtige Rolle u. a. in der Genese, Proliferation, Metastasierung, Chemo- und Strahlenresistenzen maligne entarteter Zellen.
\end{abstract}

Die Aktivierung des nukleären EGFR-Signalweges kann durch Ligandenbindung (EGF, TGF- $\alpha$ ) oder direkt durch Einwirkung von Bestrahlung, $\mathrm{H}_{2} \mathrm{O}_{2}$, Cisplatin, Hitze oder Vitamin D1 initiiert werden (Cao et al., 1995; Lin et al., 1991; Dittmann et al., 2005a; Baumann und Krause, 2004). Nach Aktivierung kommt es zu einer Translokation des Rezeptors in den Kern. Dort assoziiert der nukleäre EGFR an DNA-bindende Transkriptionsfaktoren und verstärkt die Transkription von Genen, die in Tumorgenese, Tumorproliferation, Progression und Chemoresistenz involviert sind (Lin et al., 2001; Lo et al, 2005a). Des Weiteren spielen sowohl der nukleäre EGFR als auch der zytoplasmatische EGFR eine wichtige Rolle in den DNA-Reparaturmechanismen in Folge von Bestrahlung und/oder oxidativem Stress (Dittmann et al., 2005a und b; Chen und 
Nirodi, 2007) und sind daher wichtig für die Radioprotektion eines Tumors. So korrelieren vermehrte EGFR-Expression und -Aktivität mit einer erhöhten Tumorresistenz gegenüber einer Strahlentherapie (Chen und Nirodi, 2007; Baumann und Krause, 2004). Die strahlenprotektive Wirkung der EGFR-Signalwege wird in drei Phasen geteilt (Abb. 7):

1. DNA-Reparatur durch homologe Rekombination oder nicht-homologe End-zuEnd-Verbindung (NHIJ; non homologous endjoining) (sehr frühe Phase; 1-4h)

2. Unterdrückung der durch DNA-Schäden induzierten Apoptose (frühe Phase; 424h)

3. Repopulation und Tumorprogression (späte Phase; $>24 \mathrm{~h}$ )

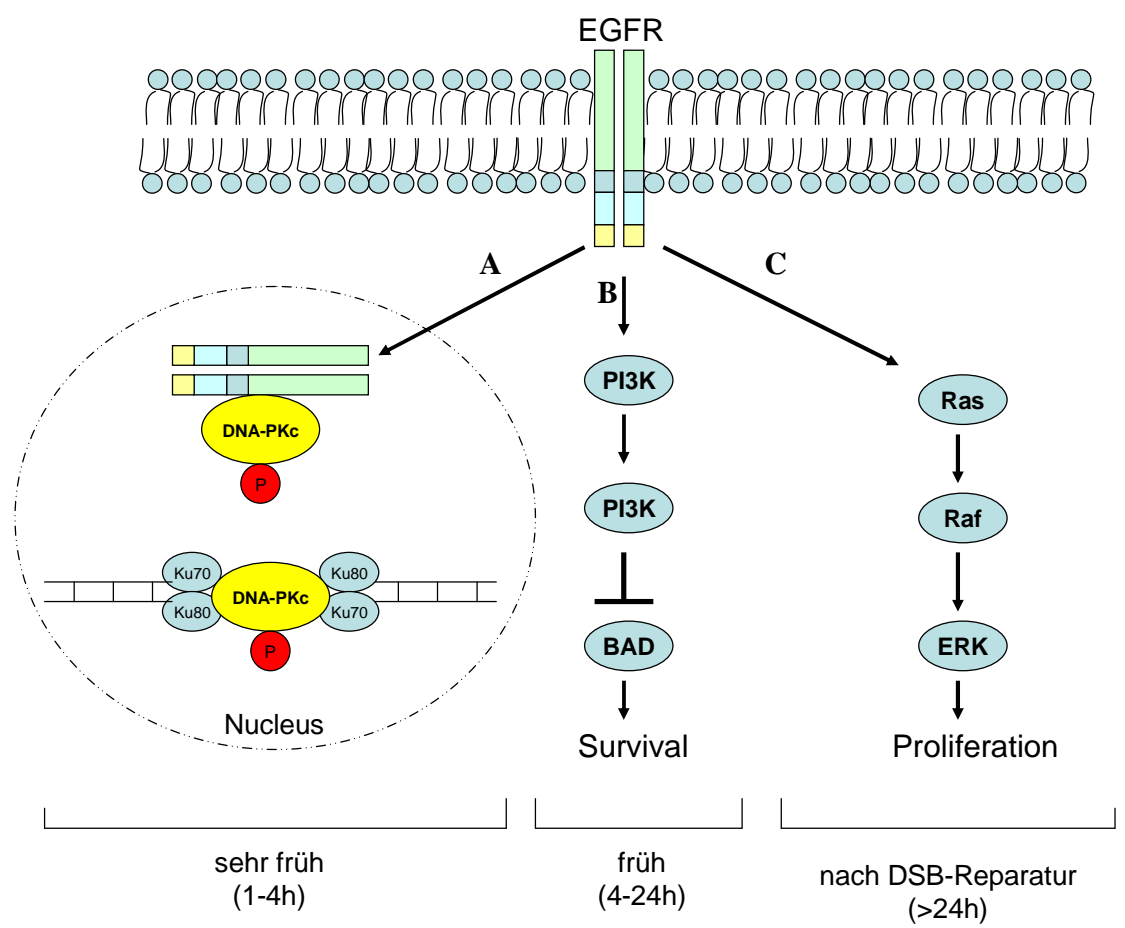

\begin{abstract}
Abbildung 7: Schema zur EGFR-vermittelten Strahlenprotektion. A) Induktion der DNAReparatur durch nicht homologe End-zu-End-Verbindung (NHIJ) innerhalb 1-4 Stunden nach Radiatio. B) Blockade der Apoptoseinduktion durch Aktivierung des PI3K-Signalweges bis 24 Stunden nach Bestrahlung. C) 24 Stunden nach Bestrahlung Aktivierung der Ras-Raf-ERKKaskade, die in Proliferation und damit in Repopulation und Tumorprogression resultiert
\end{abstract}

In verschiedenen Studien fand man heraus, dass insbesondere der ,nonhomologous endjoining"-Mechanismus (NHIJ) eine dominante Rolle bei der Reparatur strahleninduzierter Doppelstrangbrüche in strahlenresistenten Zellen spielt (Chen und Nirodi, 2007). Der NHIJ-Mechanismus ermöglicht eine Verbindung der DNA-Enden ohne homolge Sequenzen. Direkt durch die Bestrahlung wird der nukleäre EGFR-Signalweg initiiert. 
Nach Homodimerisierung und Transphosphorylierung kommt es zu einer Translokation des nun aktivierten EGFR in den Kern. Dort interagiert der nukleäre EGFR mit der katalytische Untereinheit DNA-PKC. Die regulatorischen Untereinheiten Ku70 und Ku80 (syn. Ku86) binden zunächst an die DNA-Enden und rekrutieren dann die DNAProteinkinase C. Der Komplex bestehend aus Ku70, Ku80 und DNA-PKC verhindert zunächst den vorschnellen Abbau der DNA durch Exonukleasen. Die DNA-PKC wird durch Bindung an Doppelstrangbruchenden phosphoryliert und u. a. durch Interaktion mit ATM autophosphoryliert (Chen und Nirodi, 2007). Durch die Phosphorylierung löst sich die DNA-PKC von den Enden der Doppelstrangbrüche (DSB) und ermöglicht die Aktivierung und Bindung des Artemis-Rad50-Mre11-Nbs1-Komplexes an die DSB. Der Komplex prozessiert durch seine Aktivitäten als Exonuklease, Endonuklease und Helicase die DNA-Enden und stabilisiert zusammen mit $\mathrm{Ku}$ die End-zu-End-Verbindung (De Jager et al. 2001, McElhinny et al. 2000, Walker et al. 2001). Dies ist Voraussetzung für die anschließende Verknüpfung der DNA-Enden durch den XRCC4 - Ligase IV - Komplex, welcher ebenfalls durch Phosphorylierung aktiviert wird (Leber et al. 1998).

1.

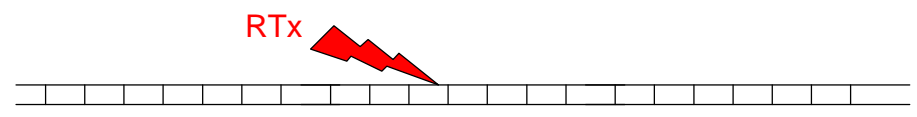

2.
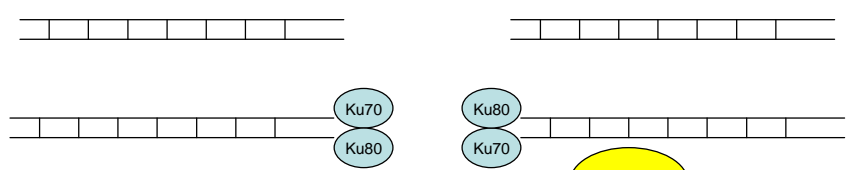

3.

4.

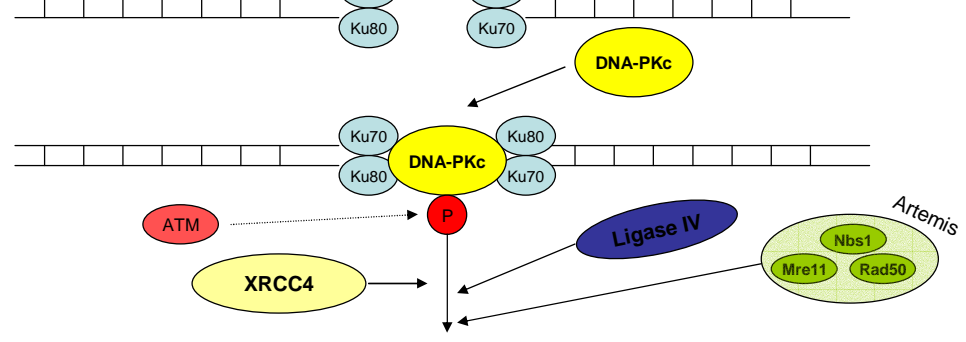

5.

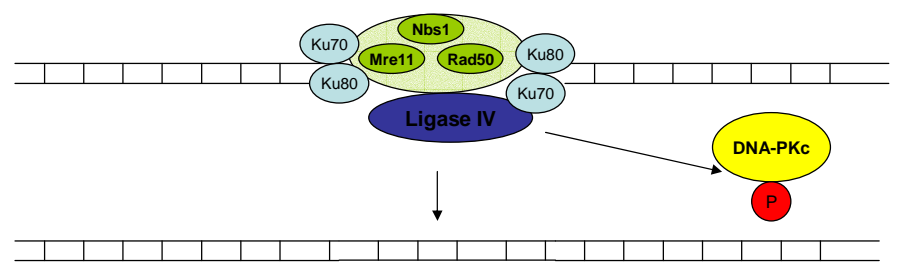

Abbildung 8: DNA-Reparatur durch nicht homologes End-Joining (NHIJ): An die durch die Bestrahlung (RTx) (1) verursachten Doppelstrangbrüche (2) bindet initial der Ku70/Ku80Komplex (3). Die durch den Komplex rekrutierte DNA-PKC bindet ebenfalls an die DNA und wird dadurch und durch Autophosphorylierung nach Interaktion mit ATM aktiviert (4). Die aktivierte DNA-PKC löst sich von der DNA, aktiviert und rekrutiert den Artemis-Mre11Rad50-Nbs-Komplex, der die DNA-Enden prozessiert (5) und aktiviert ebenso den XRCC4Ligase IV-Komplex, der die DNA- Enden verknüpft (6). 


\subsubsection{Prognose und Therapie des Nierenzellkarzinoms:}

Entscheidend für die Prognose eines Nierenzellkarzinoms ist der Grad der Metastasierung. Durch den Einsatz der Sonographie werden mittlerweile die meisten Tumoren in einem frühen Stadium als Zufallsbefund entdeckt, die Prognose hängt dann im Wesentlichen vom Lymphknotenbefall und weniger vom Typ oder der Tumorgröße ab. Bei einem metastasierten Nierenzellkarzinom beträgt die mittlere Einjahresüberlebenswahrscheinlichkeit nach Diagnose jedoch nur noch etwa 50\% (Dt. Krebsgesellschaft, 2002).

Die Therapie der Wahl ist in jedem operablen Fall eine Tumor-Nephrektomie in Kombination mit regionaler Lymphadenektomie. Bei präoperativ gesicherter Diagnose eines Nierenzellkarzinoms werden nach Ligatur der Nierengefäße das befallene Organ inklusive Fettkapsel, gerotascher Faszie und der regionalen Lymphknoten entfernt. Allerdings führt ein Organ-erhaltendes Operationsverfahren bei solitären Tumoren bis vier cm Durchmesser zu vergleichbaren Ergebnissen wie eine komplette Tumor-Nephrektomie. Ebenfalls kann bei Einzelnieren, bilateralen Tumoren und bei Niereninsuffizienz ein Organ erhaltendes Vorgehen erwogen werden.

Für das metastasierte Nierenzellkarzinom gibt es bisher keine effektive Standardtherapie (Mickisch et al., 2001). Beim primär metastasierten Nierenzellkarzinom schwenkt das kurative chirurgische Vorgehen auf einen eher palliativen Ansatz um. Eine Nephrektomie wird nun nur bei schweren Komplikationen wie z.B. Hämaturie oder therapieresistenter Schmerzsymptomatik durchgeführt, sie bietet aber keine Verbesserung der Prognose. Die Resektion von Metastasen kann einen Überlebensvorteil bieten oder aber auch bei drohenden Komplikationen wie z.B. Kompression oder drohenden pathologischen Frakturen indiziert sein.

Das Nierenzellkarzinom ist ein gegenüber Chemotherapie weitgehend resistenter Tumor (Mickisch et al. 2001). Dieses Phänomen ist u. a. auf die Effektivität von Multi-DrugResistance Transportern zurückzuführen, die physiologisch vom Tubulusepithel exprimiert werden. Klassische Chemotherapien erreichen nur in ca. $7 \%$ ein kurzzeitiges objektives Ansprechen. Dies entspricht der Erfolgsrate von Placebogaben in einer kontrollierten Studie (Gleave et al. 1998). Eine Verlängerung der Lebenserwartung durch Chemotherapie konnte bislang in keiner Untersuchung gezeigt werden.

Eine Immunchemotherapie mit Gabe von Interleukin-2 (IL-2) (subkutan), Alpha-Interferon (IF- $\alpha$ ) (subkutan) und 5-Fluorouracil (5-FU) (i. v.) führt in 20-40\% zu einer partiellen Remission und war bisher die am häufigsten verwendete palliative Therapie des 
metastasierten Nierenzellkarzinoms. Mit zunehmender Kenntnis der Molekularpathologie des renalen Karzinoms ist die Inhibition der dysregulierten Signaltranduktionskaskaden zur gezielten Therapiestrategie (,targeted therapy“) geworden. Die Behandlung des Nierenzellkarzinoms mit Tyrosinkinase-Inhibitoren wie Sorafenib oder Sunitinib hat bereits die IL-2/IF- $\alpha / 5$-FU-Immunchemotherapie als Standardtherapie des metastasierten RCCs abgelöst.

Sunitinib ist ein Rezeptor-Tyrosinkinase-Inhibitor (z.B. der VEGF- und PDGFRezeptoren) der ebenfalls sowohl das Tumorwachstum als auch die Tumorangiogenese hemmt. Die Therapie mit Sunitinib verlängert das progressionsfreie Überleben im Vergleich zur Immuntherapie um ca. sechs Monate (Motzer et al., 2007) und wird zur Zeit als Erstlinientherapie in Kombination mit Interferon empfohlen (Winterhalder, 2009). Bei einem Tumorprogress unter Therapie mit Sunitinib ist Sorafenib ist als gute Zweitlinientherapie geeignet (Winterhalder, 2009). Sorafenib ist ein Multi-KinaseHemmer, der u. a. die VEGF- und PDGF-Rezeptorkinasen sowie die Raf-Kinase hemmt und damit in die Signaltransduktionskaskaden von Zellwachstum, Proliferation und Angiogenese eingreift (Escudier et al., 2007). In klinischen Phase III-Studien konnte jedoch die mittlere Überlebensdauer durch Therapie mit Sorafenib lediglich um 3,4 Monate gegenüber Placebo-Gabe verlängert werden (Dreicer, 2006).

Therapeutische Ansätze mit EGFR-Inhibitoren wie z.B. Cetuximab (C225) oder Gefitinib (ZD1839) zeigen keine signifikanten Anti-Tumor-Effekte und haben bisher keine klinische Relevanz (Khasawneh und Bukowski, 2007).

Eine Strahlentherapie des äußerst strahlenresistenten Nierenzellkarzinoms zeigt nur bei solitären Absiedlungen geringe Erfolge. Ihr Einsatz ist vor allem palliativ und symptomorientiert im Bereich der Schmerzreduktion und insbesondere bei Knochen- oder Hirnmetastasen anzusiedeln. 


\section{Zielsetzung:}

Im Rahmen dieser Arbeit sollen die Effekte von Hypericin auf Zellen des humanen renalen klarzelligen Karzinoms (Zelllinie A498) in vitro untersucht werden.

Dabei werden zunächst die intrazelluläre Akkumulation und Persistenz des Hypericins in Zellen des klarzelligen renalen Karzinoms untersucht. Des Weiteren soll in diesem Zusammenhang mittels Rhodamin-123-Efflux-Studien überprüft werden, ob Hypericin die Funktion der MDR-Transporter (P-Glykoproteine) in A498-Zellen beeinflusst. Zur weiteren Deskription wird die Akkumulation von Hypericin in intrazellulären Membransystemen, insbesondere die Kolokalisation von Hypericin und Strukturen des Endoplasmatischen Retikulums, der Mitochondrien und des Kerns, mittels Immunfluoreszenz untersucht.

Ein Schwerpunkt dieser Arbeit ist die Untersuchung der photosensibilisierenden Effekte von Hypericin auf renale Karzinomzellen. Nach gängiger Theorie katalysiert photoaktiviertes Hypericin verschiedene Elektronen- und Energietransferreaktionen auf Sauerstoff unter der Bildung von hoch reaktivem Singulettsauerstoff. Im Rahmen dieser Arbeit soll die Entstehung bzw. Zunahme von intrazellulären reaktiven Sauerstoffspezies in renalen Karzinomzellen durch photoaktiviertes Hypericin mit Hilfe von redoxsensitivem grün fluoreszierendem Protein (roGFP) nachgewiesen werden. Nach erbrachtem Nachweis von intrazellulären ROS sollen deren zellbiologische Auswirkungen auf renale Karzinomzellen überprüft werden. Dabei stehen insbesondere die Apoptoseinduktion, der Zellmetabolismus und die Koloniebildungsfähigkeit von bzw. in A498-Zellen im Fokus der Untersuchungen. Aufgrund der gängigen Theorie ist zu erwarten, dass photoaktiviertes Hypericin in den Zellen Apoptose induziert, was vermutlich mit Veränderung des Zellmetabolismus und verminderter Koloniebildung einhergeht.

Als Kontrollbedingung werden die Effekte von nicht photoaktiviertem Hypericin auf renale Karzinomzellen untersucht. Im Vergleich $\mathrm{zu}$ den phototoxischen Effekten des Hypericins werden hier ebenfalls die Dunkelwirkungen auf die Apoptoseinduktion, den Zellmetabolismus und die Koloniebildungsfähigkeit in bzw. von A498-Zellen überprüft.

Die derzeitige Datenlage gibt Hinweise darauf, dass photoaktiviertes Hypericin eine inhibitorische Wirkung auf verschiedene Enzyme hat, jedoch gibt es bisher nur wenige Publikationen die eine solche Wirkung ebenfalls für nicht photoaktiviertes Hypericin 
nachweisen. Daher sollen in dieser Arbeit erstmalig die Dunkelwirkungen von Hypericin auf die Expression bzw. Aktivität verschiedener Proteine untersucht werden. Dabei liegt im Hinblick auf den folgenden Schwerpunkt dieser Arbeit der Fokus auf Proteinen, die an DNA-Reparaturmechanismen beteiligt sind.

Ein weiterer Schwerpunkt dieser Arbeit liegt in der Untersuchung der Effekte von Hypericin auf renale Karzinomzellen in Kombination mit Bestrahlung. Im Fokus stehen hierbei die Wirkungen von Hypericin auf den Zellmetabolismus, die Koloniebildungsfähigkeit, die Zellzyklusverteilung und die Apoptoseinduktion von bzw. in A498-Zellen. Des Weiteren sollen die den Wirkungen zugrunde liegenden Mechanismen untersucht werden. Hierbei sind insbesondere die DNA-Reparaturmechanismen Gegenstand der Untersuchungen. So sollen mittels quantitativer Echtzeit-PCR, Westernblot und Immunfluoreszenz die Effekte von Hypericin auf die Expression und die Aktivität verschiedener Proteine, die eine wichtige Rolle in den Reparaturmechanismen spielen, untersucht werden. 
3. Material und Methoden:

\section{1 Material:}

3.1.1 Verwendete Chemikalien:

\begin{tabular}{|c|c|c|}
\hline Produkt: & Firma: & Bestellnummer: \\
\hline Aceton & Merck, Darmstadt, Deutschland & 1.000 .132 .500 \\
\hline Agarose & Invitrogen, Scotland, UK & 3071229 \\
\hline Ampuwa & Fresenius Kabi & 14CA1004 \\
\hline Amoniumpersulfat APS & Sigma Steinheim, Germany & A7460 \\
\hline Beta-Mercaptoethanol & Sigma Steinheim, Germany & M3148 \\
\hline BioLyte 3/10 Ampholyte & BioRad, München, Deutschland & 163-2094 \\
\hline Bromphenolblau $0.25 \%$ & Sigma Steinheim, Germany & $120 \mathrm{~K} 3736$ \\
\hline BSA & $\begin{array}{l}\text { Paesel + Lorei, Frankfurt, } \\
\text { Germany }\end{array}$ & $04-100-810$ \\
\hline 1-Butanol & Merck, Darmstadt, Deutschland & 1.01988 .100 \\
\hline $\begin{array}{l}\text { Chaps (3[(3-Cholamido- } \\
\text { propyl)-dimethylamonio]- } \\
\text { propan-sulfonat) }\end{array}$ & Merck, Darmstadt, Deutschland & 1.11662 .0010 \\
\hline $\begin{array}{l}\text { DAPI, 4,6-Diamidin-2`- } \\
\text { phenylindol-dihydrochlorid }\end{array}$ & $\begin{array}{l}\text { La Roche, München, } \\
\text { Deutschland }\end{array}$ & $11465855-02$ \\
\hline DMEM Kulturmedium & $\begin{array}{l}\text { PAA Laboratories GmbH, } \\
\text { Pasching, Östereich }\end{array}$ & E03223-360 \\
\hline DNAse-freier RNAse & Roche, Penzberg, Deutschland & 11119915001 \\
\hline DTT & Roth, Karlsruhe, Deutschland & 69082 \\
\hline EDTA ultrapure & Paesel + Lorei, Hanau, Germany & 15586 \\
\hline Essigsäure $99 \%$ & Merck, Darmstadt, Deutschland & K 31811963310 \\
\hline Ethanol & Roth, Karlsruhe, Deutschland & K928.4 \\
\hline Ethidiumbromid $1 \%$ & Merck, Darmstadt, Deutschland & OC 134600 \\
\hline Eukitt, Eindeckmedium & Kindler, Freiburg Deutschland & 03989 \\
\hline Fötales Kälberserum (FCS) & $\begin{array}{c}\text { Gibco Life Technologies, } \\
\text { Germany }\end{array}$ & $40 \mathrm{~F} 1500 \mathrm{~K}$ \\
\hline Gelatine gepulvert & Merck, Darmstadt, Deutschland & K21568978 \\
\hline Geniticin & $\begin{array}{l}\text { PAA Laboratories GmbH, } \\
\text { Pasching, Östereich }\end{array}$ & L14122-117 \\
\hline Gentamicin & $\begin{array}{l}\text { PAA Laboratories GmbH } \\
\text { Pasching, Östereich }\end{array}$ & L $04121-332$ \\
\hline Glycerin & Merck, Darmstadt, Deutschland & 1.040 .942 .500 \\
\hline Glycerol 99\% & $\begin{array}{l}\text { Sigma Aldrich Chemie, } \\
\text { Steinheim, Germany }\end{array}$ & $121 \mathrm{~K} 0021$ \\
\hline Glycin & Roth, Karlsruhe, Deutschland & 3908.3 \\
\hline $\mathrm{H}_{2} \mathrm{O}_{2}$ & $\begin{array}{l}\text { Sigma Aldrich Chemie, } \\
\text { Steinheim, Germany }\end{array}$ & 216763 \\
\hline
\end{tabular}




\begin{tabular}{|c|c|c|}
\hline Produkt: & Firma: & Bestellnummer: \\
\hline Hepes Buffer & $\begin{array}{c}\text { Gibco, Invitrogen Corporation, } \\
\text { UK }\end{array}$ & 3076416 \\
\hline Hypericin & $\begin{array}{c}\text { PLANTA, Naturstoffe, Wien, } \\
\text { Österreich }\end{array}$ & $500-03-001$ \\
\hline Hypericin-PVP & $\begin{array}{l}\text { PLANTA, Naturstoffe, Wien, } \\
\text { Österreich }\end{array}$ & $500-03-005$ \\
\hline Immersol & Zeiss, Göttingen, Deutschland & $518 \mathrm{~F}$ \\
\hline Kristallviolett-Lösung & Merck, Darmstadt, Deutschland & 1.15940 \\
\hline $\mathrm{L}-$ Glutamine & $\begin{array}{l}\text { PAA Laboratories GmbH } \\
\text { Pasching, Östereich }\end{array}$ & J $04122-576$ \\
\hline Magermilchpulver & Merck, Darmstadt, Deutschland & 1.153 .630 .500 \\
\hline $\begin{array}{c}\text { MEM Non Essential Amino } \\
\text { Acids }\end{array}$ & $\begin{array}{l}\text { PAA Laboratories GmbH } \\
\text { Pasching, Östereich }\end{array}$ & J 03123009 \\
\hline Methanol & Roth, Karlsruhe, Deutschland & 8388.6 \\
\hline $\mathrm{NaCl}$ & Merck, Darmstadt, Deutschland & 1.064 .005 .000 \\
\hline Nuclease freies Wasser & $\begin{array}{l}\text { Applied Biosystems, Darmstadt, } \\
\text { Deutschland, ambion }\end{array}$ & AM9938 \\
\hline Paraformaldehyd & Merck, Darmstadt, Deutschland & 104.005 \\
\hline Penicillin - Streptomycin & $\begin{array}{l}\text { PAA Laboratories GmbH } \\
\text { Pasching, Östereich }\end{array}$ & L $11123-054$ \\
\hline Phosphat Buffered Saline, & $\begin{array}{c}\text { Gibco, Invitrogen Corporation, } \\
\text { UK }\end{array}$ & $3069-764$ \\
\hline Ponceau S Solution & $\begin{array}{c}\text { Serva GmbH, Heidelberg, } \\
\text { Deutschland }\end{array}$ & 33427 \\
\hline $\begin{array}{l}\text { Precision Plus Protein } \\
\text { Kaleidoscope Standards }\end{array}$ & BioRad, München, Deutschland & $161-0375$ \\
\hline $\begin{array}{l}\text { Propidiumiodid-Lösung } \\
\qquad(1 \mathrm{mg} / \mathrm{ml})\end{array}$ & $\begin{array}{l}\text { Sigma Aldrich, Taufkirchen, } \\
\text { Deutschland }\end{array}$ & P4864 \\
\hline $\begin{array}{c}\text { Proteaseinhibitor Complete } \AA \text {, } \\
\text { EDTA-frei }\end{array}$ & Roche, Penzberg, Deutschland & 04693132001 \\
\hline Rhodamin-123 & $\begin{array}{c}\text { Sigma Aldrich Chemie, Steinheim, } \\
\text { Deutschland }\end{array}$ & R8004 \\
\hline Rotiß-Blue & Roth, Karlsruhe, Deutschland & A152.1 \\
\hline Rotiphorese Gel 30 Acrylamid & Roth, Karlsruhe, Deutschland & 3029.1 \\
\hline SDS & Fluka & 71729 \\
\hline Sodium Pyruvate Solution & $\begin{array}{l}\text { PAA Laboratories GmbH } \\
\text { Pasching, Östereich }\end{array}$ & M $03121-531$ \\
\hline Temed & $\begin{array}{c}\text { Sigma Aldrich Chemie, Steinheim, } \\
\text { Deutschland }\end{array}$ & T9281 \\
\hline Thiourea & Roth, Karlsruhe, Deutschland & 9531 \\
\hline Tris & Roth, Karlsruhe, Deutschland & 27254825 \\
\hline Trypsin/EDTA & $\begin{array}{l}\text { PAA Laboratories GmbH } \\
\text { Pasching, Österreich }\end{array}$ & H04123-173 \\
\hline
\end{tabular}




\begin{tabular}{|c|c|c|}
\hline Produkt: & Firma: & Bestellnummer: \\
\hline Tween 20 & Roth, Karlsruhe, Deutschland & 9127.2 \\
Urea & Roth, Karlsruhe, Deutschland & 3941 \\
Vectashield DAPI & Vector, Linaris, Wertheim, & H-1200 \\
& Deutschland & \\
\hline
\end{tabular}

3.1.2 Verwendete Kits:

\begin{tabular}{|c|c|c|}
\hline Produktname: & Firma: & Bestellnummer: \\
\hline Bio Rad Protein Assay & Bio Rad, München Deutschland & $1-800-424-6723$ \\
\hline Cell Proliferation Kit I (MTT) & Roche, Penzberg, Deutschland & 11465007001 \\
\hline $\begin{array}{l}\text { In Situ Cell Death Detection- } \\
\text { Kit, Fluorescein (TUNEL) }\end{array}$ & Roche, Penzberg, Deutschland & 11684795910 \\
\hline Nucleofector ${ }^{\circledR}-$ Kit & $\begin{array}{c}\text { amaxa biosystems, Köln, } \\
\text { Deutschland }\end{array}$ & VPG-1003 \\
\hline $\begin{array}{c}\text { Power SYBR } ® \text { Green PCR } \\
\text { Master Mix }\end{array}$ & $\begin{array}{l}\text { Applied Biosystems, Darmstadt, } \\
\text { Deutschland }\end{array}$ & 4368706 \\
\hline $\begin{array}{l}\text { Total RNA Isolation-Kit; } \\
\text { NucleoSpin®RNA II }\end{array}$ & $\begin{array}{l}\text { Macherey-Nagel, Düren, } \\
\text { Deutschland }\end{array}$ & 740955.20 \\
\hline $\begin{array}{c}\text { Transcriptor High Fidelity } \\
\text { cDNA Synthesis Sample Kit }\end{array}$ & Roche, Penzberg, Deutschland & 05081866001 \\
\hline
\end{tabular}

\subsubsection{Verwendete Antikörper:}

\begin{tabular}{|c|c|c|}
\hline Primärantikörper: & Firma: & Bestellnummer: \\
\hline $\begin{array}{l}\text { ATM phos. (Ser1981) mouse } \\
\text { anti human IgG }\end{array}$ & Active Motif, Rixensart, Belgien & 39530 \\
\hline ß Actin mouse anti human IgG & $\begin{array}{l}\text { Sigma Aldrich Chemie, } \\
\text { Steinheim, Deutschland }\end{array}$ & A5441 \\
\hline BIP rabbit anti-human-IgG & \multicolumn{2}{|c|}{$\begin{array}{l}\text { zur Verfügung gestellt von Dr. rer. nat. Phuc van } \\
\text { Nguyen, MOLCI Göttingen }\end{array}$} \\
\hline $\begin{array}{l}\text { DNA-PKC phos. (Thr2609) } \\
\text { mouse anti human IgG }\end{array}$ & Biozol, Eching Germany & 612901 \\
\hline $\begin{array}{l}\text { EGF Receptor phos. (Tyr992) } \\
\text { rabbit anti human IgG }\end{array}$ & Active Motif, Rixensart, Belgien & 39094 \\
\hline $\begin{array}{l}\text { Histone H2AX phos. (Ser139) } \\
\text { rabbit anti human IgG }\end{array}$ & Active Motif, Rixensart, Belgien & 39118 \\
\hline
\end{tabular}

\begin{tabular}{|c|c|c|}
\hline Sekundärantikörper: & Firma: & Bestellnummer: \\
\hline $\begin{array}{c}\text { Alexa Fluor 647 goat anti-rabbit } \\
\text { IgG }\end{array}$ & $\begin{array}{c}\text { Invitrogen, Karlsruhe, } \\
\text { Deutschland }\end{array}$ & A21244 \\
\hline $\begin{array}{c}\text { Alexa Fluor 647 goat anti- } \\
\text { mouse IgG }\end{array}$ & $\begin{array}{c}\text { Invitrogen, Karlsruhe, } \\
\text { Deutschland }\end{array}$ & A21242 \\
\hline $\begin{array}{c}\text { Fitc-conjugated donkey anti- } \\
\text { rabbit IgG }\end{array}$ & $\begin{array}{c}\text { Jackson Immunoresearch, } \\
\text { Newmarket Suffolk, UK }\end{array}$ & $711-096-132$ \\
\hline $\begin{array}{c}\text { Northern Lights 493 donkey } \\
\text { anti-mouse IgG }\end{array}$ & $\begin{array}{c}\text { R\&D Systems, Wiesbaden, } \\
\text { Deutschland }\end{array}$ & NL009 \\
\hline
\end{tabular}


3.1.4 Verwendete PCR-Primer:

\begin{tabular}{|c|c|c|}
\hline Primer: & & Firma: \\
\hline$\overline{\text { EGFR_For }}$ & $\overline{5^{\prime}-\mathrm{ATG} \text { TCC TCA TTG CCC TCA AC-3' }}$ & eurofins MWG GmbH \\
\hline EGFR_Rev & 5'-GTG GTT CTG GAA GTC CAT CG-3' & eurofins MWG GmbH \\
\hline GAPDH_For & $5^{\prime}$-CCC TTC ATT GAC CTC AAC TAC-3' & eurofins MWG GmbH \\
\hline GAPDH_Rev & 5'-TGA GTC CTT CCA CGA TAC C-3' $^{\prime}$ & eurofins MWG GmbH \\
\hline Ku70_For & 5'-CTT TGA GGA ATC CAG CAA GC-3' & eurofins MWG GmbH \\
\hline Ku70_Rev & $5^{\prime}$-GGT ATC GCT AGG CAG AAG CA-3' & eurofins MWG GmbH \\
\hline Ku80_For & $5^{\prime}$-AGA AGA AGG CCA GCT TTG AG-3' & eurofins MWG GmbH \\
\hline Ku80_Rev & 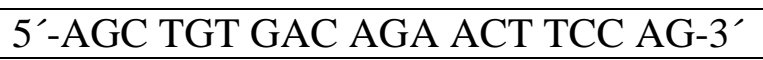 & eurofins MWG GmbH \\
\hline PI3K_For & 5'-ATT GCC GAA ATC CAT GAG AG-3' & eurofins MWG GmbH \\
\hline PI3K_Rev & 5'-ATC TTG CCC ACG TAC CAA GT-3' & eurofins MWG GmbH \\
\hline DNA-PKc_For & 5'-GAA AAG TGC TTT GGC ACT GG-3' & eurofins MWG GmbH \\
\hline DNA-PKc_Rev & $5^{\prime}$-ACG TCT CCG ATG TTG AAA CC-3' & eurofins MWG GmbH \\
\hline XRCC4_For & 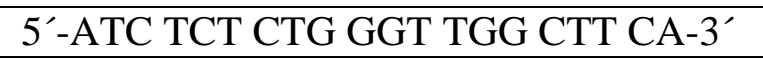 & eurofins MWG GmbH \\
\hline XRCC4_Rev & 5'-CTT CTG GGC TGC TGT TTC TC-3' & eurofins MWG GmbH \\
\hline
\end{tabular}

3.1.5 Verwendete Hilfsmittel und Verbrauchsmaterialien:

\begin{tabular}{|c|c|c|}
\hline Produkt: & Firma: & Bestellnummer: \\
\hline 24-Napf-Imaging-Platte & $\begin{array}{l}\text { Zellkontakt, Nörthen- } \\
\text { Hardenberg, Deutschland }\end{array}$ & $21313231 / 21315231$ \\
\hline 24-Napf-Kulturplatten & $\begin{array}{l}\text { Sarstedt, Nümbrecht, } \\
\text { Deutschland }\end{array}$ & 83.1836 .300 \\
\hline 4- Napf-Kulturplatten & Nunc, Wiesbaden, Deutschland & 179820 \\
\hline 6- Napf-Kulturplatten & $\begin{array}{l}\text { greiner bio-one, Frickenhausen, } \\
\text { Deutschland }\end{array}$ & 657160 \\
\hline $\begin{array}{l}\text { 96- Napf-Kulturplatten, flacher } \\
\text { Boden }\end{array}$ & $\begin{array}{c}\text { Sarstedt, Nümbrecht, } \\
\text { Deutschland } \\
\end{array}$ & 83.1835 \\
\hline 96-Napf-Imaging-Platte & $\begin{array}{c}\text { Zellkontakt, Nörthen- } \\
\text { Hardenberg, Deutschland }\end{array}$ & 21313241 \\
\hline Bottletop-Filter & $\begin{array}{l}\text { Sarstedt, Nümbrecht, } \\
\text { Deutschland }\end{array}$ & 831.822 .101 \\
\hline Deckgläschen rund $13 \mathrm{~mm}$ & $\begin{array}{l}\text { Sarstedt, Nümbrecht, } \\
\text { Deutschland }\end{array}$ & 83.1840 .002 \\
\hline $\begin{array}{l}\text { Deckgläser für Mikroskopie } \\
24 \times 50 \mathrm{~mm}\end{array}$ & Roth, Karlsruhe, Deutschland & 1871 \\
\hline Eppendorf-Cups $1,5 \mathrm{ml}$ & $\begin{array}{l}\text { Sarstedt, Nümbrecht, } \\
\text { Deutschland }\end{array}$ & 72.690 \\
\hline Eppendorf-Cups $2 \mathrm{ml}$ & $\begin{array}{l}\text { Sarstedt, Nümbrecht, } \\
\text { Deutschland }\end{array}$ & 72.695 \\
\hline FACS - Röhrchen & $\begin{array}{l}\text { Becton Dickinson, Heidelberg, } \\
\text { Deutschland }\end{array}$ & 3002994 \\
\hline Filterpapier Whatman Standard & $\begin{array}{l}\text { GE Healthcare, München, } \\
\text { Deutschland }\end{array}$ & \\
\hline Halb-Mikro-Küvette & Sarstedt, Nümbrecht Deutschland & 67.742 \\
\hline
\end{tabular}




\begin{tabular}{|c|c|c|}
\hline Produkt: & Firma: & Bestellnummer: \\
\hline Kryoröhrchen & $\begin{array}{l}\text { Sarstedt, Nümbrecht, } \\
\text { Deutschland }\end{array}$ & 72.379 \\
\hline Kulturflaschen $25 \mathrm{~cm} 2$ & Sarstedt, Heidelberg, Germany & 83.1810 .302 \\
\hline Kulturflaschen $75 \mathrm{~cm} 2$ & $\begin{array}{l}\text { Becton Dickinson, Heidelberg, } \\
\text { Deutschland }\end{array}$ & 137787 \\
\hline $\begin{array}{c}\text { Lab-Tek® 16-Napf-Kammer- } \\
\text { Objektträger }\end{array}$ & $\begin{array}{l}\text { Nunc, Langenselbold, } \\
\text { Deutschland }\end{array}$ & 178599 \\
\hline $\begin{array}{l}\text { amersham TM Hybond-ECL } \\
\text { Nitrocellulose-Membran }\end{array}$ & $\begin{array}{l}\text { GE Healthcare, München, } \\
\text { Deutschland }\end{array}$ & RPN 203D \\
\hline Objektträger & $\begin{array}{l}\text { Knittel-Gläser, Braunschweig, } \\
\text { Deutschland }\end{array}$ & VA31100001FKB \\
\hline $\begin{array}{l}\text { Objektträger } 76 \times 26 \mathrm{~mm} \text {, } \\
\text { geputzt mit Mattrand }\end{array}$ & $\begin{array}{l}\text { Knittel-Gläser, Braunschweig, } \\
\text { Deutschland }\end{array}$ & VA31110002FKB \\
\hline Pasteurpipette & Brand, Wertheim, Deutschland & 747720 \\
\hline PCR-Röhrchen & $\begin{array}{l}\text { Sarstedt, Nümbrecht, } \\
\text { Deutschland }\end{array}$ & 72.737 .992 \\
\hline PCR-Tubes Strips & $\begin{array}{l}\text { Stratagene, Amsterdam, } \\
\text { Niederlande }\end{array}$ & 401428 \\
\hline Peha Soft Handschuhe & $\begin{array}{l}\text { Hartmann, Heidenheim, } \\
\text { Deutschland }\end{array}$ & 942140 \\
\hline $\begin{array}{c}\text { Photometer Küvette Uvette } \\
220-1600 \mathrm{~nm} \text { (steril) }\end{array}$ & $\begin{array}{c}\text { Eppendorf, Hamburg, } \\
\text { Deutschland }\end{array}$ & 952010051 \\
\hline Pipettenspitzen, $10 \mu 1$ & $\begin{array}{l}\text { Sarstedt, Nümbrecht, } \\
\text { Deutschland }\end{array}$ & 70.1115 .210 \\
\hline Pipettenspitzen, $100 \mu 1$ & $\begin{array}{l}\text { Sarstedt, Nümbrecht, } \\
\text { Deutschland }\end{array}$ & 70.760 .212 \\
\hline Pipettenspitzen, $1000 \mu \mathrm{l}$ & $\begin{array}{l}\text { Sarstedt, Nümbrecht, } \\
\text { Deutschland }\end{array}$ & 70.762 .211 \\
\hline Pipettenspitzen, $2,5 \mu 1$ & $\begin{array}{l}\text { Sarstedt, Nümbrecht, } \\
\text { Deutschland }\end{array}$ & 70.1130 .212 \\
\hline Rührspatel & $\begin{array}{l}\text { Sarstedt, Nümbrecht, } \\
\text { Deutschland }\end{array}$ & 81.970PP \\
\hline Skalpell & $\begin{array}{l}\text { Becton Dickinson, Heidelberg, } \\
\text { Deutschland }\end{array}$ & 371621 \\
\hline Serologische Pipette $10 \mathrm{ml}$ & $\begin{array}{l}\text { Sarstedt, Nümbrecht, } \\
\text { Deutschland }\end{array}$ & 86.1254 .001 \\
\hline Serologische Pipette $20 \mathrm{ml}$ & greiner bio-one & $607190 / 10 \mathrm{ml}$ \\
\hline Serologische Pipette $5 \mathrm{ml}$ & $\begin{array}{l}\text { Sarstedt, Nümbrecht, } \\
\text { Deutschland }\end{array}$ & 86.1253 .001 \\
\hline Strip Caps & $\begin{array}{c}\text { Stratagene, Amsterdam, } \\
\text { Niederlande }\end{array}$ & 401425 \\
\hline Zellschaber & $\begin{array}{l}\text { Sarstedt, Nümbrecht, } \\
\text { Deutschland }\end{array}$ & $83,183.0$ \\
\hline Zentrifugationsröhrchen $15 \mathrm{ml}$ & $\begin{array}{l}\text { Sarstedt, Nümbrecht, } \\
\text { Deutschland }\end{array}$ & 62.554 .502 \\
\hline Zentrifugationsröhrchen $50 \mathrm{ml}$ & $\begin{array}{l}\text { Sarstedt, Nümbrecht, } \\
\text { Deutschland }\end{array}$ & 62.547 .254 \\
\hline
\end{tabular}


3.1.6 Verwendete Geräte:

\begin{tabular}{|c|c|}
\hline Produkt: & Firma: \\
\hline Abzug & $\begin{array}{l}\text { Norddeutscher Laborbau GmbH, Kaltenkirchen, } \\
\text { Deutschland }\end{array}$ \\
\hline Blot-System Mini Trans Blot Cell & BioRad, München, Deutschland \\
\hline Einfrierbox Mr. Frosty & NUNC, Nalgene \\
\hline $\begin{array}{l}\text { Elektrophorese-Kammer Life } \\
\text { Technologies Horizont } 58\end{array}$ & Gibco-BRL, Karlsruhe, Deutschland \\
\hline $\begin{array}{l}\text { Elektrophorese-System Mini- } \\
\text { Protean } \AA\end{array}$ & BioRad, München, Deutschland \\
\hline Elektroporator Nucleofector I & amaxa biosystems, Köln, Deutschland \\
\hline Eppendorf Bio Photometer plus & Eppendorf, Hamburg, Deutschland \\
\hline FACS Scan & Becton Dickinson, Heidelberg, Deutschland \\
\hline Feinwaage Precisa 180A & Precisa Instruments, Dietikon, Schweiz \\
\hline Fuji Image Reader FLA-500 V3.0 & Fujifilm, Düsseldorf, Deutschland \\
\hline $\begin{array}{l}\text { Gefrierschrank-20 } 20^{\circ} \text { Sanyo } \\
\text { Medical Freezer }\end{array}$ & Sanyo, AZ Etten-Leur, NL \\
\hline Heizplatte, Magnetrührplatte & IKA-Labortechnik, Göttingen, Deutschland \\
\hline HQI $^{\circledR}$-TS-Lampe & Osram, München, Deutschland \\
\hline Inkubator IR 1500 Automatic CO2 & Flow Laboratories, Thame, UK \\
\hline Gefrierschrank $-80^{\circ} \mathrm{C}$ & Sanyo, AZ Etten-Leur, NL \\
\hline Kühlschrank, Liebherr Premium & Liebherr, Ochsenhausen, Deutschland \\
\hline Photometer, Lambda 25 UV7VIS & Perkin Elmer, Waltham, USA \\
\hline Magnetrührer Ikamag RCT & IKA-Labortechnik, Göttingen, Deutschland \\
\hline $\begin{array}{l}\text { PCR-System, Master Cycler } \\
\text { personal }\end{array}$ & Eppendorf, Hamburg, Deutschland \\
\hline Mikroplatten-ELISA-Reader & $\begin{array}{c}\text { Milena Kinetic EIA Analyzer, DPC, Los } \\
\text { Angeles, USA }\end{array}$ \\
\hline $\begin{array}{c}\text { Realtime-PCR-System, } \\
\text { Mx3000PTM }\end{array}$ & Stratagene, Amsterdam, NL \\
\hline PCR Mastercycler gradient & Eppendorf, Hamburg, Deutschland \\
\hline pH-Meter & Satorius, Göttingen, Deutschland \\
\hline Pipettierhilfe, Accu-jet & Brand, Millian, USA \\
\hline Rotationsschüttler GFL 3005 & GFL, Burgwedel, Deutschland \\
\hline Scanner „Fluor-S Multimager“ & BioRAD, CA, USA \\
\hline $\begin{array}{l}\text { Spannungsquelle, Power Supply } \\
\text { PS3002 }\end{array}$ & Gibco-BRL, Karlsruhe, Deutschland \\
\hline $\begin{array}{l}\text { Spannungsquelle, } 2301 \\
\text { Mackodrive }\end{array}$ & LBB Bromma, Uppsala, Schweden \\
\hline Bestrahlungsgerät, Stabilipan & Siemens, München, Deutschland \\
\hline $\begin{array}{l}\text { Bestrahlungsgerät, X-ray research } \\
\text { System RS225 }\end{array}$ & Gulmay Medical, Camberley Surrey, UK \\
\hline Sterilbank & Gelaire Flow Laboratories, Thame, UK \\
\hline
\end{tabular}




\begin{tabular}{|c|c|}
\hline Produkt: & Firma: \\
\hline $\begin{array}{c}\text { Thermoblock,Techne Dri Block } \\
\text { DB.2D }\end{array}$ & Sigma, Osterode, Deutschland \\
\hline Trockenschrank & Heraeus, Hanau, Deutschland \\
\hline Ultraschallbad Sonorex Super & Bradelin Berlin, Deutschland \\
\hline $\begin{array}{c}\text { Ultrazentrifuge 1-15PK kühlbar, } \\
\text { Rotor 12132-H }\end{array}$ & Sigma, Osterode, Deutschland \\
\hline Vakuumpumpe & KNF Neuberger, Freiburg, Deutschland \\
\hline Vortexer, G-560 E & Schütt Labortechnik, Göttingen, Deutschland \\
\hline Waage universal U3600 & Sartorius, Göttingen, Deutschland \\
\hline Wasserbad & GFL, Burgwedel, Deutschland \\
\hline Zentrifuge 5419D, Rotor 14198 & Eppendorf, Hamburg, Deutschland \\
\hline Zentrifuge, Rotixa/K & Hettich, Tuttlingen, Deutschland \\
\hline
\end{tabular}

3.1.7 Verwendete Mikroskope und Zubehör:

\begin{tabular}{|c|c|}
\hline Mikroskope: & Firma: \\
\hline Axiotech vario-Mikroskop & Zeiss, Oberkochen, Deutschland \\
\hline Axiovert S100-Mikroskop & Zeiss, Göttingen, Deutschland \\
\hline X71-Mikroskop & Olympus, Hamburg, Deutschland \\
\hline Zellkulturmikroskop Axiovert 40 & Zeiss, Göttingen, Deutschland \\
\hline
\end{tabular}

\begin{tabular}{|c|c|}
\hline Lichtquellen: & Firma: \\
\hline $\begin{array}{c}\text { Polychrom II Xenon } \\
\text { Hochdrucklampe }\end{array}$ & Till Photonics, Gräfelfing, Deutschland \\
\hline HBO 100W & Zeiss, Göttingen, Deutschland \\
\hline Mercury Arc Lamp (HBO) 100W & Olympus, Hamburg, Deutschland \\
\hline XBO 75W HBO 100W & Zeiss, Göttingen, Deutschland \\
\hline Xenon Arc Lamp (XBO) 150W & Olympus, Hamburg, Deutschland \\
\hline
\end{tabular}

\begin{tabular}{|c|c|}
\hline Objektive: & Firma: \\
\hline UPlan FI 10x/0,30 & Olympus, Hamburg, Deutschland \\
\hline UPlan FI 20x/0,50; $\infty / 0,17$ & Olympus, Hamburg, Deutschland \\
\hline UPlan FI 40x/0,75 & Olympus, Hamburg, Deutschland \\
\hline Achroplan 10x/ 0,25 Ph1 & Zeiss, Göttingen, Deutschland \\
\hline Achroplan 40x/0,60 Korr & Zeiss, Göttingen, Deutschland \\
\hline Achroplan LD 20x/ 0,40 Korr Ph2 & Zeiss, Göttingen, Deutschland \\
\hline
\end{tabular}




\begin{tabular}{|c|c|c|}
\hline Filtersätze: & Firma: & Bestellnummer: \\
\hline $\begin{array}{c}\text { FITC: Filterset BP475/40, } \\
\text { PT 500, BP 530/50 }\end{array}$ & Zeiss, Göttingen, Deutschland \\
\hline $\begin{array}{c}\text { DAPI: Filterset G 365, FT } \\
\text { 395, BP 445/50 }\end{array}$ & Zeiss, Göttingen, Deutschland & 49 \\
\hline $\begin{array}{c}\text { PE: 15, BP546/12, FT 580, } \\
\text { LP 596 }\end{array}$ & Zeiss, Göttingen, Deutschland & 15 \\
\hline $\begin{array}{c}\text { FITC: HC Filterset } \\
\text { BP482/35, BS 506, } \\
\text { BP536/40 }\end{array}$ & AHF Analysentechnik, & F36-501 \\
\hline $\begin{array}{c}\text { PE: HC Filterset BP531/40, } \\
\text { BS 562, BP593/40 }\end{array}$ & AHF Analysentechnik, Deutschland \\
\hline $\begin{array}{c}\text { Dapi: HC Filterset } \\
\text { (Schmalband), 387/11, } \\
\text { BS409, 447/60 }\end{array}$ & AHF Analysentechnik, Deutschland & F36-542 \\
\hline
\end{tabular}

\begin{tabular}{|c|c|}
\hline Kamerasystem: & Firma: \\
\hline Imago-QE-CCD Kamera & Imago QE, PCO Imaging, Kehlheim, Deutschland \\
\hline $\begin{array}{c}\text { F-View-Soft Imaging } \\
\text { System }\end{array}$ & Olympus, Hamburg, Deutschland \\
\hline
\end{tabular}

\subsubsection{Verwendete Software:}

\begin{tabular}{|c|c|}
\hline Software: & Firma: \\
\hline Mx3000P-Software & Stratagene, Amsterdam, Niederlande \\
\hline Kaleidagraph & Synergy Software, USA \\
\hline CellF-Imaging Software & Olympus, Hamburg, Deutschland \\
\hline WinMDI 2.9 & Kostenlose Software, entwickelt von Joe Trotter \\
\hline ImageJ & Wayne Rasaband, National Institute of Health (NIH) \\
\hline AnalySIS-Software & Olympus, Hamburg, Deutschland \\
\hline TILLvisION-Software & Till Photonics, Gräfelfing, Deutschland \\
\hline $\begin{array}{c}\text { Primer3-Input 0.4.0- } \\
\text { Software }\end{array}$ & Kostenlose Software von SourceForge.net \\
\hline
\end{tabular}




\subsection{Methoden:}

\subsubsection{Zellkulturtechnik:}

\subsubsection{Kultivierung von renalen Karzinomzellen:}

Die humanen renalen Adenokarzinomzellen der Linie HTB-44 ${ }^{\mathrm{TM}}$ (syn. A-498) (LGC Promochem, Wesel, Deutschland) werden bei $37^{\circ} \mathrm{C}$ und $5 \% \mathrm{CO}_{2}$ in einem Kulturmedium mit folgender Zusammensetzung kultiviert: DMEM-Medium (PAA, Pasching, Österreich) angereichert mit 10\% fetalem Kälberserum (Gibco, Karlsruhe, Deutschland), 1\% Penicillin/Streptomycin (PAA, Pasching, Österreich), 1\% Hepes-Puffer (PAA, Pasching, Österreich) und 0,5\% Natriumpyruvat (PAA, Pasching, Österreich). Das Medium wird dreimal pro Woche erneuert.

\subsubsection{Behandlung der Zellen mit Trypsin-EDTA:}

Um die in Kultur adhärent wachsenden Tumorzellen in eine Zellsuspension zu überführen, erfolgt eine Behandlung mit Trypsin-EDTA. Zunächst wird das Kulturmedium aspiriert und die Zellen werden zweimal mit vorgewärmten PBS (1x) gespült. Nun werden die Zellen für ein bis zwei Minuten bei Raumtemperatur mit Trypsin-EDTA inkubiert. Nach Aspiration der Trypsin-EDTA-Lösung werden die Zellen durch vorsichtiges Klopfen gegen die Substratseite der Zellkulturflasche zusätzlich mechanisch gelöst und anschließend mit Zellkulturmedium vom Boden der Zellkulturflasche gespült.

\subsubsection{Zellzählung und Vitaltest mit Trypanblau:}

Die Zellzahl wird mit Hilfe eines Hämozytometers (Neubauer Zählkammer) bestimmt. Dazu wird die Zählkammer sowie das Deckglas vor der Verwendung mit 70\%igem Ethanol gereinigt. Die Zählkammer wird dann durch Anhauchen befeuchtet und das Deckglas wird mit leichtem Druck aufgelegt, so dass Newtonsche Ringe sichtbar werden.

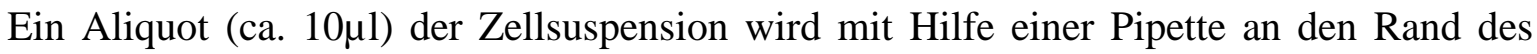
Deckgläschens pipettiert, so dass die Zellsuspension durch Kapillarkräfte passiv in die Kammer gesogen wird. Nun werden die Zellen in vier großen Quadraten des Zählnetzes unter dem Zellkulturmikroskop (Zeiss, Germany) gezählt und die Zellzahl wird mit folgenden Formeln bestimmt:

$$
\begin{gathered}
\text { MW } * 10^{4}=\text { Zellen } / \mathrm{ml} \\
\text { MW } * 10^{4} * \mathrm{~V}=\text { Gesamtzellzahl in der Suspension }
\end{gathered}
$$

(wobei gilt: $\mathrm{MW}=$ Mittelwert der gezählten Zellen aus vier großen Quadraten, $10^{4}$ = Kammerfaktor der Neubauer Zählkammer und V = Volumen der Zellsuspension) 
Soll gleichzeitig ein Vitaltest mit Trypanblau durchgeführt werden, wird das zu zählende Aliquot der Zellsuspension vor dem Aufbringen auf die Zählkammer mit einer Trypanblau-Lösung im Verhältnis 1:5 verdünnt. Dazu wird eine 0,5\%ige TrypanblauLösung in einer 0,9\%igen NaCl-Lösung verwendet, die nach dem Ansetzen steril filtriert wurde. Es werden dann die vitalen ungefärbten und die toten blau gefärbten Zellen in vier großen Quadraten des Zählnetzes gezählt und die Zahl der vitalen Zellen wird mit folgenden Formeln bestimmt:

$$
\begin{gathered}
\text { MW } * 5^{*} 10^{4}=\text { Zellen } / \mathrm{ml} \\
\text { MW } * 5 * 10^{4} * \mathrm{~V}=\text { Geamtzellzahl in der Suspension }
\end{gathered}
$$

(wobei gilt: $\mathrm{MW}=$ Mittelwert der gezählten ungefärbten Zellen aus vier großen Quadraten, Faktor 5 = Verdünnungsfaktor durch die Verdünnung der Zellsuspension mit der Trypanblau-Lösung, $10^{4}=$ Kammerfaktor der Neubauer Zählkammer und $\mathrm{V}=$ Volumen der Zellsuspension)

Der prozentuale Anteil vitaler Zellen in der Zellsuspension kann mit folgender Formel bestimmt werden:

$$
\frac{\text { ungefärbte Zellen } * 100}{\text { (gefärbte }+ \text { ungefärbte Zellen) }}=\text { Anteil lebender Zellen [\%] }
$$

\subsubsection{Kryokonservierung der Zellen:}

Zur Langzeitlagerung werden nicht benötigte Zellen kryokonserviert. Die adhärenten Zellen werden wie gewohnt trypsiniert und die gewünschte Zellzahl wird eingestellt. Die Zellen werden in einem Einfriermedium bestehend aus DMSO und dem Zellkulturmedium im Verhältnis 1:10 gut resuspendiert und in zuvor beschriftete $2 \mathrm{ml}$ Kryoröhrchen überführt. Die mit der Zellsuspension befüllten Kryoröhrchen werden nun in einem mehrstufigen Prozess unter Verwendung einer mit Isopropylalkohol gefüllten Einfrierbox (Mr. Frosty, NUNC, Nalgene) mit einer Abkühlungsrate von $1^{\circ} \mathrm{C}$ pro Minute heruntergekühlt und für 12 Stunden bei $-80^{\circ} \mathrm{C}$ aufbewahrt. Für eine Langzeitlagerung werden die Zellen in Flüssigstickstoff überführt.

\subsubsection{Auftauen von kryokonservierten Zellen:}

Die aufzutauenden Zellen werden im Kryoröhrchen mit Hilfe eines Schwimmers im auf $37^{\circ} \mathrm{C}$ vorgewärmten Wasserbad erwärmt, bis die Eiskristalle aufgetaut sind. Dann wird die 
Zellsuspension zügig unter sterilen Bedingungen in mit vorgewärmten Zellkulturmedium befüllte Zentrifugenröhrchen überführt und für 5 Minuten bei $300 \mathrm{~g}$ zentrifugiert. Der Überstand wird abgesaugt und das Zellpellet wird im Zellkulturmedium resuspendiert. Zur Überprüfung der Zellvitalität wir ein Aliquot entnommen und eine Trypanblau-Färbung (s. o.) durchgeführt.

\subsubsection{Behandlung der Zellen mit Hypericin:}

Für die unterschiedlichen Versuche werden sowohl natives wasserunlösliches Hypericin, das in Ethanol gelöst wird (Hypericin-EtOH), als auch wasserlösliches HypericinPolyvinylpyrrolidon (Hypericin-PVP) verwendet. Alle Tätigkeiten in Kombination mit Hypericin wie z.B. Ansetzen der Hypericin-Stocklösungen, Mediumwechsel werden im Dunkeln (201x) durchgeführt.

\subsubsection{Hypericin-EtOH:}

Für die Herstellung einer Hypericin-EtOH-Stocklösung mit einer Konzentration von 3mg/ml wird das native pulverförmige Hypericin (Reinheit > 99,8\%; Planta Naturstoffe, Wien, Österreich) in 70\% Ethanol (Roth, Karlsruhe, Germany) während eines 10minütigen Ultraschallbades gelöst. Die Stocklösung wird bei $4^{\circ} \mathrm{C}$ dunkel gelagert. Vor jedem Versuch wird die Stocklösung in einem 5-10-minütigen Ultraschallbad erneut durchmischt, um eventuell ausgefallene Hypericinaggregate wieder in Lösung zu bringen. Die Arbeitskonzentration wird vor jedem Versuch frisch mit Zellkulturmedium hergestellt.

\subsubsection{Hypericin-PVP:}

Durch Komplexbildung mit Polyvinylpyrrolidon wird natives wasserunlösliches Hypericin wasserlöslich. 1000mg Hypericin-PVP (PLANTA Naturstoffe, Wien, Österreich) enthalten 10mg reines natives Hypericin. Für die Versuche wird das Hypericin-PVP in Zellkulturmedium gelöst, so dass eine Stocklösung mit einer Konzentration von 1,5mg reinem Hypericin pro $\mathrm{ml}$ Medium entsteht. Die Stock-Lösung wird bei $4^{\circ} \mathrm{C}$ dunkel gelagert. Vor jedem Versuch wird die Lösung durch kräftiges Vortexen durchmischt. 


\subsubsection{Fluoreszenzmikroskopie:}

\subsubsection{Aufbau eines Fluoreszenzmikroskopes:}

Als Lichtquelle werden für Fluoreszenzmikroskope Xenon- oder Quecksilberdampflampen verwendet. Die für die Anregung des gewählten Fluorochroms geeignete Wellenlänge wird mittels Anregungsfilter aus dem Licht der Lichtquelle herausgefiltert und mit Hilfe eines dichroischen (dichromatischen) Spiegels auf das Präparat gelenkt. Dichroische Spiegel reflektieren Licht mit kleineren Wellenlängen, während größere Wellenlängen den Spiegel passieren können. Diese so genannte kritische Wellenlänge sollte zwischen dem Anregungs- und Emissionsmaximum des Fluorochroms liegen. So wird das kurzwelligere Anregungslicht durch das Objektiv zum Präparat gelenkt und das langwelligere Fluoreszenzlicht kann den Spiegel passieren und durch das Okular zum Auge bzw. der Kamera gelangen. Je besser die Trennung von Anregungs- und Fluoreszenzlicht ist, desto besser sind die abbildenden Eigenschaften des optischen Systems. Daher ist die Auswahl von geeigneten Filtersätzen und dichromatischen Spiegeln essentiell.

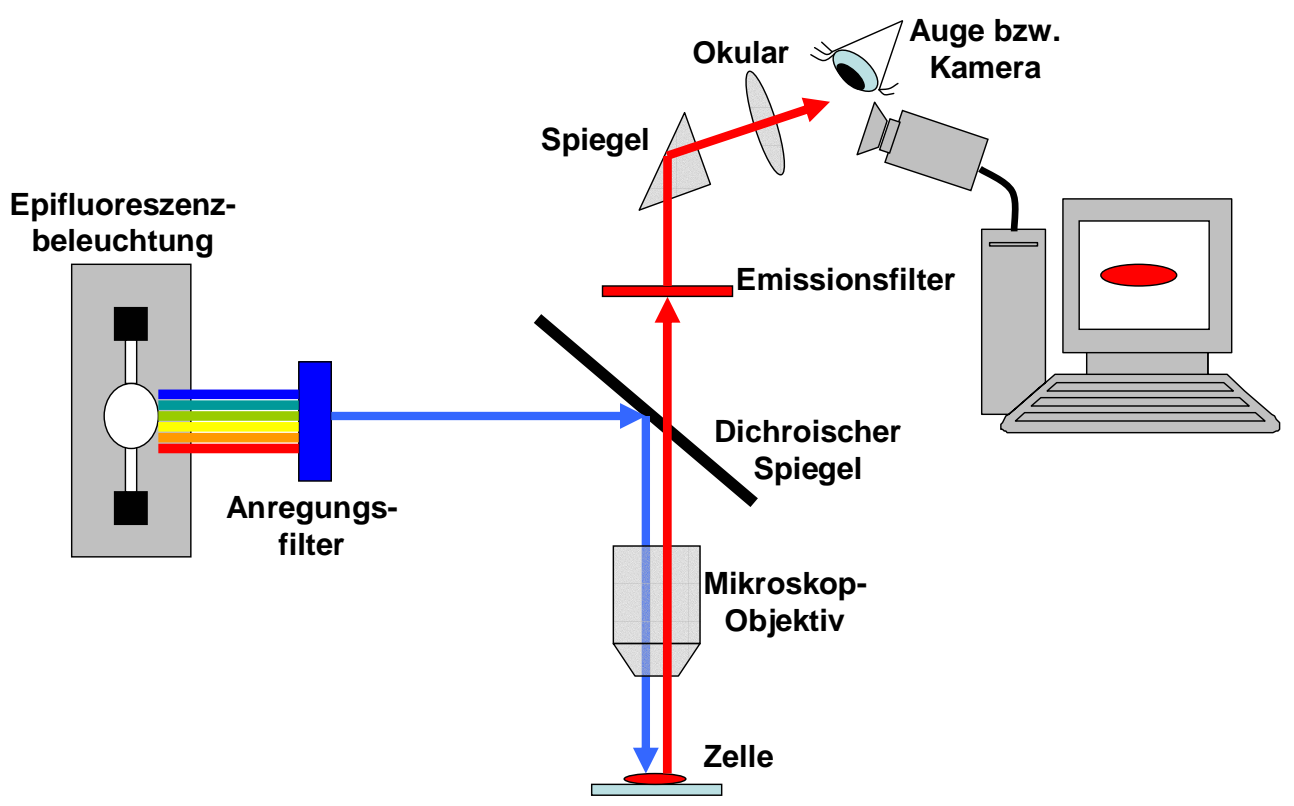

Abbildung 9: Allgemeines Schema zum Aufbau eines Fluoreszenzmikroskopes. 
3.2.4 Untersuchungen zur intrazellulären Aufnahme (Influx), Distribution, Akkumulation und Efflux von Hypericin in renalen Karzinomzellen:

3.2.4.1 Untersuchung des Hypericin-Influx und -Efflux in bzw. aus renalen KarzinomZellen:

Für die Untersuchungen des Hypericin- Influx bzw. -Efflux werden die A498-Zellen auf mit Kollagen beschichteten Deckgläschen mit einem Durchmesser von 13mm in einer 24Napf-Zellkulturplatte in einer Dichte von 7000 bis 10000 Zellen pro Napf kultiviert. Sobald die Zellen ihr typisches morphologisches Erscheinungsbild zeigen (ca. ein bis zwei Tage nach Aussaat), erfolgt die Hypericinbehandlung. Die Zellen werden mit $10 \mu \mathrm{M}$ Hypericin-EtOH bzw. 10 $\mu \mathrm{M}$ Hypericin-PVP in DMEM-Zellkulturmedium bei $37^{\circ} \mathrm{C}$ für unterschiedliche Zeiträume (1min, 10min, 20min, 30min, 60min) dunkel inkubiert. Nach der Inkubation wird die Hypericinlösung aspiriert, die Zellen werden zweimal mit vorgewärmten PBS gespült und mit frischem Zellkulturmedium versehen. Unmittelbar im Anschluss an die Inkubation bzw. 24h und $48 \mathrm{~h}$ nach der einstündigen Inkubation wird die intrazelluläre Fluoreszenz des Hypericins fluoreszenzmikroskopisch (ICys, Olympus, Hamburg, Deutschland) untersucht und quantifiziert. Dazu werden die Deckgläschen aus der 24-Napf-Platte genommen und mit einem Tropfen Vectashield-Einbettmedium mit DAPI (Vector, Linaris, Wertheim, Deutschland) invers auf einen Glasobjektträger übertragen. Die Fluoreszenzbilder werden mit einer Schwarz/Weiß-Kamera (F-View, Olympus, Hamburg, Deutschland) mit einer Belichtungszeit von 100ms aufgenommen. Die Farbbilder werden mit Hilfe der $\mathrm{Cell}^{\mathrm{F}}$ Imaging-Software (Olympus, Hamburg, Deutschland) nach Hintergrundkorrektur durch Zuordnung und Überlagerung der jeweiligen Farbkanäle erstellt. Zur Messung der Fluoreszenzintensitäten werden die Schwarz/Weiß-Bilder verwendet. Die Fluoreszenzintensitäten des intrazellulären Hypericin werden mittels Cell $^{\mathrm{F}}$ Imaging-Software (Olympus, Hamburg, Deutschland) anhand der Grauwerte ermittelt. Hierzu werden alle Zellen des jeweiligen Fokus (ca. 10-30 Zellen) im Bereich des Hypericin-Fluoreszenzsignals sowie 20-30 Bereiche des Hintergrundes manuell markiert und deren Grauwert punktuell ermittelt. Aus den jeweiligen Mittelwerten der Grauwerte der Hypericin-Fluoreszenz abzüglich der Mittelwerte des Hintergrundes werden die Fluoreszenzintensitäten des intrazellulären Hypericin bestimmt. Jedem Datenpunkt liegen 3-5 Messungen pro Versuch und mindestens drei unabhängig voneinander durchgeführte Experimente zu Grunde. 
3.2.4.2 Untersuchungen zur Akkumulation von Hypericin im Endoplasmatischen

Retikulum und im Kern renaler Karzinomzellen:

Im Rahmen der Untersuchungen zur intrazellulären Akkumulation von Hypericin in den renalen Karzinomzellen werden ca. 7000 bis 10000 A498-Zellen auf beschichteten Deckgläschen (Sarstedt) mit einem Durchmesser von $13 \mathrm{~mm}$ in einer 24-NapfZellkulturplatte kultiviert. Sobald die Zellen ihr typisches morphologisches Erscheinungsbild zeigen (ca. ein bis zwei Tage nach Aussaat), erfolgt die Hypericinbehandlung. Die Zellen werden mit einer $10 \mu \mathrm{M}$ Hypericin-EtOH- bzw. einer $10 \mu \mathrm{M}$ Hypericin-PVP-Lösung in gewöhnlichem Zellkulturmedium bei $37^{\circ} \mathrm{C}$ für unterschiedliche Zeiträume (1h, 24h, 72h) dunkel inkubiert. Nach der Inkubation wird die Hypericinlösung aspiriert und die Zellen werden zweimal mit PBS gespült. Die Zellen werden nun durch Trocknung und 20-minütiger Behandlung mit 4\%iger Paraformaldehydlösung auf den Deckgläschen fixiert. Nach dreimaligem Waschen mit PBS erfolgt die Permeabilisierung mit Aceton nach folgendem Schema:

- $2 \min 50 \%$ Aceton

- $\quad 3-4 \min 90 \%$ Aceton $\quad\}$ bei $4^{\circ} \mathrm{C}$

- $2 \min 50 \%$ Aceton

Nach der Permeabilisierung folgen ein Waschschritt mit PBS und zwei weitere mit 0,2\% Gelatine/PBS. Anschließend werden die fixierten und permeabilisierten Zellen für $1 \mathrm{~h}$ bei $37^{\circ} \mathrm{C}$ im Dunkeln mit dem Antikörper gegen Strukturen des Endoplasmatischen Retikulums inkubiert. Der Antikörper (Kaninchen gegen Mensch-IgG) gegen BIP (Immunglobulin-bindendes Protein = GRP78 Glucose-regulierendes Protein 78), der freundlicherweise von Dr. rer. nat. Phuc van Nguyen, Zentrale Serviceeinrichtung Molecular and Optical Live Cell Imaging (MOLCI), Universitätsmedizin Göttingen zur Verfügung gestellt wurde, wird 1:200 in PBS/Gelatine verdünnt.

Nach der Inkubation wird der überschüssige Primärantikörper durch dreimaliges Waschen mit PBS entfernt. Nun werden die Zellen für $1 \mathrm{~h}$ bei $37^{\circ} \mathrm{C}$ im Dunkeln mit dem 1:200 in PBS/Gelatine verdünnten FITC-konjugierten Sekundärantikörper (FITC-konjugierter Esel gegen Kaninchen-IgG) inkubiert. Es folgt ein dreifacher Waschschritt mit PBS. Nun werden die Deckgläschen aus der 24-Napf-Platte genommen und mit einem Tropfen Vectashield-Einbettmedium mit Dapi (Vector, Linaris, Wertheim, Deutschland) invers auf einen Glasobjektträger übertragen. Bis zur Auswertung (nicht länger als 24h) werden die Objektträger lichtgeschützt bei $4^{\circ} \mathrm{C}$ gelagert. Die Kolokalisation der Hypericin- und der 
FITC-Fluoreszenz wird mittels Fluoreszenzmikroskopie (ICys, Olympus, Hamburg, Deutschland) unter Verwendung spezifischer Filtersätze untersucht. Die Fluoreszenzbilder werden mit einer Schwarz/Weiß-Kamera (F-View) mit folgenden Belichtungszeiten aufgenommen:

- FITC: Belichtungszeit 500ms

- Hypericin: Belichtungszeit 100ms

- DAPI: Belichtungszeit 10ms

Die Farbbilder werden mit Hilfe der $\mathrm{Cell}^{\mathrm{F}}$ Imaging-Software (Olympus, Hamburg, Deutschland) nach Hintergrundkorrektur durch Zuordnung und Überlagerung der jeweiligen Farbkanäle erstellt.

Um die Kolokalisation der Hypericinfluoreszenz mit der Fluoreszenz der Kernfärbung mit DAPI bzw. der Färbung des Endoplasmatischen Retikulums mit FITC zu quantifizieren, werden die Schwarz/Weiß-Bilder der jeweiligen Fluoreszenz herangezogen. Mittels Cell ${ }^{\mathrm{F}}$ Imaging-Software (Olympus, Hamburg, Deutschland) wird nun manuell der Schwellenwert für jede Fluoreszenz einzeln festgesetzt. Die nach dem Schwellenwert korrigierten Fluoreszenzbilder werden nun überlagert und die Kolokalisation der unterschiedlichen Fluoreszenzen wird mit Hilfe des Kolokalisationsprogrammes der Cell ${ }^{\mathrm{F}}$ Imaging-Software (Olympus, Hamburg, Deutschland) bestimmt. Jedem Datenpunkt liegen 3-5 Messungen pro Versuch und mindestens drei unabhängig voneinander durchgeführte Experimente zu Grunde.

3.2.4.3 Untersuchung der Effekte von Hypericin auf die Transportaktivität der PGlykoproteine und zur Kolokalisation von Hypericin mit den Mitochondrien in renalen Karzinomzellen:

Um mögliche Effekte von Hypericin auf die Aktivität von MDR-Transportern zu untersuchen, werden Rhodamin-123-Effluxstudien durchgeführt. Rhodamin-123 ist ein spezifisches Transportsubstrat von P-Glykoproteinen (PGP). Es diffundiert passiv durch die Zellmembran, akkumuliert in den Mitochondrien lebender Zellen und wird durch Bindung an PGP durch aktiven Efflux aus der Zelle transportiert. Wird die Bindung an PGP verhindert oder dessen Aktivität gehemmt, so verbleibt das Rhodamin-123 in der Zelle. Aufgrund der grünen Fluoreszenz und der spezifischen Akkumulation in den Mitochondrien ist Rhodamin-123 auch ein spezifischer Mitochondrienmarker.

Zur Herstellung einer Rhodamin-123-Stocklösung wird 1mg Rhodamin-123 in $1 \mathrm{ml}$ Ethanol gelöst. Diese Stocklösung wird bei $-20^{\circ} \mathrm{C}$ dunkel gelagert. 
Für die Versuche zum Rhodamin-123-Efflux werden die A498-Zellen in speziellen Imaging-24-Napf-Platten mit Glasboden (Zellkontakt, Nörten-Hardenberg, Deutschland) in einer Dichte von 7000 bis 10000 Zellen pro Napf kultiviert. Sobald die Zellen ihr typisches morphologisches Erscheinungsbild zeigen (ca. ein bis zwei Tage nach Aussaat), erfolgt die Hypericinbehandlung. Die Zellen werden mit einer $10 \mu \mathrm{M}$ Hypericin-EtOH- bzw. einer $10 \mu \mathrm{M}$ Hypericin-PVP-Lösung in gewöhnlichem Zellkulturmedium bei $37^{\circ} \mathrm{C}$ für $1 \mathrm{~h}$ dunkel inkubiert. Nach der Inkubation wird die Hypericinlösung aspiriert, die Zellen werden zweimal mit vorgewärmten PBS gespült und mit frischem Zellkulturmedium versehen. Pro ml Medium wird nun $1 \mu 1$ einer Rhodamin123-Stocklösung hinzu gegeben und die Zellen werden für $30 \mathrm{~min}$ bei $37^{\circ} \mathrm{C}$ im Dunkeln inkubiert. Nach der Inkubation wird die Rhodaminlösung aspiriert, die Zellen werden zweimal mit vorgewärmten PBS gespült und mit frischem Zellkulturmedium versehen. Unmittelbar danach und $\mathrm{zu}$ unterschiedlichen Zeitpunkten (0min, 90min, 180min,) wird die Fluoreszenz des Rhodamin-123 (Excitation 480nm, Emission 511nm) mittels Fluoreszenzmikroskopie (ICys, Olympus, Hamburg, Deutschland) unter Verwendung spezifischer Filtersätze untersucht. Die Fluoreszenzbilder werden mit einer Schwarz/Weiß-Kamera (F-View) mit folgenden Belichtungszeiten aufgenommen:

- Rhodamin-123: Belichtungszeit 300ms

- Hypericin: Belichtungszeit 100ms

Die Farbbilder werden mit Hilfe der $\mathrm{Cell}^{\mathrm{F}}$ Imaging-Software (Olympus, Hamburg, Deutschland) nach Hintergrundkorrektur durch Zuordnung und Überlagerung der jeweiligen Farbkanäle erstellt.

Zur Messung der Fluoreszenzintensitäten werden die Schwarz/Weiß-Bilder verwendet.

Die Fluoreszenzintensitäten des intrazellulären Rhodamin-123 werden mittels Cell $^{\mathrm{F}}$ Imaging-Software anhand der Grauwerte ermittelt. Hierzu werden alle Zellen des jeweiligen Fokus (ca. 10-30 Zellen) im Bereich des Rhodamin-123-Fluoreszenzsignals sowie 20-30 Bereiche des Hintergrundes manuell markiert und deren Grauwert punktuell ermittelt. Aus den jeweiligen Mittelwerten der Grauwerte der Rhodamin-123-Fluoreszenz abzüglich der Mittelwerte des Hintergrundes werden die Fluoreszenzintensitäten des intrazellulären Rhodamin-123 bestimmt.

Um die Kolokalisation der Hypericinfluoreszenz mit der Fluoreszenz der Mitochondrienfärbung mit FITC zu quantifizieren, werden die Schwarz/Weiß-Bilder der jeweiligen Fluoreszenz herangezogen. Mittels Cell ${ }^{\mathrm{F}}$ Imaging-Software wird nun manuell der Schwellenwert für jede Fluoreszenz einzeln festgesetzt. Die nach dem Schwellenwert 
korrigierten Fluoreszenzbilder werden nun überlagert und die Kolokalisation der unterschiedlichen Fluoreszenzen wird mit Hilfe des Kolokalisationsprogrammes der Cell ${ }^{\mathrm{F}}$ Imaging-Software bestimmt.

Jedem Datenpunkt liegen 3-5 Messungen pro Versuch und mindestens drei unabhängig voneinander durchgeführte Experimente zu Grunde.

3.2.5 Untersuchungen der Effekte von photoaktiviertem und nicht photoaktiviertem Hypericin auf renale Karzinomzellen:

\subsubsection{Beleuchtung:}

Die Zellen werden, sofern nicht anders beschrieben, in 96-Napf-Platten (Sarstedt, Nümbrecht, Deutschland) bzw. in kollagenbeschichteten Kammer-Objektträgern (Nunc, Langenselbold, Deutschland) in einer Dichte von 10000 Zellen pro Napf ausgesät. Sobald die Zellen ihr typisches morphologisches Erscheinungsbild zeigen (ca. ein bis zwei Tage nach Aussaat), erfolgt die Hypericinbehandlung. Die Zellen werden mit Hypericin-EtOH unterschiedlicher Konzentration (0 bis $50 \mu \mathrm{M})$ in gewöhnlichem Zellkulturmedium bei $37^{\circ} \mathrm{C}$ für 2,5h dunkel inkubiert. Anschließend wird die Hypericinlösung aspiriert, die Zellen werden zweimal mit vorgewärmten PBS gespült und mit frischem Zellkulturmedium versehen. Die Zellen werden nun für unterschiedliche Zeitspannen (0, 10, 20 bzw. 30min) durch eine HQI ${ }^{\circledR}$-TS-Lampe (Osram, München, Deutschland) mit 50000 1x beleuchtet. Das Lichtspektrum der Lampe zeigt Emissionspeaks entsprechend der Absorptionsmaxima des Hypericins bei 548 und 590nm.

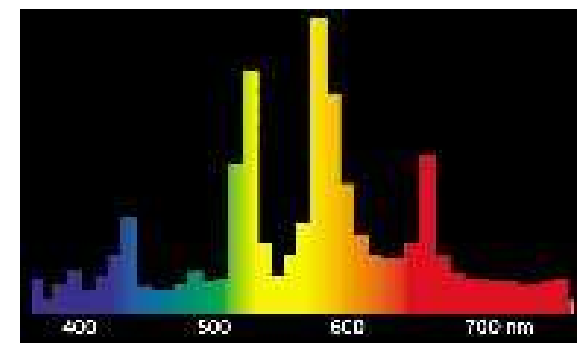

Abbildung 10: Lichtspektrum der HQI ${ }^{\circledR}$-TS-Lampe (Osram, München, Deutschland)

Nach der Beleuchtung werden die Zellen dunkel für ein, drei bzw. fünf Tage bei $37^{\circ} \mathrm{C}$ inkubiert. Alle Tätigkeiten wie z.B. Mediumwechsel werden im Dunkeln (201x) durchgeführt. Im Anschluss an die Inkubationszeit werden weitere Untersuchungen durchgeführt. 
3.2.5.2 Untersuchungen der Effekte des Hypericins auf die metabolische Aktivität renaler Karzinomzellen:

Am ersten, dritten bzw. fünften Tag nach der Beleuchtung wird die Aktivität des Metabolismus der A498-Zellen mittels MTT-Test (Roche, Penzberg, Deutschland) untersucht. Der MTT-Test beruht auf der Reduktion des wasserlöslichen gelben Farbstoffes 3-[4,5-Dimethylthiazol-2-yl]-,5-diphenyl Tetrazoliumbromid (MTT) in ein wasserunlösliches violettes Formazan in stoffwechselaktiven Zellen. Die Menge des umgesetzten Farbstoffes ist ein Maß für die Glykolyserate der Zelle und wird über die photometrische Bestimmung der optischen Dichte bei 550 bis $690 \mathrm{~nm}$ gemessen.

Entsprechend den Empfehlungen des Herstellers werden die Zellen pro Napf in $100 \mu 1$ Zellkulturmedium, dem 10 $\mu 1$ der gelben MTT-Label-Reagenz zugesetzt wurde, für vier Stunden bei $37^{\circ} \mathrm{C}$ im Dunkeln inkubiert. Danach werden $100 \mu 1$ der Solubilisation-Lösung pro Napf hinzu gegeben und über Nacht inkubiert. Die Optische Dichte des Formazans bei 550 bis $690 \mathrm{~nm}$ wird schließlich in einem Mikroplatten-ELISA-Reader (Milena Kinetic EIA Analyzer, DPC, Los Angeles, USA) bestimmt.

3.2.5.3 Untersuchungen der Effekte von Hypericin auf die Apoptoseinduktion in renalen Karzinomzellen:

Zum Nachweis der Apoptoseinduktion bei renalen Karzinomzellen durch Hypericin wird der TUNEL-Test (Roche, Penzberg, Deutschland) verwendet.

Der TUNEL-Test (Terminal deoxynucleotidyl transferase-dUTTP-nick-end-labeling) basiert auf der Fluoreszenzmarkierung von DNA-Strangbrüchen (nick-ends). Die Spaltung genomischer DNA während der Apoptose resultiert sowohl in doppelsträngigen DNAFragmenten mit niedrigem Molekulargewicht als auch in einzelsträngigen Fragmenten mit hohem Molekulargewicht. Diese Strangbrüche können durch Fluoreszenzmarkierung der freien $3 \bigcirc \mathrm{OH}-\mathrm{DNA}-E n d e n$ detektiert werden. Hierzu katalysiert die terminale Deoxynucleotidyl-Transferase (TdT) die Bindung des Fluorescein-dUTPs an die freien 3`OH-Enden der DNA-Fragmente. Dies ermöglicht die Detektion apoptotischer Zellen auf Einzelzellebene zu einem sehr frühen Stadium der Apoptose.

Die Tumorzellen werden wie oben beschrieben in einer Dichte von 10000 Zellen pro Napf in kollagenbeschichteten Kammer-Objektträgern kultiviert und behandelt. Am ersten, dritten bzw. fünften Tag nach der Beleuchtung wird der TUNEL-Test durchgeführt. Entsprechend den Empfehlungen des Herstellers werden die adhärenten Zellen mit 
4\%igem Paraformaldehyd ( $\mathrm{pH}$ 7,4) in PBS für eine Stunde bei Raumtemperatur auf dem Objektträger fixiert. Nach dem Waschen mit PBS und der Trocknung werden die Zellen in einer $0,1 \%$ igen Triton $\mathrm{X}-100$ Lösung in $0,1 \%$ igem Natriumcitrat für $2 \mathrm{~min}$ auf Eis permeabilisiert. Nach Spülung mit PBS und Trocknung werden die Zellen in 50 $\mu 1$ TUNEL-Reaktionslösung pro Napf bestehend aus $45 \mu 1$ Fluorescein-dUTP-Lösung und $5 \mu 1$ TdT-Lösung für 60 Minuten bei $37^{\circ} \mathrm{C}$ im Dunkeln inkubiert. Die Zellen der PositivKontrolle werden zuvor für $10 \mathrm{~min}$ mit DNase I (300U/ml - 3U/ml) in $50 \mathrm{mM}$ Tris- $\mathrm{HCl}$ $(\mathrm{pH}$ 7,5) mit $1 \mathrm{mg} / \mathrm{ml}$ BSA bei Raumtemperatur behandelt. Für die Negativ-Kontrolle

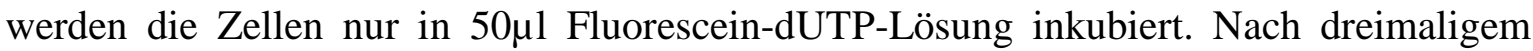
Waschen mit PBS werden die Objektträger mit einem Tropfen VectashieldEinbettmedium mit DAPI (Vector, Linaris, Wertheim, Deutschland) eingedeckelt. Die Proben $(n=3)$ werden direkt im Anschluss fluoreszenzmikroskopisch unter Verwendung spezifischer Filtersätze zur Detektion der grünen Fluoreszenz im Bereich von 515-565nm ausgewertet. Verwendet wird ein Axiovert S100-Mikroskop (Zeiss, Göttingen, Deutschland) in Kombination mit einem schwarz/weiß-Kamerasystem. Die Fluoreszenzbilder werden mit Hilfe der AnalySIS-Software (Olympus, Hamburg, Deutschland) durch Überlagerung der lichtmikroskopischen Bilder mit den Fluoreszenzsignalen erstellt.

\subsubsection{Singulett-Sauerstoff-Nachweis mittels roGFP:}

Photoaktiviertes Hypericin katalysiert verschiedene Elektronen- und Energietransferreaktionen auf Sauerstoff, wobei intrazellulär hoch reaktive Sauerstoffspezies (ROS, reactive oxygen species) vor allem Singulettsauerstoff gebildet werden. Der intrazelluläre Redoxzustand lässt sich elegant mit Hilfe von redoxsensitivem grün fluoreszierenden Protein (roGFP) darstellen, ohne dass invasive und damit potentiell schädigende Messungen nötig sind. Durch Transfektion einer Zelle mit roGFP können Schwankungen im Redox- bzw. Oxidationszustand reversibel sichtbar gemacht werden.

\subsection{Transfektion der A498-Zellen mit roGFP:}

Als Transfektion wird eine Methode bezeichnet, die dem Einschleusen von Fremd-DNA in eukaryontische Zellen dient. Hierzu wird die gewünschte DNA-Sequenz in einen Plasmidvektor integriert, der als Transportmittel dient. Es gibt verschiedene chemische (z.B. Lipofektion), physikalische (z.B. Elektroporation) und biologische (z.B. Transferinfektion) Methoden um ein Plasmid in eine Wirtszelle zu transferieren. Die 
Eignung der jeweiligen Methode für die entsprechende Verwendung ist von der Empfindlichkeit der zu transfizierenden Zelle abhängig. Man unterscheidet transiente Transfektion und stabile Transfektion. Bei der transienten Transfektion verbleibt die Fremd-DNA nur zeitweise in der Wirtszelle, da diese durch intrazelluläre Abbauprozesse eliminiert wird. Eine stabile Transfektion, bei der ein dauerhafter Einbau der Fremd-DNA in das Genom der Wirtszelle gewährleistet ist, erfolgt über einen Selektionsschritt. Das für eine stabile Transfektion $\mathrm{zu}$ verwendende Plasmid enthält dann ein Gen für eine Antibiotikaresistenz. Durch Kultur der transfizierten Zellen in einem antibiotikahaltigem Medium z.B. G418 mit zunehmender Konzentration werden daher nur die stabil transfizierten Zellen selektiert, während alle anderen Zellen zu Grunde gehen.

In diesem Versuch wird für die elektroporative Transfektion der A498-Zellen der Vektor pEGFP-N1 (Clontech, Mountain view, USA) verwendet. pEGFP-N1 kodiert für eine Variante des GFP-Wildtyps, dessen Fluoreszenz mit einem Anregungsmaximum bei 488nm und einem Emissionsmaximum bei 507nm in den Rotbereich verschoben ist. Die in die Wildtypvariante eingebrachten Mutationen C48S/T65S/S147C/Q204C führen zu strukturellen Veränderungen des GFP, so dass die Cystein-Reste 147 und 204 an der Oberfläche des Proteins lokalisiert sind (Hanson et al., 2004).

Diese strukturellen Veränderungen ermöglichen die Redoxsensitivität des GFP und damit eine sensible und dynamische ratiometrische Messung des Redox-Zustandes der transfizierten Zellen. Das redoxsensitive roGFP hat zwei Anregungsmaxima bei 395nm und 470nm. Im oxidierten Zustand kommt es zur Bildung von Disulfid-Brücken zwischen den an der Oberfläche des Proteins lokalisierten Cystein-Resten. Dies induziert eine reversible Konformationsänderung des Proteins, wodurch die Protonierung des Chromophors begünstigt wird, was in einer Verstärkung des Anregungsmaximums bei 395nm und einer Abschwächung bei 470nm resultiert. Unter reduzierten Bedingungen kann das Gegenteil beobachtet werden. Der intrazelluläre Redox-Zustand lässt sich durch das Verhältnis der Fluoreszenzintensitäten bei 395nm zu 470nm ermitteln. Durch Bildung des Quotienten werden mögliche Verfälschungen der Messung in Folge von z.B. Hintergrundfluoreszenz, ungleichmäßiger Beleuchtung oder unterschiedlich starker Expression des GFP minimiert (Hanson et al. 2004; Dooley et al., 2004).

Alle Versuche zum Nachweis der Bildung von intrazellulären ROS durch photoaktiviertes Hypericin werden in der Arbeitsgruppe von JProf. Dr. Michael Müller, Abteilung Neuround Sinnesphysiologie am Zentrum für Physiologie und Pathophysiologie, Georg-AugustUniversität Göttingen durchgeführt. Das redoxsensitive roGFP wird der Arbeitsgruppe 
Müller durch Prof. Ph.D. S. James Remington, Institute of Molecular Biology, University of Oregon zur Verfügung gestellt.

Die A498-Zellen werden, wie oben beschrieben, geerntet und die Zellzahl wird bestimmt. Pro Transfektionsansatz werden 1,5 x $10^{6}$ Zellen in ein Eppendorf-Reaktionsgefäß überführt und bei $500 \mathrm{~g}$ für $5 \mathrm{~min}$ zentrifugiert. Der Überstand wird aspiriert und die Zellen werden in $100 \mu 1$ Nucleofector ${ }^{\circledR}$-Lösung (amaxa biosystems, Köln, Deutschland) resuspendiert. Nach Zugabe von 3-4 $\mu$ g der roGFP-DNA wird die Suspension luftblasenfrei in eine amaxa zertifizierte Küvette pipettiert. Die Küvette wird in den Elektroporator Nucleofector I (amaxa biosystems, Köln, Deutschland) überführt und das ElektroporationsProgramm 0-03 wird gestartet. Nach Applikation des Elektroporationspulses wird die Zellsuspension mit 500 $\mu 1$ vorgewärmten antibiotikafreien Zellkulturmedium in der Küvette verdünnt und in ein Eppendorf-Reaktionsgefäß überführt. In jeden Napf einer 4-NapfPlatte wird ein beschichtetes Deckgläschen gegeben und je 50 $\mu 1$ der Zellsuspension werden auf die Deckgläschen pipettiert. Dabei ist zu beachten, dass die Zellsuspension in einem Tropfen auf dem Deckgläschen verbleibt, so dass die Zellen in einem begrenzten Bereich adhärent werden können. Nach zwei bis vier Stunden Inkubation bei $37^{\circ} \mathrm{C} \mathrm{im}$ Dunkeln werden die Näpfe mit Zellkulturmedium aufgefüllt. Die Transfektion der Zellen ist nicht stabil ist, da keine Selektion erfolgt, so dass die Versuche bis spätestens 48 Stunden nach der Transfektion abgeschlossen sein müssen.

\subsection{Hypericinbehandlung der transfizierten A498-Zellen:}

Die Zellen werden mit einer $10 \mu \mathrm{M}$ Hypericin-EtOH-Lösung in gewöhnlichem Zellkulturmedium bei $37^{\circ} \mathrm{C}$ über Nacht dunkel inkubiert. Am nächsten Tag wird die Hypericinlösung aspiriert, die Deckgläschen in den Näpfen werden zweimal mit PBS gespült, mit Zellkulturmedium aufgefüllt und bis zur Messung dunkel aufbewahrt.

In einem weiteren Versuchsansatz werden die Zellen ohne Vorinkubation direkt während der Messung mit einer 10 $\mathrm{M}$ Mypericin-EtOH-Lösung in Medium umspült.

3.2.5.4.3 Messung der intrazellulären Redoxbedingungen vor und während einer PDT mit Hypericin:

Die optischen Messungen zum Redoxstatus der transfizierten A498-Zellen werden an einem aufrechten Fluoreszenzmikroskop (Axiotech vario, Zeiss, Oberkochen, Deutschland) durchgeführt. Als polychromatische Lichtquelle wird eine Xenon Hochdrucklampe (Polychrom II, Till Photonics, Gräfelfing, Deutschland) verwendet, deren 
Anregungslicht mittels eines galvanometrisch gesteuerten optischen Gitters auf die gewünschte Wellenlänge $\pm 15 \mathrm{~nm}$ eingeengt wird. Ein Bandpass-Filter trennt die emittierte Fluoreszenz von dem kurzwelligeren Anregungslicht. Die Fluoreszenzbilder werden mit einer CCD Kamera (Imago QE, PCO Imaging, Kehlheim, Deutschland) aufgenommen und mittels TILLvisION-Software (Till Photonics, Gräfelfing, Deutschland) ausgewertet.

Der Versuchsaufbau ist in der Arbeitsgruppe von JProf. Dr. Michael Müller, Abteilung Neuro- und Sinnesphysiologie am Zentrum für Physiologie und Pathophysiologie, GeorgAugust-Universität Göttingen etabliert worden. Der modifizierte Objekttisch des Mikroskops enthält eine Vertiefung, die mit einem $\mathrm{Zu}$ - und Ablauf an ein zirkuläres Schlauchsystem mit angeschlossener Zirkulationspumpe angeschlossen ist. Diese Vertiefung ermöglicht die Versorgung der Zellen mit Medium während der Messung. Mit Hilfe einer Umlaufpumpe wird das Medium in das Schlauchsystem sowie in die Vertiefung des Objekttisches am Mikroskop geleitet und in ständiger Zirkulation gehalten. Dadurch kann das Medium kontinuierlich im Wasserbad auf $37^{\circ} \mathrm{C}$ erwärmt und mit Sauerstoff angereichert werden. Nach einer 10-minütiger Einlaufphase wird ein mit den transfizierten Zellen bewachsenes Deckgläschen in der Vertiefung des Objekttisches platziert. Nun wird manuell der Fokus auf die Zellen eingestellt, wobei das Objektiv in das Medium eintaucht. Die Dauer der Fokussierung ist bei mit Hypericin vorinkubierten Zellen möglichst kurz zu halten, um ein photodynamischen Schaden vor der Messung zu verhindern. Mit einer Aufnahmegeschwindigkeit von einem Bild alle 5 Sekunden wird nun die Fluoreszenzintensität bei 395 und 470nm gemessen. Die gemessenen Fluoreszenzintensitäten bei 395 und 470nm sowie die Rate aus beiden können schon während der Messung mittels der TILLvisION-Software beobachtet werden.

Über einen gewissen Zeitraum (ca. 10min) wird zunächst die sog. Baseline bestimmt, die den regulären Redoxzustand der Zellen abbildet. Um reduzierende Bedingungen zu imitieren, werden die Zellen nun mit einer 10mM DTT- Lösung umspült und die Fluoreszenzintensitäten sowie deren Rate gemessen. Hierzu werden die Pumpenschläuche in ein extra Becherglas gehängt, um eine Verunreinigung des Mediums mit DTT zu verhindern. Nach etwa fünf Minuten wird das DTT mit normalem Medium aus dem System gespült und in einem extra Behälter aufgefangen. Die Zellen werden nun wieder mit zirkulierendem Medium umspült bis der ursprüngliche Redoxzustand wieder erreicht ist. Oxidierte Bedingungen werden durch eine Umspülung der Zellen mit einer 5mM $\mathrm{H}_{2} \mathrm{O}_{2}$-Lösung nach gleichem Vorgehen imitiert. Nach Messung der Fluoreszenzintensitäten unter oxidierten Bedingungen und Entfernung des $\mathrm{H}_{2} \mathrm{O}_{2}$ aus dem System kann nach 
Wiederherstellung des ursprünglichen Redoxzustandes nun mit dem eigentlichen Versuch begonnen werden. Hierzu werden die Zellen mit 10 $\mu \mathrm{M}$ Hypericin-EtOH in Medium umspült und für etwa 10min mit der Mikroskoplampe beleuchtet. Da eine Messung während der Beleuchtung technisch nicht möglich ist, werden die Fluoreszenzintensitäten bei 395 und 470nm direkt im Anschluss an die Beleuchtung bestimmt. Bei den Zellen, die über Nacht mit Hypericin vorinkubiert wurden, ist eine Bestimmung des Basisredoxzustandes nicht möglich, daher wird direkt mit der Messung der Fluoreszenzintensitäten begonnen.

\subsubsection{Bestrahlungsversuch:}

Die photodynamische Therapie mit Hypericin ist ein interessanter Ansatz, aber in der klinischen Anwendung jedoch wegen der geringen Eindringtiefe des Lichtes nur auf oberflächennahe Behandlung beschränkt. Daher sollen in den folgenden Versuchen die Effekte von Hypericin in Kombination mit einer Bestrahlung auf renale Karzinomzellen untersucht werden.

\subsubsection{Bestrahlung:}

Die Zellen werden mit einer 50 $\mu \mathrm{M}$ Hypericin-EtOH-Lösung in gewöhnlichem Zellkulturmedium bei $37^{\circ} \mathrm{C}$ über Nacht dunkel inkubiert. Als Kontrolle werden Zellen verwendet, die in Zellkulturmedium ohne Hypericinzusatz inkubiert werden. Nach der Inkubation werden die Zellen geerntet, zweimal mit PBS gewaschen und in Zellkulturmedium resuspendiert. Um eine zügige Bearbeitung nach der Bestrahlung zu gewährleisten, wird die Zellzahl schon vor der Bestrahlung ermittelt. Nun werden die Zellen mit 0, 2, 4, 6 bzw. 8Gy bestrahlt. Die verwendeten Bestrahlungsgeräte Stabilipan (Siemens, München, Deutschland) bzw. X-ray research System RS225 (Gulmay Medical, Camberley, UK) mit einem 0,5mm Kupferfilter arbeiten bei $200 \mathrm{kV}$ und $20 \mathrm{~mA}$ mit einer Dosisrate von 1,3Gy/min bzw. 2Gy/min. Nach der Bestrahlung werden die Zellen für die anschließenden Untersuchungen in 96-Napfplatten, kollagenbeschichteten Kammerobjektträgern bzw. Kulturflaschen in frischem Zellkulturmedium mit bzw. ohne Zusatz von $50 \mu \mathrm{M}$ Hypericin-EtOH für 10 bis 13 Tage im Dunkeln inkubiert. Um einen Lichteffekt auszuschließen, werden alle Arbeitsschritte im Dunkeln durchgeführt. 
3.2.6.2 Untersuchung der Effekte von Hypericin in Kombination mit Bestrahlung auf die metabolischen Aktivität renaler Karzinomzellen:

Am ersten bzw. 13. Tag nach der Bestrahlung wird die metabolische Aktivität der Zellen mittels MTT-Test (Roche, Penzberg, Deutschland) untersucht (siehe 3.2.5.2).

3.2.6.3 Untersuchung der Effekte von Hypericin in Kombination mit Bestrahlung auf die Apoptoseinduktion in renalen Karzinomzellen:

Am ersten bzw. dritten Tag nach der Bestrahlung werden die Zellen auf Apoptose untersucht. Zum Nachweis der Apoptose wird der TUNEL-Test (Roche, Penzberg, Deutschland) verwendet (3.2.5.3).

\subsubsection{Untersuchung der Effekte von Hypericin in Kombination mit Bestrahlung auf die}

Koloniebildungsfähigkeit von renalen Karzinomzellen:

Der reproduktive Zelltod wird mit Hilfe des Koloniebildungstests quantifiziert. Dabei werden Zellen, die in einem Zeitraum von 10 bis 15 Zellzyklen Kolonien aus mindestens 50 Tochterzellen bilden können, als (klonal) überlebend definiert.

Zur Ermittlung des klonogenen Überlebens werden die A498-Zellen direkt nach der Bestrahlung in einer Dichte von 250-1000 Zellen pro Kulturflasche $\left(25 \mathrm{~cm}^{2}\right.$, Sarstedt, Newton, USA) ausgesät, die eingesetzte Ausgangszellzahl richtet sich dabei nach der Strahlendosis (siehe Tab. 1):

Tabelle 1: Eingesetzte Ausgangszellzahl zur Bestimmung des klonogenen Überlebens von A498-Zellen nach Bestrahlung mit verschiedenen Strahlendosen.

\begin{tabular}{|c|c|}
\hline $\begin{array}{c}\text { Ausgangszellzahl pro } \\
\text { Napf }\left(\mathrm{S}_{0}\right)\end{array}$ & $\begin{array}{c}\text { Strahlendosis } \\
{[\mathrm{Gy}]}\end{array}$ \\
\hline 250 & 0 \\
\hline 250 & 2 \\
\hline 500 & 4 \\
\hline 1000 & 6 \\
\hline 1000 & 8 \\
\hline
\end{tabular}

In frischem Zellkulturmedium mit bzw. ohne Zusatz von 50 $\mathrm{M}$ Hypericin-EtOH werden die Zellen nun für 10 bis 13 Tage im Dunkeln inkubiert.

Das Medium wird aspiriert und die Kulturen werden mit Ethanol (70\%) fixiert. Die Zellen werden mit einer Kristallviolett-Lösung bestehend aus 0,1ml Stammlösung (Merck, Darmstadt, Deutschland), 40ml Ethanol (100\%) und 160ml Wasser gefärbt. Nach 20 
Minuten wird die Kristallviolett-Lösung aspiriert und die Kulturen werden mit Wasser gespült, um überschüssigen Farbstoff zu entfernen. Dann werden die Kulturen über Nacht im Trockenschrank getrocknet. Unter einem Auflichtmikroskop (Zeiss, Jena, Deutschland) werden die Zellkolonien untersucht. Dabei werden Kolonien, die aus mehr als 50 Zellen bestehen, als eine überlebende Population gezählt.

Der Quotient aus der ermittelten Koloniezahl (S) und der Ausgangszellzahl ( $\left.\mathrm{S}_{0}\right)$ wird als „Plating Efficiency“ (PE) bezeichnet:

$$
\mathrm{PE}=\frac{\text { Anzahl überlebender Kolonien }(\mathrm{S})}{\text { Ausgangszellzahl }\left(\mathbf{S}_{\mathbf{0}}\right)}
$$

Die Überlebensfraktion (,ㅌurvival Fraction“ $=$ SF) ergibt sich aus der Normierung der PE behandelter Zellen auf die PE unbehandelter Zellen $\left(\mathrm{SF}_{0}\right.$ bei $0 \mathrm{~Gy}=100 \%$ bzw. $\left.=1\right)$ :

$$
\mathbf{S F}=\frac{\mathbf{P E}_{(\text {behandelte Zellen) }}}{\mathbf{P E}(\text { (unbehandelte Zellen) }}
$$

Die Überlebensfraktion der bestrahlten Zellen wird in Abhängigkeit von der Strahlendosis bestimmt und dargestellt. Jedem Dosispunkt liegen die Daten aus je drei Parallelen pro Versuch bei vier unabhängig voneinander durchgeführten Experimenten zu Grunde. Die Daten werden mittels KaleidaGraph 4.0 Software ausgewertet und graphisch dargestellt.

Die Dosiswirkungsbeziehung zwischen Strahlung und dem klonalen Überleben der Zellen kann graphisch in einer so genannten Überlebenskurve (Dosis-Effekt-Kurve) (Abb.11) dargestellt werden. Überlebenskurven folgen einer linear-quadratischen Exponentialfunktion

$$
\mathrm{SF}=\mathrm{SF}_{0} \exp \left[-\left(\alpha \mathrm{D}+\beta \mathrm{D}^{2}\right)\right] \text { bzw. } \ln \mathrm{SF} / \mathrm{SF}_{0}=-\left(\alpha \mathrm{D}+\beta \mathrm{D}^{2}\right)
$$

wobei gilt: $\mathrm{SF}_{0}=$ Überlebensfraktion der unbestrahlten Zellen, $\mathrm{SF}=$ Überlebensfraktion der bestrahlten Zellen, $\mathrm{D}=$ Dosis [Gy], $\alpha=$ Konstante, die die Toxizität der direkt erzeugten Doppelstrangbrüche beschreibt, $\beta=$ Konstante, die die Toxizität der meist indirekt erzeugten Einzelstrangbrüche beschreibt. Die Einzelstrangbrüche koinzidieren mit steigender Dosis immer häufiger im selben Basenpaar und können dann als sekundärer Doppelstrang letal werden. 


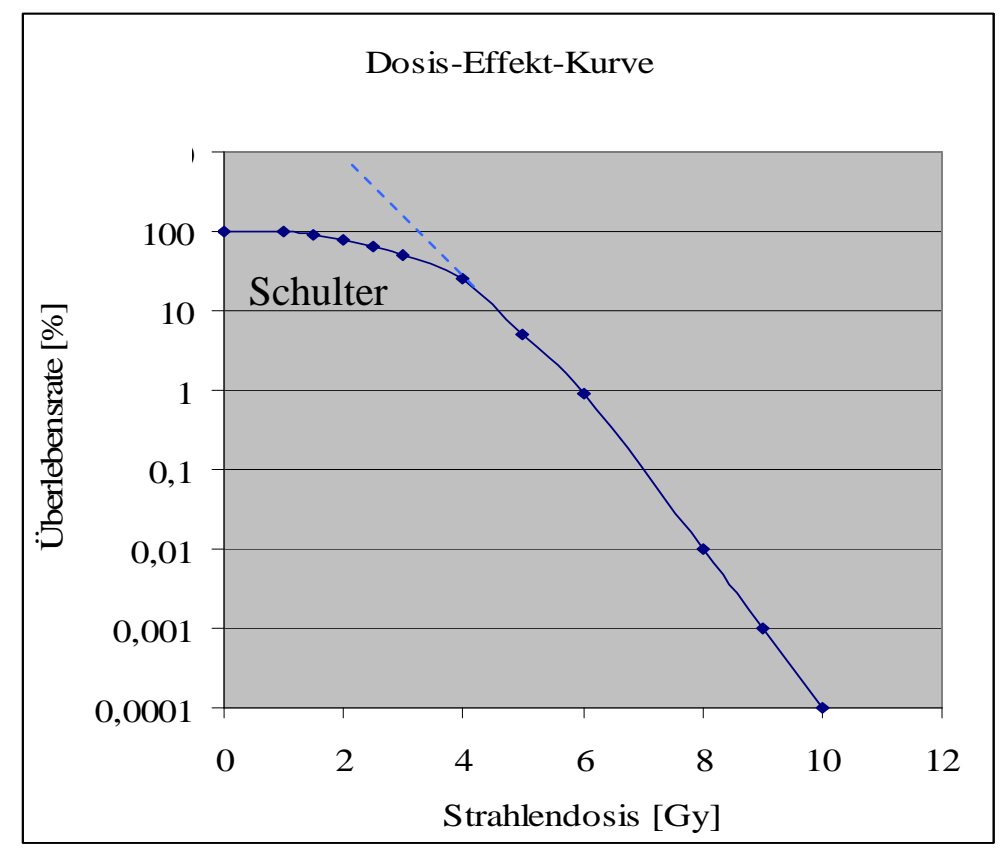

Abbildung 11: Allgemeine Darstellung einer Dosis-Effekt-Beziehung nach Bestrahlung. Die Überlebensrate [\%] ist in Abhängigkeit der Strahlendosis [Gy] dargestellt. Aufgrund der halblogarithmischen Darstellung ergibt sich eine so genannte Schulterkurve.

Bei halblogarithmischer Darstellung ergibt sich für die Dosis-Effekt-Beziehung eine so genannte Schulterkurve mit zwei Charakteristika:

1. Im geringen Dosisbereich treten häufig nur sublethale Strahlenschäden (SLD $=\underline{\text { sub }}$ lethal damage) auf, die von den Zellen repariert werden können. In der Darstellung zeigt sich dies an der sog. „Schulter“.

2. Im höheren Dosisbereich zeigt die Überlebenskurve einen exponentiellen Verlauf.

Dies zeigt eine mangelnde Erholungsfähigkeit der Zellen nach Strahlenschäden an.

Überlebenskurven, die keine oder eine geringer ausgeprägte Schulter, so wie einen fast rein exponentiellen Verlauf $\left(\mathrm{SF}=\mathrm{SF}_{0} \exp [-(\alpha \mathrm{D})]\right.$ ) aufweisen, sind zu beobachten bei:

- Zellen, die aufgrund ihrer biologischen Konstitution (z.B. Gendefekte) Strahlenschäden nicht reparieren können.

- Zellen, deren Reparaturmechanismen durch zusätzliche Behandlung (z.B. Zytostatika) inhibiert werden.

- Verwendung dicht ionisierender Strahlung, die fast ausschließlich Doppelstrangbrüche und komplexe Schäden erzeugt, die nicht oder nur schlecht repariert werden können. 
3.2.6.5 Untersuchungen der Effekte von Hypericin in Kombination mit Bestrahlung auf die Zellzyklusverteilung renaler Karzinomzellen:

Die Untersuchung des Zellzyklus mittels Durchflusszytometrie ist eine statische Analyse, bei der die prozentuale Verteilung einer Zellpopulation auf die G1, S und G2/M-Phase des Zellzyklus anhand der Fluoreszenzintensität eines DNA-Farbstoffes bestimmt wird. Hierzu wird die DNA mit stöchiometrisch interkalierenden Fluoreszenzfarbstoffen wie z.B. Propidiumiodid angefärbt und die Fluoreszenzintensität, die direkt proportional zum DNAGehalt ist, durchflusszytometrisch gemessen. Der DNA-Gehalt der Zellen ist abhängig von der Zellzyklusphase, in der sich die Zelle befindet. Zellen in der G1- bzw. Interphase haben regulär einen einfachen (diploiden, 2n) DNA-Gehalt, der durch Replikation in der Synthesephase (S-Phase) bis auf die doppelte Menge (4n) in der G2-Phase ansteigt. Die Verteilung der Zellpopulation auf die unterschiedlichen Phasen des Zellzyklus lassen sich nach durchflusszytometrischer Messung in einem DNA-Histogramm darstellen (Abb. 12).

$\mathbf{A}$

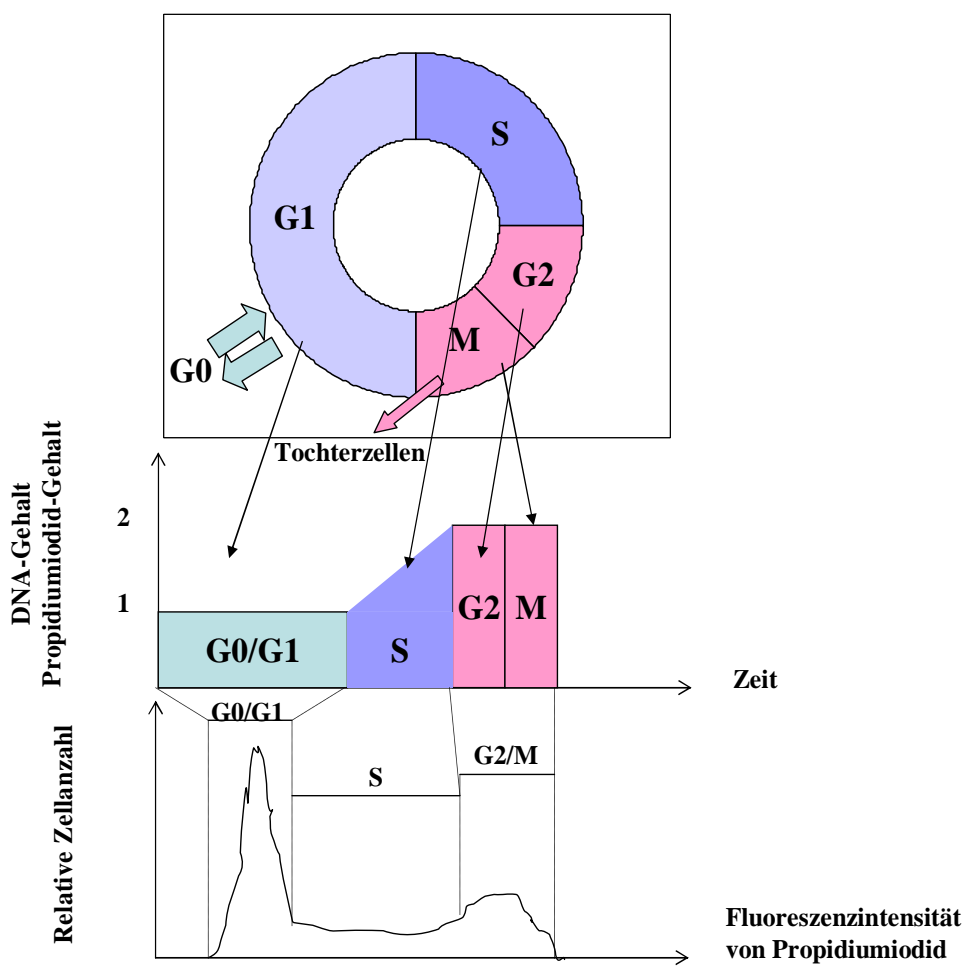

Abbildung 12: Zellzyklusanalyse. Je nach Zellzyklusphase (A), in der sich die Zelle befindet, hat die Zelle einen einfachen oder doppelten DNA-Gehalt. B) Die DNA lässt sich mit Propidiumiodid (PI) anfärben und somit ist der PI-Gehalt direkt proportional zum DNAGehalt. Die relative Verteilung der Zellen einer Population auf die einzelnen Zellzyklusphase wird durch die durchflusszytometrische Intensitätsmessung der PI-Fluoreszenz ermöglicht und lässt sich in einem DNA-Histogramm (C) darstellen. (modifiziertes Schema nach Sack et al., 2006) 
Der Zellzyklus der bestrahlten A498-Zellen wird mittels Durchflusszytometrie analysiert. Hierzu werden die Zellen am ersten und dritten Tag nach der Bestrahlung wie oben beschrieben geerntet und zweimal mit PBS gewaschen. Zur Fixierung der Zellen wird die Suspension mit eiskaltem 100\%-igem Ethanol aufgefüllt bis eine 70\%-ige EthanolEndkonzentration erreicht ist. Die Zellen werden nun $1 \mathrm{~h}$ bei $4^{\circ} \mathrm{C}$ im Dunkeln fixiert. Anschließend werden die Zellen zweimal mit PBS gewaschen und für 30 min mit 50 $\mu \mathrm{g} / \mathrm{ml}$ DNAse-freier RNAse (Roche, Penzberg, Deutschland) inkubiert. Die zelluläre DNA wird wenige Minuten vor der Analyse mit $50 \mu \mathrm{g} / \mathrm{ml}$ Propidiumiodid (Sigma Aldrich, Taufkirchen, Deutschland) angefärbt. Die Zellzyklusverteilung wird im Folgenden mittels Durchflusszytometer (FACS Scan, Becton Dickinson, Heidelberg, Deutschland) bestimmt und die Daten werden mit Hilfe der WinMDI 2.9-Software analysiert.

\subsubsection{Untersuchung der Effekte von Hypericin in Kombination mit Bestrahlung auf die} Aktivität verschiedener Enzyme in renalen Karzinomzellen mittels Immunfluoreszenz:

Die A498-Zellen werden in einer Dichte von ca. 6000 Zellen pro Napf in kollagenbeschichteten Kammer-Objektträgern kultiviert. Sobald die Zellen ihr typisches morphologisches Erscheinungsbild zeigen (ca. ein bis zwei Tage nach Aussaat), erfolgt die Hypericinbehandlung. Die Zellen werden mit einer 50 $\mu \mathrm{M}$ Hypericin-EtOH-Lösung in gewöhnlichem Zellkulturmedium bei $37^{\circ} \mathrm{C}$ für $24 \mathrm{~h}$ dunkel inkubiert. Nach der Inkubation wird die Hypericinlösung aspiriert, die Zellen werden zweimal mit PBS gespült und mit frischem Zellkulturmedium versorgt. Nun werden die Zellen mit einer Dosis von 4 Gy bestrahlt. Nach der Bestrahlung werden die Zellen dunkel für verschiedene Zeiträume (1h, $3 \mathrm{~h}, 24 \mathrm{~h}$ ) bei $37^{\circ} \mathrm{C}$ mit bzw. ohne Hypericin inkubiert.

Um einen Lichteffekt ausschließen zu können, werden alle Tätigkeiten wie z.B. Bestrahlung, Mediumwechsel im Dunkeln (201x) durchgeführt.

Die Zellen werden nun durch Trocknung und 20-minütiger Behandlung mit 4\%iger Paraformaldehydlösung fixiert. Nach dreimaligem Waschen mit PBS erfolgt die Permeabilisierung mit Aceton nach folgendem Schema:

- 2 min $50 \%$ Aceton

- 3-4 min $90 \%$ Aceton $\}$ bei $4^{\circ} \mathrm{C}$

- 2 min $50 \%$ Aceton

Nach der Permeabilisierung folgen ein Waschschritt mit PBS und zwei weitere mit 0,2\% Gelatine/PBS. Anschließend werden die fixierten und permeabilisierten Zellen für $1 \mathrm{~h}$ bei 
$37^{\circ} \mathrm{C}$ im Dunkeln mit dem jeweiligen Antikörper inkubiert. Die Antikörper werden dabei wie folgt verdünnt:

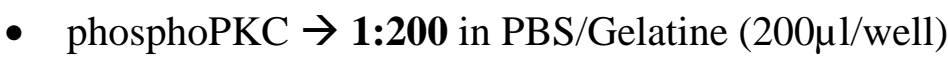

- $\gamma \mathrm{H} 2 \mathrm{AX} \rightarrow \mathbf{1 : 2 0 0}$ in PBS/Gelatine $(200 \mu 1 /$ well $)$

Nach der Inkubation werden die überschüssigen Primärantikörper durch dreimaliges Waschen mit PBS entfernt. Nun werden die Zellen für $1 \mathrm{~h}$ bei $37^{\circ} \mathrm{C}$ im Dunkeln mit dem 1:200 in PBS/Gelatine verdünnten Sekundärantikörper (FITC-konjugierter Esel gegen Kaninchen-IgG für $\gamma \mathrm{H} 2 \mathrm{AX}$ bzw. Northern Lights 493 Esel gegen Maus-IgG phosphoPKC) inkubiert. Es folgt ein dreifacher Waschschritt mit PBS. Nun werden die Objektträger mit einem Tropfen Vectashield-DAPI-Einbettmedium (Vector, Linaris, Wertheim, Deutschland) eingedeckelt. Bis zur Auswertung (nicht länger als 24h) werden die Objektträger lichtgeschützt bei $4^{\circ} \mathrm{C}$ gelagert. Die Färbungen werden mittels Fluoreszenzmikroskopie (ICys, Olympus, Hamburg, Deutschland) untersucht. Die Fluoreszenzbilder werden mit einer Schwarz/Weiß-Kamera (F-View, Olympus, Hamburg, Deutschland) mit folgenden Belichtungszeiten aufgenommen:

- FITC: Belichtungszeit 500ms

- Hypericin: Belichtungszeit 100ms

- DAPI: Belichtungszeit 10ms

Die Farbbilder werden mit Hilfe der $\mathrm{Cell}^{\mathrm{F}}$ Imaging-Software (Olympus, Hamburg, Deutschland) nach Hintergrundkorrektur durch Zuordnung und Überlagerung der jeweiligen Farbkanäle erstellt. Nun wird der prozentuale Anteil der Zellen, die eine FITCFluoreszenz aufweisen, an der Gesamtzellzahl innerhalb des jeweiligen Fokus bestimmt. Jedem Datenpunkt liegen 3-5 Messungen pro Versuch und mindestens drei unabhängig voneinander durchgeführte Experimente zu Grunde.

3.2.6.7 Untersuchung der Effekte von Hypericin in Kombination mit Bestrahlung auf die Aktivität verschiedener Enzyme in renalen Karzinomzellen mittels Westernblot:

Der Westernblot (auch Immunoblot genannt) ist eine Technik, bei der die zuvor durch Gelelektrophorese nach Größe aufgetrennten Proteine per Kapillar- oder Elektotransfer auf eine Membran (Nitrocellulose, Nylon, oder PVDF (Polyvinylidenfluorid)) übertragen werden. Die Proteine bleiben aufgrund hydrophober Wechselwirkungen an der Membranoberfläche haften, wobei das Muster der elektrophoretischen Auftrennung 
erhalten bleibt. Die Proteine sind nun immobilisiert und können mit nachfolgenden Untersuchungsmethoden wie z.B. einer Immundetektion analysiert werden. Die BlottingTechnik wurde 1975 zur Auftrennung von DNA-Fragmenten und anschließender Hybridisierung (Southern-Blot) von Edwin Southern erfunden. Die Methode des Proteinblottings wurde 1979 von J. Renart et al. für Diazobenzyloxymethyl-Papier eingeführt und von H. Towbin et al. (1979) auf Nitrocellulose umgestellt.

\subsection{Probenvorbereitung für die Western Blot-Analyse:}

Die Zellen werden in Zellkulturflaschen in Zellkulturmedium kultiviert bis der Flaschenboden konfluent bewachsen ist. Nun erfolgt die Behandlung: hierzu werden die Zellen ohne bzw. mit einer 50 $\mu \mathrm{M}$ Hypericin-EtOH-Lösung in DMEM-Zellkulturmedium bei $37^{\circ} \mathrm{C}$ für $24 \mathrm{~h}$ dunkel inkubiert. Nun werden die Zellen mit einer Dosis von $4 \mathrm{~Gy}$ bestrahlt. Nach der Bestrahlung werden die Zellen dunkel bei $37^{\circ} \mathrm{C}$ für unterschiedliche Zeiträume (3h, 24h) inkubiert. Die Kontrollzellen werden ebenfalls für $24 \mathrm{~h}$ bei $37^{\circ} \mathrm{C}$ mit

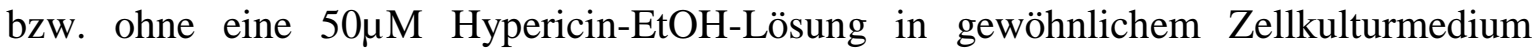
inkubiert, erhalten jedoch keine Bestrahlung. Um einen Lichteffekt ausschließen zu können, werden alle Tätigkeiten wie z.B. die Bestrahlung und Probenvorbereitung im Dunkeln (201x) durchgeführt.

\subsection{Zelllyse:}

Vor bzw. zu unterschiedlichen Zeitpunkten (3h, 24h) nach der Bestrahlung wird das Medium aspiriert. Die Zellen werden zweimal mit PBS (1x) gespült, mit Hilfe eines ZellSchabers vom Flaschenboden der Kulturflasche gelöst und in PBS (1x) resuspendiert. Nach Zentrifugation der Probe und Aspiration von PBS (1x) wird das Zellpellet in Lysepuffer ( 1 x $10^{6}$ Zellen in 100 $\mu 1$ Lysepuffer; Lysepuffer: 7M Urea, 2M Thiourea, 4\% Chaps, 50mM DTT, Proteaseinhibitor Complete ${ }^{\circledR}$ EDTA-frei) resuspendiert und kräftig vermischt. Dann werden die Proben auf Eis über einen Zeitraum von 30min in 10minütigen Intervallen für je 1-2min kräftig gemischt. Um die Viskosität des Lysates zu reduzieren, werden die Proben kurz in das Ultraschallbad gegeben. Nun werden die Proben für 30min mit $15000 \mathrm{RPM}$ bei $4^{\circ} \mathrm{C}$ zentrifugiert. Falls nach der Zentrifugation noch ein Pellet im Zentrifugenröhrchen befindet, wird der Überstand in ein neues Zentrifugenröhrchen überführt und erneut für 30min mit $15000 \mathrm{RPM}$ bei $4^{\circ} \mathrm{C}$ zentrifugiert. Das Pellet wird verworfen. Die Zentrifugation wird so oft wiederholt bis sich kein Pellet mehr bildet. 


\subsection{Acetonfällung:}

Um das restliche Hypericin aus den Zelllysaten zu entfernen wird eine Aceton-Fällung durchgeführt. Hierzu werden die Proben mit der dreifachen Menge an Aceton (100\%) über Nacht bei $-20^{\circ} \mathrm{C}$ gefällt. Am nächsten Tag werden die Proben für 30min mit 15000 RPM bei $4^{\circ} \mathrm{C}$ zentrifugiert. Der Überstand wird aspiriert und die Pellets der jeweiligen Proben werden unter der Sterilbank bei Raumtemperatur im Dunkeln getrocknet. Nach der Trocknung werden die Pellets jeweils im regulären Lysepuffer resuspendiert und bis zur weiteren Verwendung bei $-20^{\circ} \mathrm{C}$ gelagert.

\subsection{Proteinbestimmung:}

Für die Proteinbestimmung wird jeder Probe ein Aliquot entnommen und mit Ampuwa im Verhältnis 1:10 verdünnt. Die Proteinbestimmung erfolgt nach der Methode von Bradford (1976) mittels Bio Rad Protein Assay. Der Bradford-Test basiert darauf, dass sich bei der Bindung von Coomassie Brilliant Blau G-250 (BioRad, München, Deutschland) an Proteine das Absorbtionsmaximum der Farbe von 465nm (ohne Proteinbindung) nach 595nm (mit Proteinbindung) verschiebt. Die Zunahme der Absorption bei 595nm ist ein Maß für die Proteinkonzentration in der Probe und kann mit Hilfe eines Spektrophotometers gemessen werden. Als Referenzprotein wird Bovines Serumalbumin (BSA) verwendet.

\subsection{Westernblot:}

Zunächst werden die Polyacrylamidgele für die Proteingelelektrophorese vorbereitet. Je nach Größe des zu untersuchenden Proteins werden 8\%- bzw. 15\%-ige Trenngele und 4\%ige Sammelgele nach Lämmli (1970) verwendet:

Tabelle 2: Zusammensetzung der Trenn- bzw. Sammelgele für die Proteingelelektrophorese

\begin{tabular}{c|c|c|c|c} 
& $\begin{array}{c}8 \% \text {-iges Trenngel } \\
\text { für Proteine }>100 \mathrm{kd}\end{array}$ & $\begin{array}{c}15 \% \text {-iges Trenngel } \\
\text { für Proteine <30kd }\end{array}$ & \multicolumn{2}{|c}{$4 \%$ Sammelgel } \\
\cline { 1 - 3 } Tris-HCl pH=8,8 & $11,7 \mathrm{ml}$ & $15 \mathrm{ml}$ & Wasser & $15 \mathrm{ml}$ \\
Acrylamid & $6,35 \mathrm{ml}$ & $15 \mathrm{ml}$ & Tris-HCl pH=6,8 & $6,3 \mathrm{ml}$ \\
$10 \%$ SDS & $6,6 \mathrm{ml}$ & $30 \mathrm{ml}$ & $10 \%$ SDS & $250 \mu \mathrm{ml}$ \\
$10 \%$ APS & $250 \mu \mathrm{l}$ & $600 \mu \mathrm{l}$ & $10 \%$ APS & $125 \mu 1$ \\
Temed & $125 \mu \mathrm{l}$ & $300 \mu \mathrm{l}$ & Temed & $25 \mu \mathrm{l}$
\end{tabular}




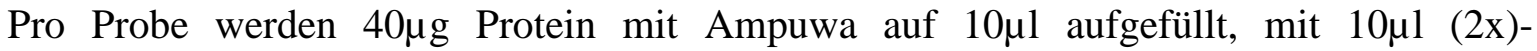
Elektrophorese-Proben-Puffer (125mM Tris- $\mathrm{HCl}$ pH=6,8, 4\% SDS, 20\% Glycerol, 0,006\% Bromphenolblau, 2\% Beta-Mercaptoethanol) verdünnt und für $10 \mathrm{~min}$ bei $97^{\circ} \mathrm{C}$ im Thermoblock erhitzt. Nun werden die Taschen des Polyacrylamidgels mit $10 \mu 1$

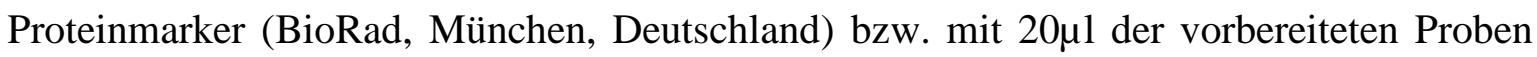
beladen. Die Gele werden in die Elektrophoresekammer (BioRad, München, Deutschland) überführt und mit Elektrophoresepuffer (15g Tris, 72g Glycin, 5g SDS gelöst in 11 Wasser) aufgefüllt. Die Elektrophorese wird auf Eis durchgeführt, startet für $10 \mathrm{~min}$ bei 150V und wird mit 180-200V fortgeführt. Nach der Elektrophorese werden die Gele auf eine Nitrocellulose-Membran (Amersham) geblottet. Hierzu wird die Membran zuvor ca. 15min in Transferpuffer (950mM Glycin, 125mM Tris, 0,25\% SDS, 20\% Methanol) equilibriert. Das Gel und die Membran werden luftblasenfrei aufeinander gelagert und beidseitig von in Transferpuffer getränktem Filterpapier und Filterflies bedeckt. Die Proteine werden nun über Nacht bei $4^{\circ} \mathrm{C}$ und $40 \mathrm{~V}$ in einer mit Transferpuffer gefüllten Blotkammer auf die Membran übertragen. Nach dem Blotten werden das Gel und die Membran aus der Blotkammer entnommen. Zur Kontrolle, ob der Blottvorgang erfolgreich war, werden die auf die Membran geblotteten Proteinbanden mit Ponceau-Rot angefärbt. Hierzu wird die Membran ca. 2-5min in dem Farbstoff geschwenkt. Die Membran wird zunächst in 5\%iger Essigsäure und danach in Waschpuffer $(0,1 \%$ Tween $20,10 \mathrm{mM}$ Tris $\mathrm{pH}=7,5,100 \mathrm{mM}$ $\mathrm{NaCl}$ ) gewaschen, um überschüssige Farbe zu entfernen und im Anschluss daran bei Raumtemperatur getrocknet.

Um überschüssige freie Proteinbindungsstellen der Blotmembran abzusättigen, wird die Membran für $2 \mathrm{~h}$ in Blockpuffer (Waschpuffer mit $5 \%$ Milchpulver) bei $37^{\circ} \mathrm{C}$ geschwenkt. Anschließend wird die geblockte Membran für $1 \mathrm{~h}$ bei $37^{\circ} \mathrm{C}$ bzw. über Nacht bei $4^{\circ} \mathrm{C}$ im Dunkeln mit dem jeweiligen 1.Antikörper inkubiert. Die Antikörper werden dabei wie folgt in Blockpuffer verdünnt:

- DNA-PKCs phosphorylated (Thr2609) Antikörper1:1000 (Maus)

- Phospho-EGF- Rezeptor (Tyr992) Antikörper 1:1000 (Kaninchen)

Nach der Inkubation werden die überschüssigen Primärantikörper durch dreimaliges Waschen für je 10-15min mit Waschpuffer entfernt. Nun wird die Membran für $2 \mathrm{~h}$ bei $37^{\circ} \mathrm{C}$ im Dunkeln mit dem in Blockpuffer verdünnten (1:2000) Sekundärantikörper (Alexa Fluor 647 Ziege anti-Kaninchen IgG-Antikörper bzw. Alexa Fluor 647 Ziege anti-Maus IgG-Antikörper) inkubiert. Es folgt ein dreifacher Waschschritt für je 10-15min mit 
Waschpuffer. Nun wird die Membran getrocknet und in einen Fujifilm FLA-5100 Scanner überführt. Die Fluoreszenz des Sekundärantikörpers wird mit dem 635nm Laser angeregt und mittels Scanner detektiert. Die Auswertung der Fluoreszenzintensitäten der Banden erfolgt mit Hilfe der Image J-Software.

3.2.6.8 Untersuchung der Effekte von Hypericin auf die Expression bestimmter Proteine in renalen Karzinomzellen mittels quantitativer Echtzeit-PCR:

Die quantitative Echtzeit-PCR (qRT-PCR, quantitative real time PCR) ist eine Methode, mit der DNA nach dem Prinzip der Polymerase-Ketten-Reaktion (PCR, Polymerase Chain Reaction) vervielfältigt werden kann und gleichzeitig eine Quantifizierung der Nucleinsäuren ermöglicht wird. Die Quantifizierung der PCR-Produkte erfolgt dabei über die Messung der Fluoreszenzintensitäten DNA-bindender Fluoreszenzfarbstoffe wie z.B. SYBR-Green. Die Fluoreszenzintensität der Farbstoffe nimmt bei der Bindung an doppelsträngige DNA zu. Die Zunahme der Fluoreszenzintensität des Farbstoffes ist daher direkt proportional zu der Zunahme der PCR-Produkte.

\subsection{Probenvorbereitung:}

Die A498-Zellen werden in Zellkulturflaschen in Zellkulturmedium kultiviert bis der Flaschenboden konfluent bewachsen ist. Nun erfolgt die Behandlung: hierzu werden die Zellen ohne bzw. mit einer $50 \mu \mathrm{M}$ Hypericin-EtOH-Lösung in gewöhnlichem Zellkulturmedium bei $37^{\circ} \mathrm{C}$ für $24 \mathrm{~h}$ dunkel inkubiert. Nun werden die Zellen mit einer Dosis von 4 Gy bestrahlt. Nach der Bestrahlung werden die Zellen dunkel bei $37^{\circ} \mathrm{C}$ für unterschiedliche Zeiträume (3h und 24h) inkubiert. Die Kontrollzellen werden ebenfalls für $24 \mathrm{~h}$ bei $37^{\circ} \mathrm{C}$ mit bzw. ohne eine $50 \mu \mathrm{M}$ Hypericin-EtOH-Lösung in gewöhnlichem Zellkulturmedium inkubiert, erhalten jedoch keine Bestrahlung. Um einen Lichteffekt ausschließen zu können, werden alle Tätigkeiten wie z.B. die Bestrahlung und Probenvorbereitung im Dunkeln (201x) durchgeführt.

\subsection{RNA-Isolation:}

Die RNA wird mit Hilfe des Total RNA Isolation-Kit (NucleoSpin®RNA II; MachereyNagel, Düren, Deutschland) aus den Proben gewonnen. Die Isolierung wird nach den Herstellerangaben wie folgt durchgeführt:

Zunächst werden die Zellen wie oben beschrieben geerntet und deren Zellzahl bestimmt. Pro Isolationsansatz werden maximal 5 x $10^{6}$ Zellen eingesetzt. Das Medium wird durch 
zweimaliges Waschen mit PBS entfernt. Das Zellpellet wird in 350 $\mu 1$ Lysepuffer (RA1Puffer) mit 10\% $\beta$-Mercaptoethanol gut resuspendiert und kräftig gemischt. Das Lysat wird durch eine 0,9mm Spritzenkanüle homogenisiert (ggf. 5x) und in einen NucleoSpin ${ }^{\circledR}$ Filter überführt. Durch Zentrifugation für 1min bei $11000 \mathrm{x}$ g wird das Lysat filtriert. Durch Zugabe von 350 $\mu 1$ Ethanol (70\%) und kräftiges Mischen werden verbesserte RNABindungsbedingungen für den folgenden Schritt geschaffen. Das Lysat wir nun auf die NucleoSpin ${ }^{\circledR}$ RNA II-Säule in einem $2 \mathrm{ml}$ Zentrifugenröhrchen überführt. Bei der Zentrifugation für 30 Sekunden bei 11000 x g bindet die RNA an die Säule. Das Filtrat wird verworfen und die Säule in ein neues Zentrifugenröhrchen überführt. Durch Zugabe von 350 $\mu 1$ MDB (Membrane Desalting Buffer) und anschließender Zentrifugation für 1min bei 11000 x g wird die Säulenmembran entsalzt, wodurch ein effektiverer DNA-Verdau ermöglicht wird. Für den DNA-Verdau werden $95 \mu 1$ einer rDNase-Lösung bestehend aus

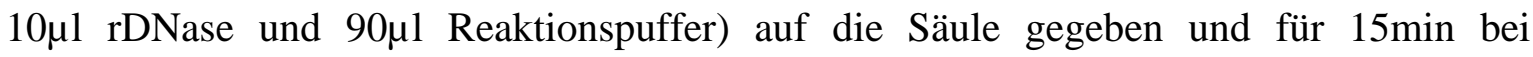
Raumtemperatur inkubiert. Um die rDNase zu inaktivieren, wird die Säule mit 200 $\mu 1$ RA2Puffer für 30sec bei 11000 x $\mathrm{g}$ zentrifugiert. Die Säule wird in ein neues Zentrifugenröhrchen überführt und zweimalig mit RA3-Puffer durch Zentrifugation für 30sec bzw. 2 min bei 11000 x g gewaschen. Die Säule wird nun in ein steriles RNase-freies

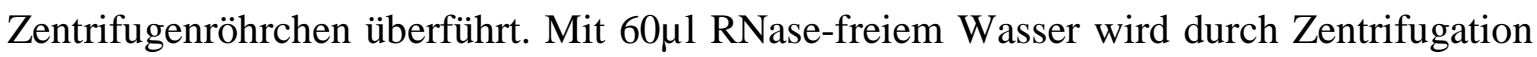
für 1min bei $11000 \mathrm{x}$ g die aufgereinigte isolierte RNA aus der Säule eluiert und sofort auf Eis gekühlt. Für die RNA-Gehaltsbestimmung wird ein Aliquot entnommen und die übrige RNA wird bis zur weiteren Verwendung bei $-80^{\circ} \mathrm{C}$ gelagert.

\subsection{Bestimmung des RNA-Gehaltes:}

Die RNA-Konzentration wird über die Messung der optischen Dichte (OD) bei einer Wellenlänge von 260nm bestimmt. Hierzu wird das Probenaliquot im Verhältnis 1:5 bzw. 1:10 mit RNasefreiem Wasser verdünnt. 50 $\mu 1$ der verdünnten Probe werden in eine Einmal-Photometerküvette überführt und die optische Dichte der Lösung bei 260nm wird in einem Photometer gemessen. 
Die RNA-Konzentration errechnet sich durch folgende Gleichung:

$$
\mathrm{c}[\mu \mathrm{g} / \mathrm{ml}]=\mathrm{OD}_{260} \times \mathrm{V} \times \mathrm{F}
$$

(wobei gilt: $\mathrm{c}=$ Konzentration, $\mathrm{OD}_{260}=$ Absorption bei $260 \mathrm{~nm}, \mathrm{~V}=$ Verdünnungsfaktor, $\mathrm{F}$ $=$ Multiplikationsfaktor $=40$ für RNA).

Das Verhältnis der optischen Dichte bei $260 \mathrm{~nm}$ zu der OD bei $280 \mathrm{~nm}$ zeigt eventuelle Proteinkontaminationen der Probe an und sollte für proteinfreie RNA-Proben bei 1,8 liegen.

\subsubsection{4 cDNA-Synthese/Reverse Transkription:}

Die RNA- Umschreibung in cDNA wird mit Hilfe des Transcriptor High Fidelity cDNA Synthesis Sample Kit (Roche, Penzberg, Deutschland) nach den Herstellerangaben wie folgt durchgeführt:

Vor der cDNA-Synthese wird der PCR-Cycler (BioRad, München, Deutschland) auf $65^{\circ} \mathrm{C}$ vorgewärmt, alle Reagenzien werden aufgetaut, kurz zentrifugiert und während der gesamten Pipettierarbeit auf Eis gelagert. Zunächst wird pro Probe ein Proben-Primer-Mix bestehend aus 500ng RNA, 2,5 $\mu \mathrm{M}$ Oligo-dT-18-Primer und nucleasefreiem Wasser mit einem Gesamtvolumen von $11,4 \mu \mathrm{l}$ in nucleasefreien PCR-Reaktionsgefäßen auf Eis angesetzt. Der Proben-Primer-Mix wird dann für $10 \mathrm{~min}$ bei $65^{\circ} \mathrm{C}$ im PCR-Cycler erhitzt, um sekundäre RNA-Strukturen zu denaturieren. Danach wird der Mix sofort auf Eis gekühlt. Nach Zugabe von $\mathrm{MgCl}_{2}$-Puffer (8mM), RNase-Inhibitor (20U), Nucleotid-Mix $(1 \mathrm{mM})$, DTT $(5 \mathrm{mM})$ und Reverse Transkriptase (10U) wird der Ansatz mit einem Gesamtvolumen von $20 \mu 1$ vorsichtig durchmischt und für $30 \mathrm{~min}$ bei $45-55^{\circ} \mathrm{C}$ im ThermoCycler inkubiert. Die Reverse Transkriptase wird nun durch Erhitzen auf $85^{\circ} \mathrm{C}$ für $5 \mathrm{~min}$ inaktiviert. Die Reaktion wird auf Eis gestoppt. Die cDNA wird 1:5 mit nucleasefreiem Wasser verdünnt und bis zur weiteren Verwendung bei $-20^{\circ} \mathrm{C}$ gelagert.

\subsection{Quantitative Real-Time-PCR:}

Die quantitative Real-Time-PCR wird mittels Power SYBR® Green PCR Mastermix (Applied Biosystems) in dem Mx3000 $\mathrm{P}^{\mathrm{TM}}$-Real-Time-PCR-Cycler (Stratagene) durchgeführt. Die spezifischen Oligonukleotide für das jeweilige Gen werden zuvor mit Hilfe der Primer3-Input 0.4.0-Software ausgewählt. Für jedes Primerpaar wird ein Supermix nach folgendem Rezept angesetzt: Pro PCR-Ansatz mit einem

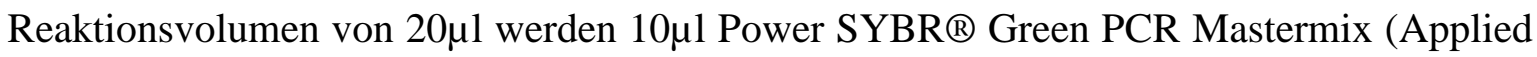

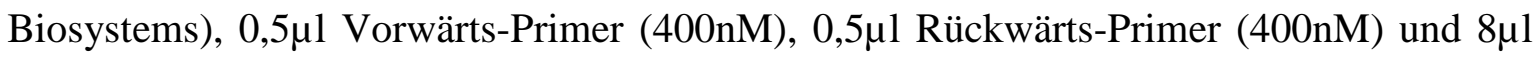


nucleasefreies Wasser zu einem Supermix vermengt. Zunächst werden $19 \mu 1$ des Supermix luftblasenfrei in jedes PCR-Reaktionsgefäß (Strip-Tubes von Stratagene) pipettiert, danach wird je $1 \mu 1$ der verdünnten cDNA hinzugegeben. Jeder Ansatz wird in Triplikaten durchgeführt. Um die Bildung von Primer-Dimeren oder eine Verunreinigung des Supermixes z.B. durch Handhabung oder verunreinigte Lösungen auszuschließen, wird pro Supermix zusätzlich ein Kontroll-Ansatz (NTC, no template control) pipettiert, bei der die cDNA durch nucleasefreies Wasser ersetzt wird. Die Gefäße werden mit Deckeln (StripCaps von Stratagene) verschlossen und in den Real-Time-PCR-Cycler (Mx3000P ${ }^{\mathrm{TM}}$, Stratagene) eingesetzt. Das Programm besteht aus folgenden Bedingungen: Einem initialen Denaturierungszyklus für $10 \mathrm{~min}$ bei $95^{\circ} \mathrm{C}, 40$ Zyklen bestehend aus jeweils einem Denaturierungsschritt für $30 \mathrm{sec}$ bei $95^{\circ} \mathrm{C}$, einem Annealingschritt für $1 \mathrm{~min}$ bei $60^{\circ} \mathrm{C}$ und einem Elongationsschritt für 30 Sekunden bei $72^{\circ} \mathrm{C}$ und einem finalen Zyklus bestehend aus einem Denaturierungsschritt für 30 Sekunden bei $95^{\circ} \mathrm{C}$, einem Annealingschritt für 1 Minute bei $60^{\circ} \mathrm{C}$ und einem weiteren Denaturierungsschritt für 30 Sekunden bei $95^{\circ} \mathrm{C}$.

Die Bestimmung des Schwellenwert-Zyklus (Ct, treshold cycle), d.h. der Zyklus bei dem die Fluoreszenz erstmalig signifikant über die Hintergrundfluoreszenz ansteigt, und die weitere Auswertung erfolgt mit der Mx3000P-Software (Stratagene). Die Software ermittelt die relativen Expressionsunterschiede nach der $\Delta \Delta \mathrm{Ct}$-Methode: Hierbei beschreibt $\Delta \mathrm{Ct}$ die Differenz zwischen dem Ct-Wert des Zielgens und dem Ct-Wert des Housekeeping-Gens Glycerinaldehyd-3-Phosphat-Dehydrogenase (GAPDH) in einer Probe. Die Differenz der $\Delta \mathrm{Ct}$-Werte der behandelte Probe und der unbehandelte Probe (Kalibrator) wird als $\Delta \Delta \mathrm{Ct}$-Wert bezeichnet. Der relative Expressionsunterschied (R) zwischen den zu vergleichenden Proben wird mit der Formel $\mathrm{R}=2^{-\Delta \Delta \mathrm{Ct}}$ berechnet.

Nach der PCR werden die PCR-Produkte zur Kontrolle elektrophoretisch in einem 1\% Agarosegel aufgetrennt, mit Ethidiumbromid angefärbt und mit einem Foto dokumentiert.

\subsubsection{Statistik:}

Die hier vorgestellten Ergebnisse sind jeweils als Mittelwerte \pm Standardabweichung angegeben. Die Signifikanz der durch die Behandlung induzierten Veränderungen gegenüber unbehandelten Kontrollen wurde mit dem 2-seitigen t-Test nach Student bestimmt. Als Statistikprogramm wurde Microsoft Excel verwendet In den Diagrammen sind signifikante Unterschiede mit * $(\mathrm{P}<0.05)$ und höchstsignifikante Unterschiede mit ** $(\mathrm{P}<0.01)$ angegeben. 


\section{Ergebnisse:}

\subsection{Ergebnisse zur intrazellulären Aufnahme (Influx), Distribution, Akkumulation und Efflux von Hypericin in bzw. aus renalen Karzinomzellen:}

\subsubsection{Ergebnisse der Hypericin-Influx und -Efflux-Untersuchungen:}

Die Untersuchungen zum Hypericin-Influx bzw. Efflux zeigen, dass die Intensität der intrazellulären Hypericinfluoreszenz mit zunehmender Inkubationsdauer ansteigt. So ist bereits nach einminütiger Inkubationsdauer eine intrazelluläre Hypericinfluoreszenz nachweisbar, deren Intensität etwa 27-30\% der Fluoreszenzintensität nach einstündiger Inkubation beträgt. Mit zunehmender Zeitspanne nach einstündiger Inkubation nimmt die die intrazelluläre Hypericinfluoreszenz langsam ab (siehe Abb.13), wobei auch 48 Stunden nach der Inkubation noch ca. 34-44\% der Fluoreszenzintensität nachweisbar sind. Die Zunahme der Fluoreszenzintensität erfolgt demnach schneller als die Abnahme (siehe Tab. 3 und Abb.14).
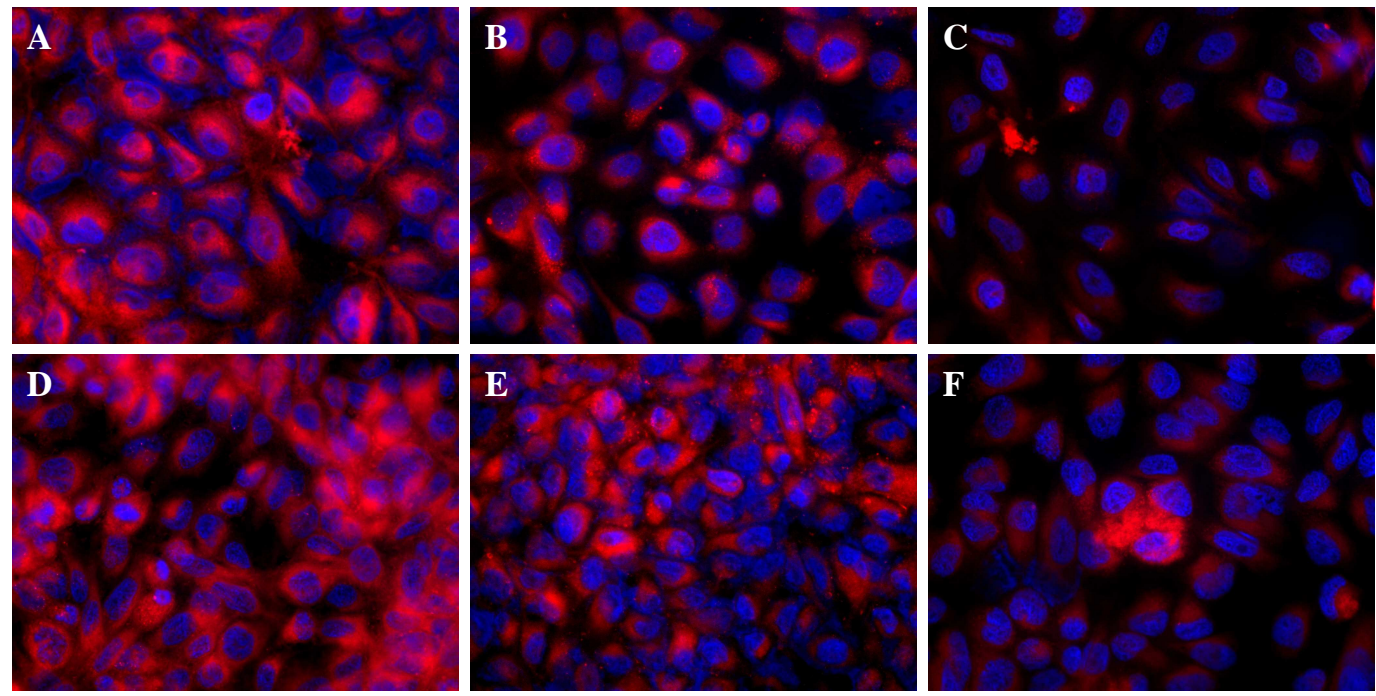

Abbildung 13: Fluoreszenzmikroskopische Bilder des Hypericin-Efflux aus renalen Karzinomzellen. Dargestellt ist die Fluoreszenz von Hypericin-EtOH (A, B, C) und HypericinPVP (D, E, F) in A498-Zellen 4h (A, D), 24h (B, E) und 48h (C, F) nach einer einstündigen Inkubation mit einer 10 $\mu \mathrm{M}$-en Hypericin-Lösung (blaue Fluoreszenz = Kernfärbung mit DAPI, rote Fluoreszenz = Hypericin, Vergrößerung 200x). 
Tabelle 3: Hypericin-Influx und -Efflux in bzw. aus humanen renalen Karzinomzellen. Dargestellt sind die Mittelwerte der intrazellulären Fluoreszenzintensitäten des Hypericins [Grauwert] sowie deren prozentualer Anteil an der Fluorezenzintensität nach 60 Minuten Inkubation zu verschiedenen Zeitpunkten während der einstündigen Inkubation (Influx) und

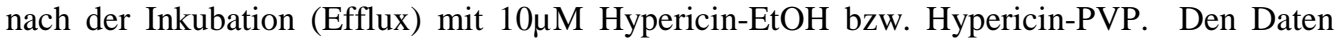
liegen drei unabhängig voneinander durchgeführte Experimente zu Grunde.

\begin{tabular}{|c|c|c||c|c||}
\hline & \multicolumn{2}{|c||}{ Hyp-EtOH } & \multicolumn{2}{c||}{ Hyp-PVP } \\
\hline & $\begin{array}{c}\text { Fluoreszenz- } \\
\text { intensität }\end{array}$ & $\begin{array}{c}\text { prozent. } \\
\text { Anteil }\end{array}$ & $\begin{array}{c}\text { Fluoreszenz- } \\
\text { intensität }\end{array}$ & $\begin{array}{c}\text { prozent. } \\
\text { Anteil }\end{array}$ \\
\hline $1 \mathrm{~min}$ & 61,7 & $27 \%$ & 65,0 & $30 \%$ \\
$10 \mathrm{~min}$ & 56,1 & $25 \%$ & 72,5 & $33 \%$ \\
$20 \mathrm{~min}$ & 100,4 & $44 \%$ & 134,6 & $62 \%$ \\
$30 \mathrm{~min}$ & 117,3 & $52 \%$ & 125,9 & $58 \%$ \\
\hline $60 \mathrm{~min}$ & 226,4 & $100 \%$ & 216,9 & $100 \%$ \\
\hline $1440 \mathrm{~min}$ & 112,5 & $50 \%$ & 83,1 & $38 \%$ \\
$2880 \mathrm{~min}$ & 76,9 & $34 \%$ & 96,3 & $44 \%$ \\
\hline
\end{tabular}

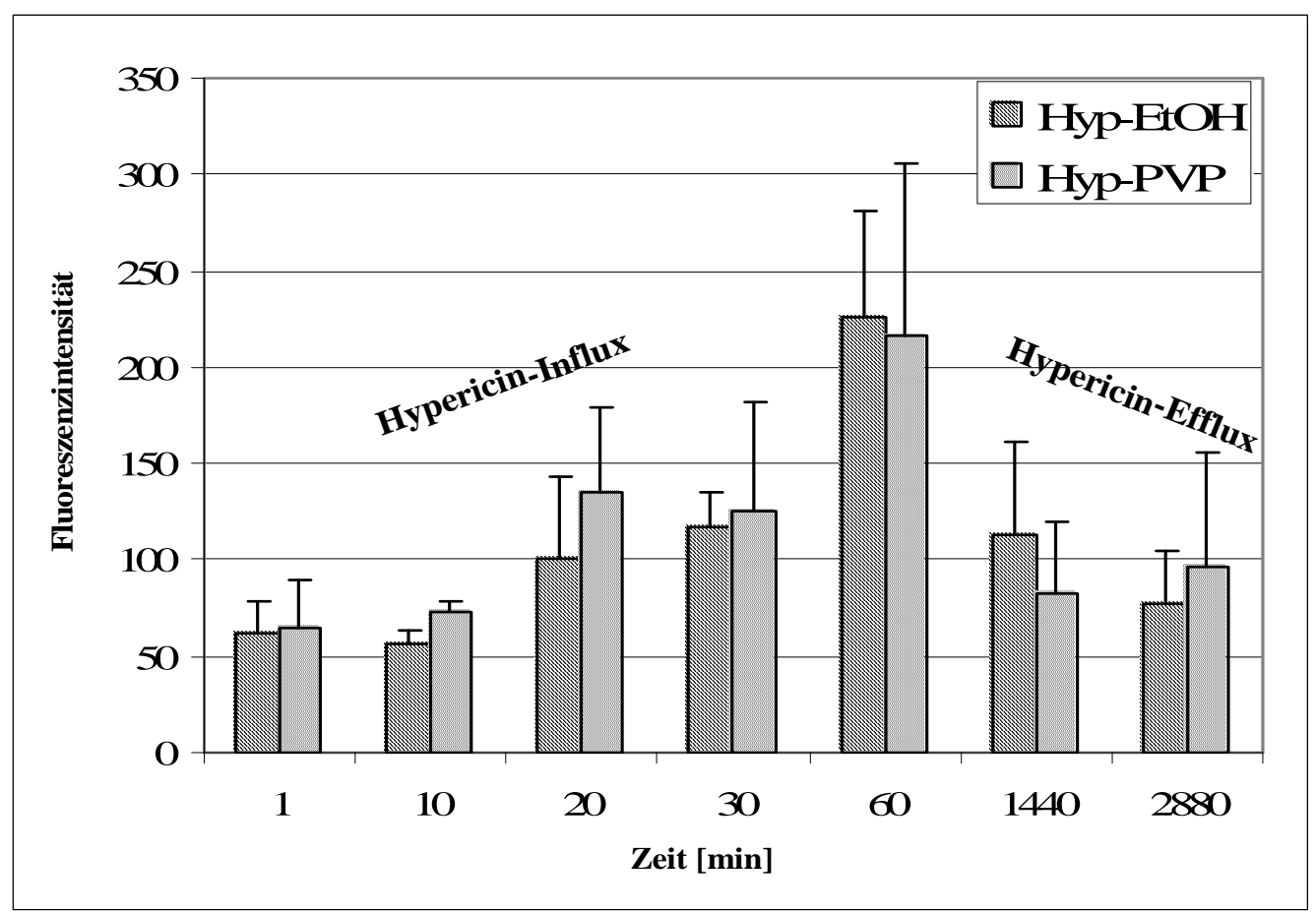

Abbildung 14: Hypericin-Influx und -Efflux in bzw. aus humanen renalen Karzinomzellen. Dargestellt sind die Mittelwerte der intrazellulären Fluoreszenzintensität [Grauwerte] des Hypericins in Abhängigkeit von der Inkubationszeit (Influx) bzw. der Zeitspanne nach einstündiger Inkubation (Efflux) mit 10 $\mu \mathrm{M}$ Hypericin-EtOH bzw. 10 $\mu \mathrm{M}$ Hypericin-PVP.

Das wasserunlösliche Hypericin-EtOH und das wasserlösliche Hypericin-PVP zeigen ein ähnliches Influx- und Effluxverhalten, wobei jedoch sowohl Influx als auch Efflux von Hypericin-PVP tendenziell schneller erfolgt als von Hypericin-EtOH. Dieser Unterschied ist jedoch nicht signifikant. 


\title{
4.1.2 Ergebnisse zur intrazellulären Hypericin-Distribution:
}

Nach der intrazellulären Aufnahme wird die intrazelluläre Distribution des Hypericins, insbesondere die Akkumulation des Hypericin in verschiedenen Zellkompartimenten wie dem Kern, dem Endoplasmatischen Retikulum und den Mitochondrien untersucht. Die Aussagen zum intrazellulären Akkumulationsverhalten des Hypericins basieren auf Kolokalisationsexperimenten.

\subsubsection{Hypericin-Akkumulation im Zellkern:}

Eine Akkumulation von Hypericin im Zellkern ist im Rahmen dieser Arbeit zu keinem Zeitpunkt nachweisbar. Weder die Fluoreszenzen des Hypericin-PVP noch des HypericinEtOH sind innerhalb der verwendeten Inkubationszeiten mit der Fluoreszenz des Kernfarbstoffes DAPI kolokalisiert (siehe Abb. 13).

\subsubsection{Hypericin-Akkumulation im Endoplasmatischen Retikulum:}

Sowohl das wasserunlösliche Hypericin-EtOH als auch das wasserlösliche Hypericin-PVP akkumulieren intrazellulär im Endoplasmatischen Retikulum in einer zeitabhängigen Weise (siehe Abb. 15).
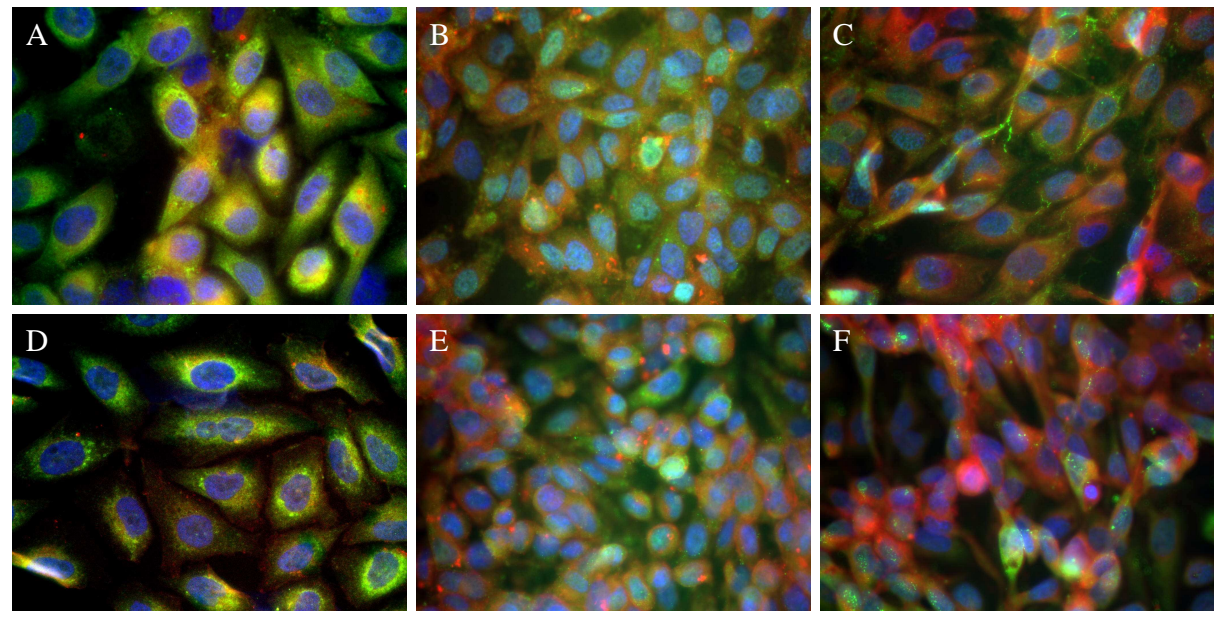

\begin{abstract}
Abbildung 15: Fluoreszenzbilder zur Akkumulation von Hypericin im Endoplasmatischen Retikulum in renalen Karzinomzellen. Die Abbildungen zeigen die Kolokalisation der Fluoreszenz von Hypericin-EtOH (A,B,C) bzw. Hypericin-PVP (D, E, F) mit der Fluoreszenz des FITC-markierten BIP nach 10-minütiger (A, D), nach 60-minütiger (B, E) und 24stündiger $(\mathrm{C}, \mathrm{F})$ Hypericin-Inkubation (grüne Fluoreszenz = FITC-konjugierter Antikörper gegen BIP, rote Fluoreszenz $=$ Hypericin, gelbe Fluoreszenz $=$ Kolokalisation von Hypericin und FITC, blaue Fluoreszenz = Kernfärbung mit DAPI, Vergrößerung 400x).
\end{abstract}

Dabei ist eine Zunahme der Akkumulation mit steigender Inkubationsdauer bis zu einer Stunde nachweisbar, während bei längeren Inkubationszeiten (drei Stunden bis 24 Stunden) die Akkumulation wieder abnimmt. Die Kolokalisation der Fluoreszenzen von 
Hypericin-EtOH und dem fluoreszenzmarkierten Immunglobulin-bindenden Protein (BIP) nimmt im Vergleich zu Hypericin-PVP schneller zu, erreicht höhere maximale Werte nach einer Stunde Inkubationszeit und nimmt langsamer wieder ab. So ist nach bereits 10 Minuten eine ca. 63\%-ige Kolokalisation der Fluoreszenzen von Hypericin-EtOH und BIP im Vergleich zu 34\% bei Hyp-PVP nachweisbar. Nach einer Stunde sind 97\% bzw. 91\% und nach 24 Stunden 88\% bzw. 69\% der BIP-Fluoreszenz mit Hyp-EtOH bzw. -PVP kolokalisiert (siehe Tab. 4 und Abb. 16).

Tabelle 4: Akkumulation von Hypericin und dem Endoplasmatischen Retikulum in renalen Karzinomzellen. Dargestellt ist die Kolokalisation als prozentualer Anteil der roten HypericinFluoreszenz (Hyp-PVP bzw. Hyp-EtOH) innerhalb der grünen Fluoreszenz des FITCmarkierten Immunglobulin-bindenden Proteins in Abhängigkeit von der Inkubationszeit des Hypericins. Den Daten liegen drei unabhängig voneinander durchgeführte Experimente zu Grunde.

\begin{tabular}{|c||c|c|}
\hline Inkubationszeit [min] & Hyp-EtOH/FITC & Hyp-PVP/FITC \\
\hline 0 & $0 \%$ & $0 \%$ \\
10 & $63 \%$ & $34 \%$ \\
30 & $72 \%$ & $77 \%$ \\
60 & $97 \%$ & $91 \%$ \\
1440 & $88 \%$ & $69 \%$ \\
\hline
\end{tabular}

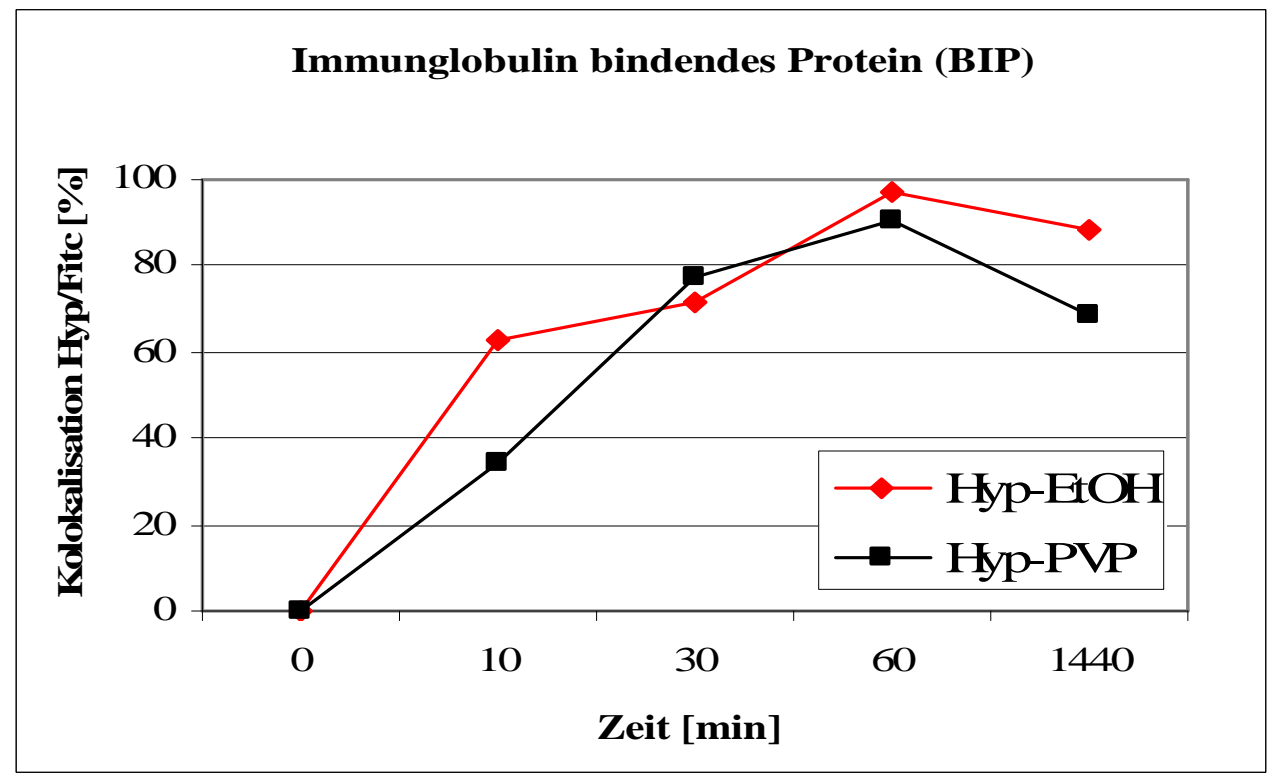

Abbildung 16: Akkumulation von Hypericin im Endoplasmatischen Retikulum in renalen Karzinomzellen. Dargestellt ist die Kolokalisation als prozentualer Anteil der roten HypericinFluoreszenz (Hyp-PVP bzw. Hyp-EtOH) innerhalb der grünen Fluoreszenz des FITCmarkierten Immunglobulin-bindenden Proteins in Abhängigkeit von der Inkubationszeit [min] des Hypericins. Den Daten liegen drei unabhängig voneinander durchgeführte Experimente zu Grunde. 
4.1.2.3 Akkumulation von Hypericin in den Mitochondrien:

Eine 50-60\%-ige Kolokalisation der Fluoreszenz von Hypericin-EtOH bzw. HypericinPVP mit der Fluoreszenz des spezifischen Mitochondrienmarkers Rhodamin-123 ist in renalen Karzinomzellen mittels Fluoreszenzmikroskopie nachweisbar (siehe Abb.17).
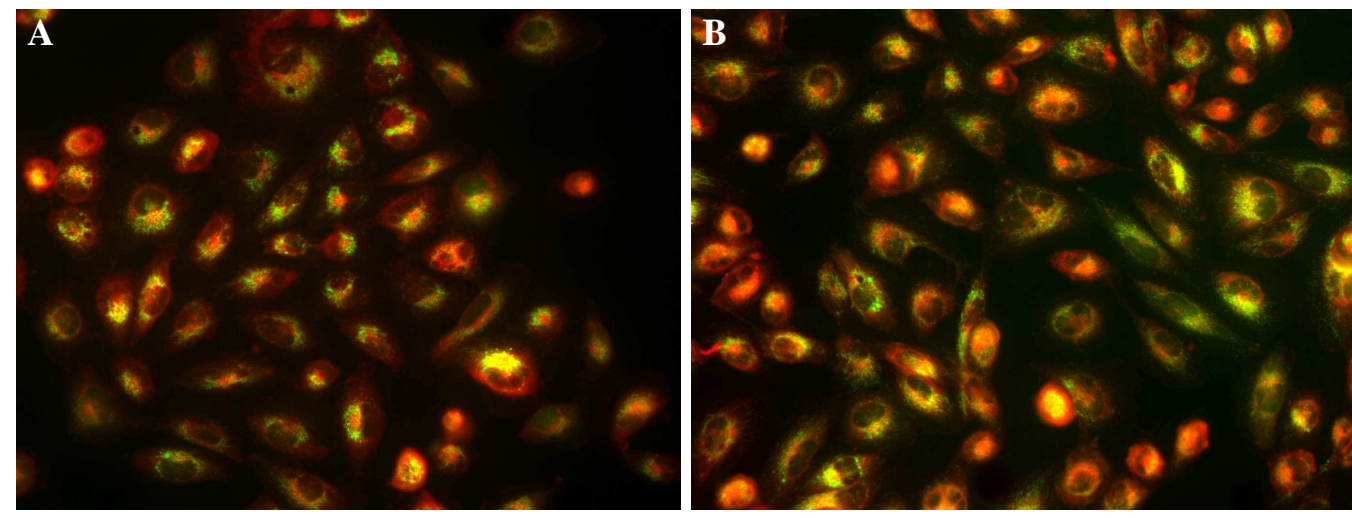

Abbildung 17: Kolokalisation von Hypericin mit den Mitochondrien. Die Abbildungen zeigen die Kolokalisation der Fluoreszenz von Hypericin-EtOH (A) bzw. Hypericin-PVP (B) mit der Fluoreszenz des Mitochondrienmarkers Rhodamin-123 (grüne Fluoreszenz = Rhodamin-123, rote Fluoreszenz = Hypericin, gelbe Fluoreszenz $=$ Kolokalisation von Hypericin und Rhodamin-123, Vergrößerung 200x).

\subsubsection{Ergebnisse zum Rhodamin-123-Efflux aus renalen Karzinomzellen:}

Um einen möglichen Einfluss von Hypericin auf die Aktivität von MDR-Transportern z.B. p-Glykoprotein (Pgp) zu überprüfen, werden Rhodamin-123-Effluxstudien durchgeführt. Rhodamin-123 ist ein spezifisches Transportsubstrat von Pgp. Es diffundiert passiv durch die Zellmembran, akkumuliert in den Mitochondrien lebender Zellen und wird durch Bindung an Pgp aktiv aus der Zelle transportiert. Wird die Bindung an Pgp verhindert oder deren Aktivität gehemmt, so verbleibt das Rhodamin-123 in der Zelle.

Die Ergebnisse aus den Effluxstudien zeigen, dass Rhodamin-123 aus A498-Zellen transportiert wird (siehe Abb. 18). 

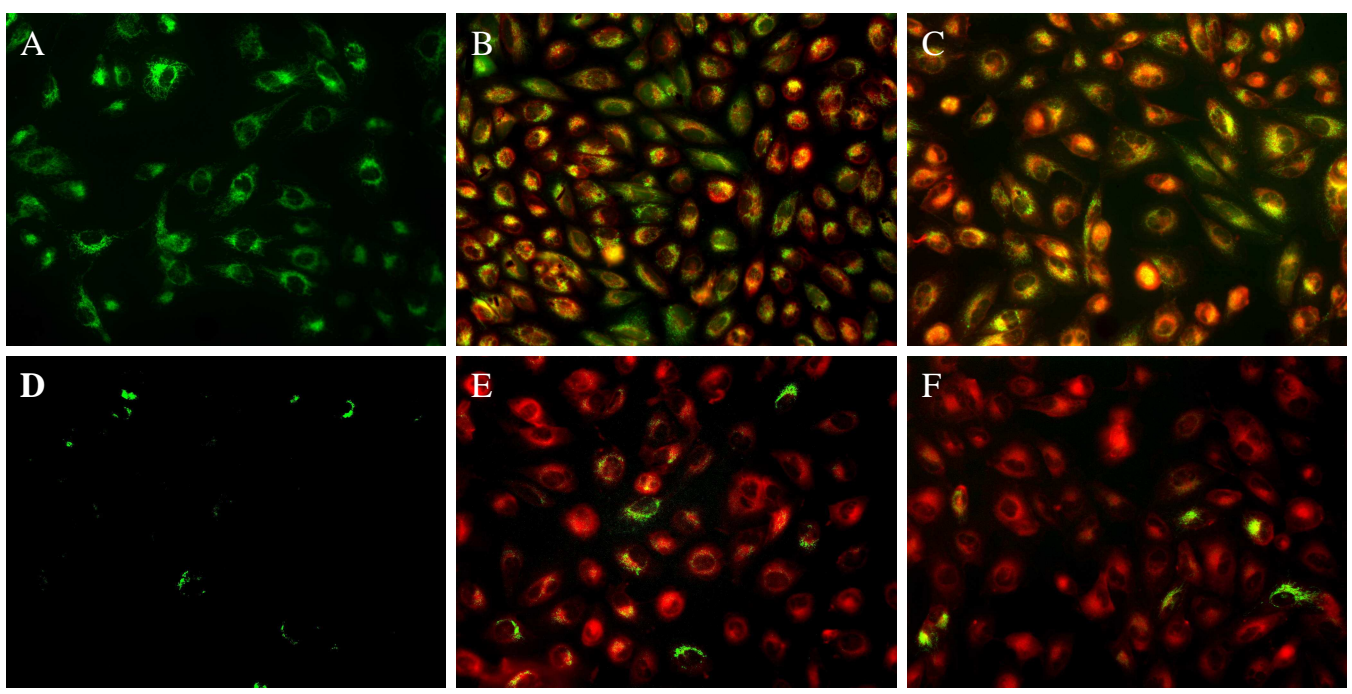

Abbildung 18: Fluoreszenzbilder zum Rhodamin-123-Efflux aus humanen renalen Karzinomzellen. Dargestellt sind exemplarische Fluoreszenzbilder für Zellen ohne HypericinBehandlung (A, D) und mit Hypericin-EtOH- (B, E) bzw. Hypericin-PVP-Behandlung (C, F) zu Beginn der Effluxzeit (A, B, C) und nach 180 Minuten Effluxzeit (D, E, F) (grüne Fluoreszenz $=$ Rhodamin-123; rote Fluoreszenz $=$ Hypericin, gelbe Fluoreszenz = Kolokalisation von Hypericin und Rhodamin-123, Vergrößerung 200x).

Die Transportgeschwindigkeit nimmt unabhängig von der Versuchbedingung mit zunehmender Zeitspanne nach der Inkubation ab (siehe Abb. 19 bzw. Tab. 5).

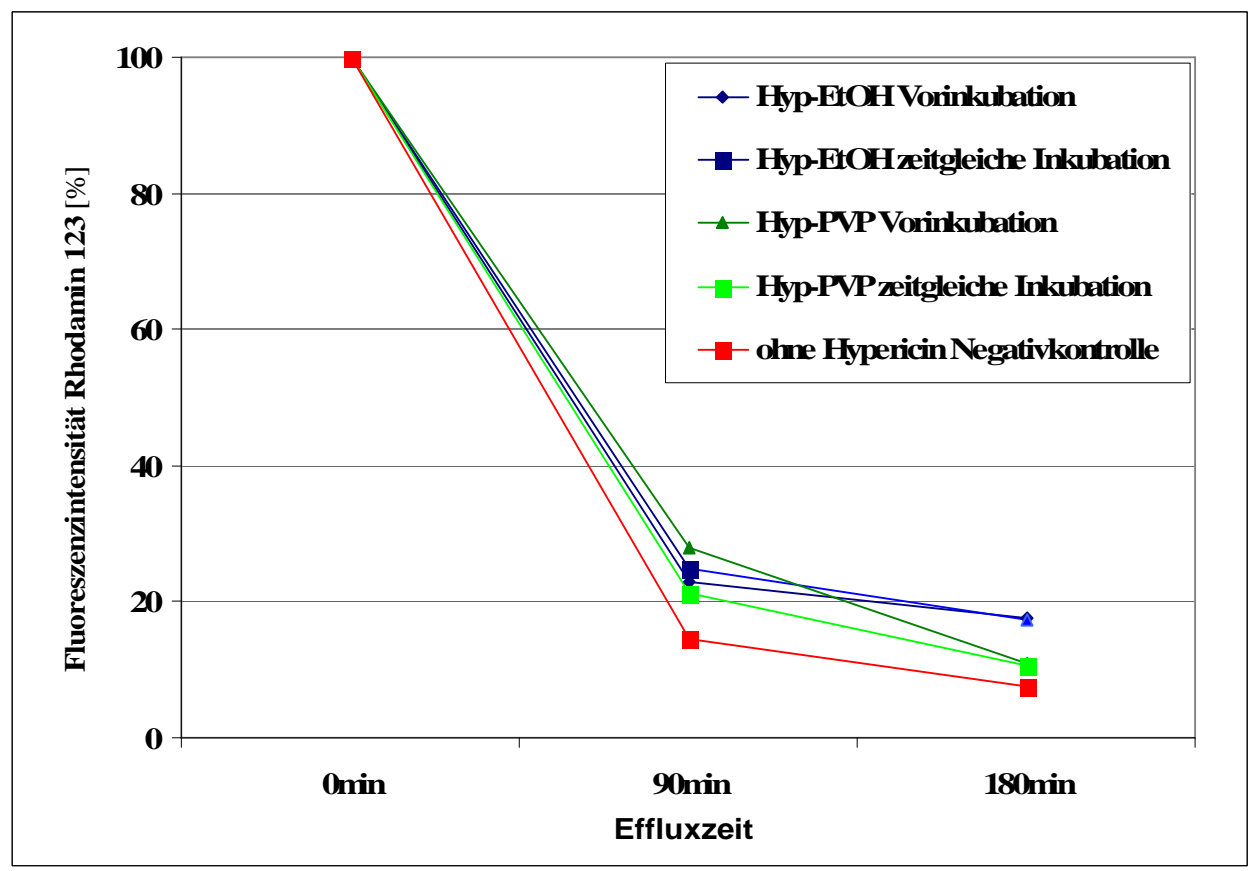

Abbildung 19: Rhodamin-123-Efflux aus humanen renalen Karzinomzellen mit und ohne Hypericin-Behandlung. Dargestellt ist die Fluoreszenzintensität [\%] von Rhodamin-123 in Abhängigkeit von der Effluxzeit [min] nach der Inkubation für Zellen ohne Hypericinbehandlung (rot), Zellen mit Hypericin-PVP-Behandlung (grün) und Zellen mit Hypericin-EtOH-Behandlung (blau). Den Daten liegen drei unabhängig voneinander durchgeführte Experimente zu Grunde. 
Tabelle 5: Rhodamin-123-Efflux aus humanen renalen Karzinomzellen. Dargestellt sind die ermittelten Fluoreszenzintensitäten [\%] von Rhodamin-123 zu Beginn (0 Minuten) und nach 90 bzw. 180 Minuten Effluxzeit in Zellen mit und ohne Hypericinbehandlung. Den Daten liegen drei unabhängig voneinander durchgeführte Experimente zu Grunde.

\begin{tabular}{|cc|c|c|c|}
\hline & & \multicolumn{3}{|c|}{ Fluoreszenzintensität von Rhodamin-123 } \\
& & nach 0 min & nach 90min & nach 180 min \\
\cline { 2 - 5 } & ohne Hypericin & $100 \%$ & $14,4 \%$ & $7,5 \%$ \\
\hline \multirow{2}{*}{ Hyp-PVP } & Vorinkubation & $100 \%$ & $27,9 \%$ & $10,9 \%$ \\
& zeitgleiche Inkubation & $100 \%$ & $21,2 \%$ & $10,6 \%$ \\
\hline \multirow{2}{*}{ Hyp-EtOH } & Vorinkubation & $100 \%$ & $23,0 \%$ & $17,7 \%$ \\
& zeitgleiche Inkubation & $100 \%$ & $24,8 \%$ & $17,2 \%$ \\
\hline
\end{tabular}

Innerhalb der ersten 90 Minuten werden bereits 85,6\% des Rhodamins aus Zellen ohne Hypericinbehandlung eliminiert, nach drei Stunden sind lediglich 7,5\% der ursprünglichen Rhodaminfluoreszenz in den Zellen vorhanden. Zellen, die mit Hypericin behandelt wurden, enthalten nach drei Stunden mehr Rhodamin-123 als unbehandelte Zellen. So beträgt die Fluoreszenzintensität zu diesem Zeitpunkt bei Zellen nach Hypericin-PVPBehandlung noch 10,9\% (nach Hyp-Vorinkubation) bzw. 10,6\% (nach gleichzeitiger Inkubation von Hyp und Rhodamin-123). Zellen, die mit Hypericin-EtOH behandelt wurden, enthalten im Vergleich zur Ausgangsmenge nach drei Stunden mit 17,7\% bzw. 17,2\% die höchsten Fluoreszenzintensitäten von Rhodamin-123 (siehe Tab.5).

\subsection{Untersuchungsergebnisse zu den Effekten von photoaktiviertem und nicht photoaktiviertem Hypericin auf renale Karzinomzellen:}

\section{$\underline{\text { 4.2.1 Ergebnisse zu den Dunkelwirkungen von Hypericin auf den Zellmetabolismus von }}$ renalen Karzinomzellen:}

Die Effekte von Hypericin auf den Zellmetabolismus werden mittels MTT-Test untersucht. Den Daten liegen mindestens drei unabhängige Versuche mit je 12-20 Wiederholungen zu Grunde.

Um den alleinigen Effekt von Hypericin auf A498-Zellen zu untersuchen, werden Dunkelversuche durchgeführt. Die Hypericinbehandlung unter Lichtausschluss zeigt dabei keinen hemmenden Effekt auf den Zellmetabolismus. Die Zellen, die mit hohen Hypericinkonzentrationen $(25$ und $50 \mu \mathrm{M})$ inkubiert werden, weisen in Abhängigkeit zur HypericinKonzentration eine signifikant gesteigerte metabolische Aktivität gegenüber den Zellen 
ohne Hypericinbehandlung auf (siehe Abb. 20A). Am fünften Tag nach der Hypericinbehandlung ist kein signifikanter Unterschied zwischen dem Metabolismus unbehandelter und hypericinbehandelter Zellen erkennbar (siehe Abb. 20B).
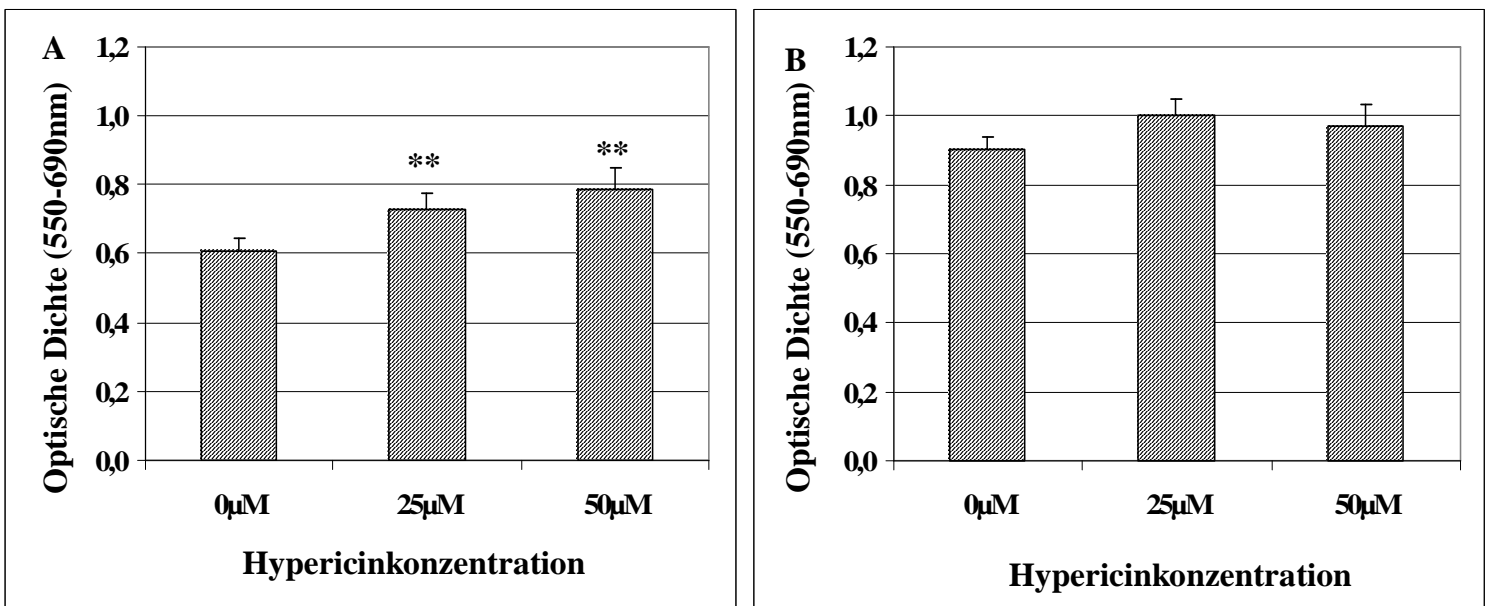

Abbildung 20: Dunkelwirkung von Hypericin auf die metabolische Aktivität von renalen Karzinomzellen. Dargestellt ist die Optische Dichte (bei 550nm-690nm) als Maß für die metabolische Aktivität von A498-Zellen einen Tag (A) und fünf Tage (B) nach einer Behandlung ohne, mit $25 \mu \mathrm{M}$ oder 50 $\mu \mathrm{M}$ Hypericin unter dunklen Bedingungen (max. 201x). Den Daten liegen drei unabhängig voneinander durchgeführte Experimente zu Grunde (** $\mathrm{p}<0,01)$.

\subsubsection{Untersuchungsergebnisse zu den Wirkungen von photoaktiviertem Hypericin auf den}

\section{Zellmetabolismus von renalen Karzinomzellen:}

Während die alleinige Hypericinbehandlung unter Lichtausschluss keinen hemmenden Effekt auf die metabolische Aktivität der renalen Karzinomzellen hat, zeigt sich unter Lichteinfluss ein völlig gegensätzliches Bild.

Zunächst werden A498-Zellen (siehe Abb. 21A) ohne bzw. mit mittleren HypericinKonzentrationen ( 5 und $10 \mu \mathrm{M}$ ) behandelt und für $20 \mathrm{bzw}$. 30 Minuten beleuchtet. Es zeigt sich, dass unabhängig von der verwendeten Konzentration und Beleuchtungsdauer die Hypericinbehandlung in Kombination mit der Beleuchtung zu einem nahezu 100\%-igen Abfall des Zellmetabolismus führt. Eine Zunahme der metabolischen Aktivität fünf Tage nach der Behandlung lässt sich nicht nachweisen (siehe Abb. 21B).

Bei sehr geringen Hypericin-Konzentrationen $(0,25-1 \mu \mathrm{M})$ ist eine von der Hypericinkonzentration abhängige Abnahme der metabolischen Aktivität der Zellen

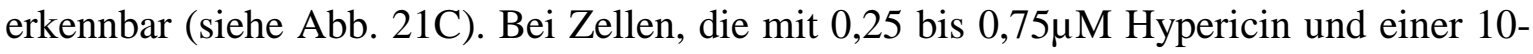

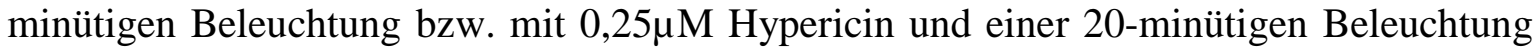
behandelt werden, haben gegenüber der Kontrolle ohne Hypericinbehandlung einen signifikant erniedrigten Zellmetabolismus (siehe Abb. 21C), der jedoch bis zum fünften 
Tag nach Behandlung ansteigt (siehe Abb. 21D). Die metabolische Aktivität von A498Zellen beträgt einen Tag nach einer Behandlung mit $1 \mu \mathrm{M}$ Hypericin in Kombination mit einer 10-minütigen Beleuchtung nur noch 10\% im Vergleich zu unbehandelten Zellen und nimmt bis zum fünften Tag nicht zu. Durch eine 20-minütige Beleuchtung der Zellen bei gleicher Hypericin-Behandlung $(1 \mu \mathrm{M})$ ist keine metabolische Aktivität mehr messbar.
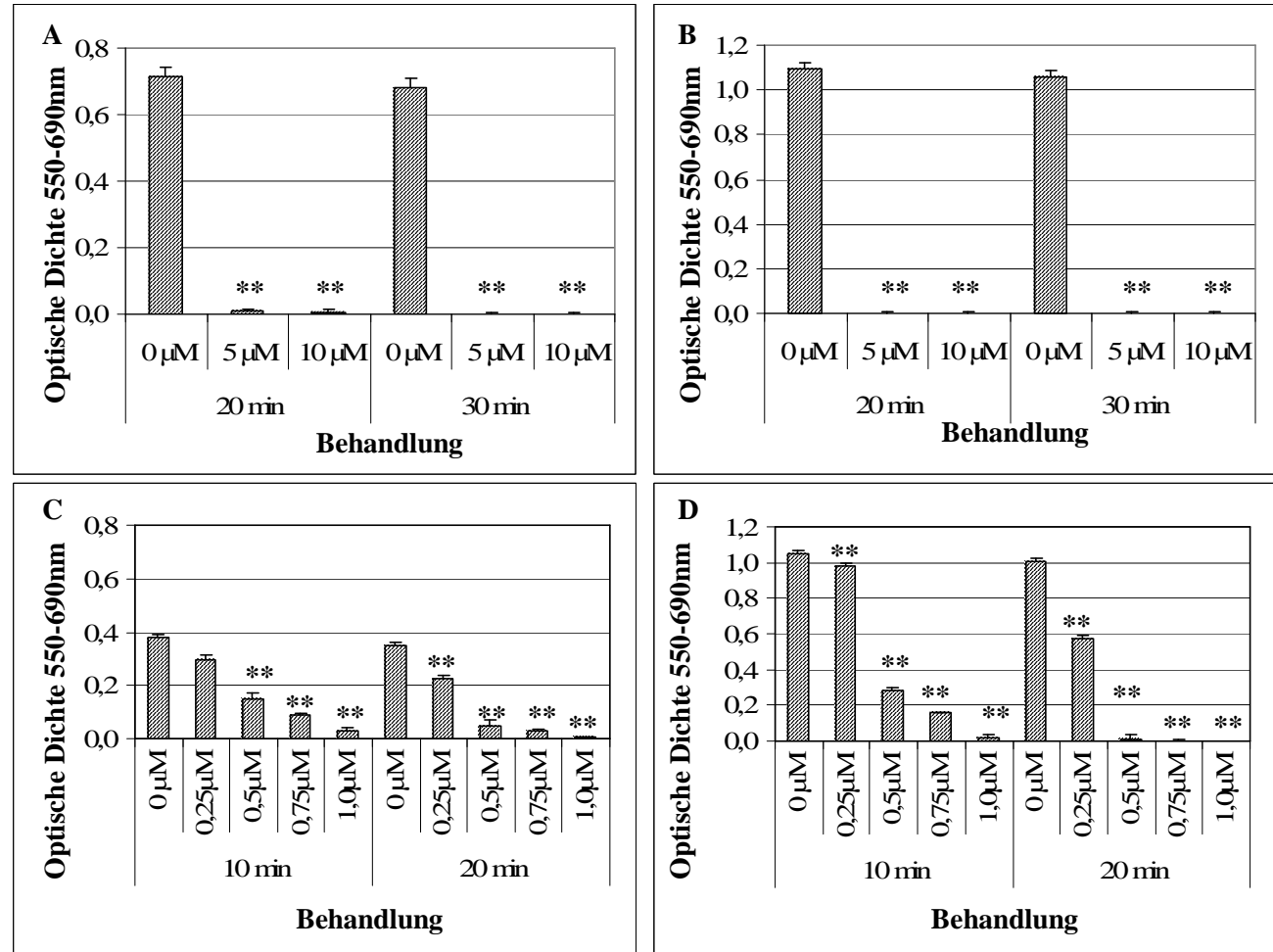

Abbildung 21: Wirkung von photoaktiviertem Hypericin auf die metabolische Aktivität von renalen Karzinomzellen. Dargestellt ist die Optische Dichte bei 550-690nm als Maß für die metabolische Aktivität von A498-Zellen einen Tag (A, C) und fünf Tage (B, D) nach einer Behandlung ohne bzw. mit Hypericin in Kombination mit einer Beleuchtung. A, B) Nach Behandlung der Zellen mit mittleren Hypericin-Konzentrationen (25 und $50 \mu \mathrm{M}$ ) in Kombination mit 20- bzw. 30-minütiger Beleuchtung kommt die metabolische Aktivität unabhängig von der Hypericin-Konzentration und Beleuchtungsdauer zum erliegen. B) Bei einer Behandlung der Zellen mit Licht (10 bzw. 20min) und geringen HypericinKonzentrationen $(0,25 \mu \mathrm{M}, 0,5 \mu \mathrm{M}, 0,75 \mu \mathrm{M}$ bzw. $1,0 \mu \mathrm{M})$ nimmt die metabolische Aktivität hypericinbehandelter Zellen gegenüber der der unbehandelten Zellen mit zunehmender Konzentration $\mathrm{ab}$. $\mathrm{Ab}$ einer Behandlung mit $1 \mu \mathrm{M}$ Hypericin-Lösung und 20-minütiger Beleuchtung ist keine metabolische Aktivität mehr messbar.

4.2.3 Versuchsergebnisse $\mathrm{zu}$ den Dunkeleffekten von Hypericin auf die

Koloniebildungsfähigkeit von renalen Karzinomzellen:

Die Untersuchungen zur Koloniebildung zeigen keinen hemmenden Effekt von Hypericin auf die Koloniebildungsfähigkeit von renalen Karzinomzellen unter Lichtausschluss. So bilden A498-Zellen ohne Hypericinbehandlung aus 250 Ausgangszellen innerhalb von 12 bis 15 Tagen im Mittel 65 Kolonien, während hypericinbehandelte A498-Zellen binnen 
dieses Zeitraumes aus der gleichen Ausgangszellzahl im Mittel 58 Kolonien bilden. Die so genannte Plating Efficiency, ermittelt durch den Quotienten aus der Anzahl der gebildeten Kolonien und der Ausgangszellzahl (250 Zellen), beträgt für hypericinbehandelte Zellen 0,23 und für Zellen ohne Hypericinbehandlung 0,26 (siehe Abb. 22).

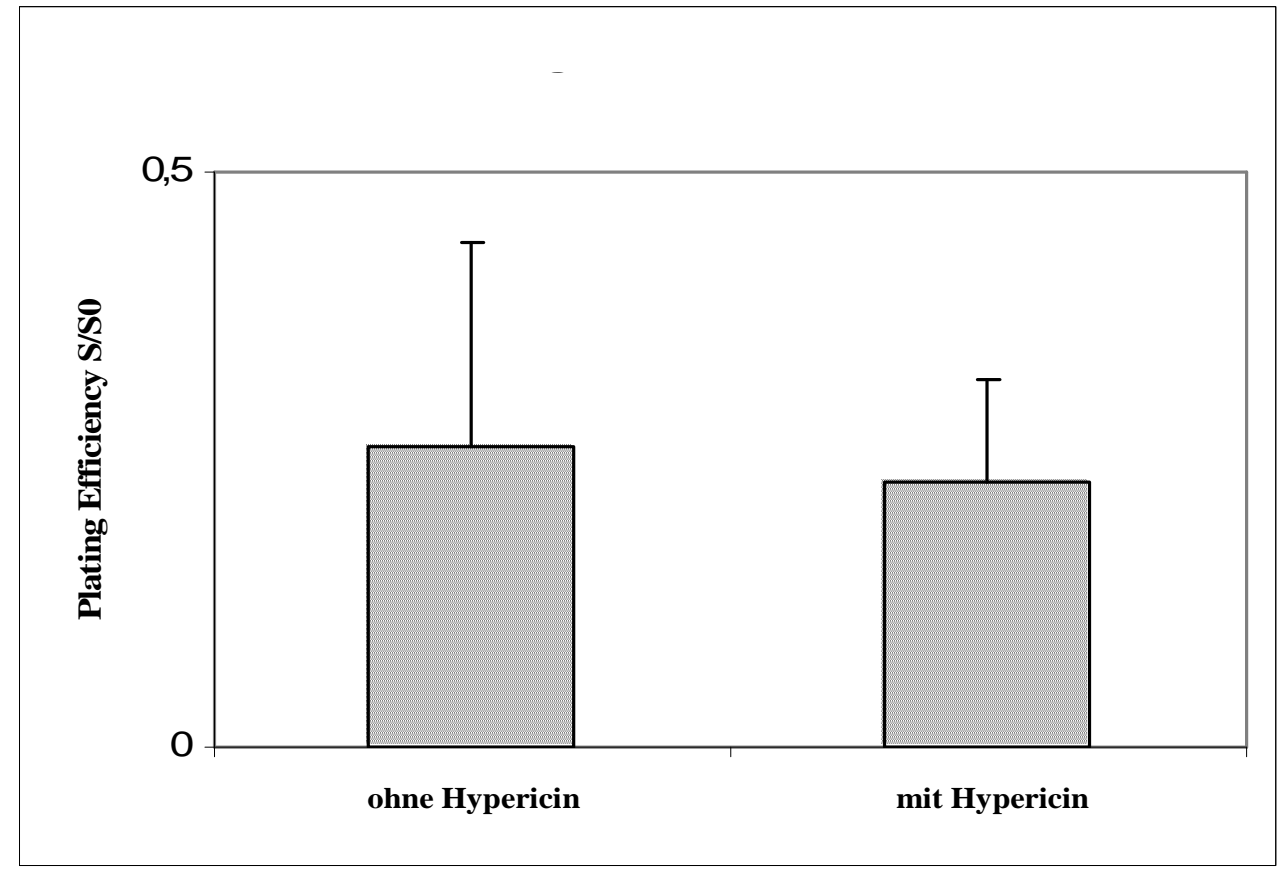

\begin{abstract}
Abbildung 22: Dunkelwirkung von Hypericin auf die Koloniebildungsfähigkeit von renalen Karzinomzellen. Dargestellt ist die so genannte Plating Efficiency S/S0 von A498-Zellen 12 Tage nach einer Behandlung ohne bzw. mit 50 $\mathrm{M}$ Hypericin unter dunklen Bedingungen (max. 30lx) mit $\mathrm{S}=$ Anzahl der gebildeten Kolonien und $\mathrm{S} 0=$ Ausgangszellzahl. Die Koloniebildungsfähigkeit von hypericinbehandelten Zellen ist gegenüber der der unbehandelten Zellen insignifikant erniedrigt.
\end{abstract}

4.2.4 Untersuchungsergebnisse zur Apoptoseinduktion durch Hypericin in Kombination mit bzw. ohne Beleuchtung in renalen Karzinomzellen:

Die Apoptoserate in Folge von Hypericinwirkung wird mittels TUNEL-Test bestimmt. Der TUNEL-Test (Terminal deoxynucleotidyl transferase-dㅁTP-nick-end-labeling) basiert auf der Fluoreszenzmarkierung von DNA-Strangbrüchen (nick-ends) durch Bindung des Fluorescein-dUTPs an die freien $3{ }^{`} \mathrm{OH}-E n d e n$ der DNA-Fragmente.

In A498-Zellen, die mit hohen Konzentrationen von Hypericin $(50 \mu \mathrm{M})$ unter Lichtausschluss behandelt werden, kann mittels TUNEL-Test keine Apoptose nachgewiesen werden. Werden hypericinbehandelte A498-Zellen jedoch beleuchtet (10 Minuten), ist eine Apoptoseinduktion auch schon bei geringen Hypericinkonzentrationen $(10 \mu \mathrm{M})$ in $100 \%$ der Zellen nachweisbar (siehe Abb. 23). 

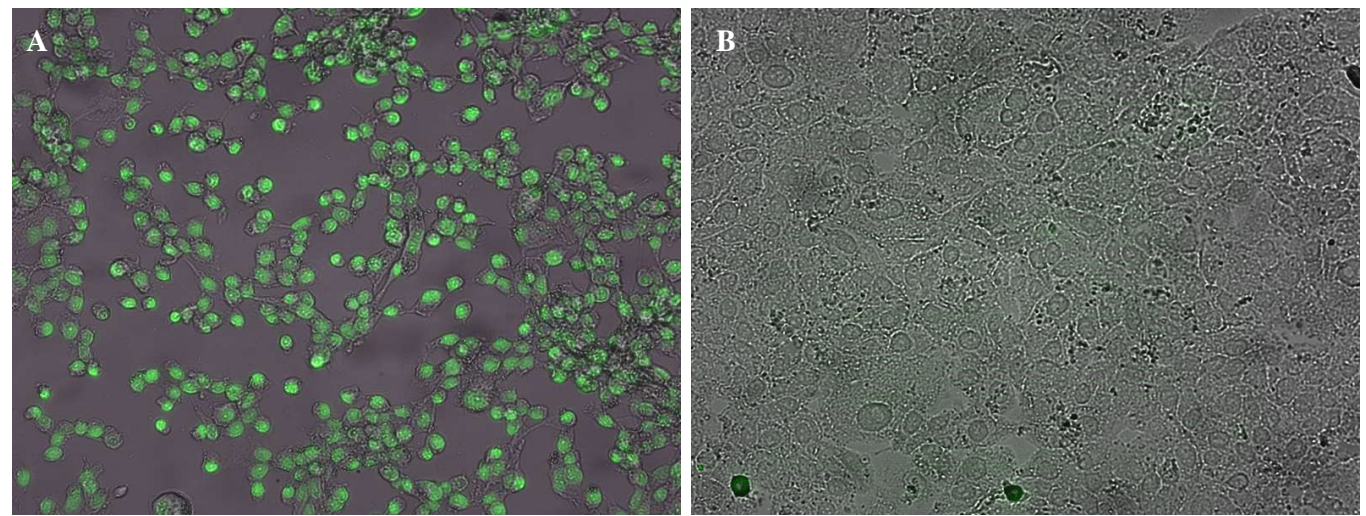

Abbildung 23: Apoptosenachweis in hypericinbehandelten A498-Zellen mittels TUNEL-Test. In $100 \%$ der Zellen, die mit $10 \mu \mathrm{M}$ Hypericin behandelt wurden, kann nach einer Beleuchtung (10 Minuten) Apoptose nachgewiesen werden (A). Die Hypericinbehandlung auch mit hohen Konzentrationen $(50 \mu \mathrm{M})$ der A498-Zellen induziert ohne Lichteinwirkung keine Apoptose (B) (grüne Fluoreszenz = TUNEL-Reagenz, Vergrößerung 200x).

\subsubsection{Ergebnisse des Singulett-Sauerstoff-Nachweis mittels redoxsensitivem GFP:}

Messung der intrazellulären Redoxbedingungen vor und während einer Photodynamischen Therapie (PDT) mit Hypericin:

Bei der Photodynamischen Therapie mit Hypericin entstehen intrazellulär hoch reaktive Sauerstoffspezies (ROS, reactive oxygen species) vor allem Singulettsauerstoff. Der intrazelluläre Redoxzustand vor und während einer PDT mit Hypericin wird mit Hilfe von redoxsensitivem GFP (roGFP) gemessen. Es wurden pro Versuchsansatz drei voneinander unabhängige Experimente durchgeführt, deren Ergebnisse kongruent zueinander sind. Aufgrund der Darstellungsweise werden im Folgenden die Ergebnisse exemplarischer Messungen vorgestellt.

Zur Überprüfung der Funktionalität des roGFP werden Testmessungen durchgeführt. Hierzu wird zunächst der Grundzustand (Baseline) der intrazellulären Redoxbedingungen der transfizierten A498-Zellen ermittelt. Das Verhältnis der Fluoreszenzintensitäten bei 395nm/470nm (Ratio) beträgt im regulären Redoxzustand ca. 370 bis 380. Nach Zugabe einer 10mM DTT-Lösung nimmt die Fluoreszenzintensität bei 470nm zu und damit der Quotient 395nm/470nm auf ca. 360 ab. Nach Zugabe einer 5mM $\mathrm{H}_{2} \mathrm{O}_{2}$-Lösung steigt die Fluoreszenzintensität bei $395 \mathrm{~nm}$ und damit der Quotient 395nm/470nm auf ca. 850 stark an. Nach Elimination des $\mathrm{H}_{2} \mathrm{O}_{2}$ aus dem System nimmt die Fluoreszenz bei 395nm wieder langsam ab. Die Änderung der Ratio nach Zugabe von $\mathrm{H}_{2} \mathrm{O}_{2}$ ist größer als nach Zugabe von DTT (siehe Abb. 24:). 


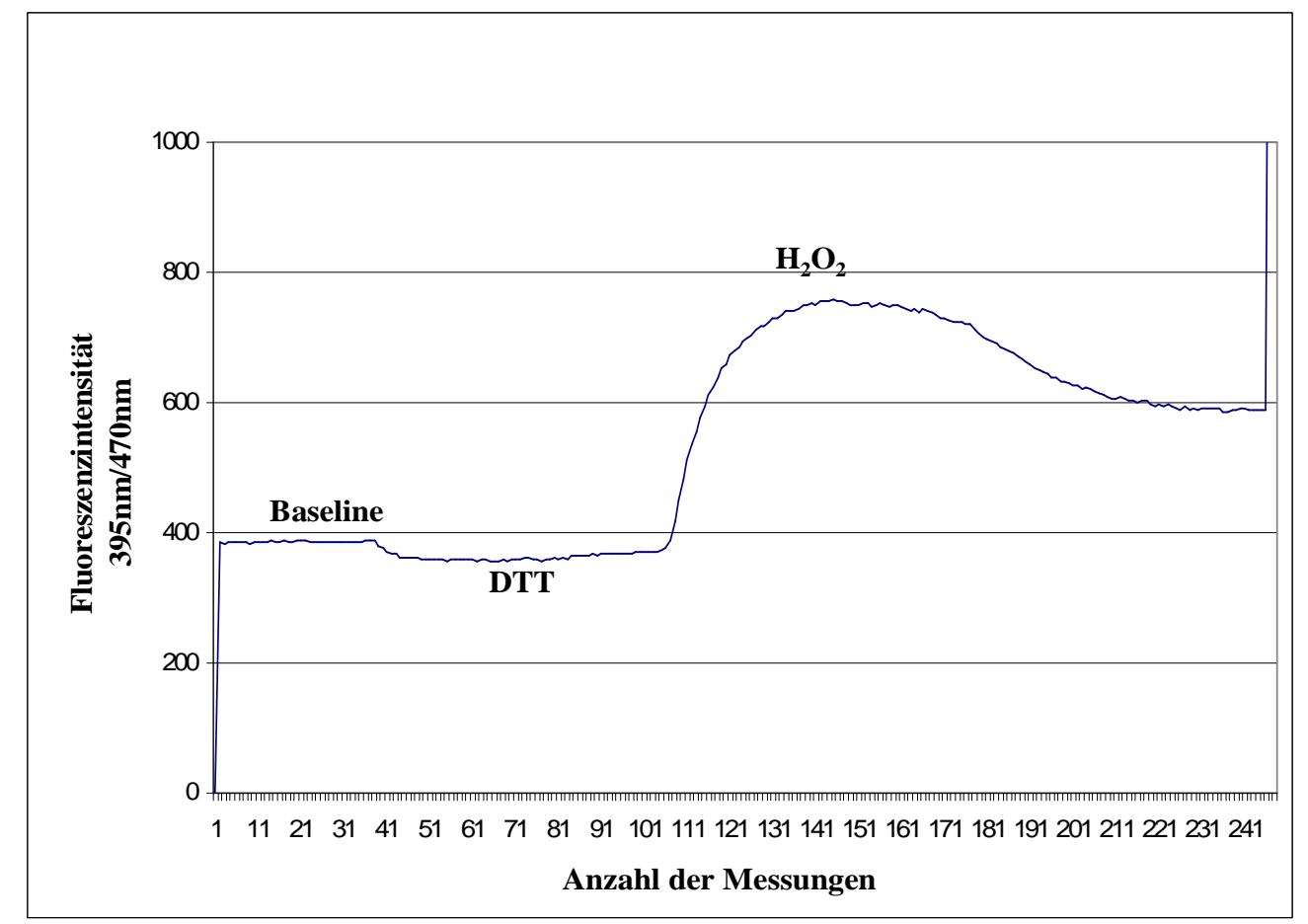

Abbildung 24: Testmessung zur Überprüfung der Funktionalität des roGFP und zur Ermittlung der Baseline des intrazellulären Redoxzustandes von mit roGFP transfizierten A498-Zellen. Exemplarisch dargestellt ist das Verhältnis der Fluoreszenzintensitäten bei $395 \mathrm{~nm} / 470 \mathrm{~nm}$ über die Zeit (Anzahl der Messungen [Messung/5sec]). Die Baseline beträgt im regulären Redoxzustand ca. 370. Nach Zugabe einer 10mM DTT-Lösung nimmt der Quotient $395 \mathrm{~nm} / 470 \mathrm{~nm}$ auf ca. $360 \mathrm{ab}$. Nach Zugabe einer 5mM $\mathrm{H}_{2} \mathrm{O}_{2}$-Lösung steigt der Quotient $395 \mathrm{~nm} / 470 \mathrm{~nm}$ auf ca. 850 stark an. Nach Elimination des $\mathrm{H}_{2} \mathrm{O}_{2}$ aus dem System nimmt die Fluoreszenz bei $395 \mathrm{~nm}$ wieder langsam ab.

Nach der Testmessung wird in einem neuen Ansatz mit der eigentlichen Versuchsmessung begonnen. Das Verhältnis der Fluoreszenzintensitäten bei 395nm/470nm beträgt bei dieser Messung im regulären Redoxzustand ca. 384. Nach Zugabe von $5 \mathrm{mM} \mathrm{H}_{2} \mathrm{O}_{2}$ in das System nimmt der Quotient der Fluoreszenzintensitäten bei 395nm/470nm auf im Mittel 577 zu. Nach Entfernung des $\mathrm{H}_{2} \mathrm{O}_{2}$ aus dem System wird der ursprüngliche intrazelluläre Redoxzustand wieder hergestellt und der Quotient der Fluoreszenzintensitäten bei 395nm/470nm geht auf den Basiswert zurück. Nach der Zugabe einer 10 $\mu \mathrm{M}$ HypericinEtOH-Lösung und anschließender ca. 10-minütiger Beleuchtung kann eine Zunahme der Fluoreszenzintensität bei $395 \mathrm{~nm}$ bzw. 395nm/470nm auf 556 gemessen und damit intrazelluläre ROS nachgewiesen werden (siehe Tab.6 und Abb.25). 
Tabelle 6: Verhältnis der Fluoreszenzintensitäten bei 395nm/470nm für A498-Zellen im regulären Redoxzustand (Baseline), nach Zugabe von 10 $\mu \mathrm{M}$ Hypericin-EtOH in Kombination mit einer 10-minütigen Beleuchtung und nach Zugabe von $5 \mathrm{mM} \mathrm{H}_{2} \mathrm{O}_{2}$. Dargestellt sind die Maximalwerte so wie die Mittelwerte mit Standardabweichung der Ratio einer Messung.

\begin{tabular}{|c|c|c|c|}
\hline & Baseline & $\mathrm{H}_{2} \mathrm{O}_{2}$ & Hyp \\
\hline Maximalwert & 389 & 587 & 563 \\
Mittelwert & 384 & 577 & 556 \\
Standardabweichung & 2,76 & 7,41 & 5,50 \\
\hline
\end{tabular}

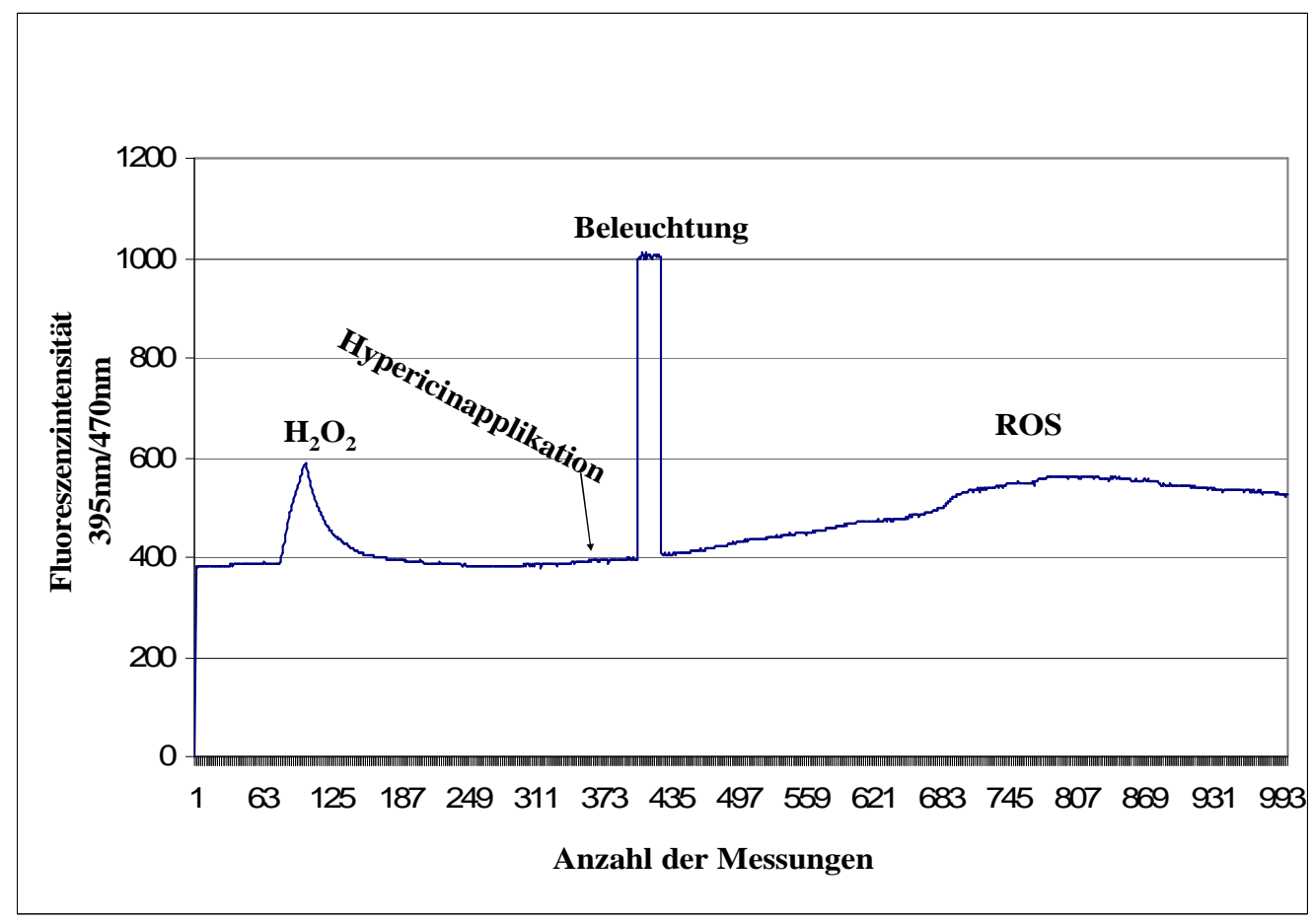

Abbildung 25: Messung des intrazellulären Redoxzustandes von mit roGFP transfizierten A498-Zellen nach Hypericinapplikation in Kombination mit Beleuchtung. Dargestellt ist das Verhältnis der Fluoreszenzintensitäten bei 395nm/470nm über die Zeit (Anzahl der Messungen [Messung/5sec]). Nach der Ermittlung der Baseline wird zur Kontrolle eine $5 \mathrm{mM} \mathrm{H}_{2} \mathrm{O}_{2-}$ Lösung in das System gegeben und eine Zunahme der Ratio beobachtet. Nach Elimination des $\mathrm{H}_{2} \mathrm{O}_{2}$ aus dem System wird der ursprüngliche intrazelluläre Redoxzustand wieder hergestellt und der Quotient der Fluoreszenzintensitäten bei 395nm/470nm geht auf den Basiswert von 380 zurück. Nach der Zugabe einer $10 \mu \mathrm{M}$ Hypericin-EtOH-Lösung und anschließender Beleuchtung (ca. 10min) kann eine Zunahme der Fluoreszenzintensität bei 395nm bzw. $395 \mathrm{~nm} / 470 \mathrm{~nm}$ gemessen werden.

Bei mit roGFP transfizierten A498-Zellen, die 24 Stunden vor der Messung mit $10 \mu \mathrm{M}$ Hypericin-EtOH inkubiert wurden, ist eine Ermittlung des regulären Redoxzustandes nicht möglich, weil das Hypericin die Messungen von Beginn an konfundiert. Das Verhältnis der Fluoreszenzintensitäten bei 395nm/470nm steigt innerhalb der ersten zwei Messungen (ca. 
10 Sekunden) steil an und bleibt während 12 weiteren Messungen (ca. 60 Sekunden) auf einem Plateau von im Mittel 867. Innerhalb der nächsten 7 Messungen (ca. 35 Sekunden) nimmt das Verhältnis der Fluoreszenzintensitäten bei $395 \mathrm{~nm} / 470 \mathrm{~nm}$ stark bis auf ca. 400 $a b$, in den folgenden Messungen ist eine weitere ständige Abnahme der Ratio messbar (siehe Abb. 26).

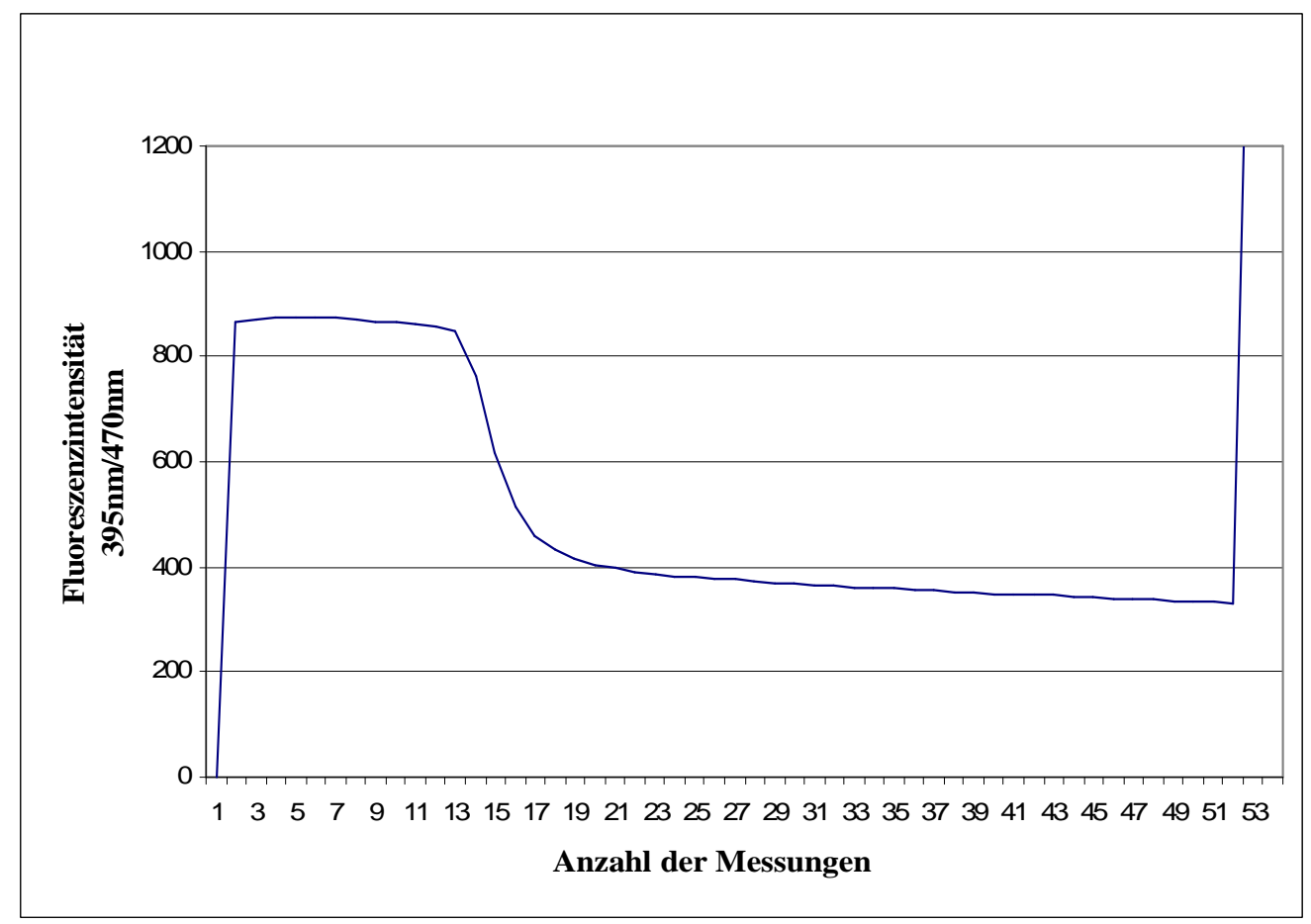

Abbildung 26: Messung des intrazellulären Redoxzustandes von mit roGFP transfizierten A498-Zellen nach 24-stündiger Vorinkubation mit $10 \mu \mathrm{M}$ Hypericin. Dargestellt ist das Verhältnis der Fluoreszenzintensitäten bei $395 \mathrm{~nm} / 470 \mathrm{~nm}$ über die Zeit (Anzahl der Messungen, 1 Messung alle 5 Sekunden). Das Verhältnis der Fluoreszenzintensität bei $395 \mathrm{~nm} / 470 \mathrm{~nm}$ steigt innerhalb der ersten zwei Messungen steil an, verbleibt während ca. 7 Messungen auf einem Plateau und fällt im Folgenden zunächst steil und dann langsam stetig ab.

\subsection{Ergebnisse aus den Bestrahlungsversuchen:}

\subsubsection{Untersuchungsergebnisse zur Wirkung von Hypericin in Kombination mit}

Bestrahlung auf den Zellmetabolismus von renalen Karzinomzellen:

Die Effekte von Hypericin auf den Zellmetabolismus werden mittels MTT-Test untersucht.

Der Nachweis des Zellmetabolismus mit Hilfe des MTT-Tests beruht auf der metabolischen Umwandlung des gelben, wasserlöslichen Farbstoffes 3-(4,5Dimethylthiazol-2-yl)-2,5-diphenyltetrazoliumbromid (MTT) in ein blau-violettes, wasserunlösliches Formazan. Die Menge des umgesetzten Farbstoffs, die über die optische 
Dichte bei 550-690nm gemessen wird, entspricht der Glykolyserate der Zellen und ist somit ein Maß für die metabolische Aktivität der Zellen. Den Daten liegen mindestens drei unabhängige Versuche mit je 10 bis 20 Wiederholungen zu Grunde. Dargestellt sind die Mittelwerte und deren Standardabweichungen.

Die mittels MTT-Test ermittelten Daten zeigen eine Zunahme der metabolischen Aktivität von Zellen sowohl mit als auch ohne Hypericinbehandlung vom ersten bis zum 13. Tag nach der Bestrahlung. Dabei ist die metabolische Aktivität hypericinbehandelter Zellen sowohl am ersten als auch am 13. Tag nach der Behandlung signifikant gegenüber dem Metabolismus von Zellen ohne Hypericinbehandlung erhöht (siehe Abb. 27).

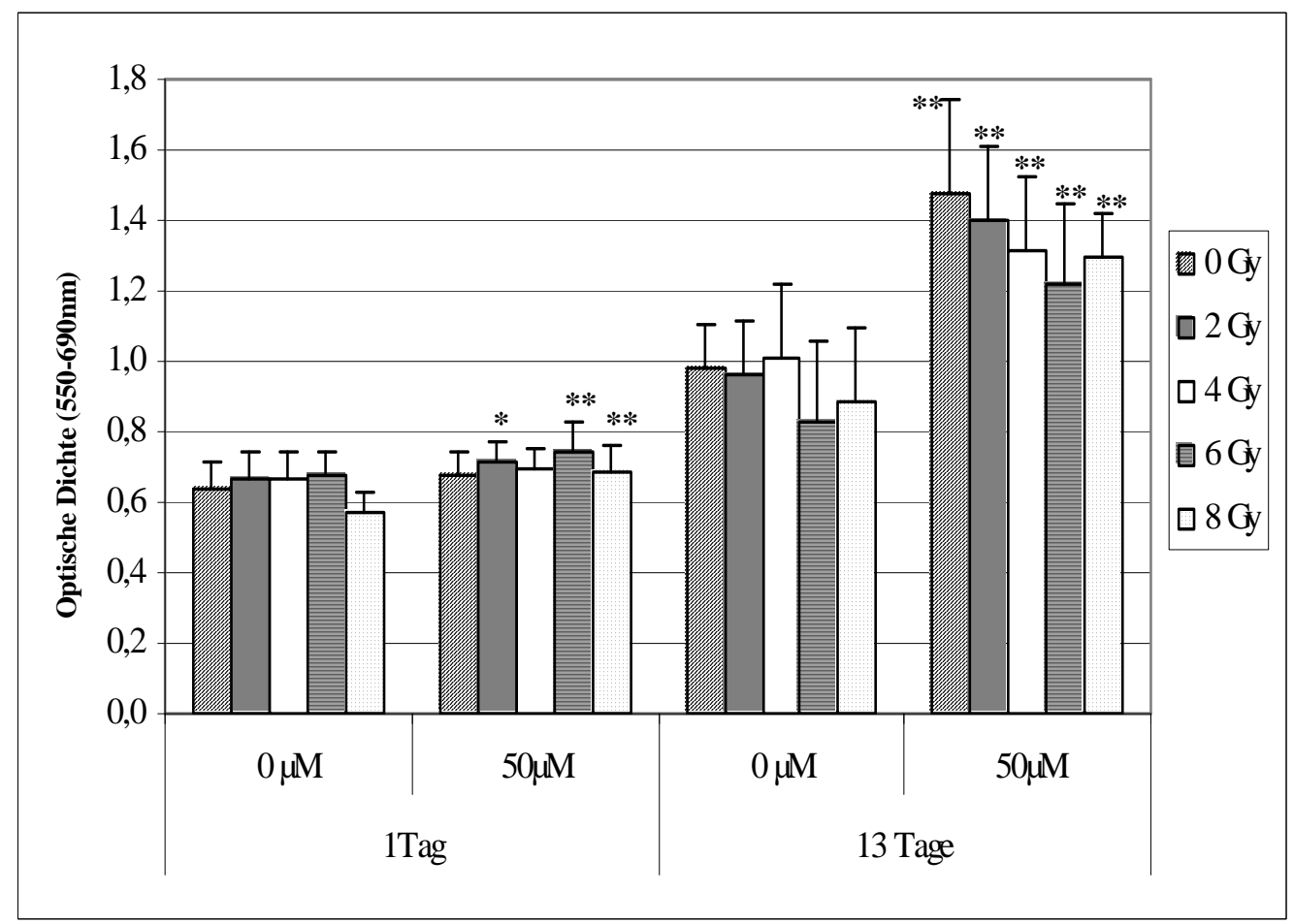

Abbildung 27: Strahlensensibilisiernde Wirkung von Hypericin auf den Zellmetabolismus von renalen Karzinomzellen. Dargestellt ist die metabolische Aktivität gemessen als optische Dichte bei 550-690nm von A498-Zellen ohne und mit Hypericinbehandlung (50 $\mu \mathrm{M}) 1$ Tag und 13 Tage nach einer Bestrahlung (0-8Gy) $(* \mathrm{p}=0,05 ; * * \mathrm{p}=0,01)$.

4.3.2 Untersuchungsergebnisse zur Apoptoseinduktion durch Hypericin in Kombination mit Bestrahlung in renalen Karzinomzellen:

Die Apoptoserate in Folge von Hypericinwirkung wird mittels TUNEL-Test bestimmt. Der TUNEL-Test (Terminal deoxynucleotidyl transferase-dㅁTP-ñick-end-labeling) basiert auf der Fluoreszenzmarkierung von DNA-Strangbrüchen (nick-ends) durch Bindung des Fluorescein-dUTPs an die freien 3`OH-Enden der DNA-Fragmente.

Werden A498-Zellen mit einer Dosis von 2Gy bestrahlt, ist in ca. 2,5\% der Zellen Apoptose mittels TUNEL-Test nachweisbar (siehe Abb.28). Es gibt keinen signifikanten 
Unterschied bezüglich der Apoptoserate in Folge von Bestrahlung zwischen hypericinbehandelten Zellen und Zellen ohne Hypericinbehandlung. Auch höhere Strahlendosen induzieren in A498-Zellen wenig Apoptose. So ist nur in ca. 5\% der A498Zellen nach einer 4 Gy-Bestrahlung Apoptose nachweisbar.
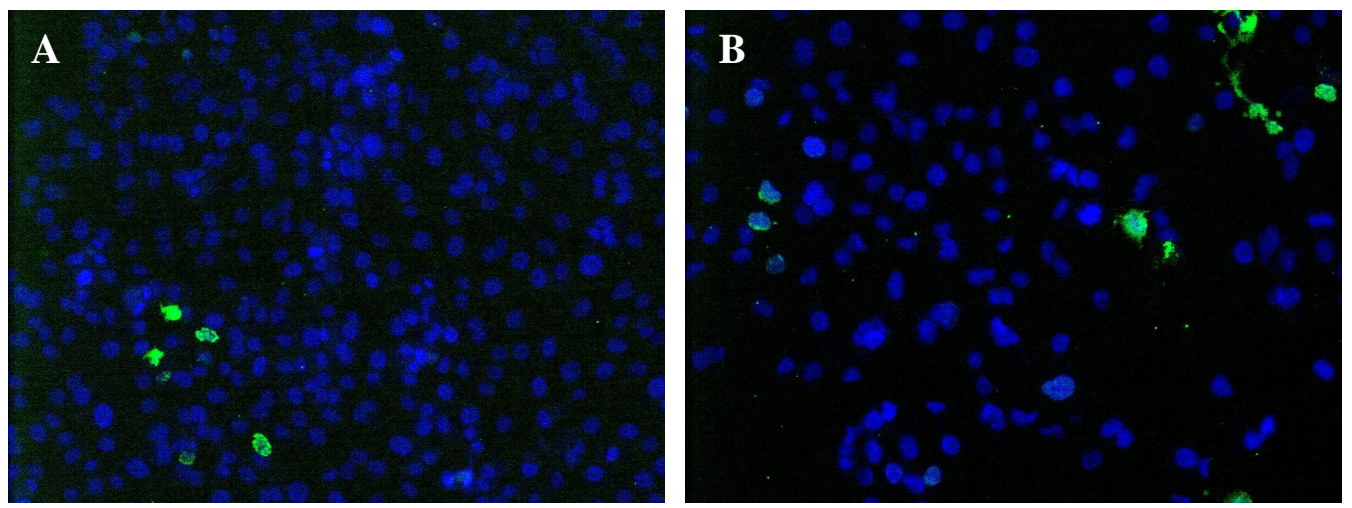

Abbildung 28: Exemplarischer Apoptosenachweis mittels TUNEL-Test in A498-Zellen nach Bestrahlung mit einer Dosis von 2Gy mit (A) bzw. ohne (B) Behandlung mit 50 $\mu$ M Hypericin (blaue Fluoreszenz $=$ Kernfärbung mit DAPI; grüne Fluoreszenz = TUNEL; Vergrößerung 200x).

\subsubsection{Untersuchungsergebnisse $\mathrm{zu}$ den Effekten von Hypericin in Kombination mit}

Bestrahlung auf die Koloniebildungsfähigkeit von renalen Karzinomzellen:

Der reproduktive Zelltod wird mit Hilfe des Koloniebildungstests bestimmt. Dabei werden Zellen, die in einem Zeitraum von 10 bis 15 Zellzyklen nach der Bestrahlung Kolonien aus mindestens 50 Tochterzellen bilden können, als (klonal) überlebend definiert.

Die Ergebnisse aus dem Koloniebildungstest zeigen, dass eine Bestrahlung in Kombination mit einer Hypericinbehandlung das klonogene Überleben von A498-Zellen im Vergleich zu bestrahlten Zellen ohne Hypericinbehandlung verringern kann (siehe Abb. 29). 


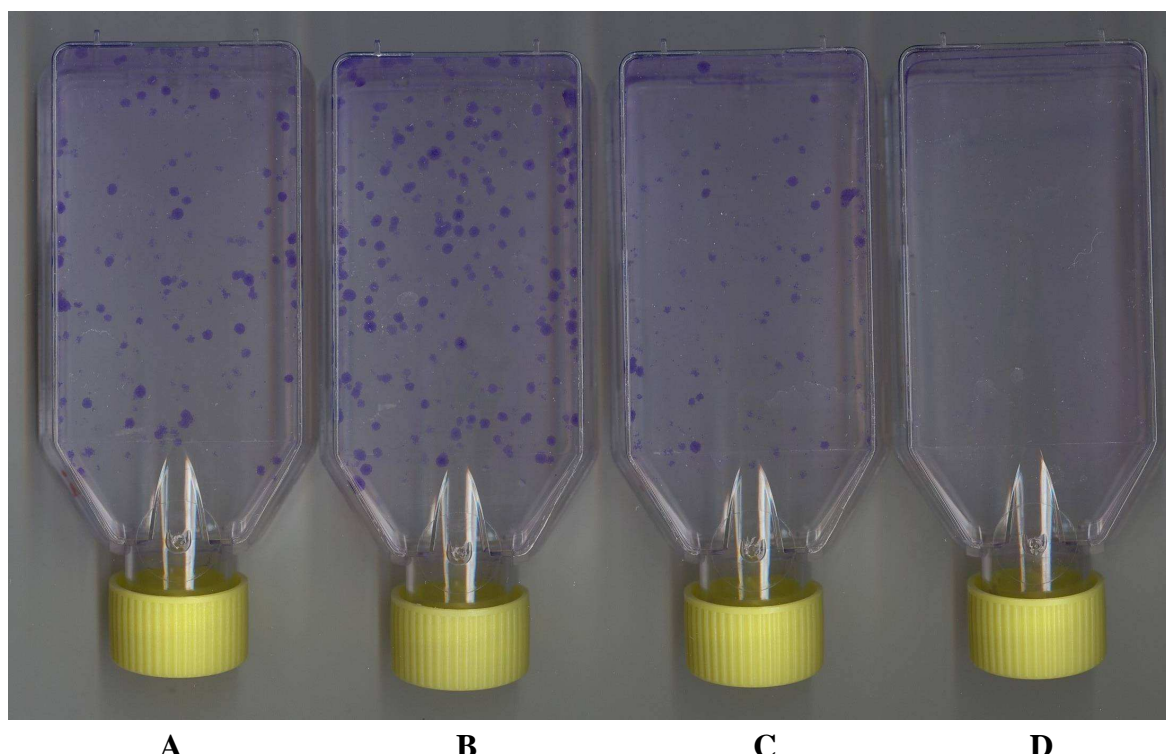

\begin{abstract}
Abbildung 29: Koloniebildungstest. Exemplarisch dargestellt sind mit Kristallviolett angefärbte Zellkolonien von A498-Zellen, die aus 250 ursprünglich eingesetzten Zellen in 13 Tagen nach vorangegangener Behandlung gebildet wurden. A) Koloniebildung von Zellen ohne Hypericinbehandlung und ohne Bestrahlung, B) Koloniebildung von Zellen mit Hypericinbehandlung $(50 \mu \mathrm{M})$ aber ohne Bestrahlung, C) Koloniebildung von Zellen nach einer Bestrahlung mit 4Gy ohne Hypericinbehandlung, D) Koloniebildung von hypericinbehandelten $(50 \mu \mathrm{M})$ Zellen nach einer 4Gy-Bestrahlung.
\end{abstract}

Ca. 75\% der Zellen ohne Hypericinbehandlung überleben eine Bestrahlung mit 2Gy, während das klonogene Überleben von Zellen mit vorangegangener Hypericinbehandlung bei gleicher Strahlendosis auf 52\% und von Zellen, die eine Vor- und Nachbehandlung mit Hypericin erhalten haben, sogar auf 13\% reduziert ist. Während noch ca. 5\% der A498Zellen eine hohe Strahlendosis von 6 Gy reproduktiv überleben, ist eine Reproduktion bei Hypericin-vor- und nachbehandelten Zellen nach einer 6Gy-Bestrahlung nur noch in 0,4\% vorhanden (siehe Tab.7 und Abb. 30).

Tabelle 7: Klonogenes Überleben von renalen Karzinomzellen nach Radiatio. Dargestellt ist die klonogene Überlebensrate [\%] von A498-Zellen nach vorangegangener Bestrahlung mit einer Dosis von 0-8Gy in Kombination mit bzw. ohne Hypericinbehandlung $(50 \mu \mathrm{M})$ vor $(24$ Stunden) bzw. vor und nach (10-12 Tage) der Bestrahlung.

\begin{tabular}{|c|c|c|c|}
\hline & ohne Hyp & $\begin{array}{c}\text { Hyp-Inkubation } \\
\text { vor RTx }\end{array}$ & $\begin{array}{c}\text { Hyp- Inkubation } \\
\text { vor + nach RTx }\end{array}$ \\
\hline $\mathbf{0 G y}$ & $100 \%$ & $100 \%$ & $100 \%$ \\
$\mathbf{2 G y}$ & $57 \%$ & $52 \%$ & $13 \%$ \\
$\mathbf{4 G y}$ & $22 \%$ & $11 \%$ & $2 \%$ \\
$\mathbf{6 G y}$ & $5 \%$ & $7 \%$ & $0 \%$ \\
$\mathbf{8 G y}$ & $1 \%$ & $0 \%$ & $0 \%$ \\
\hline
\end{tabular}


Die Dosiswirkungsbeziehung zwischen Strahlung und dem klonalen Überleben der Zellen kann graphisch in einer so genannten Überlebenskurve (Dosis-Effekt-Kurve) dargestellt werden. Die Dosis-Effekt-Kurve der bestrahlten A498-Zellen ohne Hypericinbehandlung zeigt bei halblogarithmischer Darstellung Charakteristika einer Schulterkurve, d. h. die Steigung der Kurve ist im geringen Dosisbereich (bis ca. 4Gy) geringer, während die Überlebenskurve im höheren Dosisbereich einen exponentiellen Verlauf zeigt (Abb.). Bei den bestrahlten Zellen mit vorangegangener Hypericinbehandlung ist die Schulter der Überlebenskurve etwas schwächer ausgeprägt, während die Dosis-Effekt-Kurve der bestrahlten Zellen mit Hypericin-Vor- und Nachbehandlung einen rein exponentiellen Verlauf ohne Schulterbereich aufweist.

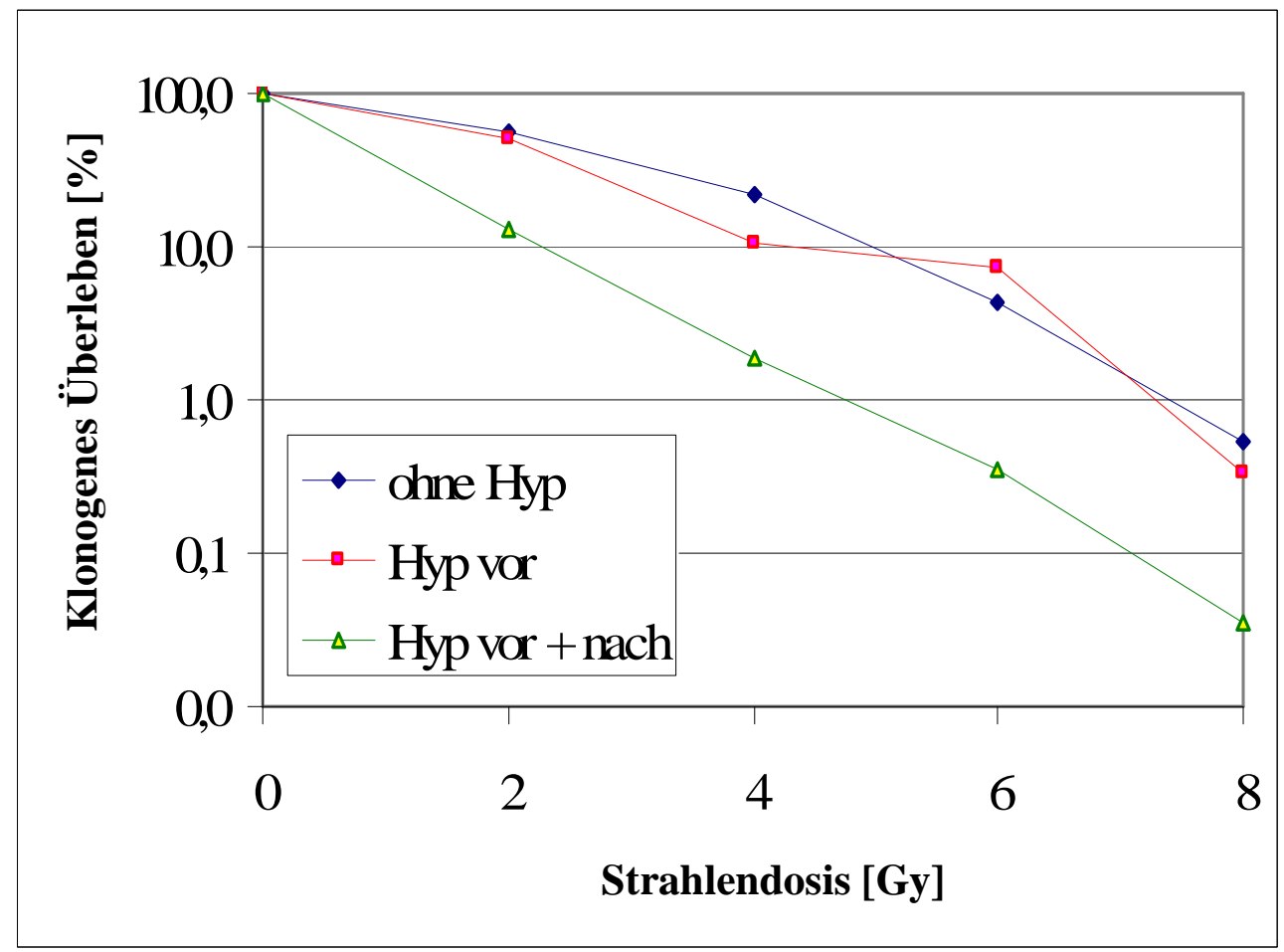

Abbildung 30: Überlebenskurve von renalen Karzinomzellen nach Radiatio. Dargestellt ist das klonogene Überleben [\%] von A498-Zellen in Abhängigkeit von der applizierten Strahlendosis

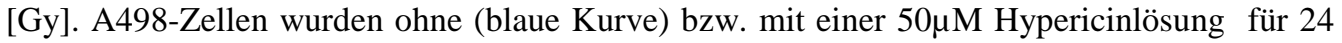
Stunden vor der Bestrahlung (rote Kurve) und für 24 Stunden vor und zwölf Tage nach der Bestrahlung (grüne Kurve) inkubiert und mit einer Dosis von 0-8Gy bestrahlt.

$\underline{\text { 4.3.4 Untersuchungsergebnisse } \mathrm{zu} \text { den Effekten von Hypericin in Kombination mit }}$ Bestrahlung auf die Zellzyklusverteilung von renalen Karzinomzellen:

Im Folgenden werden die Ergebnisse der durchflusszytometrischen Zellzyklusanalyse dargestellt (siehe Abb.31). Den Daten liegen ein bis zwei unabhängig voneinander durchgeführte Experimente zu Grunde. 


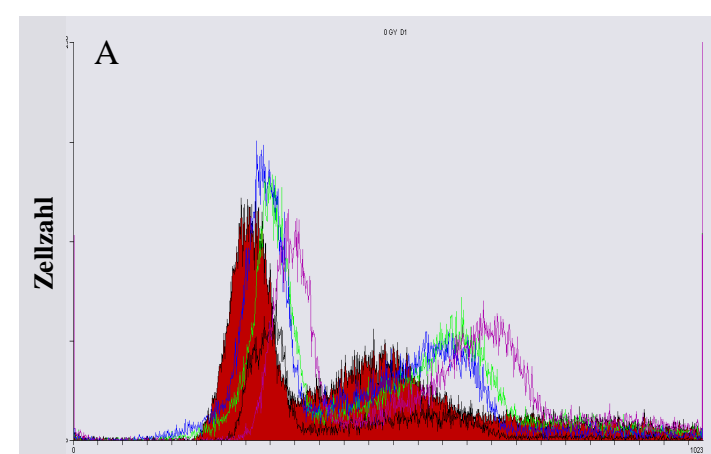

Propidiumiodidgehalt

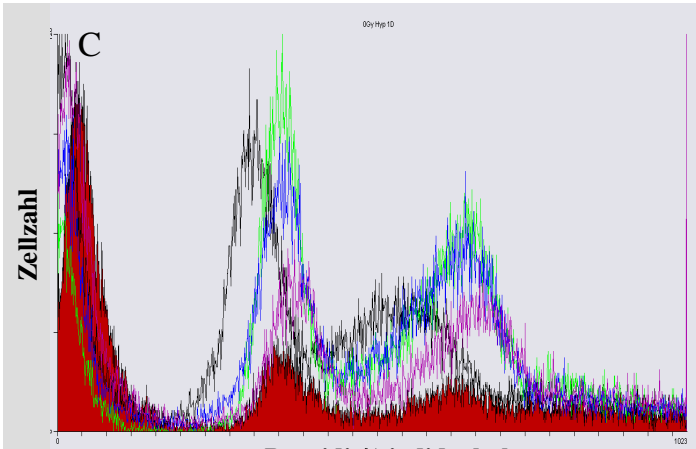

Propidiumiodidgehalt
B

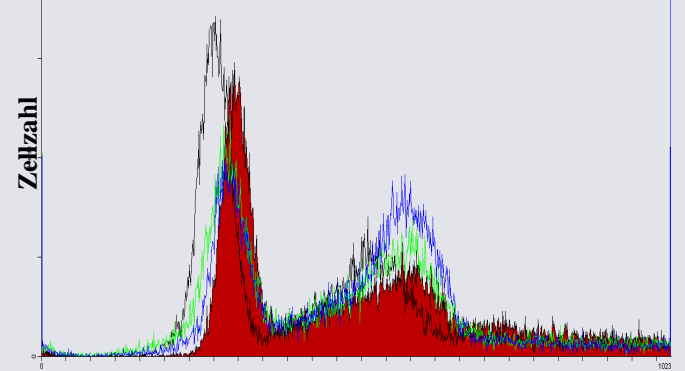

Propidiumîbdidgehalt

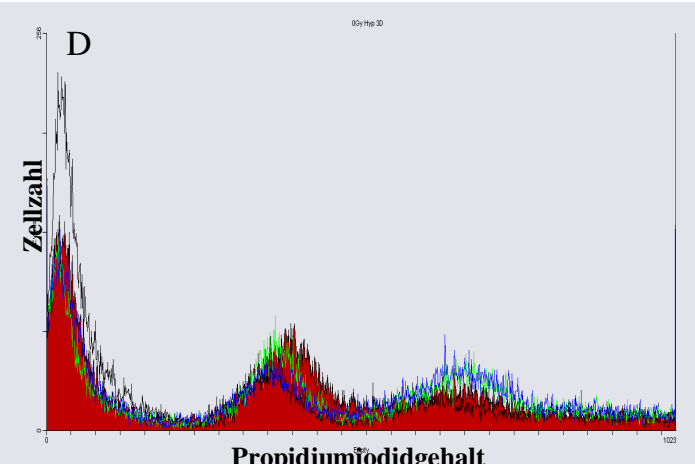

Abbildung 31: Durchflusszytometrische Zellzyklusanalyse von renalen Karzinomzellen mit Propidiumiodid. Dargestellt sind die DNA-Histogramme von A498-Zellen 1 Tag (A, C) und 3 Tage (B, D) nach Bestrahlung mit einer Dosis von 0Gy (rot), 2 Gy (schwarz), 4Gy (grün), 6Gy (blau) bzw. 8 Gy (lila) ohne (A, B) bzw. in Kombination mit (C, D) einer Hypericinbehandlung $(50 \mu \mathrm{M})$. Dargestellt ist die ermittelte Zellanzahl in Abhängigkeit vom zellulären Propidiumiodidgehalt.

Der prozentuale Anteil der A498-Zellen ohne Hypericinbehandlung, die sich drei Tage nach einer Bestrahlung in der G0/G1-Phase des Zellzyklus befinden, ist im Vergleich zu unbestrahlten Zellen höher. Hypericinbehandelte und bestrahlte Zellen akkumulieren im Vergleich zu unbestrahlten Zellen einen Tag nach Bestrahlung vermehrt und nach drei Tagen vermindert in der G0/G1-Phase.

Drei Tage nach Bestrahlung nimmt der Anteil der Zellen ohne Hypericinbehandlung, die sich in der S-Phase befinden, leicht im Vergleich zur Kontrolle zu, während der Anteil der hypericinbehandelten Zellen in der S-Phase nach Bestrahlung im Vergleich zur Kontrolle abnimmt.

Sowohl einen Tag als auch drei Tage nach der Bestrahlung steigt der prozentuale Anteil der Zellen, die sich in der der G2/M-Phase des Zellzyklus befinden, im Vergleich zur unbestrahlten Kontrolle strahlendosisabhängig an. Diese dosisabhängige Zunahme ist sowohl bei Zellen ohne als auch mit Hypericinbehandlung erkennbar.

Im Mittel befinden sich einen Tag nach Bestrahlung etwa $0,7 \%$ der Zellen ohne Hypericinbehandlung in der subG1-Phase, drei Tage nach der Bestrahlung steigt der Anteil auf 1,2\% bzw. 1,7\% bei hohen Strahlendosen (4 bzw. 6Gy) an. Etwa 29-37\% 
hypericinbehandelter Zellen befinden sich schon ohne Bestrahlung in der subG1-Phase. Dieser Anteil nimmt sowohl einen Tag als auch drei Tage nach Bestrahlung ab.

Des Weiteren weist die Zellzyklusanalyse eine Ansammlung von Zellen nach, die nicht eindeutig einer Zellzyklusphase zugeordnet werden können, da der Propidiumgehalt in diesen Zellen höher ist als regulär in der G2/M-Phase des Zellzyklus. Diese Gruppe von Zellen wird als unspezifischer Rest bezeichnet und ist bei allen Versuchsbedingungen in einem Anteil von 11-38\% zu finden. Der prozentuale Anteil der Zellen, die dieser Gruppe zugeordnet werden, nimmt bei Zellen ohne Hypericinbehandlung sowohl am ersten als auch am dritten Tag nach der Bestrahlung gegenüber unbestrahlten Zellen ab. Bei hypericinbehandelten Zellen steigt der Anteil am dritten Tag gegenüber dem der unbestrahlten Zellen an (siehe Tab.8 und Abb. 32) .

Tabelle 8: Zellzyklusverteilung von A498-Zellen 1 Tag (oben) und 3 Tage (unten) nach einer Bestrahlung (0Gy-8Gy) ohne (links) bzw. in Kombination mit (rechts) einer Hypericinbehandlung $(50 \mu \mathrm{M})$. Dargestellt ist die ermittelte Zellmenge [\%] pro Zellzyklusphase bezogen auf 100000 gezählte Zellen. Zellen, die aufgrund ihres Propidiumiodidgehaltes keiner Zellzyklusphase eindeutig zugeordnet werden können, sind als unspezifischer Rest zusammengefasst.

\begin{tabular}{|c|c|c|c|c|c|c|c|c|c|c|c|}
\hline $\begin{array}{c}1 d \\
\text { pRTx }\end{array}$ & $\begin{array}{c}\text { G0/G1 } \\
{[\%]}\end{array}$ & $\begin{array}{c}S \\
{[\%]}\end{array}$ & $\begin{array}{c}\text { G2 } \\
{[\%]}\end{array}$ & \begin{tabular}{c|} 
sub \\
G1 \\
{$[\%]$}
\end{tabular} & $\begin{array}{c}\text { unspez. } \\
\text { Rest } \\
{[\%]}\end{array}$ & $\begin{array}{c}\text { 1d } \\
\text { pRTx }\end{array}$ & $\begin{array}{c}\text { G0/G1 } \\
{[\%]}\end{array}$ & $\begin{array}{c}S \\
{[\%]}\end{array}$ & $\begin{array}{c}\text { G2 } \\
{[\%]}\end{array}$ & $\begin{array}{c}\text { sub } \\
\text { G1 } \\
{[\%]}\end{array}$ & $\begin{array}{c}\text { unspez. } \\
\text { Rest } \\
{[\%]}\end{array}$ \\
\hline 0Gy & 42,9 & 4,8 & 27,6 & 0,7 & 24,0 & 0Gy & 11,8 & 3,1 & 10,0 & 36,6 & 38,6 \\
\hline $2 G y$ & 51,3 & 4,4 & 31,4 & 0,6 & 12,3 & $2 G y$ & 31,6 & 2,4 & 27,7 & 20,6 & 17,8 \\
\hline $4 G y$ & 39,5 & 5,7 & 36,3 & 0,8 & 17,8 & 4Gy & 28,2 & 4,7 & 33,9 & 9,7 & 23,5 \\
\hline 6Gy & 47,8 & 5,6 & 34,9 & 0,6 & 11,1 & 6Gy & 27,6 & 3,5 & 34,5 & 15,7 & 18,7 \\
\hline 8Gy & 32,9 & 3,5 & 40,2 & 0,7 & 22,8 & 8Gy & 17,7 & 2,7 & 24,5 & 25,7 & 29,4 \\
\hline \multicolumn{6}{|c|}{ ohne Hypericin } & \multicolumn{6}{|c|}{ mit Hypericin } \\
\hline $\begin{array}{c}\mathbf{3 d} \\
\text { pRTx }\end{array}$ & $\begin{array}{c}\text { G0/G1 } \\
{[\%]}\end{array}$ & $\begin{array}{c}S \\
{[\%]}\end{array}$ & $\begin{array}{c}\text { G2 } \\
{[\%]}\end{array}$ & $\begin{array}{c}\text { sub } \\
\text { G1 } \\
{[\%]}\end{array}$ & $\begin{array}{c}\text { unspez. } \\
\text { Rest } \\
{[\%]}\end{array}$ & $\begin{array}{c}\text { 3d } \\
\text { pRTx }\end{array}$ & $\begin{array}{c}\text { G0/G1 } \\
{[\%]}\end{array}$ & $\begin{array}{c}S \\
{[\%]}\end{array}$ & $\begin{array}{c}\text { G2 } \\
{[\%]}\end{array}$ & $\begin{array}{c}\text { sub } \\
\text { G1 } \\
{[\%]}\end{array}$ & $\begin{array}{c}\text { unspez. } \\
\text { Rest } \\
{[\%]}\end{array}$ \\
\hline 0Gy & 34,3 & 4,2 & 32,1 & 0,5 & 28,9 & 0Gy & 24,7 & 6,2 & 12,6 & 28,9 & 27,7 \\
\hline $2 G y$ & 45,5 & 2,3 & 34,1 & 0,5 & 17,6 & $2 G y$ & 13,6 & 1,5 & 10,3 & 44,3 & 30,3 \\
\hline 4Gy & 35,9 & 4,4 & 41,1 & 1,2 & 17,4 & 4Gy & 19,7 & 2,1 & 21,1 & 23,0 & 34,3 \\
\hline 6Gy & 28,1 & 4,6 & 49,2 & 1,7 & 16,6 & $6 \mathrm{~Gy}$ & 16,2 & 1,6 & 25,4 & 25,5 & 31,3 \\
\hline
\end{tabular}



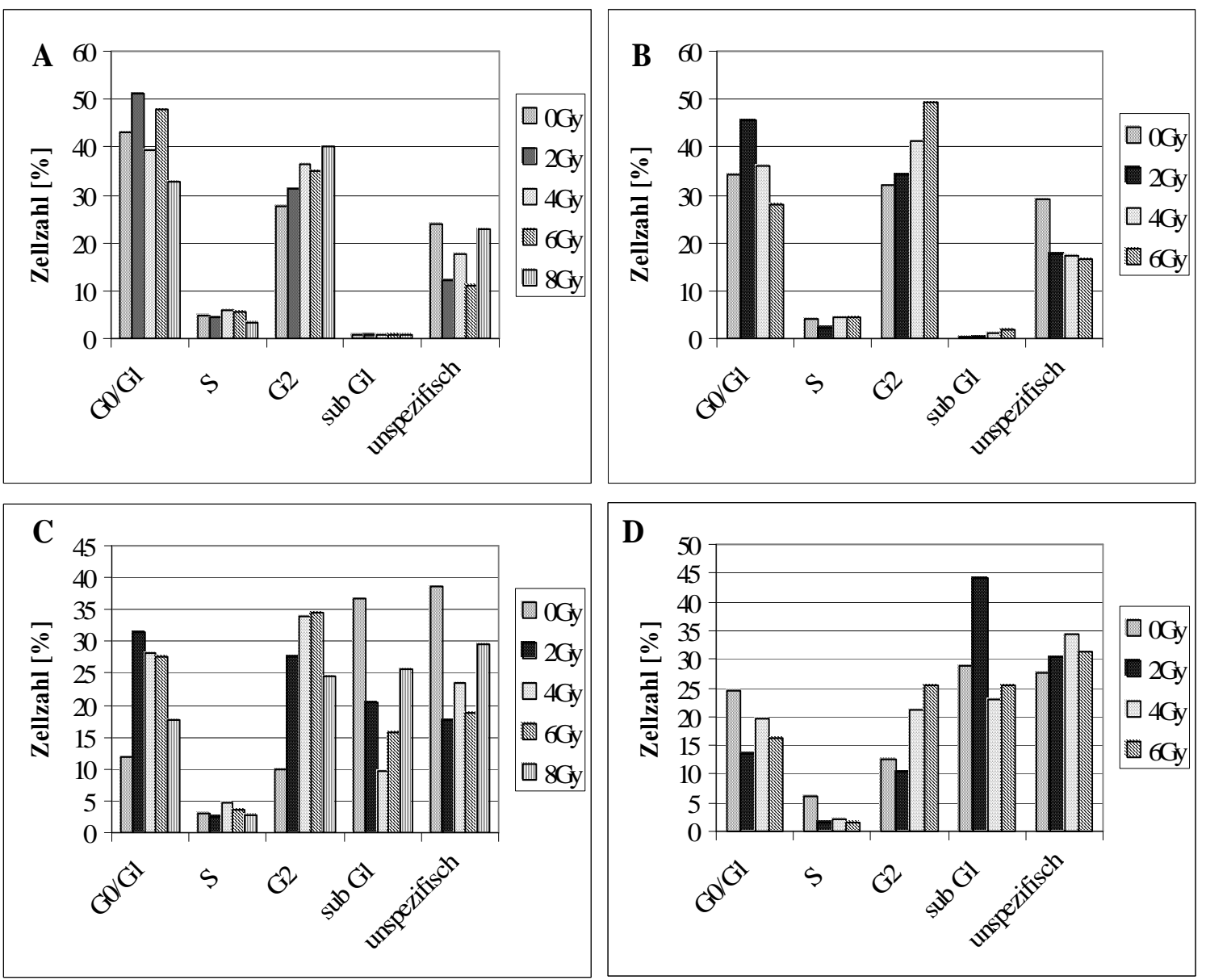

Abbildung 32: Zellzyklusverteilung von A498-Zellen 1 Tag (A, C) und 3 Tage (B, D) nach einer Bestrahlung (0Gy-8Gy) ohne (A, B) bzw. in Kombination mit (C, D) einer Hypericinbehandlung $(50 \mu \mathrm{M})$. Dargestellt ist die ermittelte Zellmenge [\%] pro Zellzyklusphase bezogen auf 100000 gezählte Zellen. Zellen, die aufgrund ihres Propidiumiodidgehaltes keiner Zellzyklusphase eindeutig zugeordnet werden können, sind als unspezifischer Rest zusammengefasst. 
4.3.5 Nachweis strahleninduzierter Doppelstrangbrüche in renalen KarzinomzellenErgebnisse der Immunfluoreszenz-Untersuchungen:

Eine Bestrahlung mit einer Dosis von 4Gy induziert DNA-Doppelstrangbrüche (DSB) in A498-Zellen. Drei Stunden nach der Bestrahlung sind in ca. $80 \%$ der Zellen unabhängig von der Hypericinbehandlung DSB mittels Fluoreszenzmarkierung der $\gamma \mathrm{H} 2 \mathrm{AX}$-Foci nachweisbar. 24 Stunden nach der Bestrahlung weisen nur noch 20\% der Zellen ohne Hypericinbehandlung aber $76 \%$ der hypericinbehandelten Zellen strahleninduzierte DSB auf (siehe Abb. 33 und 34A).
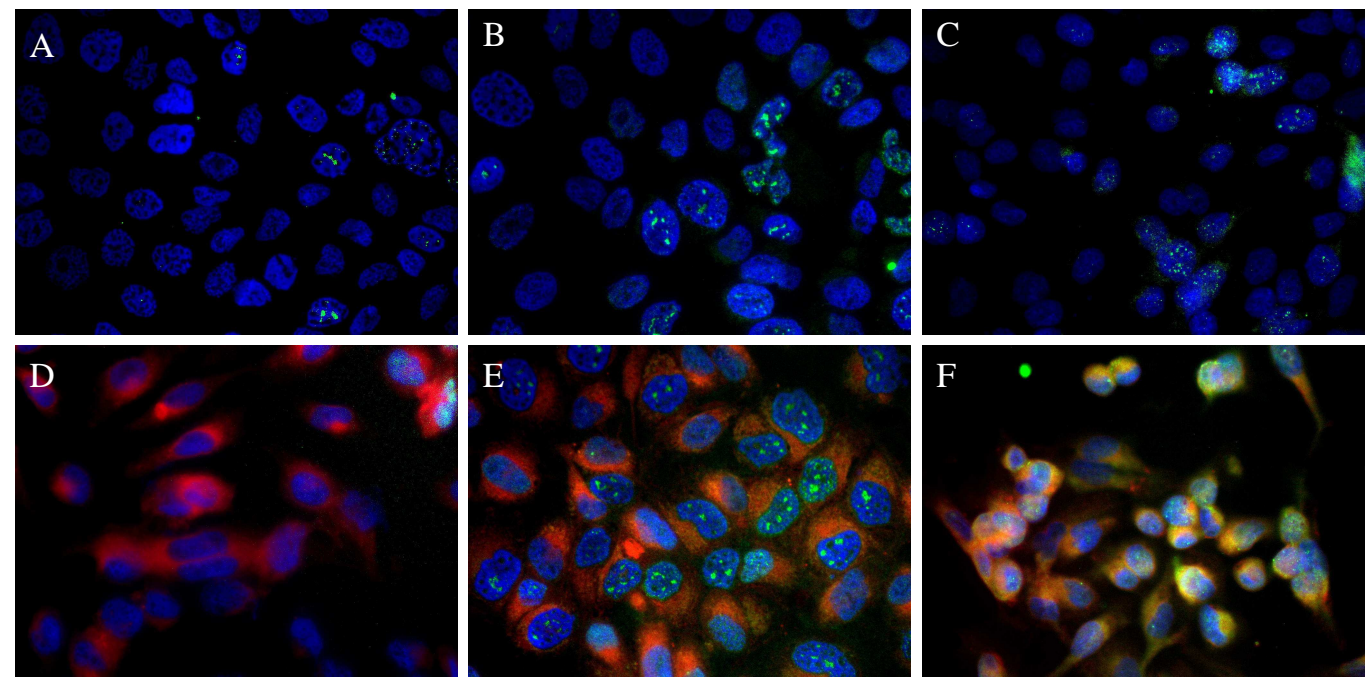

Abbildung 33: Fluoreszenzmikroskopische Bilder zum Nachweis strahleninduzierter Doppelstrangbrüche in renalen Karzinomzellen: Dargestellt sind A498-Zellen ohne (obere Reihe) und mit (untere Reihe) Hypericinbehandlung $(50 \mu \mathrm{M})$ ohne Bestrahlung $(\mathrm{A}, \mathrm{D})$ und drei Stunden (B, E) bzw. 24 Stunden (C, F) nach einer Bestrahlung mit 4Gy (rote Fluoreszenz = Hypericin, blaue Fluoreszenz $=$ Kernfärbung mit DAPI, grüne Fluoreszenz = FITCkonjugierter Antikörper gegen $\gamma \mathrm{H} 2 \mathrm{AX}$ ).

Betrachtet man die Stärke der Fluoreszenzsignale der $\gamma \mathrm{H} 2 \mathrm{AX}-\mathrm{Foci}$ innerhalb der Kernsignale, so zeigen sich ähnliche Ergebnisse. Drei Stunden nach einer 4GyBestrahlung enthalten ca. $31 \%$ der Kernsignale von Zellen ohne Hypericinbehandlung sowie ca. 24\% der Kernsignale von hypericinbehandelten Zellen $\gamma \mathrm{H} 2 \mathrm{AX}$-Foci. 24 Stunden nach der Bestrahlung weisen nur noch $4 \%$ der Kernsignale von Zellen ohne Hypericinbehandlung aber 52\% der Kernsignale von hypericinbehandelten Zellen strahleninduzierte DSB in Form von $\gamma \mathrm{H} 2 \mathrm{AX}$-Foci auf (siehe Abb. 34B). 

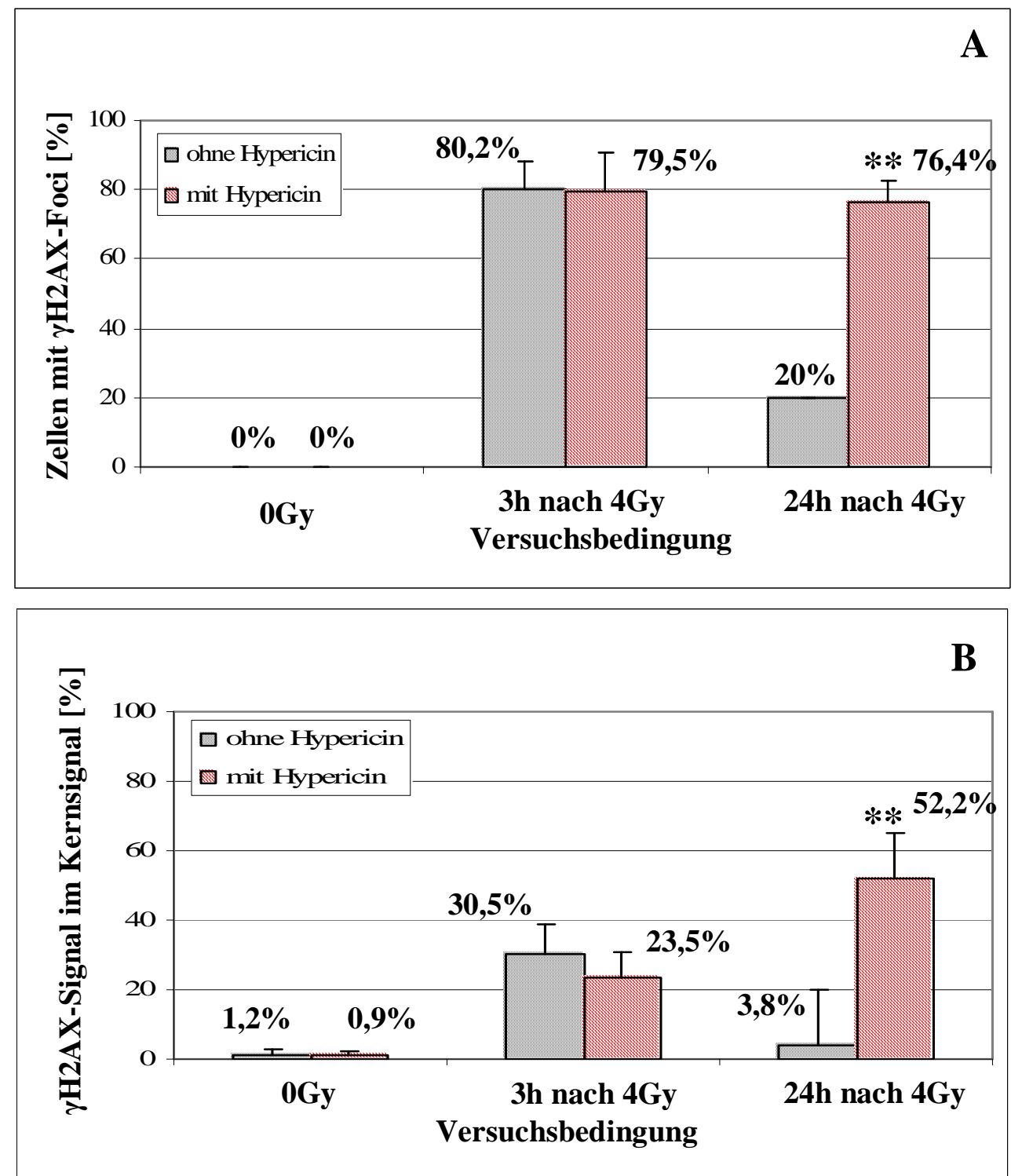

Abbildung 34: Nachweis strahleninduzierter Doppelstrangbrüche in A498-Zellen mittels Immunfluoreszenz. A) Dargestellt ist der Anteil der Zellen mit fluoreszenzmarkierten $\gamma \mathrm{H} 2 \mathrm{AX}-$ Foci (=Doppelstrangbrüche) [\%] bzw. B) der Anteil der Kernfluoreszenz [\%], der mit der $\gamma \mathrm{H} 2 \mathrm{AX}$-Fluoreszenz kolokalisiert ist, in Abhängigkeit von den Versuchsbedingungen $(* * \mathrm{p}<0,01)$. 
4.3.6 Wirkungen von Hypericin auf die Expression und Aktivität der Epidermalen Wachstumsfaktor Rezeptoren in renalen Karzinomzellen- Ergebnisse aus quantitativer Echtzeit-PCR, Westernblot- und Immunfluoreszenzuntersuchungen:

Die Daten aus der quantitativen Echtzeit-PCR zeigen, dass unbestrahlte A498-Zellen, die mit Hypericin behandelt wurden, ca. 10\% weniger des Epidermalen WachstumsfaktorRezeptors (EGFR) exprimieren als unbestrahlte Zellen ohne Hypericinbehandlung (Kontrolle). Eine Bestrahlung mit einer Dosis von 4 Gy führt sowohl bei A498-Zellen mit als auch ohne Hypericinbehandlung zu einer Zunahme der EGFR-Expression. So ist die Expression drei Stunden nach der Bestrahlung bei Zellen ohne Hypericinbehandlung um ca. 10\% und nach 24 Stunden noch um ca. $7 \%$ gegenüber der nicht bestrahlten Kontrolle erhöht. Hypericinbehandelte Zellen exprimieren drei Stunden nach der Bestrahlung ca. $18 \%$ und 24 Stunden danach ca. $11 \%$ mehr EGFR als die unbestrahlten hypericinbehandelten Zellen. Im Vergleich $\mathrm{zu}$ den bestrahlten Zellen ohne Hypericinbehandlung ist die Expression jedoch drei Stunden nach Bestrahlung ca. 2\% und 24 Stunden nach Bestrahlung um sogar 6\% erniedrigt (siehe Tab. 9A und Abb. 35A).

Die Ergebnisse aus dem Westernblot sind kongruent zu den Ergebnissen der quantitativen Echtzeit-PCR. In unbestrahlten A498-Zellen, die mit Hypericin behandelt wurden, sind ca. 9\% weniger Epidermale Wachstumsfaktor-Rezeptoren (phospho-EGFR) phosphoryliert als in unbehandelten Zellen. In Folge einer 4Gy-Bestrahlung kommt es in Zellen ohne Hypericinbehandlung zu einer Zunahme der EGFR-Phosphorylierung. So sind drei Stunden nach der Bestrahlung ca. 48\% und nach 24 Stunden noch ca. 34\% mehr EGFR phosphoryliert als in nicht bestrahlten Kontroll-Zellen. In hypericinbehandelten Zellen sind drei Stunden nach der Bestrahlung ca. 17\% mehr, nach 24 Stunden jedoch ca. 53\% weniger EGFR phosphoryliert als in unbestrahlten hypericinbehandelten Zellen. Im Vergleich zu den bestrahlten Zellen ohne Hypericinbehandlung sind drei Stunden nach Bestrahlung ca. $40 \%$ und 24 Stunden nach Bestrahlung sogar 96\% weniger EGFR phosphoryliert (siehe Tab. 9B und Abb.35B). 
Tabelle 9: Expression und Aktivität der Epidermalen Wachstumsfaktor Rezeptoren in renalen Karzinomzellen. A) Ergebnisse aus der quantitativen Echtzeit-PCR ( $\mathrm{n}=18)$. Dargestellt ist die relative Quantität der EGFR-Expression bei A498-Zellen in Abhängigkeit von den Versuchsbedingungen im Vergleich zu Negativkontrolle (0Gy) nach Gennormalisierung an GAPDH. B) Ergebnisse aus dem Westernblot $(n=4)$. Dargestellt ist die an der Negativkontrolle (0Gy) relativierte Fluoreszenzintensität des Antikörpers gegen phosphorylierten EGFR bei A498-Zellen ohne Bestrahlung mit bzw. ohne Hypericinbehandlung und $\mathrm{zu}$ verschiedenen Zeitpunkten ( $3 \mathrm{~h}$ und $24 \mathrm{~h}$ ) nach einer 4GyBestrahlung in Kombination mit bzw. ohne Hypericinbehandlung.

\begin{tabular}{|c|c|c|c|c|}
\hline & \multicolumn{2}{|c|}{ A } & \multicolumn{2}{c|}{ B } \\
& \multicolumn{2}{|c|}{$\begin{array}{c}\text { EGFR-Expression } \\
\text { ohne }\end{array}$} & mit 50 $\mu \mathrm{M}$ & \multicolumn{2}{c|}{$\begin{array}{c}\text { ohnespho-EGFR } \\
\text { ohnit } 50 \mu \mathrm{M}\end{array}$} \\
& Hypericin & Hypericin & Hypericin & Hypericin \\
\hline 0Gy & 1,00 & 0,90 & 1,00 & 0,91 \\
3h nach 4Gy & 1,10 & 1,08 & 1,48 & 1,08 \\
24h nach 4 Gy & 1,07 & 1,01 & 1,34 & 0,38 \\
\hline
\end{tabular}
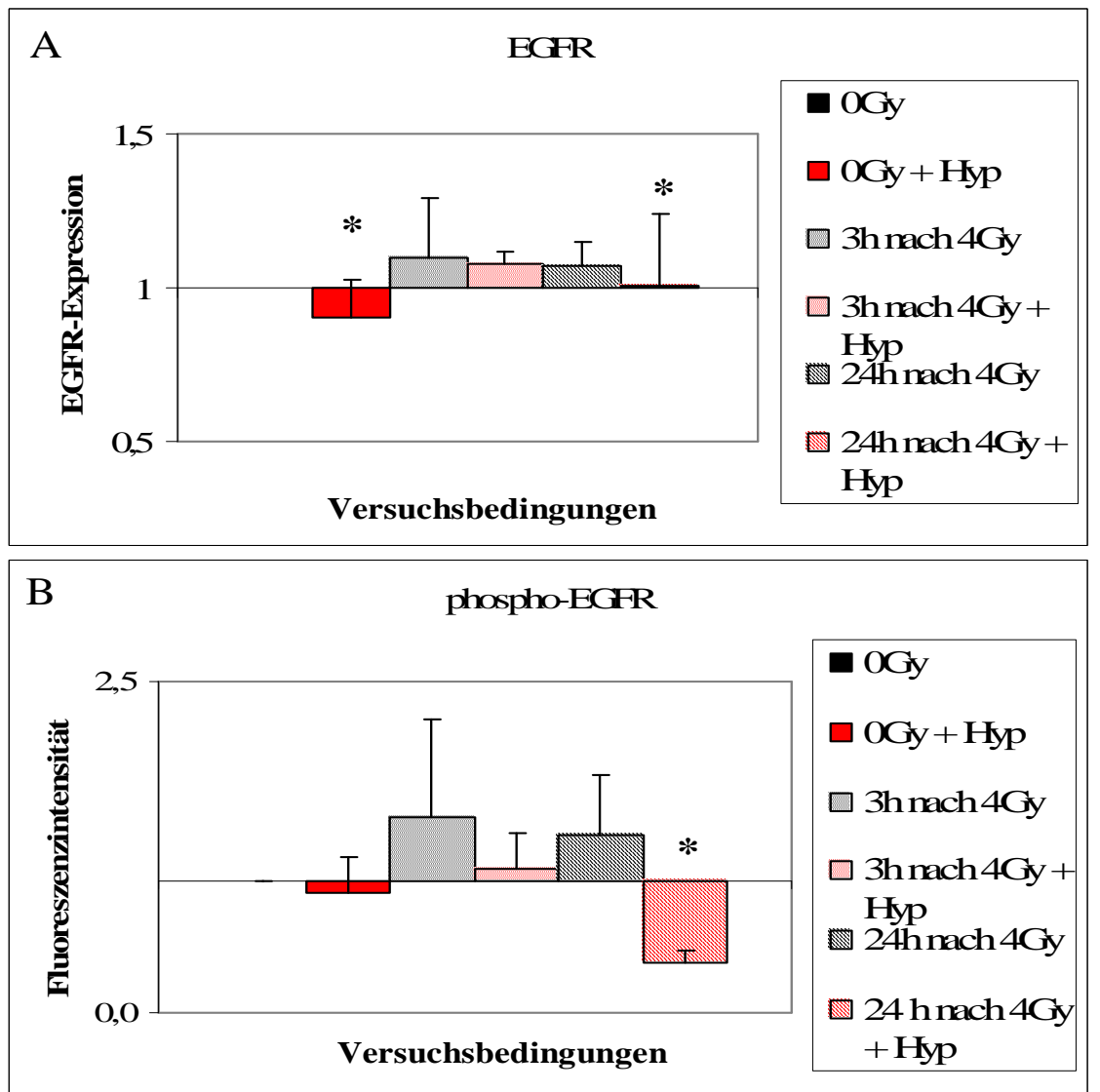

Abbildung 35: Expression und Aktivität der Epidermalen Wachstumsfaktor Rezeptoren in renalen Karzinomzellen. A) Ergebnisse aus der quantitativen Echtzeit-PCR $(\mathrm{n}=18)$. Dargestellt ist die relative Quantität der EGFR-Expression bei A498-Zellen in Abhängigkeit von den Versuchsbedingungen im Vergleich $\mathrm{zu}$ Negativkontrolle (0Gy) nach Gennormalisierung an GAPDH. B) Ergebnisse aus dem Westernblot $(n=4)$. Dargestellt ist die an der Negativkontrolle (0Gy) relativierte Fluoreszenzintensität des Antikörpers gegen phosphorylierten EGFR bei A498-Zellen ohne Bestrahlung mit bzw. ohne Hypericinbehandlung und $\mathrm{zu}$ verschiedenen Zeitpunkten ( $3 \mathrm{~h}$ und $24 \mathrm{~h}$ ) nach einer 4GyBestrahlung in Kombination mit bzw. ohne Hypericinbehandlung. (*p<0,05) 
4.3.7 Wirkungen von Hypericin auf die Aktivität der DNA-Proteinkinase C (DNA-PKC) in renalen Karzinomzellen-Ergebnisse aus Westernblot- und Immunfluoreszenzuntersuchungen:

Die Ergebnisse aus dem Westernblot zeigen, dass unbestrahlte A498-Zellen, die mit Hypericin behandelt wurden, ca. 3\% weniger phosphorylierte DNA-Proteinkinase C (phospho-DNA-PKC) enthalten als unbehandelte Kontrollzellen. In Folge einer 4GyBestrahlung kommt es in Zellen ohne Hypericinbehandlung zu einer Zunahme der PKCPhosphorylierung. So sind drei Stunden nach der Bestrahlung ca. 48\% und nach 24 Stunden jedoch nur noch ca. 1\% mehr DNA-PKC phosphoryliert als in nicht bestrahlten Kontrollzellen. In hypericinbehandelten Zellen sind drei Stunden nach einer Bestrahlung ca. 9\% mehr, nach 24 Stunden jedoch ca. 53\% weniger DNA-PKC phosphoryliert als in unbestrahlten hypericinbehandelten Zellen. Im Vergleich zu den bestrahlten Zellen ohne Hypericinbehandlung sind drei Stunden nach Bestrahlung ca. 42\% und 24 Stunden nach Bestrahlung sogar 57\% weniger DNA-PKC phosphoryliert (siehe Tab. 10A und Abb. 36A).

Die durch Immunfluoreszenz ermittelten Daten zeigen eine ähnliche Tendenz wie die Daten aus dem Westernblot. In 53\% der unbehandelten A498-Zellen und in ca. 31\% der hypericinbehandelten Zellen ist phosphorylierte-DNA-PKC mittels Immunfluoreszenz nachweisbar. Drei Stunden nach einer 4Gy-Bestrahlung zeigen ca. 92\% bzw. 75\% und nach 24 Stunden ca. 95\% bzw. 72\% der Zellen ohne bzw. mit Hypericinbehandlung die Fluoreszenz des FITC-konjugierten Antikörpers gegen phospho-DNA-PKC. (siehe Tab. 10B und Abb. 36B).

Tabelle 10: Aktivität der DNA-Proteinkinase C in renalen Karzinomzellen. Ergebnisse der Westernblot-Untersuchungen $(n=4)$. Dargestellt ist die Intensität [Grauwert] der Fluoreszenzmarkierung der phosphorylierten DNA-Proteinkinase $\mathrm{C}$ in behandelten A498Zellen im Verhältnis zur unbehandelten Kontrolle in Abhängigkeit von den Versuchsbedingungen. B) Ergebnisse aus den Immunfluoreszenzuntersuchungen $(\mathrm{n}=10)$. Dargestellt ist der Anteil der Zellen mit fluoreszenzmarkierter phospho-DNA-PKC [\%], in Abhängigkeit von den Versuchsbedingungen.

\begin{tabular}{|c|c|c|c|c|}
\hline & \multicolumn{2}{|c|}{$\begin{array}{c}\text { A } \\
\text { Fluoreszenzintensität } \\
\text { [Grauwert] }\end{array}$} & \multicolumn{2}{|c|}{$\begin{array}{c}\text { B } \\
\text { Zellen mit } \\
\text { Fluoreszenzsignal [\%] }\end{array}$} \\
\hline & $\begin{array}{c}\text { ohne } \\
\text { Hypericin }\end{array}$ & $\begin{array}{l}\text { mit } 50 \mu M \\
\text { Hypericin }\end{array}$ & $\begin{array}{c}\text { ohne } \\
\text { Hypericin }\end{array}$ & $\begin{array}{l}\text { mit } 50 \mu M \\
\text { Hypericin }\end{array}$ \\
\hline 0 Gy & 1,00 & 0,97 & 53 & 31 \\
\hline 3h nach $4 G y$ & 1,48 & 1,06 & 92 & 75 \\
\hline 24h nach $4 G y$ & 1,01 & 0,44 & 95 & 72 \\
\hline
\end{tabular}



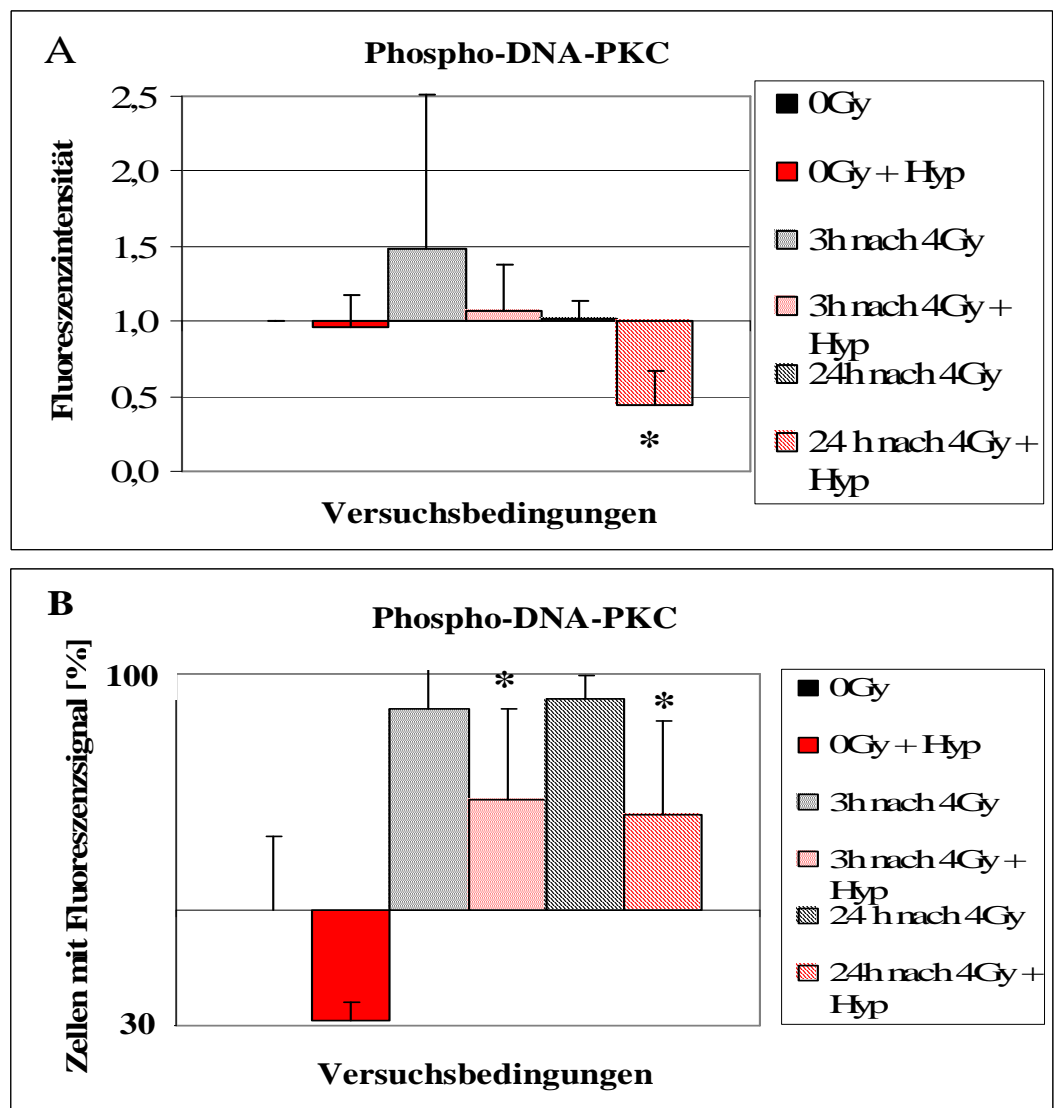

Abbildung 36: Aktivität der DNA-Proteinkinase C in renalen Karzinomzellen. Ergebnisse der Westernblot-Untersuchungen $(n=4)$. Dargestellt ist die an der unbehandelten Kontrolle (0Gy, ohne Hypericin) relativierte Intensität [Grauwert] der Fluoreszenzmarkierung der phosphorylierten DNA-Proteinkinase $\mathrm{C}$ in A498-Zellen in Abhängigkeit von den Versuchsbedingungen. B) Ergebnisse aus den Immunfluoreszenzuntersuchungen $(\mathrm{n}=10)$. Dargestellt ist der Anteil der Zellen mit fluoreszenzmarkierter phospho-DNA-PKC [\%], in Abhängigkeit von den Versuchsbedingungen. $\left({ }^{*} \mathrm{p}<0,05\right)$

4.3.8 Wirkungen von Hypericin auf die Expression von DNA-Proteinkinase C und deren $\underline{\text { regulatorischen Untereinheiten } \mathrm{Ku} 70 \text { und Ku80 in renalen Karzinomzellen- Ergebnisse der }}$ quantitativer Echtzeit-PCR:

Die Daten der quantitativen Echtzeit-PCR zeigen, dass die Expression von DNA-PKC, Ku70 und Ku80 in Zellen ohne Hypericinbehandlung im Vergleich zur unbehandelten Kontrolle drei Stunden nach der Bestrahlung zunächst zu- und 24 Stunden danach abnimmt. Bei hypericinbehandelten Zellen dagegen nimmt die Expression von DNA-PKC, Ku70 und Ku80 im Vergleich zu hypericinbehandelten aber unbestrahlten Zellen drei Stunden nach der Radiatio zunächst ab und 24 Stunden danach zu (siehe Tab. 11).

Unbestrahlte A498-Zellen, die mit Hypericin behandelt wurden, exprimieren ca. $1 \%$ weniger DNA-PKC, $16 \%$ weniger Ku70 und ca. $13 \%$ weniger Ku80 als unbehandelte Kontrollzellen. 
Drei Stunden nach einer Bestrahlung ist in hypericinbehandelten Zellen die Expression von DNA-PKC um $15 \%$ und die von Ku70 bzw. Ku80 jeweils um $26 \%$ gegenüber bestrahlten Zellen ohne Hypericinbehandlung erniedrigt. 24 Stunden nach Radiatio ist in hypericinbehandelten Zellen die Expression von DNA-PKC um 52\% und die von Ku70 um $11 \%$ und die von Ku80 um 56\% gegenüber bestrahlten Zellen ohne Hypericinbehandlung (siehe Tab. 11 und Abb. 37)

Tabelle 11: Relative Expression von DNA-Proteinkinase $\mathrm{C}$ und den regulatorischen Untereinheiten Ku70 bzw. Ku80. Ergebnisse der quantitativen Echtzeit-PCR. Dargestellt sind die an der Negativkontrolle (0Gy) relativierte und an GAPDH normalisierte Expression von DNA-PKC, Ku70 und Ku80 in renalen Karzinomzellen in Abhängigkeit von den Versuchsbedingungen. DNA-PKC (n=9), Ku $70(\mathrm{n}=21)$ und Ku80 (n=12).

\begin{tabular}{|c|c|c|c|c|c|c|}
\hline & 0Gy & $\begin{array}{c}\text { 0Gy } \\
+ \text { Hyp }\end{array}$ & $\begin{array}{c}\text { 3h nach } \\
\text { 4Gy }\end{array}$ & $\begin{array}{c}\text { 3h nach } \\
\text { 4Gy } \\
\text { + Hyp }\end{array}$ & $\begin{array}{c}\text { 24h nach } \\
\text { 4Gy }\end{array}$ & $\begin{array}{c}\text { 24h nach } \\
\text { 4Gy } \\
+ \text { Hyp }\end{array}$ \\
\hline DNA-PKC & 1,00 & 0,99 & 1,12 & 0,97 & 0,77 & 1,29 \\
Ku70 & 1,00 & 0,84 & 1,05 & 0,79 & 0,77 & 0,88 \\
Ku80 & 1,00 & 0,87 & 1,01 & 0,75 & 0,55 & 1,11 \\
\hline
\end{tabular}
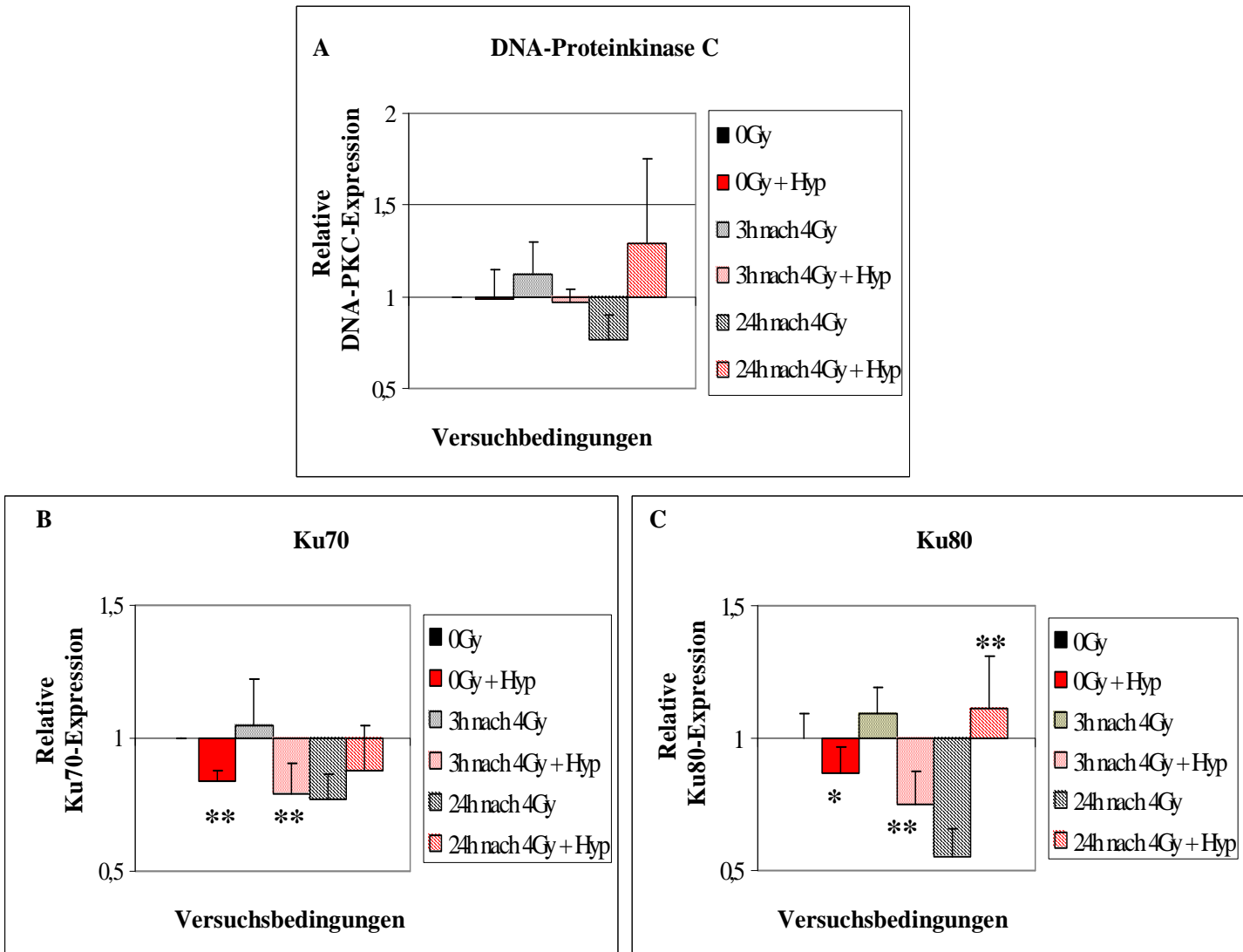

Abbildung 37: Relative Expression von DNA-Proteinkinase $\mathrm{C}$ und den regulatorischen Untereinheiten Ku70 bzw. Ku80. Ergebnisse der quantitativen Echtzeit-PCR. Dargestellt sind die an der Negativkontrolle (0Gy) relativierte und an GAPDH normalisierte Expression von DNA-PKC, Ku70 und Ku80 in renalen Karzinomzellen in Abhängigkeit von den Versuchsbedingungen. DNA-PKC $(n=9), \mathrm{Ku} 70(\mathrm{n}=21)$ und $\mathrm{Ku} 80(\mathrm{n}=12),(* \mathrm{p}<0,05$, $* * \mathrm{p}<0,01)$. 
4.3.9 Wirkungen von Hypericin auf die Expression von Phosphoinositol-3-Kinase und XRay Repair Cross Complementing-Faktor-4 in renalen Karzinomzellen- Ergebnisse der quantitativer Echtzeit-PCR:

Die Daten aus der quantitativen Echtzeit-PCR zeigen, dass A498-Zellen, die mit Hypericin behandelt wurden, ca. $1 \%$ weniger X-Ray Repair Cross Complementing-Faktor4 (XRCC4) und ca. 13\% weniger Phosphoinositol-3-Kinase (PI3K) exprimieren als unbehandelte Zellen. Drei Stunden nach einer 4Gy-Bestrahlung ist bei Zellen ohne Hypericinbehandlung die Expression von XRCC4 um ca. $11 \%$ gegenüber der nicht bestrahlten Kontrolle erhöht, die PI3K-Expression unterscheidet sich nicht. Die Expression von XRCC4 ist nach 24 Stunden um 3\% erniedrigt und die von PI3K um 7\% gegenüber der nicht bestrahlten Kontrolle erhöht. Hypericinbehandelte Zellen exprimieren drei Stunden nach der Bestrahlung ca. 9\% mehr XRCC4, 2\% weniger PI3K und 24 Stunden danach ca. 34\% mehr XRCC4, 18\% mehr PI3K als die unbestrahlten hypericinbehandelten Zellen. Im Vergleich zu den bestrahlten Zellen ohne Hypericinbehandlung ist drei Stunden nach Bestrahlung die Expression von XRCC4 ca. 3\%, von PI3K um ca. 11\% erniedrigt. 24 Stunden nach der Radiatio ist in hypericinbehandelten Zellen die Expression von XRCC4 um ca. $36 \%$ erhöht und die von PI3K um 2\% erniedrigt (siehe Tab. 12, Abb. 38).

Tabelle 12 Relative Expression von X-Ray Repair Cross Complementing-Faktor-4 und Phosphoinositol-3-Kinase in renalen Karzinomzellen. Ergebnisse der quantitativen EchtzeitPCR. Dargestellt sind die an der Negativkontrolle (0Gy) relativierte und an GAPDH normalisierte Expression von XRCC4 $(n=15)$ und Phosphoinostiol-3-Kinase $(n=18)$ in Abhängigkeit von den Versuchsbedingungen.

\begin{tabular}{|c|c|c|c|c|}
\hline & \multicolumn{2}{|c|}{ A } & \multicolumn{2}{c|}{ B } \\
& $\begin{array}{c}\text { XhCC4 } \\
\text { ohne }\end{array}$ & mit & Phne & mit \\
& Hypericin & Hypericin & Hypericin & Hypericin \\
\hline 0Gy & 1,00 & 0,99 & 1,00 & 0,87 \\
3h nach 4Gy & 1,11 & 1,08 & 1,00 & 0,89 \\
24hnach 4Gy & 0,97 & 1,33 & 1,07 & 1,05 \\
\hline
\end{tabular}



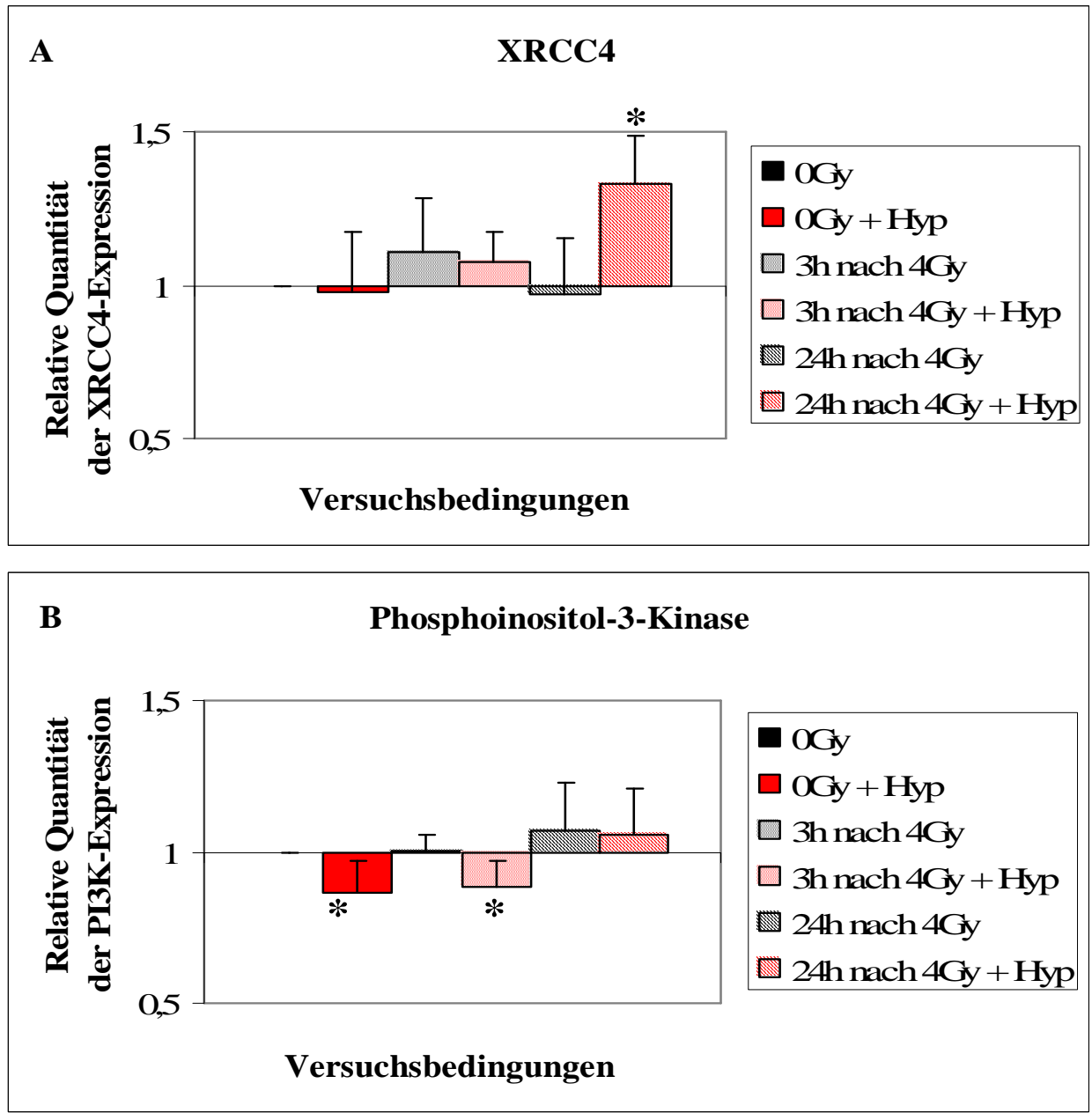

Abbildung 38: Relative Expression von X-Ray Repair Cross Complementing-Faktor-4 und Phosphoinositol-3-Kinase in renalen Karzinomzellen. Ergebnisse der quantitativen EchtzeitPCR. Dargestellt ist die an der Negativkontrolle (0Gy) relativierte und an GAPDH normalisierte Expression von XRCC4 $(n=15)$ und Phosphoinostiol-3-Kinase $(n=18)$ in Abhängigkeit von den Versuchsbedingungen. $(* \mathrm{p}<0,05, * * \mathrm{p}<0,01)$. 


\section{Diskussion:}

5.1 Aufnahme, Distribution, Akkumulation und Efflux von Hypericin in bzw. aus renalen Karzinomzellen:

5.1.1 Aufnahme und Persistenz von Hypericin in renalen Karzinomzellen:

Das renale Karzinom gehört zu den sehr chemoresistenten Neoplasien. Einer der Gründe für die ausgeprägte Chemoresistenz des RCC ist die verminderte intrazelluläre Akkumulation von Medikamenten aufgrund der physiologisch bedingten hohen Expression von sehr effektiven ATP-Bindungs-Kassette- (ABC-) Transporter- Effluxpumpen wie z.B. P-Glykoprotein (Pgp) (Fergusen et al., 2005). Die physiologische Aufgabe des Pgp ist neben dem Transport von Zytokinen die Elimination von exogenen Toxinen bzw. toxischen Metaboliten zum Schutz des renalen Gewebes. Die transmembranen Pgp sind in der Lage ein breites Spektrum an Wirkstoffen, vor allem hydrophobe Moleküle, zu binden und aus den Zellen zu transportieren (Lehne, 2000). Interessanterweise zeigen die Ergebnisse dieser Arbeit, dass Hypericin in renalen Karzinomzellen trotz Pgp akkumuliert. Der Hypericingehalt von A498-Zellen gemessen anhand der Fluoreszenzintensität des Hypericins nimmt mit zunehmender Inkubationsdauer schnell zu, während die Elimination von Hypericin aus der Zelle nur langsam voranschreitet. Das wasserunlösliche HypericinEtOH und das wasserlösliche Hypericin-PVP zeigen ein ähnliches Influx- und Effluxverhalten. Nach gängiger Meinung erfolgt die zelluläre Aufnahme von Hypericin direkt durch die Membran über passive Diffusion oder durch Endozytose (Thomas und Pardini, 1992; Siboni et al., 2002; Ali und Olivo, 2002; Galanou et al., 2008), des weiteren zeigt Hypericin eine ausgeprägte Affinität zu zellulären Lipidmembranstrukturen (Mazur und Meruelo, 1993; Thomas und Pardini, 1992). P-Glykoproteine durchspannen mit je 12 Transmembrandomänen, die an der Bindung von Substraten beteiligt sind, die Zellmembran. So interagieren Pgp mit Substraten bereits an der Innenseite der Lipiddoppelschicht und transportieren diese aus der Zelle. Vor allem hydrophobe oder amphiphile Wirkstoffe, die durch die Membran diffundieren oder in der Membran interkalieren, werden so schnell von den Pgp gebunden und aus der Zelle transportiert (Lehne, 2000). Das hydrophobe Hypericin mit seiner Affinität zu Lipidmembranstrukturen scheint demnach ein geeignetes Substrat für Pgp vermittelten Efflux zu sein. Im Rahmen diese Arbeit kann jedoch noch 48 Stunden nach einstündiger Inkubation Hypericin in renalen Karzinomzellen nachgewiesen werden. Eine mögliche Erklärung dafür wäre, dass das Hypericin mit Pgp interagiert und die Transportaktivität hemmt. Viele Wirkstoffe, die mit Pgp interagieren und deren Aktivität hemmen, zeigen ähnliche Charakteristika wie 
Hypericin. Es handelt sich häufig um große (Molekulargewicht $>400 \mathrm{~g} / \mathrm{mol}$ ), hydrophobe oder amphiphile Moleküle mit planaren Ringstrukturen (Lehne, 2000). Zur Klärung dieser Hypothese werden Rhodamin-123-Effluxstudien durchgeführt. Rhodamin123 ist ein spezifisches Transportsubstrat von Pgp. Es diffundiert passiv durch die Zellmembran, akkumuliert in den Mitochondrien lebender Zellen und wird durch Bindung an PGlykoproteine aktiv aus der Zelle transportiert. Wird die Bindung an Pgp verhindert oder die Aktivität von Pgp gehemmt, so verbleibt das Rhodamin-123 in der Zelle. Die Ergebnisse der Effluxstudien zeigen, dass Rhodamin-123 aus renalen Karzinomzellen transportiert wird. Der Rhodamin-123-Efflux scheint jedoch bei hypericinbehandelten Zellen vermindert oder zumindest verlangsamt zu sein. So ist der Rhodamingehalt von A498-Zellen, die mit Hypericin-PVP $(10 \mu \mathrm{M})$ bzw. Hypericin-EtOH $(10 \mu \mathrm{M})$ behandelt wurden, nach drei Stunden Effluxzeit ca. 3\% bzw. 9-10\% höher als der Rhodamingehalt von Zellen ohne Hypericinbehandlung. Demnach scheint Hypericin mit P-Glykoproteinen oder unmittelbar assoziierten Prozessen zu interagieren. In der Literatur gibt es hierzu unterschiedliche z. T. widersprüchliche Aussagen. So wird berichtet, dass Hypericin bei hohen Konzentrationen eine vermehrte Expression von P-Glykoproteinen in LS180-Zellen induziert (Moore et al., 2000; Gutmann et al., 2006). Tian et al. (2005) können keinen Effekt von Hypericin auf die Expression von Pgp und keine inhibitorische Wirkung auf die Pgp-Aktivität in LS180-Zellen nachweisen, verwenden jedoch nur geringe Hypericinkonzentrationen $(0,1 \mu \mathrm{M})$ in ihren Versuchen. Perloff et al. (2001) zeigen jedoch, dass in humanen Kolonkarzinomzellen Caco-2 die Funktion von P-Glykoproteinen durch Hypericin $(0,3$ und $3 \mu \mathrm{M})$ gehemmt wird. So ist es denkbar, dass die widersprüchlichen Aussagen in der Literatur hinsichtlich der Wirkung von Hypericin auf die Pgp-Aktivität und -Expression auf die unterschiedlichen Versuchsbedingungen z.B. die eingesetzte Hypericinkonzentration zurückzuführen ist. Die Aktivierung des Pgp wird über die Phosphorylierung durch Proteinkinase C reguliert (Lehne, 2000). Zahlreiche Publikationen berichten von der inhibitorischen Wirkung des Hypericins auf Enzyme wie u. a. die Proteinkinase C (PKC) (Kubin , 2005; Takahashi et al., 1989; Agostinis et al. 1995; Utsumi, 1995). Daher wäre es denkbar, dass Hypericin mit Pgp interagiert, deren Aktivierung durch Inhibition der PKC hemmt und somit die eigene schnelle Elimination aus der Zelle durch Pgp verhindert. Zur Bestätigung dieser Theorie wären weitere Untersuchungen nötig, die nicht Bestandteil dieser Arbeit sind. 


\subsubsection{Intrazelluläre Distribution und Akkumulation von Hypericin in renalen}

\section{Karzinomzellen:}

Die Ergebnisse dieser Arbeit zeigen, dass sowohl das wasserunlösliche Hypericin-EtOH als auch das wasserlösliche Hypericin-PVP intrazellulär im Endoplasmatischen Retikulum von A498-Zellen in einer zeitabhängigen Weise akkumulieren. Dabei ist eine Zunahme der Kolokalisation mit steigender Inkubationsdauer bis zu einer Stunde nachweisbar, während nach längeren Inkubationszeiten (drei Stunden bis 24 Stunden) die Kolokalisation wieder abnimmt. Möglicherweise wird das Hypericin mit voranschreitender Zeit in den GolgiApparat transportiert, wodurch die Abnahme des Hypericingehaltes im ER zu erklären wäre. Die mit steigender Inkubationsdauer zu beobachtende zunehmende Lokalisation von Hypericin in der perinukleären Region, die häufig mit der Lage des Golgi-Apperates assoziiert ist, gibt zumindest einen Hinweis darauf. Die Kinetiken der zeitlichen Zu- bzw. Abnahme der Kolokalisation für das Hypericin-PVP bzw. Hypericin-EtOH mit BIP sind unterschiedlich. Die Kolokalisation der Fluoreszenzen von Hypericin-EtOH und BIP nimmt im Vergleich zu Hypericin-PVP schneller zu, erreicht höhere maximale Werte nach einer Stunde Inkubationszeit und nimmt langsamer wieder ab. BIP reguliert u. a. ATPabhängig die Öffnung von wässrigen Poren in den Membranen des Endoplasmatischen Retikulums. Eine mögliche Erklärung für die schnellere Akkumulation von HypericinEtOH im ER wäre eventuell, dass das hydrophobe Hypericin-EtOH frei durch die ERMembran diffundiert, während das wasserlösliche Hypericin-PVP erst nach ATPabhängiger Öffnung der Pore in das ER gelangen kann. In der Literatur gibt es derzeit keine vergleichenden Untersuchungen bezüglich der ER-Akkumulation von HypericinPVP und Hypericin-EtOH. Zahlreiche Publikationen berichten jedoch ebenfalls von einer intrazellularen Akkumulation von Hypericin in den Membranen des Endoplasmatischen Retikulums und des Golgi-Apparates (Ritz et al., 2008; Kubin, 2005; Galanou et al., 2008; Siboni et al., 2002; Agostinis et. al., 2002).

Neben der Akkumulation von Hypericin im Endoplasmatischen Retikulum kann in dieser Arbeit eine Kolokalisation der Rhodamin123-Fluoreszenz mit der Hypericinfluoreszenz beobachtet werden. $\mathrm{Da}$ Rhodamin-123 ein spezifischer mitochondrialem Fluoreszenzmarker ist, kann darauf geschlossen werden, dass Hypericin ebenfalls in den Membranen der Mitochondrien akkumuliert. Während keine Kolokalisation von Hypericin und Mitochondrienmembranen in HeLa-Zellen nachgewiesen werden kann (Agostinis et al., 2002), berichten Ali und Olivo (2002) von einer Hypericinakkumulation in den Mitochondrien von Nasopharyngealkarzinomzelle, Kolon- und Blasenkarzinomzellen. 
Galanou et al. (2008) berichten ebenfalls von einer Hypericinakkumulation in Mitochondrien von Prostatakarzinomzellen nach einstündiger Inkubation. Während Hypericin in Kolonkarzinomzellen der Linie Caco-2 sowohl in zytoplasmatischen als auch in nukleären Membranen (Kubin, 2005) akkumuliert, kann eine Akkumulation von Hypericin in den Kernmembranen von renalen Karzinomzellen in dieser Arbeit nicht nachgewiesen werden. Die intrazelluläre Hypericindistribution scheint zum einen abhängig vom Zelltyp zu sein (Sattler et al., 1997; Agostinis et al., 2000; Vandenbogaerde, 1997), zum anderen sind die unterschiedlichen zum Teil widersprüchlichen Aussagen zur intrazellulären Akkumulation des Hypericins vermutlich durch die unterschiedlichsten Versuchsbedingungen und Untersuchungsmethoden $\mathrm{zu}$ erklären. So sind Kolokalisationsstudien z.B. mittels einfacher Fluoreszenzmikroskopie nur bedingt aussagekräftig, weil durch die Überlagerung der unterschiedlichen Farbkanäle eine Kolokalisation fälschlicherweise suggeriert werden kann, da die dreidimensionale Auflösung fehlt. Daher sollten Kolokalisationsstudien entweder mit Konfokalmikroskopie (3D) oder FRET-Mikroskopie (Försterscher Resonanz Energie Transfer) durchgeführt werden. Das Prinzip der FRET-Mikroskopie basiert auf einer Energieübertragung zwischen zwei nahe beieinander liegenden Fluorophoren. Die Anregung eines Fluorophors mit geeigneter Wellenlänge führt zur Fluoreszenzemission, deren Wellenlänge der Excitationswellenlänge eines zweiten Fluorophors entspricht. Die Energieübertragung vom ersten auf das zweite Fluorophor ist nur möglich, wenn beide Fluorophore nahe beieinander liegen $(<10 \mathrm{~nm})$ also kolokalisiert sind. Die emittierte Fluoreszenz des zweiten Fluorophors wäre demnach ein Indikator für die Kolokalisation.

\subsection{Dunkelwirkung von Hypericin auf renale Karzinomzellen:}

Die Ergebnisse aus den Dunkelversuchen zeigen, dass auch hohe Konzentrationen von Hypericin (25 und $50 \mu \mathrm{M}$ ) unter Lichtausschluss keine toxischen Effekte auf renale Karzinomzellen haben. So gibt es keine signifikanten Unterschiede im Zellmetabolismus oder der Koloniebildungsfähigkeit von hypericinbehandelten A498-Zellen und Zellen ohne Hypericinbehandlung. Des Weiteren ist keine Apoptoseinduktion durch Hypericin unter dunklen Bedingungen nachweisbar. Auch andere Arbeitsgruppen bestätigen, dass Hypericin keine oder nur eine minimale Dunkeltoxizität besitzt (Ali und Olivo, 2002; Agostinis et al., 2002; Kubin, 2005). In Kombination mit Licht ändern sich die Effekte von Hypericin jedoch dramatisch. 


\subsection{Phototoxische Wirkung von Hypericin auf renale Karzinomzellen:}

Im Rahmen dieser Arbeit kann gezeigt werden, dass schon geringe Hypericinkonzentrationen in Kombination mit Licht den Zellmetabolismus von renalen Karzinomzellen so wie die Koloniebildungsfähigkeit zum erliegen bringen. Des Weiteren ist eine Apoptoseinduktion in 100\% der Zellen nachweisbar, die mit 10-50 $\mu \mathrm{M}$ Hypericin und einer 10-30-minütigen Beleuchtung behandelt wurden. Die phototoxischen Wirkungen von Hypericin sind nach gängiger Meinung darauf zurück zuführen, dass Hypericin unter oxischen Bedingungen und Lichtexposition verschiedene Elektronen- und Energietransferreaktionen auf Sauerstoff katalysiert. Der dabei intrazellulär entstehende hoch reaktive Singulettsauerstoff kann Apoptose bzw. Nekrose in den Zellen induzieren (Agostinis et al., 2000; Agostinis et al., 2002; Kubin, 2005). Die intrazelluläre Entstehung von reaktiven Sauerstoffspezies (ROS) in renalen Karzinomzellen durch eine Behandlung mit Hypericin in Kombination mit Licht kann in dieser Arbeit unter Verwendung eines redoxsensitiven GFP nachgewiesen werden. Das roGFP hat zwei Anregungsmaxima bei 395nm und 470nm. Im oxidierten Zustand kommt es zur Bildung von Disulfid-Brücken zwischen den an der Oberfläche des Proteins lokalisierten Cystein-Resten. Dies induziert eine reversible Konformationsänderung des Proteins, wodurch die Protonierung des Chromophors begünstigt wird, was in einer Verstärkung des Anregungsmaximums bei 395nm und einer Abschwächung bei 470nm resultiert. Unter reduzierten Bedingungen kann das Gegenteil beobachtet werden. Der intrazelluläre Redox-Zustand lässt sich durch das Verhältnis der Fluoreszenzintensitäten bei 395nm zu 470nm ermitteln. Durch Bildung des Quotienten werden mögliche Verfälschungen der Messung in Folge von z.B. Hintergrundfluoreszenz, ungleichmäßiger Beleuchtung oder unterschiedlich starker Expression des GFP minimiert (Hanson et al. 2004; Dooley et al., 2004). Das ermittelte Verhältnis der Fluoreszenzintensitäten bei $395 \mathrm{~nm} / 470 \mathrm{~nm}$ beträgt in renalen Karzinomzellen im regulären Redoxzustand ca. 370 bis 380. Nach Zugabe einer 10mM DTT-Lösung nimmt die Fluoreszenzintensität bei 470nm zu und damit der Quotient $395 \mathrm{~nm} / 470 \mathrm{~nm}$ auf 360 ab. Nach Zugabe einer 5mM $\mathrm{H}_{2} \mathrm{O}_{2}$-Lösung steigt die Fluoreszenzintensität bei $395 \mathrm{~nm}$ und damit der Quotient 395nm/470nm auf ca. 850 stark an. Die Reaktion des roGFP auf oxidierende Einflüsse wie $\mathrm{H}_{2} \mathrm{O}_{2}$ fällt stärker aus als auf reduzierende Reagenzien wie DTT. Dies ist dadurch zu erklären, dass im Zytosol lebender Zellen reduzierende Bedingungen vorherrschen und demnach das roGFP im Grundzustand reduziert vorliegt. Eine Zugabe von $1 \mathrm{mM} \mathrm{H}_{2} \mathrm{O}_{2}$ führt $\mathrm{zu}$ einer maximalen reversiblen 
Oxidation des roGFPs, während 10mM DTT eine maximale reversible Reduktion bewirkt (Hanson et al., 2004). Die in dieser Arbeit erhobenen Daten zeigen, dass die Behandlung von A498-Zellen mit $10 \mu \mathrm{M}$ Hypericin in Kombination mit einer zehnminütigen Beleuchtung eine annähernd maximale Oxidation des roGFP hervorruft. Der mittlere Quotient der Fluoreszenzintensitäten bei 395nm/470nm für renale Karzinomzellen nach Hypericin-Behandlung ist mit 556 etwas niedriger als nach $\mathrm{H}_{2} \mathrm{O}_{2}$-Behandlung mit 577 . Dabei ist zu beachten, dass das Hypericin für diese Messung in das die Zelle umspülende Nährmedium gegeben wird und erst bei bereits begonnener Beleuchtung und Messung in die Zelle diffundieren kann. So ist es möglich, dass ein großer Teil der entstehenden ROS aus dem System diffundiert ohne intrazellulär wirken zu können. Bei Zellen, die mit Hypericin vorinkubiert wurden, können jedoch gleich zu Beginn der Messung für ca. 35 Sekunden Werte ermittelt werden, die mit 867 ca. 50\% höher sind als die gemessenen Werte nach einer $\mathrm{H}_{2} \mathrm{O}_{2}$-Behandlung. Nach 35 Sekunden ist ein steiler Abfall der Ratio nachweisbar. Dies ist darauf zurück zu führen, dass das Hypericin bereits zu Beginn der Beleuchtung und Messung in der Zelle lokalisiert ist und die entstehenden ROS direkt intrazellulär wirken können. So ist der schnelle Abfall der ermittelten Ratio vermutlich dadurch bedingt, dass das GFP bzw. die Zelle durch die starken oxidierenden Bedingungen irreversibel geschädigt wird. Das roGFP zeigt generell intrazelluläre Redoxänderungen ohne Affinität zu bestimmten reaktiven Sauerstoffspezies wie z.B. Singulettsauerstoff. So kann in dieser Arbeit die intrazelluläre Entstehung von reaktiven Sauerstoffspezies durch eine Behandlung mit Hypericin in Kombination mit Licht (Photodynamische Therapie) in renalen Karzinomzellen mittels roGFP nachgewiesen werden.

Eine Induktion der Apoptose durch photoaktiviertes Hypericin erfolgt über den intrinsischen mitochondrialen Weg (Agostinis et al., 2000). Die Bildung von durch die Photoaktivierung von Hypericin entstehenden reaktiven Sauerstoffspezies ist assoziiert mit einem rapiden Zusammenbruch des mitochondrialen Membranpotentials (Chaloupka et al., 1999). Dies führt $\mathrm{zu}$ einer Cytochrom C-Freisetzung aus dem mitochondrialem Intermembranraum in das Zytosol, wodurch die Bildung des Apoptosom-Komplexes ermöglicht wird, der wiederum die Caspasen-Kaskade aktiviert, die letztlich zum apoptotischen Zelltod führt. Im Rahmen dieser Arbeit kann eine Apoptose in $100 \%$ der renalen Karzinomzellen in Folge einer Behandlung mit Hypericin in Kombination mit Beleuchtung nachgewiesen werden. Andere Arbeitsgruppen berichten, dass eine Apoptoseinduktion bei niedrigen Hypericinkonzentrationen und geringen Lichtintensitäten beobachtet werden kann, während hohe Hypericinkonzentrationen und Lichtintensitäten zu 
Nekrose führen (Agostinis et al., 2000; Ali und Olivo, 2003). Im Gegensatz dazu kann in dieser Arbeit eine Apoptose ebenfalls bei hohen Hypericinkonzentrationen ( 25 und $50 \mu \mathrm{M})$ nachgewiesen werden. Dies ist möglicherweise darauf zurück zu führen, dass der TUNELTest eine Apoptose zu einem sehr frühen Stadium nachweisen kann. Auch bei extremen oxidativem Stress in Folge einer Photodynamischen Therapie kommt es zunächst zu einer Initiierung der Apoptose, die dann im Verlauf jedoch durch Akkumulation von oxidativen Schäden in eine Nekrose konvertiert (Agostinis et al., 2000).

Viele Publikationen bestätigen die phototoxischen Effekte von Hypericin auf verschiedene neoplastische Zellen (Kubin, 2005), so dass die Photodynamische Therapie mit Hypericin eine neue viel versprechende Therapieoption zur Behandlung von Neoplasien darstellt. Daher gibt es derzeit vielfältige intensive Untersuchungen zur Behandlung verschiedener Malignome wie Bronchial- und Blasenkarzinom, Neoplasien der Augen, Ovarien und der Haut durch eine Photodynamische Therapie mit Hypericin (Agostinis et al., 2002). Wegen der geringen Gewebepenetration von Licht ist eine PDT nur für oberflächliche Tumoren geeignet. Obwohl das renale Karzinom kein oberflächliches Malignom ist, kann es einer PDT mit Hypericin während einer Nephrektomie zugänglich gemacht werden, da die Tumor-Nephrektomie derzeit die Therapie der Wahl bei nicht metastasierten RCC ist. Bei etwa $20-50 \%$ der Patienten entwickeln sich lokale Rezidive oder Metastasen nach einer Nephrektomie (Lilleby und Fosså, 2005), daher könnte eine intraoperative PDT mit Hypericin das Risiko für lokale Rezidive verringern. Der mögliche Einsatz einer Photodynamischen Therapie mit Hypericin ist lokal beschränkt und eignet sich daher nicht für die Behandlung metastasierter Neoplasien. Möglicherweise könnte eine Strahlentherapie, mit der auch tief im Gewebe liegende Tumoren erfasst werden können, hier Abhilfe schaffen.

\subsection{Strahlensensitivierende Wirkung von Hypericin auf renale Karzinomzellen:}

Das renale Karzinom ist äußerst strahlenresistent, daher wird eine Strahlentherapie nicht kurativ sondern vor allem palliativ und symptomorientiert im Bereich der Schmerzreduktion und insbesondere bei Knochen- oder Hirnmetastasen eingesetzt. Eine Strahlensensitivierung von RCC-Zellen könnte hier möglicherweise das therapeutische Outcome verbessern. Daher wird in dieser Arbeit untersucht, ob Hypericin renale Karzinomzellen strahlensensitiviert. Um phototoxische Effekte des Hypericins auszuschließen, die eventuell fälschlicherweise strahlensensitivierende Effekte suggerieren könnten, werden alle Versuche zur Strahlensensitivierung unter Lichtausschluss 
durchgeführt. Im Rahmen dieser Arbeit kann eine strahlensensitivierende Wirkung von Hypericin auf renale Karzinomzellen nachgewiesen werden. Die Ergebnisse legen die Vermutung nahe, dass die strahlensensitivierenden Effekte von Hypericin auf renale Karzinomzellen nicht auf den gleichen Mechanismen beruhen wie bei einer Photodynamischen Therapie. Ein möglicher Grund dafür könnte sein, dass Hypericin durch eine Bestrahlung (Wellenlänge 5pm-10nm) nicht in gleicher Weise angeregt wird wie durch sichtbares Licht, da die Wellenlänge nicht mit den Absorptionsmaxima (548nm und 590nm) von Hypericin korrespondiert.

Im Rahmen dieser Arbeit kann gezeigt werden, dass eine Bestrahlung in renalen Karzinomzellen DNA-Doppelstrangbrüche (DSB) verursacht. Eine der ersten zellulären Reaktionen auf induzierte DSB ist die Phosphorylierung des Histons H2AX durch die Ataxia Telangiectasia Mutated- (ATM-) Kinase innerhalb der ersten drei Minuten nach Eintreten des Schadens. Daher gilt die phosphorylierte Form von $\mathrm{H} 2 \mathrm{AX}(\gamma \mathrm{H} 2 \mathrm{AX})$ als Marker für DSB (Taneja et al., 2004; Paull et al., 2000). Drei Stunden nach einer Bestrahlung mit 4Gy kann eine $\gamma \mathrm{H} 2 \mathrm{AX}-$ Fokus-Bildung in gleichem Ausmaß bei A498Zellen sowohl mit als auch ohne Hypericinbehandlung mittels Immunfluoreszenz nachgewiesen werden. Die Anzahl der $\gamma \mathrm{H} 2 \mathrm{AX}$-Foci bei Zellen ohne Hypericinbehandlung ist gegenüber hypericinbehandelten Zellen 24 Stunden nach einer 4Gy-Bestrahlung signifikant reduziert. Demnach scheint eine Bestrahlung zunächst gleich viele DSB in A498-Zellen mit und ohne Hypericinbehandlung zu induzieren. Jedoch nimmt die Anzahl der DSB mit zunehmender Zeit nach Bestrahlung bei Zellen ohne Hypericinbehandlung signifikant ab, während hypericinbehandelte Zellen weiterhin eine ausgeprägte $\gamma \mathrm{H} 2 \mathrm{AX}$ Fokus-Formation aufweisen. Taneja et al. (2004) beobachten ebenfalls zunächst eine gleichartige $\gamma \mathrm{H} 2 \mathrm{AX}$-Fokus-Bildung in strahlensensitiven und strahlenresistenten Tumorzellen in Folge einer Bestrahlung, wobei die $\gamma \mathrm{H} 2 \mathrm{AX}$-Foci länger in strahlensensitiven Tumorzellen nachweisbar sind. Demnach scheint die Persitenz von $\gamma \mathrm{H} 2 \mathrm{AX}$ nach einer Radiatio ein Indikator für das zelluläre Ansprechen auf die Bestrahlung zu sein.

Generell gibt es verschiedene Reaktionen von Zellen auf durch Bestrahlung induzierte Schäden. Sind die verursachten Schäden lethal, so kommt es zu einer Nekroseinduktion, die durch einen schnellen und vollständigen Funktionsverlust mit sofortigem Zelluntergang und in vivo mit einhergehender Entzündungsreaktion in der Umgebung gekennzeichnet ist. Bei sublethalen Schäden verbleiben die Zellen zunächst in einem Zellzyklusarrest vor allem in der G1- und G2-Phase um die DNA-Schäden zu reparieren. Nach erfolgter 
Reparatur, die innerhalb weniger Minuten bis Tage erfolgen kann, wird der reguläre Zellzyklus fortgeführt. Können die Schäden nicht oder nur fehlerhaft repariert werden, kommt es zu einer Apoptoseinduktion oder zum mitotischen (klonogenen) Zelltod. Intrinsische Strahlenresistenzen von Tumorzellen sind häufig auf defekte Zellzykluskontrollmechanismen oder verstärkte DNA-Reparaturmechanismen zurück zu führen (Blank et al., 2003).

Kongruent zur Theorie zeigen die hier ermittelten Daten, dass bestrahlte renale Karzinomzellen im Vergleich zur unbestrahlten Kontrolle am ersten Tag nach einer Bestrahlung vermehrt in der G0/G1- Phase und am dritten Tag vermehrt in der G2-Phase zu finden sind. Die Gruppe von Zellen (unspezifischer Rest), die aufgrund ihres hohen Propidiumiodidgehaltes keiner der Zellzyklusphasen eindeutig zugeordnet werden können, ist bei allen Versuchsbedingungen in einem großen Anteil (11-38\%) zu finden. Möglicherweise ist diese Gruppe von Zellen durch eine Polyploidie gekennzeichnet, die bei renalen Karzinomzellen beobachtet werden kann (siehe Abb. 39).

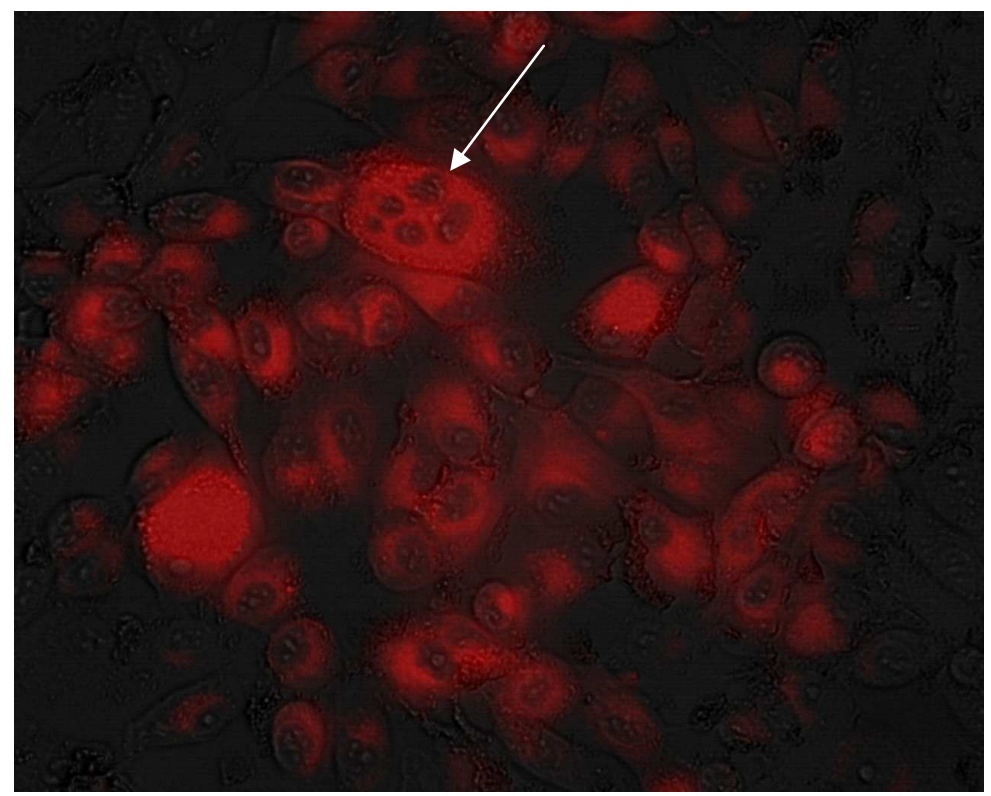

Abbildung 39: Polyploidie bei renalen Karzinomzellen (Zelllinie A498) (rote Fluoreszenz = Hypericin, Vergrößerung 400x).

Diese Zellen scheinen stärker von der Bestrahlung geschädigt zu werden, denn der prozentuale Anteil dieser Zellen nimmt sowohl am ersten als auch am dritten Tag nach der Bestrahlung gegenüber unbestrahlten Zellen ab. Die Ergebnisse der Zellzyklusanalyse liefern keinen Hinweis auf eine verstärkte Apoptoseinduktion in Folge von Bestrahlung, da der Anteil an Zellen, die sich in der subG1-Phase befinden, kaum zunimmt. Die Daten der Zellzyklusanalyse für hypericinbehandelte Zellen sind nicht auswertbar, da es vermutlich 
aufgrund der ähnlicher Fluoreszenzen von Propidiumiodid (Excitation: 488nm, Emission 630nm) und Hypericin (Excitation: 485nm, 600nm Emission 583nm, 595nm und 613nm ) zu einer Verfälschung der Ergebnisse kommt.

Eine Apoptoseinduktion in Folge einer Radiatio mit einer Dosis von 2Gy bzw. 4Gy ist lediglich in ca. 2,5\% bzw. ca. 5\% der A498-Zellen mit und ohne Hypericinbehandlung mittels TUNEL-Test nachweisbar. Die Apoptose ist demnach nicht die vorherrschende Form des Zelltodes von renalen Karzinomzellen nach einer Bestrahlung. Generell ist die Apoptose in Folge einer Bestrahlung hauptsächlich bei embryonalen oder hämatopoetischen Zellen zu finden, während in der Regel bei soliden Tumoren durch Bestrahlung der mitotische Zelltod induziert wird (Ross, 1999; Blank et al., 2003). Bei einem mitotischen Zelltod bleiben die zellulären Funktionen wie z.B. der Metabolismus über einen gewissen Zeitraum bestehen, jedoch verlieren die Zellen ihre Teilungsfähigkeit und gehen langfristig zugrunde. Die Ergebnisse dieser Arbeit lassen ebenfalls darauf schließen, dass in Folge von Bestrahlung der mitotische Zelltod in renalen Karzinomzellen induziert wird. Der Zellmetabolismus der Zellen nimmt unabhängig von Strahlendosis und Hypericinbehandlung vom ersten bis zum 13. Tag nach der Bestrahlung zu. Dabei ist jedoch die metabolische Aktivität von hypericinbehandelten Zellen um ca. 4-19\% nach einem Tag bzw. 30-50\% nach 13 Tagen gegenüber der metabolischen Aktivität von Zellen ohne Hypericinbehandlung erhöht. Die Ergebnisse aus dem Koloniebildungstest zeigen jedoch ein vermindertes klonogenes Überleben von A498-Zellen nach einer Bestrahlung besonders in Kombination mit einer Hypericinbehandlung. So beträgt z.B. die klonogene Überlebensrate von renalen Karzinomzellen nach einer 4Gy-Bestrahlung noch $22 \%$, während Zellen, die 24 Stunden vor der Bestrahlung bzw. vor und 12 Tage nach der Bestrahlung mit $50 \mu \mathrm{M}$ Hypericin behandelt werden lediglich eine klonogene Überlebensrate von $11 \%$ bzw. $2 \%$ aufweisen.

Zhang et al. (1996) weisen ähnliche strahlensensitivierende Effekte von Hypericin auf maligne Gliomzellen nach. So ist das klonogene Überleben nach Bestrahlung von hypericinbehandelten Gliomzellen signifikant gegenüber Zellen ohne Hypericinbehandlung erniedrigt. Im Gegensatz zu den in dieser Arbeit erhobenen Daten beobachten Zhang et al. zusätzlich eine hypericinabhängige Verringerung der metabolischen Aktivität nach Bestrahlung. Allerdings gibt es in der Publikation keinen Hinweis darauf, dass die Untersuchungen unter Lichtausschluss durchgeführt wurden. Daher könnten die Ergebnisse sowohl auf strahlensensitivierenden als auch auf 
phototoxischen Wirkungen von Hypericin beruhen. Weitere Arbeiten zu strahlensensitivierenden Effekten von Hypericin gibt es derzeit nicht.

Die in dieser Arbeit nachgewiesene ansteigende metabolische Aktivität bei gleichzeitig verminderter Teilungsfähigkeit von A498-Zellen insbesondere nach Hypericinbehandlung in Kombination mit Bestrahlung ist möglicherweise eine Stressreaktion der Zellen auf induzierte Strahlenschäden, die scheinbar nicht repariert werden können und damit zum mitotischen Zelltod führen. Bei halblogarithmischer Darstellung der Daten des Koloniebildungstests ergibt sich für die Dosis-Effekt-Beziehung von Zellen ohne Hypericinbehandlung eine so genannte Schulterkurve, deren Schulterbereich sublethale Strahlenschäden anzeigt, die von der Zelle repariert werden können. Die Überlebenskurven von hypericinbehandelten Zellen zeigen eine geringer ausgeprägte Schulter für Zellen, die mit Hypericin vorbehandelt wurden, und einen fast rein exponentiellen Verlauf für Zellen, die mit Hypericin vor- und nachbehandelt wurden. Diese Verläufe von Überlebenskurven sind generell bei Zellen zu beobachten, die aufgrund ihrer biologischen Konstitution (z.B. Gendefekte) Strahlenschäden nicht reparieren können oder deren Reparaturmechanismen durch zusätzliche Behandlung (z.B. Zytostatika) inhibiert werden. Demnach ist die strahlensensitivierende Wirkung des Hypericins vermutlich auf die Inhibition von Reparaturmechanismen in den sonst strahlenresistenten renalen Karzinomzellen zurück zu führen.

Intrinsische Strahlenresistenzen von Tumorzellen sind häufig auf defekte Zellzykluskontrollmechanismen oder verstärkte DNA-Reparaturmechanismen zurück zu führen (Blank et al., 2003). Insbesondere der Epidermale Wachstumsfaktor Rezeptor spielt eine wichtige Rolle für die DNA-Reparaturmechanismen in Folge von Bestrahlung und/oder oxidativem Stress (Dittmann et al., 2005a,b; Chen und Nirodi, 2007) und ist daher wichtig für die Radioprotektion eines Tumors. So korrelieren vermehrte EGFRExpression und -Aktivität mit einer erhöhten Tumorresistenz gegenüber einer Strahlentherapie (Chen und Nirodi, 2007; Baumann und Krause, 2004; Lo und Hung, 2006a). In renalen Karzinomzellen sind sowohl der EGF-Rezeptor als auch die Liganden EGF und TGF- $\alpha$ überexprimiert, was in einer unregulierten Aktivierung der EGFRvermittelten Signalkaskaden resultiert (Störkel, 2007; Khasawneh und Bukowski, 2007). Darüber hinaus ist generell eine direkte Aktivierung des EGFR durch Bestrahlung möglich. Die Inhibition der EGFR-Aktivität durch Hypericin könnte demnach ein Grund für die verstärkte Sensitivität von renalen Karzinomzellen sein. Auch andere Arbeitsgruppen zeigen eine Strahlensensitivierung von Kopf-Hals-Tumorzellen (z.B. HSC-Zellen, SCC- 
Zellen) in Folge einer Inhibition der EGFR-TK (Baumann und Krause, 2004). Im Rahmen dieser Arbeit kann mittels Westernblot gezeigt werden, dass die EGFR-Aktivität in renalen Karzinomzellen nach Radiatio tendenziell zunimmt, dabei ist die Aktivität von hypericinbehandelten Zellen immer geringer als die der Zellen ohne Hypericinbehandlung. Lediglich 24 Stunden nach der Bestrahlung ist die EGFR-Aktivität hypericinbehandelter Zellen gegenüber der Grundaktivität in Zellen ohne Hypericinbehandlung signifikant erniedrigt. Mittels quantitativer Echtzeit-PCR lässt sich ähnliches für die EGFRExpression nachweisen. Die EGFR-Expression nimmt nach Radiatio tendenziell zu, wobei die Expression in hypericinbehandelten Zellen immer geringer ist als in Zellen ohne Hypericinbehandlung, allerdings ist dieser Unterschied nur 24 Stunden nach Bestrahlung signifikant. Unterschiedliche Publikationen berichten von einer strikt lichtabhängigen inhibitorischen Wirkung von Hypericin auf die Tyrosinkinase des EGFR (Agostinis et al., 1995; de Witte et al., 1993). Des Weiteren beschreiben die Autoren, dass die inhibitorische Wirkung irreversibel ist. Möglicherweise werden die Tyrosinkinasen oder die Rezeptoren durch die durch photoaktiviertes Hypericin entstehenden ROS irreversibel geschädigt und daher irreversibel gehemmt. Ein phototoxischer Einfluss kann im Rahmen der hier vorliegenden Untersuchungen ausgeschlossen werden. Möglicherweise interagiert das Hypericin aufgrund seiner unspezifischen Affinität zu Proteinen mit dem EGFR. Eine Verringerung der EGFR-Aktivität könnte dadurch erklärt werden, dass das Hypericin tatsächlich die Tyrosinkinase direkt hemmt, den Rezeptor blockiert oder die TK-Domänen maskiert, so dass eine Homodimerisierung oder eine Trans-Phosphorylierung und damit eine Translokation verhindert wird. Der EGFR spielt eine wichtige Rolle im „,nonhomologous end-joining“-Reparatur-Mechanismus (NHIJ) strahleninduzierter Doppelstrangbrüche (Chen und Nirodi, 2007). Nach Aktivierung und Translokation zum Kern interagiert der EGFR mit der katalytischen Untereinheit DNA-PKC, die Zusammen mit den regulatorischen Untereinheiten Ku70 und Ku80 die Proteinkinase bildet. Des Weiteren initiiert der strahleninduzierte EGFR durch Aktivierung der Phospho-Inositol-3Kinase (PI3K) die PI3K/Akt-Kaskade, die zum einen die apoptotische Signalkaskade blockiert und zum anderen ebenfalls in einer Aktivierung der DNA-PKC resultiert (Toulany et al., 2007; Chen und Nirodi, 2007). Die Ergebnisse dieser Arbeit zeigen eine signifikant geringere Expression von PI3K in hypericinbehandelten Zellen vor und drei Stunden nach einer 4Gy-Bestrahlung, jedoch ist keine übermäßige Apoptoseinduktion durch Bestrahlung in hypericinbehandelten A498-Zellen nachweisbar. Viele Publikationen berichten, dass eine verstärkte Strahlenresistenz nicht auf ein vermehrte Apoptoseinduktion 
durch Blockierung der PI3K/Akt-Kaskade zurückzuführen ist, sondern eher auf eine verminderte Reparatur von DSB durch die Blockade der EGFR-vermittelten Signalwege (Dittmann et al., 2005a,b; Toulany et al. 2005). Die Hemmung oder Blockierung des EGFR führt letztlich dazu, dass die DNA-PKC im Zytoplasma verbleibt und nicht aktiviert wird (Rodemann et al., 2007). Die DNA-PKC wiederum ist aber essentiell für die Reparatur von DSB.

Die Ergebnisse des Westernblot zeigen eine gegenüber der unbehandelten Kontrolle erhöhte Aktivität der DNA-Proteinkinase C in renalen Karzinomzellen drei Stunden nach einer 4Gy-Bestrahlung. Dabei ist die DNA-PKC-Aktivität von hypericinbehandelten Zellen jedoch ca. 42\% geringer als die der Zellen ohne Hypericinbehandlung. Nach 24 Stunden ist die Aktivität bei Zellen ohne Hypericinbehandlung nur noch um $1 \%$ gegenüber der Kontrolle erhöht, während bei hypericinbehandelten Zellen die Aktivität signifikant vermindert ist. Zahlreiche Publikationen berichten von der lichtabhängigen inhibitorischen Wirkung des Hypericin auf Proteinkinase C (Kubin , 2005; Takahashi et al., 1989; Agostinis et al. 1995; Utsumi, 1995), doch auch wenige Publikationen weisen eine Dunkelwirkung von Hypericin auf PKC nach (Kubin, 2005). Virsik-Köpp et al. (2005) zeigen nach Bestrahlung eine verstärkte Chromosomen-Aberration in strahlenresistenten WiDr-Tumorzellen in Folge einer Hemmung der DNA-PKC-Aktivität durch Wortmannin. Um diesen Effekt zu erzielen ist eine Anwesenheit des PKC-Inhibitors während der Bestrahlung nicht nötig, jedoch ist eine Wortmannin-Zugabe bis spätestens eine Stunde nach der Bestrahlung essentiell. Ein ähnlicher zeitabhängiger Effekt kann im Rahmen dieser Arbeit ebenfalls gezeigt werden. So ist nach einer Bestrahlung das klonogene Überleben von A498-Zellen, die 24 Stunden vor der Bestrahlung mit Hypericin inkubiert wurden, zwar schon gegenüber dem der Zellen ohne Hypericinbehandlung vermindert, jedoch zeigen renale Karzinomzellen, die auch nach der Radiatio mit Hypericin inkubiert werden ein viel geringeres klonogenes Überleben. Demnach ist die strahlensensitivierende Wirkung von Hypericin möglicherweise auf die Verringerung der PKC-Aktivität zurück zu führen. Schon eine geringe Abnahme der DNA-PKC-Aktivität führt zu einer verminderten Reparaturkapazität und damit zu einer Verstärkung der zellulären Strahlensensitivität (Rodemann et al. 2007).

Des Weiteren zeigen die Ergebnisse, dass die Expression von DNA-PKC, Ku70 und Ku80 in hypericinbehandelten Zellen vor und drei Stunden nach einer 4Gy-Bestrahlung vermindert ist, während die Expression bei Zellen ohne Hypericinbehandlung nach Radiatio zunimmt. Shintani et al. (2003) zeigen ebenfalls eine verminderte Expression von 
DNA-PKC, Ku70 und Ku80 in oralen Karzinomzellen (HSC2 und HSC3) in Folge einer Bestrahlung in Kombination mit dem EGFR-Inhibitor Gefitinib. Die regulatorischen Untereinheiten Ku70 und Ku80 haben eine hohe Affinität zu DNA-Enden, binden als Heterodimer an diese und rekrutieren dann die DNA-Proteinkinase C. Der Komplex bestehend aus Ku70, Ku80 und DNA-PKC verhindert zunächst den vorschnellen Abbau der DNA durch Exonucleasen. Die DNA-PKC wird durch Bindung an DSB-Enden und u. a. durch Interaktion mit ATM, AKT oder EGFR phosphoryliert (Chen und Nirodi, 2007). Kim et al. (2002) zeigen, dass nach Blockierung der Ku80-Bindungsdomäne von Mammakarzinomzellen z.B. durch ein Peptid weder eine Bindung des Ku70/Ku80Komplexes an die DSB-Enden noch eine Bindung an die DNA-PKC erfolgt. Eine Aktivität der DNA-PKC ist in einem solchen Fall noch vorhanden, jedoch ist diese um ca. 50\% gegenüber der Kontrolle ohne Blockierung der Bindungsdomäne vermindert. Aufgrund seiner unspezifischen Affinität zu Proteinen wäre es möglich, dass Hypericin ebenfalls an den Ku70/Ku80-Komplex bindet, die Ku80-Bindungsdomäne maskiert und dadurch die DNA-PKC-Aktivität in renalen Karzinomzellen reduziert. Allerdings kann eine Lokalisation von Hypericin im Kern renaler Karzinomzelle im Rahmen dieser Arbeit nicht nachgewiesen werden, daher ist eine Interaktion von Hypericin mit dem Ku70/Ku80Komplex eher unwahrscheinlich.

Durch die Phosphorylierung löst sich die DNA-PKC von den Enden der Doppelstrangbrüche (DSB) und ermöglicht die Aktivierung und Bindung des ArtemisRad50-Mre11-Nbs1-Komplexes an die DSB. Der Komplex prozessiert durch seine Aktivitäten als Exonuklease, Endonuklease und Helicase die DNA-Enden und stabilisiert zusammen mit $\mathrm{Ku}$ die End-zu-End-Verbindung (De Jager et al. 2001, McElhinny et al. 2000, Walker et al. 2001). Dies ist Voraussetzung für die anschließende Verknüpfung der DNA-Enden durch den XRCC4 - Ligase IV - Komplex und damit letztlich für die Reparatur der DSB (Leber et al. 1998). Die Expression von XRCC4 in renalen Karzinomzellen ohne Hypericinbehandlung ist drei Stunden nach Bestrahlung erhöht und nach 24 Stunden wieder annähernd auf dem Niveau der unbestrahlten Kontrolle. DSB werden bei strahlenresistenten Zellen bereits innerhalb weniger Stunden nach der Bestrahlung repariert, insofern wird in dieser Zeit eine vermehrte Menge von XRCC4 benötigt und demnach vermehrt exprimiert. Nach 24 Stunden ist die DSB-Reparatur in der Regel abgeschlossen, daher nimmt die XRCC4-Expression wieder ab. Bei den hypericinbehandelten Zellen nimmt die XRCC4-Expression ebenfalls innerhalb der ersten drei Stunden nach Radiatio zu, nach 24 Stunden wird XRCC4 noch stärker exprimiert. 
Dies lässt sich möglicherweise dadurch erklären, dass aufgrund der inhibierten DNAReparatur noch vermehrt DSB zu diesem Zeitpunkt vorliegen und die Zelle als Reaktion darauf vermehrt Gene exprimiert, die für wichtige Proteine kodieren, die eine wichtige Rolle in der DNA-Reparatur spielen wie z.B. XRCC4, Ku80, DNA-PKC. Die Expression der in dieser Arbeit untersuchten Proteine ist in hypericinbehandelten A498-Zellen innerhalb der ersten drei Stunden häufig zumindest leicht geringer als in renalen Karzinomzellen ohne Hypericinbehandlung. Ein möglicher Grund dafür könnte eine zeitlich verzögerte oder verminderte NF- $\mathrm{B}$-vermittelte Transkription sein. Der Transkriptionsfaktor NF- $\kappa \mathrm{B}$ liegt generell durch Bindung an inhibitorische $\kappa \mathrm{B}$-Proteine $(\mathrm{I} \kappa \mathrm{B} \alpha)$ inaktiviert im Zytoplasma vor. Aufgrund seiner geringen Spezifität und seiner schnellen Aktivierbarkeit (z.B. durch Bestrahlung) ist NF-kB an der schnellen Regulation wichtiger zellulärer Prozesse und unter anderem an der Radioprotektion maligner Zellen beteiligt. So kann die Strahlensensitivität maligner Zellen durch die Inhibition der NF-кBAktivität erhöht werden (Magné et al., 2005). Pajonk et al. (2005) zeigen, dass Hypericin

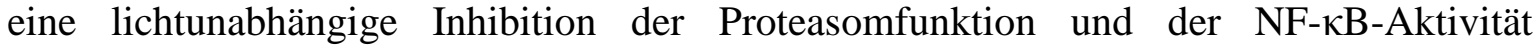
verursacht. Möglicherweise bindet das Hypericin aufgrund der unspezifischen Affinität zu Proteinen an NF- $\kappa \mathrm{B}$ oder die inhibitorische $\kappa \mathrm{B}$-Proteine und verhindert oder verzögert die Phosphorylierung der $\kappa \mathrm{B}$-Proteine und damit die schnelle Aktivierung und Translokation von $\mathrm{NF}-\kappa \mathrm{B}$.

Im Rahmen dieser Arbeit kann erstmals ein strahlensensitivierender Effekt von Hypericin auf renale Karzinomzellen nachgewiesen werden. Dieser beruht vermutlich auf der Inhibition von DNA-Reparaturmechanismen. Die Ergebnisse geben erste Hinweise darauf, dass Hypericin die Expression bzw. Aktivität verschiedener an den Reparaturmechanismen beteiligter Proteine verringert bzw. verlangsamt und dadurch möglicherweise zu einem verminderten klonogenen Überleben von renalen Karzinomzellen in Folge von Bestrahlung beiträgt. Die Wirkungen sind sicherlich vielfältig und erfordern weitere Untersuchungen insbesondere funktionelle Untersuchungen auf Proteinebene. 


\section{Zusammenfassung:}

Das Gewöhnliche Johanniskraut (Hypericum perforatum L.) ist eine seit der Antike bekannte Heilpflanze. Einer seiner Inhaltsstoffe, das so genannte Hypericin, ist namensgebend für diese Pflanzengattung und wird in speziellen Drüsen auf Blütenblättern und Blättern produziert. Es dient der Pflanze als Fraßschutz, denn nach Aufnahme führt es in Organismen bei gleichzeitiger Lichtexposition zu massiven Zellschäden entsprechender Regionen. Des Weiteren gibt es aktuell auch erste Hinweise darauf, dass Hypericin ein Multikinasehemmer zu sein scheint. Die lichtsensibilisierende (photosensibilisierende) Wirkung beruht auf intrazellulärem oxidativen Stress, der durch die Bildung von u. a. Singulettsauerstoff ausgelöst wird, während die Multikinase-inhibitorische Wirkung vermutlich auf eine direkte Interaktion des Hypericins mit Proteinen zurückzuführen ist.

In dieser Arbeit sollen erstmals die photosensibilisierenden und Multikinaseinhibitorischen Effekte von Hypericin auf Zellen des humanen renalen Karzinoms in vitro untersucht werden.

Hypericin wird binnen einer Minute am ehesten durch Diffusion in renalen Karzinomzellen aufgenommen. Es akkumuliert danach vor allem im Endoplasmatischen Retikulum und den Mitochondrien, jedoch nicht im Zellkern. Nach intrazellulärer Aufnahme zeigt es eine intensive und stabile rote Fluoreszenz, die auch noch nach 48 Stunden nachweisbar bleibt. Dabei ist besonders erwähnenswert, dass RCC-Zellen physiologisch eine hohe Expression von sog. MDR-Transportern (Multi-Drug-Resistance) aufweisen, die effektiv chemische Noxen (z.B. Medikamente) aus den Zellen schleusen. Sie sind u. a. für eine Resistenz der Zellen gegenüber Zytostatika verantwortlich. Hypericin scheint diesem Mechanismus zu entgehen und verlangsamt darüber hinaus den Transport von spezifischen MDR-Substraten wie z.B. dem Farbstoff Rhodamin-123 (in hypericinbehandelten Zellen wird nach drei Stunden 10\% mehr Rhodamin-123 im Vergleich zur Kontrolle nachgewiesen).

Eine Hypericinbehandlung renaler Karzinomzellen in Kombination mit einer Beleuchtung, führt schon bei geringen Konzentrationen $(1 \mu \mathrm{M})$ zu einem signifikanten Rückgang der metabolischen Aktivität und Koloniebildungsfähigkeit. Des Weiteren wird in 100\% der Zellen eine Apoptose induziert. Diese phototoxischen Wirkungen werden durch oxidativen Stress hervorgerufen. Die intrazelluläre Bildung des oben erwähnten Singulettsauerstoffs spielt dabei die Schlüsselrolle. Letzterer wird hier erstmals mit Hilfe eines redoxsensitiven Fluoreszenzfarbstoffs (roGFP) intrazellulär in lebenden Zellen nachgewiesen. 
Eine Hypericinbehandlung im Dunkeln dagegen hat selbst bei hohen Konzentrationen $(25 \mu \mathrm{M}, 50 \mu \mathrm{M})$ keine toxischen Effekte auf renale Karzinomzellen. Die metabolische Aktivität ist im Vergleich zur unbehandelten Kontrolle nach einem Tag signifikant $(\mathrm{p}<0,01)$ erhöht. Die Koloniebildungsfähigkeit ist unbeeinflusst, und eine Apoptose wird nicht induziert.

Unter der Annahme, dass Hypericin ein Multikinase-Inhibitor sei, werden Versuchsbedingungen in Kombination mit Bestrahlung durchgeführt, da Strahlenschadenreparaturmechanismen u. a. kinaseabhängige Vorgänge sind. In diesem Zusammenhang steigert Hypericin die Empfindlichkeit der bekanntermaßen sehr strahlenresistenten renalen Karzinomzellen. Es zeigt sich, dass Hypericin die Koloniebildungsfähigkeit renaler Karzinomzellen nach einer 2Gy Bestrahlung um ca. 44\% und nach einer 4Gy-Bestrahlung um ca. $20 \%$ gegenüber der bestrahlten Kontrolle vermindert. Die metabolische Aktivität der Zellen nimmt mit zunehmender Zeitspanne nach der Bestrahlung zu. Dabei sind hypericinbehandelte Zellen z.B. nach 13 Tagen signifikant metabolisch aktiver $(30-50 \%, \mathrm{p}<0,01)$ als Zellen ohne Hypericinbehandlung. Eine Apoptoseinduktion in Folge einer Radiatio mit einer Dosis von 2Gy bzw. 4Gy kann lediglich in ca. 2,5\% bzw. ca. 5\% der Zellen unabhängig von der Hypericinbehandlung nachgewiesen werden. Diese Ergebnisse lassen darauf schließen, dass eine Bestrahlung in Kombination mit Hypericin den mitotischen Zelltod renaler Karzinomzellen induziert. Bei einem mitotischen Zelltod bleiben die zellulären Funktionen wie z.B. der Metabolismus über einen gewissen Zeitraum bestehen, jedoch verlieren die Zellen aufgrund irreparabeler Strahlenschäden ihre Teilungsfähigkeit und gehen längerfristig zugrunde. Dabei spielen insbesondere strahleninduzierte DNA-Doppelstrangbrüche (DSB) eine wichtige Rolle. In dieser Arbeit werden drei Stunden nach einer 4Gy-Bestrahlung Doppelstrangbrüche (Detektion über Fluoreszenzmarkierung von $\gamma \mathrm{H} 2 \mathrm{AX}$-Foci) in ca. $80 \%$ der renalen Karzinomzellen nachgewiesen. In Folge von DNA-Reparaturmechanismen weisen nach 24 Stunden lediglich noch $20 \%$ der Zellen DSB auf. Bestrahlt man die Zellen dagegen in Kombination mit einer Hypericinbehandlung ist die Situation drei Stunden nach Strahlenexposition vergleichbar, jedoch nach 24 Stunden zeigt sich ein gänzlich anderes Bild, da DSB noch in $76 \%$ der hypericinbehandelten Zellen nachweisbar sind. Demnach scheint Hypericin die DNA-Reparaturmechanismen in renalen Karzinomzellen zu inhibieren. Ausgehend von der Annahme, dass der erzielte Effekt auf der Hemmung von an der DNA-Reparatur beteiligten Signaltransduktionskaskaden beruht, werden die Expression und Aktivität u. a. von epidermalen Wachstumsfaktor-Rezeptoren (EGFR) und 
DNA-Proteinkinase C (PKC) untersucht, die eine wichtige Rolle in den DNAReparaturmechanismen spielen. Es zeigt sich, dass in hypericinbehandelten Zellen drei Stunden nach einer 4Gy-Bestrahlung 40\% bzw. 24 Stunden danach ca. 96\% weniger EGFR aktiviert vorliegt als in bestrahlten Kontrollzellen. Des Weiteren wird 24h nach der Bestrahlung in hypericinbehandelten Zellen im Vergleich zur bestrahlten Kontrolle signifikant weniger EGFR exprimiert $(\mathrm{p}<0,05)$. Eine Hemmung oder Blockierung des EGFR führt letztlich dazu, dass die für die Reparatur von DSB essentielle DNA-PKC vermindert aktiviert wird (Rodemann et al., 2007). Die Ergebnisse sind zu dieser Theorie kongruent, denn in hypericinbehandelten Zellen ist drei bzw. 24 Stunden nach einer Bestrahlung signifikant $(\mathrm{p}<0,05)$ weniger aktive DNA-PKC nachweisbar als in den Kontrollzellen. Des Weiteren werden in hypericinbehandelten Zellen vor bzw. drei Stunden nach einer 4Gy-Bestrahlung im Vergleich zur Kontrolle signifikant weniger $(\mathrm{p}<0,05$ und $\mathrm{p}<0,01)$ der für die Aktivierung der DNA-PKC nötigen regulatorischen Untereinheiten Ku70 und Ku80 exprimiert. Schon eine geringe Abnahme der DNA-PKCAktivität führt zu einer verminderten Reparaturkapazität und damit zu einer Verstärkung der zellulären Strahlensensitivität (Rodemann et al. 2007).

Im Rahmen dieser Arbeit kann erstmals ein signifikanter strahlensensitivierender Effekt von Hypericin auf renale Karzinomzellen nachgewiesen werden. Dieser beruht vermutlich auf der Inhibition von DNA-Reparaturmechanismen. Die Ergebnisse geben erste Hinweise darauf, dass Hypericin die Expression bzw. Aktivität verschiedener an den Reparaturmechanismen beteiligter Proteine verringert bzw. verlangsamt und dadurch möglicherweise $\mathrm{zu}$ einem verminderten klonogenen Überleben von renalen Karzinomzellen in Folge von Bestrahlung und damit zu einer Strahlensensitivierung beitragen könnte. 


\section{Abkürzungsverzeichnis:}

\begin{tabular}{|c|c|}
\hline $5-\mathrm{FU}$ & 5-Fluorouracil \\
\hline Apaf-1 & apoptotischer Protease-Aktivierungsfaktor-1 \\
\hline ATM & Ataxie-Teleangiektasie mutiert (ataxia teleangiectatica mutated) \\
\hline ATP & Adenosintriphosphat \\
\hline BIP & $\begin{array}{l}\text { Immunglobulin-bindendes Protein }=\text { GRP78 Glucose-regulierendes Protein } \\
78\end{array}$ \\
\hline BSA & Bovines Serumalbumin \\
\hline CAIX & Kohlenstoff-Anhydrase IX (carbonic anhydrase IX), \\
\hline $\mathrm{CO}_{2}$ & Kohlendioxid \\
\hline $\mathrm{Ct}$ & Schwellenwert-Zyklus (treshold cycle) \\
\hline DAPI & 4’,6-Diamidino-2-Phenylindol \\
\hline DED & Todeseffektordomäne (death effector domain) \\
\hline DNA & Desoxyribonucleinsäue \\
\hline DSB & Doppelstrangbruch \\
\hline DTT & Dithiothreitol \\
\hline EGF & Epidermaler Wachstumsfaktor (epidermal growth factor) \\
\hline EGFR & Epidermaler Wachstumsfaktor-Rezeptor (epidermal growth factor receptor) \\
\hline EtOH & Ethanol \\
\hline Facs & $\begin{array}{l}\text { Fluoreszenzaktiviertes Sortieren von Zellen (fluorescence activated cell } \\
\text { sorting) }\end{array}$ \\
\hline FADD & Fas assoziiertes Protein mit Todesdomäne \\
\hline FITC & Fluoresceinisothiocyanat \\
\hline GFP & grün fluoreszierendes Protein \\
\hline HIF & Hypoxie-induzierter Transkriptionsfaktor (hypoxia inducible factor) \\
\hline Hyp & Hypericin \\
\hline IF- $\alpha$ & Alpha-Interferon \\
\hline $\operatorname{IgG}$ & Immunglobulin $\mathrm{G}$ \\
\hline IL-2 & Interleukin-2 \\
\hline MDR & multi drug resistence \\
\hline MTT & 3-[4,5-Dimethylthiazol-2-yl]-,5-diphenyl Tetrazoliumbromid \\
\hline NHIJ & nicht homologe End-zu-End-Verbindung (non homologous end-joining) \\
\hline $\mathrm{nm}$ & Nanometer \\
\hline NTC & Kontrolle ohne Probe (no template control) \\
\hline PBS & Phosphat gepufferte Salzlösung (phosphate buffered saline) \\
\hline PCR & Polymerase-Ketten-Reaktion (polymerase chain reaction) \\
\hline PDGF & Platelet-derived Wachstumsfaktor (platelet-derived growth factor) \\
\hline PDT & Photodynamische Therapie \\
\hline Pgp & P-Glykoprotein \\
\hline PI3K & Phosphatidylinositol 3-Kinase \\
\hline PKA & Proteinkinase A \\
\hline PKC & Proteinkinase $\mathrm{C}$ \\
\hline pVHL & von Hippel-Lindau-Genprodukt \\
\hline
\end{tabular}


Abkürzungsverzeichnis

\begin{tabular}{|l|l|}
\hline PVP & Polyvinylpropylen \\
\hline RCC & Nierenzellkarzinom (renal cell carcinoma) \\
\hline roGFP & $\begin{array}{l}\text { redoxsensitives grün fluoreszierendes Protein (redoxsensitive green } \\
\text { fluorescence protein) }\end{array}$ \\
\hline ROS & Reaktive Sauerstoffspezies (reactive oxygen species) \\
\hline RPM & Umdrehungen pro Minute (rounds per minute) \\
\hline RTx & Bestrahlung \\
\hline TGF & Transformierender Wachstumsfaktor (transforming growth factor) \\
\hline TK & Tyrosinkinase \\
\hline TNF & Tumornekrosefaktor \\
\hline TRADD & TNF-Rezeptor assoziierte Protein \\
\hline $\begin{array}{l}\text { TSC2- } \\
\text { Gen }\end{array}$ & Tuberosklerose-Gen-2 \\
\hline TUNEL & Terminal deoxynucleotidyl transferase-dUTP-nick-end-labeling \\
\hline VEGF & $\begin{array}{l}\text { Vaskulärer endothelialer Wachstumsfaktor (vascular endothelial growth } \\
\text { factor), }\end{array}$ \\
\hline VHL & von Hippel-Lindau \\
\hline XRCC4 & X-ray repair cross complementing \\
\hline
\end{tabular}




\section{Abbildungsverzeichnis:}

Abbildung 1: Blüte (A, B) und Blätter (C, D) des Gewöhnlichen Johanniskrauts

(Hypericum perforatum $\mathrm{L}$. .).

Abbildung 2: Chemische Struktur des nativen Hypericins. ................................................. 3

Abbildung 3: Excitations- und Emissionsspektrum von Hypericin (Head et al., 2006), .... 6

Abbildung 4: Jablonski-Diagramm. ............................................................................... 7

Abbildung 5: Schematische Darstellung der bei einer Apoptose ablaufenden extrinsischen

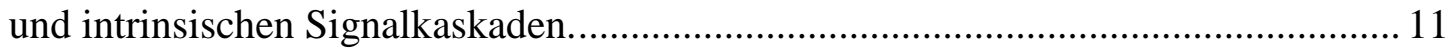

Abbildung 6: Schema der EGFR-vermittelten Signaltransduktionskaskaden. ................... 15

Abbildung 7: Schema zur EGFR-vermittelten Strahlenprotektion. ................................... 16

Abbildung 8: DNA-Reparatur durch nicht homologes End-Joining (NHIJ ........................ 17

Abbildung 9: Allgemeines Schema zum Aufbau eines Fluoreszenzmikroskopes. .............. 33

Abbildung 10: Lichtspektrum der HQI ${ }^{\circledR}$-TS-Lampe (Osram, München, Deutschland) ..... 38

Abbildung 11: Allgemeine Darstellung einer Dosis-Effekt-Beziehung nach Bestrahlung. 47

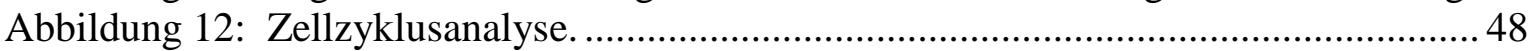

Abbildung 13: Fluoreszenzmikroskopische Bilder des Hypericin-Efflux aus renalen

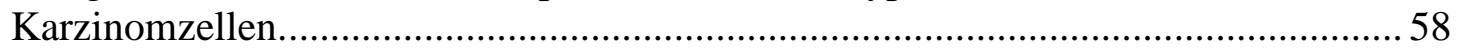

Abbildung 14: Hypericin-Influx und-Efflux in bzw. aus humanen renalen

Karzinomzellen.

Abbildung 15: Fluoreszenzbilder zur Akkumulation von Hypericin im Endoplasmatischen

Retikulum in renalen Karzinomzellen

Abbildung 16: Akkumulation von Hypericin im Endoplasmatischen Retikulum in renalen

Karzinomzellen.

Abbildung 17: Kolokalisation von Hypericin mit den Mitochondrien.

Abbildung 18: Fluoreszenzbilder zum Rhodamin-123-Efflux aus humanen renalen Karzinomzellen.

Abbildung 19: Rhodamin-123-Efflux aus humanen renalen Karzinomzellen mit und ohne Hypericin-Behandlung.

Abbildung 20: Dunkelwirkung von Hypericin auf die metabolische Aktivität von renalen Karzinomzellen

Abbildung 21: Wirkung von photoaktiviertem Hypericin auf die metabolische Aktivität von renalen Karzinomzellen.

Abbildung 22: Dunkelwirkung von Hypericin auf die Koloniebildungsfähigkeit von renalen Karzinomzellen.

Abbildung 23: Apoptosenachweis in hypericinbehandelten A498-Zellen mittels TUNELTest.

Abbildung 24: Testmessung zur Überprüfung der Funktionalität des roGFP und zur Ermittlung der Baseline des intrazellulären Redoxzustandes von mit roGFP transfizierten A498-Zellen.

Abbildung 25: Messung des intrazellulären Redoxzustandes von mit roGFP transfizierten A498-Zellen nach Hypericinaplikation in Kombination mit Beleuchtung.. 70

Abbildung 26: Messung des intrazellulären Redoxzustandes von mit roGFP transfizierten A498-Zellen nach 24-stündiger Vorinkubation mit $10 \mu \mathrm{M}$ Hypericin.

Abbildung 27: Strahlensensibilisiernde Wirkung von Hypericin auf den Zellmetabolismus von renalen Karzinomzellen.

Abbildung 28: Exemplarischer Apoptosenachweis mittels TUNEL-Test in A498-Zellen nach Bestrahlung.

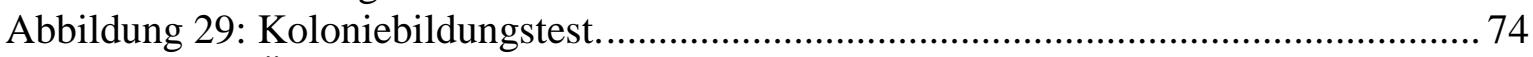

Abbildung 30: Überlebenskurve von renalen Karzinomzellen nach Radiatio.................... 75 
Abbildung 31: Durchflusszytometrische Zellzyklusanalyse von renalen Karzinomzellen

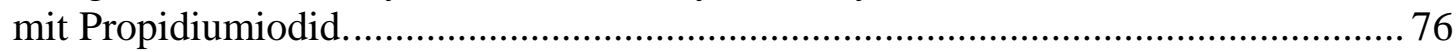

Abbildung 32: Zellzyklusverteilung von A498-Zellen 1 Tag (A, C) und 3 Tage (B, D) nach einer Bestrahlung (0Gy-8Gy) ohne (A, B) bzw. in Kombination mit (C, D) einer

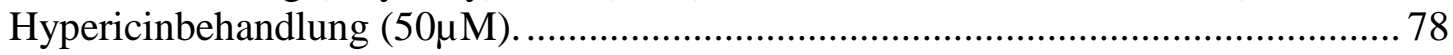

Abbildung 33: Fluoreszenzmikroskopische Bilder zum Nachweis strahleninduzierter Doppelstrangbrüche in renalen Karzinomzellen ........................................................ 79

Abbildung 34: Nachweis strahleninduzierter Doppelstrangbrüche in A498-Zellen mittels Immunfluoreszenz. 80

Abbildung 35: Expression und Aktivität der Epidermalen Wachstumsfaktor Rezeptoren in

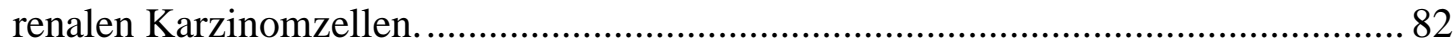

Abbildung 36: Aktivität der DNA-Proteinkinase C in renalen Karzinomzellen.................. 84

Abbildung 37: Relative Expression von DNA-Proteinkinase $\mathrm{C}$ und den regulatorischen

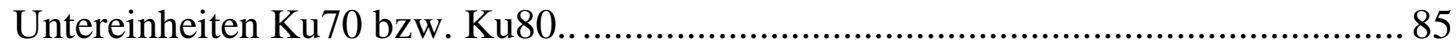

Abbildung 38: Relative Expression von X-Ray Repair Cross Complementing-Faktor-4 und Phosphoinositol-3-Kinase in renalen Karzinomzellen. ................................................ 87

Abbildung 39: Polyploidie bei renalen Karzinomzellen . ................................................... 96 


\section{Tabellenverzeichnis:}

Tabelle 1: Eingesetzte Ausgangszellzahl zur Bestimmung des klonogenen Überlebens von A498-Zellen nach Bestrahlung mit verschiedenen Strahlendosen.

Tabelle 2: Zusammensetzung der Trenn- bzw. Sammelgele für die Proteingelelektophorese

Tabelle 3: Hypericin-Influx und -Efflux in bzw. aus humanen renalen Karzinomzellen... 59

Tabelle 4: Akkumulation von Hypericin und dem Endoplasmatischen Retikulum in renalen Karzinomzellen

Tabelle 5: Rhodamin-123-Efflux aus humanen renalen Karzinomzellen.. 64

Tabelle 6: Verhältnis der Fluoreszenzintensitäten bei 395nm/470nm für A498-Zellen im regulären Redoxzustand (Baseline), nach Zugabe von 10 $\mu \mathrm{M}$ Hypericin-EtOH in Kombination mit einer 10-minütigen Beleuchtung und nach Zugabe von $5 \mathrm{mM} \mathrm{H}_{2} \mathrm{O}_{2}$.

Tabelle 7: Klonogenes Überleben von renalen Karzinomzellen nach Radiatio.

Tabelle 8: Zellzyklusverteilung von A498-Zellen 1 Tag (oben) und 3 Tage (unten) nach einer Bestrahlung (0Gy-8Gy) ohne (links) bzw. in Kombination mit (rechts) einer Hypericinbehandlung $(50 \mu \mathrm{M})$.

Tabelle 9: Expression und Aktivität der Epidermalen Wachstumsfaktor Rezeptoren in renalen Karzinomzellen.

Tabelle 10: Aktivität der DNA-Proteinkinase $\mathrm{C}$ in renalen Karzinomzellen.

Tabelle 11: Relative Expression von von DNA-Proteinkinase C und den regulatorischen Untereinheiten Ku70 bzw. Ku80.

Tabelle 12 Relative Expression von X-Ray Repair Cross Complementing-Faktor-4 und Phosphoinositol-3-Kinase in renalen Karzinomzellen. 


\section{Literaturverzeichnis:}

Agostinis P., Vandenbogaerde A., Donella-Deana A., Pinna LA., Lee KT., Goris J., Vandenheede JR., Merlevede W. und De Witte PA. (1995) Photosensitized inhibition of growth factor regulated protein kinases by hypericin. Biochem. Pharmacol. 49(11), 1615-1622.

Agostinis P., Assefa Z., Vantieghem A., Vandenheede JR., Merlevede W. und De Witte PA. (2000) Apoptotic and anti-apoptotic signaling pathways induced by photodynamic therapy by hypericin. Adv. Enzyme Regul. 40, 157-182.

Agostinis P., Vantieghem A., Merlevede W. und De Witte PA. (2002): Hypericin in cancer treatment: more light on the way. The International Journal of Biochemistry \& Cell Biology, 34, 221-241.

Alecu M., Ursaciuc C., Halalau F., Coman G., Merlevede W., Waelkens E. und De Witte PA. (1998) Photodynamic treatment of basal cell carcinoma and squamos cell carcinoma with hypericin. Anticancer Research 18(6B), 4651-5654.

Ali SM. und Olivo M. (2002) Bio-distribution and subcellular localization of Hypericin and its role in PDT induced apoptosis in cancer cells. International Journal of Oncology 21, 531-540.

Ali SM. und Olivo M. (2003) Mechanisms of action of phenanthroperylenquinones in photodynamic therapy. Int. J. Oncol. 22(6), 1181-91.

Anker L., Gopalakrishna R., Jones KD., Law RE. und Couldwell WT. (1995) Hypericin in adjuvant brain tumor therapy. Drugs of Future 20(5), 511-517.

Barnes J., Anderson LA. und Phillipson J. (2001) St John’s wort (Hypericum perforatum L.): a review of its chemistry, pharmacology and clinical properties. Journal of Pharmacy and Pharmacology 53, 583-600.

Baumann M. und Krause M. (2004) Targeting the epidermal growth factor receptor in radiotherapy: radiobiological mechanisms, preclinical and clinical results. Radiotherapy and Oncology 72, 257-266.

Blank M., Mandel M., Keisari Y., Meruelo D. und Lavie G (2003) Enhanced ubiquitinylation of heat shock protein 90 as a potential mechanism for mitotic cell death in cancer induced with Hypericin. Cancer Research 63, 8241-8247. 
Bradford M. (1976) A rapid and sensitive method for the quantification of microgram quantitits of protein utilizing the priciples of protein-dye binding. Anal. Biochem. 72, 248-254.

Brockmann H., Falkenhausen EH. und Dolares A. (1950) Naturwissenschaften 37, 540.

Brockmann H., Haschad MN., Maier K. und Pohl F. (1939) Naturwissenschaften 32: 550.

Brockmann H., Pohl F., Maier K. und Haschad MN. (1942) Ann. Chem 553, 1-52.

Buentig N., Störkel S. und Atzpodien J. (2002) Molekulargenetische Veränderungen im Nierenzellkarzinom. Urologe (A) 41, 475-481.

Cao H., Lei ZM., Bian L. und Rao CV. (1995) Functional nuclear epidermal growth factor receptors in human choriocarcinoma JEG-3 cells and normal human plazenta. Endocrinology 136, 3163-3172.

Chaloupka R., Obsil T., Plasek J. und Sureau F. (1999) The effect of hypericin and hyprocellin-A on lipid membranes and membrane potential of 3T3 fibroblasts. Biochem. Biophys. Acta 1418 (1), 39-47.

Chen B. und De Witte PA. (2000) Photodynamic therapy efficacy and tissue distribution of hypericin in a mouse P388 lymphoma tumor model. Cancer Lett. 150, 111-117.

Chen B., Zupko I. und De Witte PA. (2001a) Photodynamic therapy by hypericin in a mouse P388 tumor model: vascular effects determine the efficacy. Int. J. Oncol. 18, 737-742.

Chen B., Xu Y., Roskams T., Delaey E., Agostinis P., Vandenheede JR. und De Witte PA. (2001b) Efficacy of antitumoral photodynamic therapy by hypericin: relatioship between biodistribution and photodynamic effects in the RIF-1 mouse tumor model. Int. J. Cancer 93, 75-282.

Chen B., Roskams T. und De Witte PA. (2002) Antivascular tumor eradication by hypericin-mediated photodynamic therapy. Photochem. Photobiol. 76, 509-513.

Chen DJ. und Nirodi CS. (2007) The Epidermal Growth Factor Receptor: A Role in Repair of Radiation-Induced DNA-Damage. Clin Cancer Res 13(22), 6555-6560.

Conaway JW., Kamura T. und Conaway RC. (1998) The Elongin BC complex and the von Hippel-Lindau tumor suppressor protein. Biochem Biophys Acta 1377, M49-54.

De Jager M., van Noort J., van Gent DC., Dekker C., Kanaar R. und Wyman C. (2001) Human Rad50/Mre11 is a flexible complex that can tether DNA ends. Mol Cell 8, 1129-1135. 
De Witte P., Agostinis P., Van Lint J., Merlevede W. und Vandenheede JR. (1993) Inhibition of epidermal growth factor receptor tyrosine kinase activity by hypericin. Biochem Pharmacol 46(11), 1929-1936.

D’Hallewin MA., De Witte P., Waelkens E., Merlevede W. und Baert L. (2000) Fluorescence detection of flat bladder carcinoma in situ after intravesical instillation of hypericin. J Urol 164(2), 349-351.

Dittmann K., Mayer C., Fehrenbacher B., Schaller M., Raju U., Milas L., Chen DJ., Kehlbach R. und Rodemann HP. (2005a) Radiation-induced epidermal growth factor receptor nuclear import is linked toactivation of DNA-dependent protein kinase. J Biol Chem 280, 31182-31189.

Dittmann K., Mayer C. und Rodemann HP. (2005b) Inhibition of radiation-induced EGFR nuclear import by C225 (Cetuximab) suppresses DNA-PK activity. Radiother Oncol 76, 157-161.

Dreicer R. (2006) Tyrosine Kinase Inhibitors Compared with Cytokine Therapy for Metastatic Renal Cell Carcinoma: Overview of Recent Clinical Trials Differentiating Clinical Response and Adverse Effects. Clin Genitourin Cancer $5(1), 19-23$.

Dt. Krebsgesellschaft (2002) Kurzgefasste Interdisziplinäre Leitlinien 2002, 3. Auflage 2002, im Internet verfügbar unter Skript http://www.uni-duesseldorf.de/awmf/llna/032-037.htm)

Escudier B., Eisen T., Stadler W., Szczylik C., Oudard S., Siebels M., Negrier S., Chevreau C., Solska E., Desai A., Rolland F., Demkow T., Hutson TE., Gore M., Freeman S., Schwartz B., Shan M., Simantov R., Bukowski R., und Group T.A.R.G.E.T.S (2007) Sorafenib in advanced clear-cell renal-cell-carcinoma. N Engl J Med 356(2), 125-134.

Falk H. (1999) Vom Photosensibilisator Hypericin zum Photorezeptor Stentorin- die Chemie der Phenanthroperylenchinone. Angew. Chem. 111, 3306-3326.

Ferguson RE., Jackson SM., Stanley AJ., Joyce AD., Harnden P, Morrison EE., Patel PM., Phillips RM., Selby PJ., und Banks RE. (2005) Intrincic chemotherapy resitance to tubulin-binding antimitotic agents in renal cell carcinoma. Int. J. Cancer 115(1), 155-163. 
Furge KA., Tan MH., Dykema K., Kort E., Stadler W., Yao X., Zhou M. und Teh BT. (2007) Identification of deregulated oncogenic pathways in renal cel carcinoma: an integrated oncogenomic approach based on gene expression profiling. Oncogene 26, 1346-1350.

Frew T., Powis G., Berggren M., Abraham RT., Ashendel CL. und Zalkow LH. (1994) A multiwell assay for inhibitors of phosphatidylinositol-3-kinase and the identification of natural product inhibitors. Anticancer Reserarch 14(6B), 2425-8.

Galanou MC., Theodossiou TA., Tsiourvas D., Sideratou Z. und Paleos MC. (2008) Interactive Transport, subcellular relocation and enhanced phototoxicity of Hypericin encapsulated in guanidinylated Liposomes via molecular recognition. Photochemistry and Photobiology 84(5), 1073-1083.

Gleave ME, Elhilali M., Fradet Y., Davis I., Venner P., Saad F., Klozu LH., Moore MJ., Paton V. und Bajamonde A. (1998) Interferon gamma-1b compared with placebo in metastatic renal-cell carcinoma. Canadian Urologic Oncology Group N Engl J Med $338,1265-1271$.

Gutmann H., Poller B., Berger-Büter K., Pfrunder A., Schaffner W. und Drewe J. (2006) Hypericum perforatum: Which constituents may induce intestinal MDR1 and CYP3A4 mRNA expression? Planta Med 72, 685-690.

Hausmann, W. (1923) Grundzüge der Lichtbiologie und Lichtpathologie, Strahlentherapie VIII, Sonderband, Urban \& Schwarzenberg, Berlin.

Head CS., Luu Q., Sercarz I. und Saxton R. (2006) Photodynamic therapy and tumor imaging of hypericin-treated squamous cell carcinoma. World Journal of Surgical Oncology 4, 87.

Heldin CH., Ostmann A. und Ronnstrand L. (1998): Signal transduction via plateletderived growth factor receptors. Biochem Biophys Acta; 1378: F79-F113.

Iliopoulos O. (2006) Molecular Biology of Renal Cell Cancer an the Identification of Therapeutic Targets. Journal of Clinical Oncology 24(35), 5593-5600.

Johnson SA. und Pardini RS. (1998) Antioxidant enzyme response to hypericin in EMT6 mouse mammary carcinoma cells. Free Raduc Biol Med 24(5), 817-826.

Kamuhabwa A., Agostinis P., D’Hallewin MA., Baert L. und de Witte P. (2001)Cellular photodestruction induced by hypericin in AY-27 rat bladder carcinoma cells. Photochem Photobiol 74(2), 126-132. 
Kamuhabwa A., Agostinis P., Ahmed B., Landuyt W., van Cleynenbreugel B., van Poppel H. und de Witte P. (2004) Hypericin as a potential phototherapeutic agent in superficial transitional cell carcinoma of the bladder. Photochem Photobiol Sci 3(8), 772-780.

Kastan MB. und Lim DS. (2000) The many substrates and functions of ATM. Molecular Cell Biology 1, 179-186.

Khasawneh MK. und Bukowski RM. (2006) Pathways of Dysregulation in Renal Cell Carcinoma: Rational Approaches to Development of Novel Treatment. Clinical Genitourinary Cancer 5(1), 7-18.

Kim CH., Park SJ. und Lee SH. (2002) A targeted inhibition of DNA-dependent protein kinase sensitizes breast cancer following ionizing radiation. The Journal of Pharmacology and Experimental Therapeutics, 303(2), 753-759.

Klatte T., Pantuck AJ., Kleid MD. und Belldegrun AS. (2007) Understanding the Natural Biology of Kidney Cancer: Implications for Targeted Therapy. Reviews in Urology $9(2), 47-56$.

Kubin A., Kolbabek H., Jindra RH. Dobrovsky W., Alth G. und Wierrani F. (2000) Photodynamic therapy by local application of hypericin- A case report. Res Adv Photochem Photobiol 1, 147-153.

Kubin A., Burner U., Loew HG., Wierrani F., Kolbabeck H. und Alth G. (2003) Hypericin complex bound to Polyvinylpyrrolidone (PVP) - a novel therapeutic and diagnostic application? American Society for Photobiology $31^{\text {st }}$ Annual Meeting, Baltimore 2003, vol 31, pp abstract 226.

Kubin A., Wierrani F., Burner U., Alth G. und Grünberger W. (2005) Hypericin-The Facts About a Controversial Agent. Current Pharmaceutical Design 11, 233-253.

Kunec F. und Wolff JM. (2009) Der Mann und seine Niere: Therapiefortschritte beim metastarsierten Nierenzellkarzinom. Blickpunkt der Mann 7(2), 34-37.

Kusari S., Lamshöft M., Zühlke S. und Spiteller M. (2008) An Endophytic Fungus from Hypericum perforatum that produces Hypericin. Journal of Natural Products 71(2), $159-162$.

Lämmli UK. (1970) Cleavage of structural proteins during assambly of the head of bacteriophage T4. Nature 227, 680-685.

Leber R., Wise T., Mizuta R. und Meek K. (1998) The XRCC4 gene product is target for and interacts with DNA-dependent protein kinase. J Biol Chem 273, 1794-1801. 
Lehne G. (2000) P-glycoprotein as a drug target in the treatment of multidrug resistant cancer. Current Drug Targets 1, 85-99.

Leppert JT., Lam JS., Pantuck AJ., Figlin RA. und Belldegrun AS. (2005) Carbonic anhydrase IX and the future of molecular markers in renal cell carcinoma. BJU Int. 96, 281-285.

Lilleby W. und Fosså SD. (2005) Chemotherapy in metastatic renal cell cancer. World J. Urol. 23, 175-179.

Lin SY., MakinoK, Xia W., Matin A., Wen Y., Kwong KY., Bourguignon L. und Humg MC. (2001) Nuclear localization of EGF-rezeptor and its potential role as a transcription factor. Nat Cell Biol 3, 802-808.

Lisztwan J., Imbert G., Wirbelauer C., Gstaiger M. und Krek W. (1999) The von Hippel Lindau tumor suppressor protein is a component of an E3-ubiquitin-protein ligase activity. Genes Dev 13, 1822-1833.

Lo HW., Hsu SC., Ali-Seyed M., Gunduz M, Xia W., Wei Y., Bartholomeusz G., Shih JY., und Hung MC (2005a) Nuclear interaction of EGFR andSTAT3 in the activation of iNOS/NO pathway. Cancer cell 7, 575-589.

Lo HW., Xia W., Wei Y., Ali-Seyed M., Huang SF. und Hung MC. (2005b) Novel prognostic value of nuclear EGF receptor in breast cancer. Cancer Res. 65, 338 348.

Lo HW. und Hung MC. (2006a) Nuclear EGFR signalling network in cancers: linking pathway to cell cycle progression, nitric oxide pathway and patient survival. British Journal of Cancer 94, 184-188.

Lo HW., Hsu SC. und Hung MC. (2006b) EGFR signalling pathway in breast cancers: from traditional signal transduction to direct nuclear translocalization. Breast Cancer Res Treat 95(3), 211-218.

Magné N., Toillon RA., Boterro V., Didelot C., Houtte PV., Gerad JP. Und Peyron JF. (2005) NF-kB modulation and ionizing radiation: mechanisms and future directions for cancer treatment. Cancer Letters 231, 158-168.

Marti U., Burwen SJ., Wells A., Barker ME., Huling S., Feren AM. und Jones AL. (1991) Localization of epidermal growth factor receptor in hepatocyte nuclei. Hepatology $13,15-20$.

Mazur Y. und Meruelo D. (1993) Ion pairs of hypericin compounds having antiviral activity, WO 93/15607 (Patent Cooperation Treaty). 
McElhinny S., Snowden C., McCarville J. und Ramsden DA. (2000) Ku recruits the XRCC4-ligase-IV complex to DNA ends. Mol Cell Biol 20, 2966-3003.

Mickisch GH., Carballido J., Hellsten S., Schulze H. und Mensink H (2001) Guidelines on renal cell cancer. Eur Urol 40, 252-255.

Miskovsky P. (2002) Hypericin- a new antiviral and anittumor photosensitizer: mechanism of action and interaction with biological macromolecules. Curr Drug Targets, 3(1), $55-84$.

Moore LB., Goodwin B., Jones SA., Wisely GB., Serabjit-Singh CJ., Millson TM., Collins JL. und Kliewer SA. (2000) St. John's wort induces hepatic drug metabolism through activation of the pregnane X receptor. Proc Natl Acad Sci USA 97, 7500 7502.

Motzer RJ. und Bukowski RM. (2006) Targeted therapy for metastatic renal cell carcinoma. J Clin Oncol 35, 5601-5608.

Moussavi-Harami F., Mollano A., Martin JA., Ayoob A., Domann FE., Gitelis S. und Buckwalter JA. (2006) Intrinsic radiation resistance in human chondrosarcoma cells. Biochemical and Biophysical Research Communications 346, 379-385.

Olivo M., Lau W., Manivasager V., Tan PH., Soo KC. und Cheng C. (2003) Macro microscopic fluorescence of human bladder cancer using hypericin fluorescence cytoscopy and laser confocal microscopy. Int J Oncol 23(4), 983-990.

Pajonk F., Scholber J. und Fiebich B. (2005) Hypericin-an inhibitor of proteasome function. Cancer Chemother. Pharmacol. 55, 439-446.

Pass HI. (1993) Photodynamic therapy in oncology: mechanisms and clinical use. Journal of the National Cancer Institut 85 (6), 443-456.

Paull TT., Rogakou EP., Yamazaki V., Kirchgesser CU., Gellert M. und Bonner WM. (2000) A critical role for histone H2AX in recruitment of repair factors to nuclear foci after DNA damage. Current Biology 10, 886-895.

Perloff MD, Von Moltke LL., Störmer E., Shader RI. und Greenblatt DJ. (2001) Saint John's wort: an in vitro analysis of P-glycoprotein induction due to extended exposure. Br J Pharmacol 134, 1601-1608.

Psyrri A., Yu Z., Weinberger PM., Sasaki C., Haffty B., Camp R., Rimm D. und Burtness BA. (2005) Quantitative determination of nuclear and cytoplasmatic epidermal growth factor receptor expression in oropharyngeal squamous cell cancer by using automated quantitative analysis. Clin Cancer Res 11, 5856-5862. 
Pytel A. und Schmeller N. (2002) New aspect of photodynamic diagnosis of bladder tumors: fluorescence cytology. Urology 59(2), 216-219.

Ritz R, Roser F., Radomski N., Strauss W., Tatagiba M. und Gharabaghi A. (2008) Subcellular colocalization of Hypericin with respect to endoplasmatic reticulum and golgi apparatus in glioblastoma cells. Anticancer Reserarch 28, 2033-2038.

Robson NKB. (2003) Hypericum botany. In: Edzard Ernst (Hrsg.): Hypericum: The Genus Hypericum. CRC Press, 2003, ISBN 0415369541, 1-22.

Rodemann HP., Dittmann K., und Toulany M. (2007) Radiation-induced EGFR-signaling and control of DNA-damage repair. Int J Radiat Biol 83(11-12), 781-791.

Ross GM. (1999) Induction of cell death by radiotherapy. Endocrine-Related Cancer 6, 41 44.

Roth L. (1990) Hypericum-Hypericin. Botanik, Inhaltsstoffe, Wirkung. In: Ecomed Arzneipflanzen-Monographie, ed. Series. Landsberg/Lech: Ecomed.

Sack U., Tárnok A. und Rothe G. (2007) Zelluläre Diagnostik: Grundlagen, Methoden und klinische Anwendungen der Durchflusszytometrie. Basel, Karger-Verlag, 2007.

Sattler S., Schaefer U., Schneider W., Hoelzl J. und Lehr CM. (1997) Binding, uptake and transport of hypericin by Caco-2 cell monolayers. J. Pharm. Sci. 86, 1120-1126.

Shintani S., Li C., Mihara M., Terakado M., Yano J., Nakashiro K. und Hamakawa H. (2003) Enhancement of tumor radioresponse by combined treatment with gefitinib (Iressa, ZD1839), an epidermal growth factor receptor tyrosine kinase inhibitor, is accompanied by inhibition of DNA damage repair and cell growth in oral cancer. Int J Cancer 107, 1030-1037.

Siboni G., Weitmann H., Freeman D., Mazur Y., Malik Z. und Ehrenberg B. (2002) The correlation between hydrophilicity of hypericins and helianthrone: internalization mechanisms, subcellular distribution and photodynamic action in colon carcinoma cells. Photochem. Photobiol. Sci. 1, 483-491.

Skalkos D., Gioti E., Stalikas CD., Meyer H., Papazoglou TG. und Filippidis G. (2006) Photophysical properties of Hypericum perforatum L. Extracts - Novel photosensitizers for PDT. J Photochem. Photobiol. B 82(2), 146-151.

Störkel S. (2007) Pathologie und Molekularpathologie epithelialer Nierentumoren und therapeutische Implikationen. Onkologie heute 2, 12-20. 
Takahashi I., Nakanishi S., Kobayashi E., Nakano H., Suzuki K. und Tamaoki T. (1989) Hypericin and pseudohypericin specifically inhibit protein kinase C: possible relation to their antiretroviral activity. Biochem. Biophys. Res. Commun. 165(3), 1207-1212.

Taneja N., Davis M., Choy JS., Beckett MA., Singh R., Kron SJ. und Weichselbaum RR. (2004) Histone H2AX phosphorylation as a predictor of radiosensitivity and target for radiotherapy. The Journal of Biological Chemistry 279(3), 2273-2280.

Thomas C., Mac Gill RS. und Pardini RS. (1992) Photoactivation of hypericin generates singlet oxygen in mitochondria and inhibits succinoxidase. Photochem Photobiol $55(1), 47-53$.

Thomas C. und Pardini RS. (1992) Oxygen dependence of hypericin-induced phototoxicity to EMT6 mouse mammary carcinoma cells. Photochem Photobiol 55, 831-837.

Thoenes W., Störkel S. und Rumpelt HJ.(1986) Histopathology and classification of renal cell tumors (adenomas, oncocytomas and carcinomas). The basic cytological and histopathological elements and their use for diagnostics. Pathol Res Pract 181(2), 125-143.

Tian R., Koyabu N., Morimoto S., Shoyama Y., Ohtani H. und Sawada Y. (2005) Functional induction and de-induction of P-glycoprotein by St. John's wort and its ingredients in a human colon carcinoma cell line. Drug Metabolism and Disposition 33(4), 547-554.

Toulany M., Dittmann K., Kruger M., Baumann M. und Rodemann HP. (2005) Radioresistance of K-Ras mutated tumor cells is mediated through EGFR dependent activation of PI3K-AKT pathway. Radiotherapy \& Oncology 76, 143 150.

Toulany M., Baumann M. und Rodemann HP. (2007) Stimulated PI3K-AKT signaling mediated through ligand or radiation-induced EGFR depends indirectly, but not directly, on constitutive K-Ras activity. Molecular Cancer Research 5, 863-872.

Uhlmann DL., Nguyen P., Manivel JC., Zhang G., Hagen K., Fraley E., Aeppli D. und Niehans GA. (1995) Epidermal growth factor $\alpha$ expressionin papillary and non papillary renal cell carcinoma : correlation with metastatic behavior and prognosis. Clin Cancer Res 1, 913-920. 
Utsumi T., Okuma M., Kanno T., Yasuda T., Kobuchi H., Horton AA. und Utsumi K. (1995) Light-dependent inhibition of protein kinase C and superoxide generation of neutrophils by hypericin an antiretroviral agent. Arch Biochem Biophys 316(1), 493-497.

Van de Putte M., Roskams T., Bormans G., Verbruggen A. und De Witte PA. (2006) The impact of aggregation on the biodistribution of hypericin. Int. J. Oncol. 28, 655 660.

Vandenbogaerde AL., Cuveele JF., Proot P., Himpens BE., Merlevede WJ. und De Witte PA. (1997) Differential cytotoxic effects induced after photosensitization by hypericin. J. Photochem. Photobiol. B 38, 136-142.

Virsik-Köpp P., Hofmann-Hüther H., Rave-Fränk M. und Schmidberger H. (2005) The effect of Wortmannin on radiation-induces chromosomea aberration formation in te radioresistant tumor zell line WiDr. Radiation Research 164, 148-156.

Vonarburg B. (2005) Homöotanik - Farbiger Arzneipflanzenführer der klasssischen Homöopathie, Band 2 Blütenreicher Sommer, 2.Auflage Haug Thieme Verlag: 29.

Walker JR., Corpina RA. und Goldberg J. (2001) Structure of Ku heterodimer bound to DNA and its implications for doublestrand break repair. Nature 412, 607-614.

Winterhalder R. (2009) Das metastarsierte Nierenzellkarzinom-Onkologische Therapieoptionen. Onkologie 3, 8-12.

Zhang W., Anker L., Law RE., Hinton DR., Gopalakrishna R., Pu Q., Gundimeda U., Weiss MH. und Couldwell WT. (1996) Enhancement of Radiosensitivity in Human Malignant Glioma Cells by Hypericin in Vitro. Clinical Cancer Research 2, 843 846. 


\section{Eigene Veröffentlichungen und Tagungsbeiträge:}

\section{Eigene Veröffentlichung:}

Wessels JT, Busse AC, Rave-Fränk M., Zänker S., Herrmann R., Grabbe E. und Müller GA. (2008) Photosensitizing and radiosensitizing effects of hypericin on human renal carcinoma cells in vitro. Photochem. Photobiol. 84(1), 228-235.

\section{Tagungsbeiträge:}

Laffers W., Busse AC, Mahrt J., Gerstner AOH. und Wessels JT. (2008) Analysis of photodynamic effects of hypericin on head and neck cancer in vitro and in vivo. Posterpräsentation, 79. Jahresversammlung der Deutschen Gesellschaft für Hals-NasenOhren-Heilkunde, Kopf- und Hals-Chirurgie e.V., 30.04.-04.05. 2008 in Bonn.

Busse AC, Grabbe E., Müller GA. und Wessels JT (2008) Photo-and radiosensitizing effects of Hypericin on human RCC in vitro. 39. Posterpräsentation, 39. Kongress der Gesellschaft für Nephrologie (GfN), 41. Jahrestagung der Deutschen Arbeitsgemeinschaft für Klinische Nephrologie (DAGKN), 27.09.-30.09.2009 in Tübingen. 


\section{Danksagung:}

Mein herzlicher Dank geht an Herrn Prof. Dr. G. A. Müller, Abteilung Nephrologie und Rheumatologie und Herrn Prof. Dr. E. Grabbe, Abteilung Diagnostische Radiologie, durch deren Kooperation und die Bereitstellung des Arbeitsplatzes und der finanziellen Mittel die Anfertigung dieser Arbeit ermöglicht wurde.

Herrn Dr. rer. nat. Johannes Wessels, Abteilung Nephrologie und Rheumatologie, danke ich für die Vergabe des interessanten Themas, eine zwanglose Arbeitsatmosphäre und dass er meinen Ideen immer aufgeschlossen gegenüber stand.

Frau Prof. Dr. S. Hoyer-Fender und Prof. Dr. med. U. Groß danke ich für die Übernahme des Koreferates bzw. Referates dieser Arbeit.

Ich danke Jens Mahrt, Dr. rer. nat. Phuc van Nguyen und Elke Brunst-Knoblich für die gute Stimmung im Labor und die wertvollen Tipps, die mir im täglichen Laboralltag oft weiterhalfen.

Dem Team der Strahlentherapie mit Frau Dipl.-Biol. Magret Rave-Fränk, Dr. med. Robert Herrmann, PD Dr. med. Hans Christiansen, Alexandra Bitter und Juliane Karsten-Krapp möchte ich dafür danken, dass es mir jederzeit die Durchführung meiner Bestrahlungsversuche ermöglichte.

Ich danke PD Dr. rer. nat. Hassan Dihazi und Prof. Dr. med. Frank Strutz für die Möglichkeit die Westernblot-Untersuchungen bzw. quantitative Echtzeit-PCR in ihrem Labor durchzuführen

JProf. Dr. rer. nat. Michael Müller und Belinda Hildebrand, Abteilung Neuro- und Sinnesphysiologie danke ich für die intensive Zusammenarbeit im Rahmen der Messungen des intrazellulären Singulettsauersoffes mittels redoxsensitiven GFP. 


\section{Lebenslauf:}

Name:

Vorname:

Geburtsdatum:

Geburtsort:

Familienstand:

Staatsangehörigkeit:

Adresse:
Busse

Ann-Christin

30.09.1976

Einbeck

verheiratet

deutsch

Im Kleinen Felde 36

37136 Waake-Bösinghausen

Schulbildung:
1983-1987
1987-1989
Grundschule Salzderhelden-Vogelbeck
1989-1996
Orientierungsstufe Einbeck
Goetheschule Einbeck (Gymnasium)

Wissenschaftlicher und beruflicher Werdegang:

1996-2003

08.2003-08.2004

2004-2005

02.2005-05.2005

seit 04. 2006
Studium der Biologie

Georg-August-Universität Göttingen

Abschluss: Diplom

Thema: „Struktur der Collembolengemeinschaften in Beständen von Fichte und Douglasie - ein Beitrag zur Ökologie eines Neophyten“"

Tätigkeit als Vertretungslehrerin an der Grundschule Salzderhelden-Vogelbeck

Erstellung von Biotopkartierungen für ein Gewässerrenaturierungsprojektes der Gesellschaft für Naturland Einbeck und Umgebung e.V.

Laborpraktikum

Abteilung Nephrologie und Rheumatologie,

Universitätsmedizin Göttingen

Promotion

Abteilung Diagnostische Radiologie

Zentrum Radiologie

Universitätsmedizin Göttingen

in Kooperation mit

Abteilung Nephrologie und Rheumatologie,

Zentrum Innere Medizin,

Universitätsmedizin Göttingen 